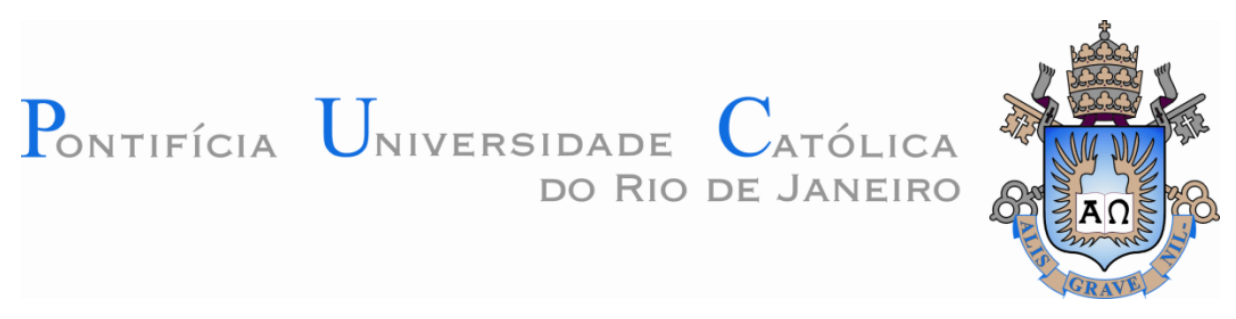

Bruno Rodrigues Amorim

Estudo de treliças espaciais de aço ou mistas para vigamentos principais de galpões de grandes dimensões

Dissertação de Mestrado

Dissertação apresentada como requisito parcial para obtenção do grau de Mestre pelo Programa de Pós-Graduação em Engenharia Civil do Departamento de Engenharia Civil e Ambiental da PUC-Rio.

Orientador: Prof. Sebastião Arthur Lopes de Andrade

Rio de Janeiro

Março de 2018 


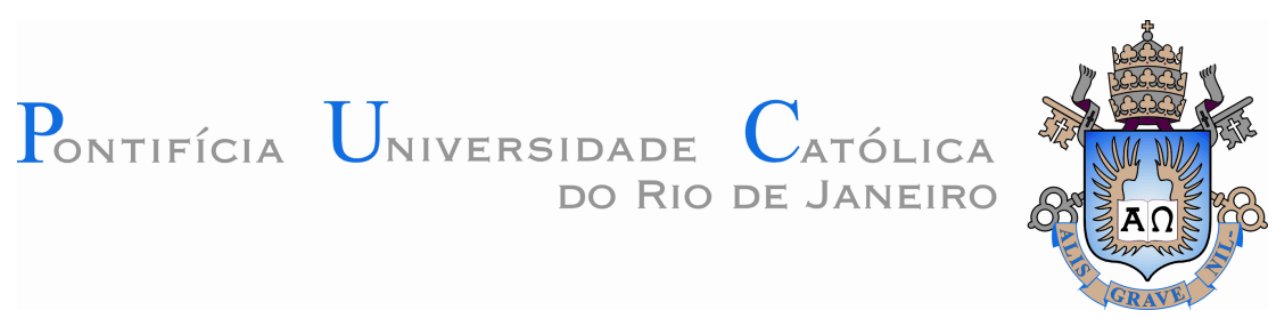

Bruno Rodrigues Amorim

\section{Estudo de treliças espaciais de aço ou mistas para vigamentos principais de galpões de grandes dimensões}

Dissertação apresentada como requisito parcial para obtenção do grau de Mestre pelo Programa de Pós-Graduação em Engenharia Civil do Departamento de Engenharia Civil e Ambiental do Centro Técnico Científico da PUC-Rio. Aprovada pela Comissão Examinadora abaixo assinada.

Prof. Sebastião Arthur Lopes de Andrade.

Orientador

Departamento de Engenharia Civil - PUC-Rio

Prof. Raul Rosas e Silva

Departamento de Engenharia Civil - PUC-Rio

Prof. Luciano Rodrigues Ornelas de Lima

Universidade do Estado do Rio de Janeiro

Prof. Márcio da Silveira Carvalho

Coordenador Setorial do Centro

Técnico Científico - PUC-Rio

Rio de Janeiro, 23 de março de 2018 
Todos os direitos reservados. É proibida a reprodução total ou parcial do trabalho sem autorização da universidade, da autora e do orientador.

\section{Bruno Rodrigues Amorim}

Graduou-se em Engenharia Civil pela Universidade Estadual Vale do Acaraú - UVA em 2016. Ingressou no mestrado na PUC-Rio em 2016, desenvolvendo dissertação na área de Estruturas, linha de pesquisa Estruturas Mistas.

Ficha Catalográfica

Amorim, Bruno Rodrigues

Estudo de treliças espaciais de aço ou mistas para vigamentos principais de galpões de grandes dimensões / Bruno Rodrigues Amorim; orientador: Sebastião Arthur Lopes de Andrade. Rio de Janeiro: PUC, Departamento de Engenharia Civil e Ambiental, 2018.

133 f. il; $29,7 \mathrm{~cm}$.

1. Dissertação (Mestrado em Engenharia Civil) - Pontifícia Universidade Católica do Rio de Janeiro, Departamento de Engenharia Civil e Ambiental.

Inclui referências bibliográficas.

1. Engenharia Civil - Teses. 2. Análise Não-linear de Estruturas 3. Treliças mistas 4. Galpões de grandes dimensões 5. Estruturas de aço. I. Andrade, Sebastião Arthur Lopes de Andrade. II. Pontifícia Universidade Católica do Rio de Janeiro. III. Departamento de Engenharia Civil. IV. Título. 


\section{Agradecimentos}

Agradeço primeiramente a Deus por me amparar nos momentos difíceis e me fazer crer a cada dia que nada é impossível quando se tem fé e perseverança.

Ao professor Sebastião Andrade pelo conhecimento transmitido, auxílio na realização deste trabalho e paciência.

Agradeço a todos meus familiares, em especial aos meus pais, Rita e Eudes, pelo amor interminável e por me darem condições de poder concluir o mestrado.

À minha noiva, Maria Flávia, pelo amor, companhia, compreensão e estímulo em superar todas as dificuldades .

Aos amigos que me deram ânimo e me ajudaram a não desistir. 


\section{Resumo}

Amorim, Bruno Rodrigues; Andrade, Sebastião Artur Lopes (Orientador). Estudo de treliças espaciais de aço ou mistas para vigamentos principais de galpões de grandes dimensões. Rio de Janeiro, 2018. 133p. Dissertação de Mestrado - Departamento de Engenharia Civil e Ambiental, Pontifícia Universidade Católica do Rio de Janeiro.

Os sistemas de cobertura constituem uma parcela considerável dos custos finais de galpões de grandes dimensões. Os carregamentos desse sistema são transferidos para os pilares a partir dos vigamentos principais. Dúvidas sobre qual é a melhor solução para o dimensionamento do vigamento principal podem surgir devido aos grandes vãos que essas estruturas devem cumprir. Esta dissertação apresenta um estudo das configurações estruturais e uso de diferentes materiais para o projeto, fabricação e montagem de coberturas de galpões de grandes dimensões. Foram desenvolvidos diversos projetos de uma estrutura modelo onde se variou o tipo de perfil das cordas, o comprimento dos vãos, a geometria da seção transversal da treliça e a inclinação das diagonais. A partir dos resultados obtidos, realizou-se uma análise paramétrica buscando-se a solução que apresenta o menor peso estrutural dos vigamentos principais. A grande vantagem da utilização de treliças multiplanares é o bom comportamento fora do plano que esse tipo de estrutura oferece, podendo reduzir custos com travamentos e elementos secundários. Também foi realizado um estudo determinístico para dar apoio às decisões na escolha da melhor solução para os diversos tipos de galpões de grandes dimensões estudados. Os resultados preliminares obtidos indicam que a solução de cordas tubulares mistas, em partes selecionadas da estrutura, representa uma das soluções mais competitivas para este tipo de estrutura.

\section{Palavras-chave}

Análise Não-linear de Estruturas; treliças mistas; galpões de grandes dimensões; estruturas de aço. 


\begin{abstract}
Amorim, Bruno Rodrigues; Andrade, Sebastião Artur Lopes (Advisor) Study of spatial steel and composite trusses for girders of large single-storey building. Rio de Janeiro, 2018. 133p. Dissertação de Mestrado - Departamento de Engenharia Civil, Pontifícia Universidade Católica do Rio de Janeiro.
\end{abstract}

Roofing systems constitute a considerable part of the final costs of large single-storey buildings. The loads of this system are transferred to the columns from the girders. During the design process may be raised the question of what may be the best solutions for the roof supporting girders, mainly due to the large spans required. This dissertation presents a study of the structural configurations and the use of different materials for the design, manufacture and assembly of roofs of large single-storey buildings. Several designs of a model structure were developed where the type of profile of the main chords, the length of the spans, the geometry of the cross-section of the truss and the angulation of diagonals were varied. Based on the obtained results, a parametric analysis was performed focused on solutions presenting the lower structural weight of the girders. The great advantage of using multiplanar trusses is the good behavior out of plane that this type of structure offers, which can reduce costs with bracing and secondary elements. A deterministic study was also carried out in order to support decisions in choosing the best solution for the various types of large single-storey buildings studied. The preliminary results obtained indicate that the solution of concrete filled steel tubular chords in selected parts of the structure represents one of the most competitive solutions for this type of construction.

\title{
Keywords
}

Nonlinear analysis of structures; composite truss; large single-storey buildings; steel structures. 


\section{Sumário}

1 Introdução 20

1.1. Contexto e motivação 20

1.2. Objetivos 25

1.3. Apresentação e organização do trabalho 26

2 Sistemas estruturais de cobertura $\quad 27$

2.1. Edifícios industriais convencionais 27

2.2. Sistema de travamento 29

2.3. Coberturas de grandes vãos 33

2.4. Treliças multiplanares 35

2.5. Treliças com elementos mistos 37

2.5.1. Comportamento da estrutura CFST 38

2.5.2. Dimensionamento de colunas CFST à força axial de compressão de acordo com a AISC $\quad 41$

2.6. Treliças multiplanares com elementos mistos 43

3 Critérios de projeto estrutural 46

3.1. Projeto de estrutura exemplo 46

3.2. Configurações estruturais 49

3.2.1. Geometria da treliça 49

3.2.2. Seções transversais utilizadas 49

3.2.3. Inclinação das diagonais 50

3.2.4. Restrições 51

3.2.5. Detalhes 52

3.2.6. Perfis utilizados $\quad 54$

4 Projeto de um galpão com 60 metros de vão e 190 m de comprimento 
4.1. Carregamentos adotados 65

4.1.1. Esforços de projeto 66

$\begin{array}{ll}\text { 4.2. Materiais } & 67\end{array}$

4.3. Considerações da análise estrutural 68

4.4. Dimensionamento estrutural 69

4.4.1. Dimensionamento das regiões mais solicitadas 70

4.4.2. Perfis utilizados para a solução tubular 71

4.4.3. Discretização das diagonais e montantes 72

4.5. Resultados das treliças 73

5 Resultados da análise estrutural das treliças multiplanares 75

5.1. Modos de falha 75

5.2. Diâmetros adotados nas treliças com perfis tubulares e mistos 80

5.3. Resultados de consumo de aço e verificação das flechas 84

5.4. Testes de hipótese e intervalo de confiança 95

5.5. Influência das variáveis de projeto no consumo de aço 97

5.5.1. Tipo de perfil das cordas 98

5.5.2. Variação da seção transversal da treliça 101

5.5.3. Análise do efeito das inclinações das diagonais 103

5.6. Comportamento estrutural em serviço 104

5.6.1. Deslocamentos verticais 104

5.6.2. Deslocamentos horizontais da treliça 109

5.7. Resumo dos melhores resultados encontrados 111

5.7.1. Evolução dos resultados com o comprimento do vão 113

6 Estudo da solução de menor consumo de material da estrutura 115

6.1. Seleção dos perfis das cordas 115

6.1.1. Relação M/PL: Economia e intervalos de confiança 116

6.1.2. Mapeamento das regiões mistas dentro da treliça 121

6.2. Variação na geometria da seção transversal da treliça 123

6.3. Análise das inclinações das diagonais das treliças 124

7 Considerações finais e conclusões 126

$\begin{array}{lr}\text { 7.1. Considerações finais } & 127\end{array}$ 
7.2. Sugestões para trabalhos futuros

8 Referências bibliográficas 


\section{Lista de figuras}

Figura 1.1 - Galeria das Máquinas - Paris, 1889.......................................... 21

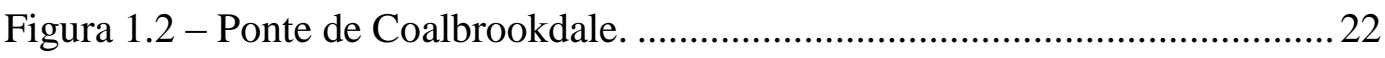

Figura 1.3 - Cobertura de estacionamento. .................................................... 22

Figura 1.4 - Centro de distribuição das Casas Bahia - Jundiaí............................... 23

Figura 1.5 - Galpão em construção - Rio de Janeiro............................................ 24

Figura 2.1 - Componentes de um galpão (CBCA, 2010).................................... 28

Figura 2.2 - Cobertura de galpões com tesoura e treliçado,

respectivamente (Adaptado de BELLEI, 1998). ...............................................2 29

Figura 2.3 - Sistema discreto de travamento (Adaptado de: AISC, 2016). ........... 30

Figura 2.4 - Sistema de travamento relativo (Galambos, 2008)......................... 30

Figura 2.5 - Terças gerando flexão nas barras da tesoura e apresentando

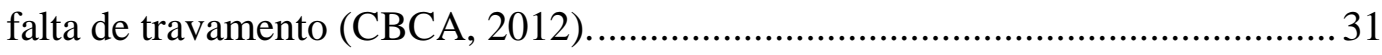

Figura 2.6 - Travamento relativo em X da cobertura (CBCA, 2012).................. 32

Figura 2.7 - Travamento diagonal entre tesouras............................................... 32

Figura 2.8 - Detalhe: mão francesa (Adaptado de CBCA, 2012)......................... 32

Figura 2.9 - Contraventamento em X (Carneiro e Martins, 2008)........................ 33

Figura 2.10 - Esquema do sistema steel joist (Adaptado de: CBCA, 2007)......... 34

Figura 2.11 - Cobertura com steel joist......................................................... 34

Figura 2.12 - Travamentos entre joists: em quadro (a) e em diagonal (b)........... 35

Figura 2.13 - Mão francesa da ligação do joist com a estrutura principal............ 35

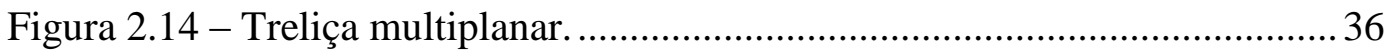

Figura 2.15 - Treliça multiplanar (VIEIRA et al, 2010).................................... 37

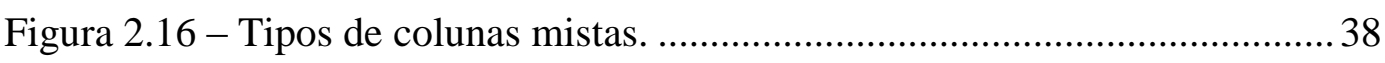

Figura 2.17 - Modos de falha das colunas (HAN, 2016) .................................... 40

Figura 2.18 - Região de introdução de carregamentos (AISC, 2016)................... 43

Figura 2.19 - Seções triangular e triangular inversa (CHEN, 2015)..................... 44

Figura 2.20 - Seções quadrada e trapezoidal (CHEN, 2015) .............................. 44

Figura 3.1 - Plano de cobertura da estrutura exemplo que será utilizada nesse estudo. 
Figura 3.2 - Dimensões da viga de cobertura estudada...................................... 47

Figura 3.3 - Primeira combinação de ações. ..................................................... 48

Figura 3.4 - Segunda combinação de ações. ..................................................... 48

Figura 3.5 - Treliça tipo Howe (planos laterais). ............................................... 49

Figura 3.6 - Treliça tipo Warren com montantes (planos horizontais)................. 49

Figura 3.7 - Seção transversal ST4 nas regiões dos apoios e centros de vão. ........50

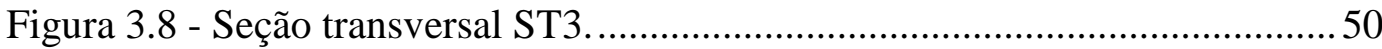

Figura 3.9 - Inclinação das diagonais da treliça...................................................51

Figura 3.10 - Restrições dos apoios da estrutura................................................52

Figura 3.11 - Elementos diagonais na estrutura reticulada (em realce)...............53

Figura 3.12 - Região dos apoios da estrutura ST3 (em realce)...........................53

Figura 3.13 - Detalhe do nó do apoio da corda superior' da estrutura ST3...........53

Figura 3.14 - Detalhe: perfis WT - Diagonal do apoio das seções ST4. ...............54

Figura 3.15 - Detalhe de nó típico (Adaptado de Souza, 2003)...........................55

Figura 3.16 - Presilhas utilizadas nas diagonais e montantes das treliças

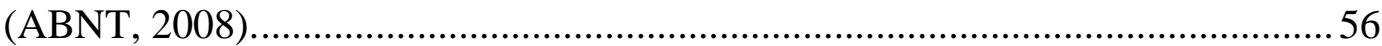

Figura 3.17 - Eixo de maior inércia do perfil trabalhando no plano (a) e fora do plano (b)

Figura 3.18 - Ligações com os elementos das diagonais e montantes para

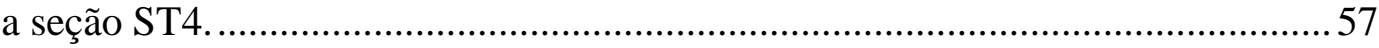

Figura 3.19 - Ligações com os elementos de travamento para a seção ST4. ........58

Figura 3.20 - Ligações com as diagonais para a seção ST3 .................................58

Figura 3.21 - Perfis duplos soldados nas mesas. ....................................................58

Figura 3.22 - Detalhe da chapa soldada na mesa do perfil WT...........................59

Figura 3.23 - Placa soldada no tubo circular para ligação com as

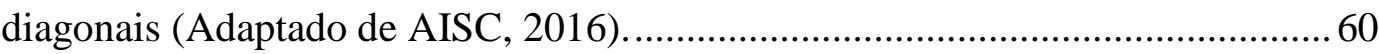

Figura 3.24 - Falha por plastificação da parede do tubo (CHEN, 2015).............. 62

Figura 3.25 - Localização das seções mistas (realçadas) - vão genérico. .............. 62

Figura 3.26 - Diagrama de forças axiais das cordas da treliça. ............................. 62

Figura 3.27 - Detalhe construtivo do tubo misto..................................................... 63

Figura 4.1 - (a) Aplicação do carregamento na estrutura; (b) seção transversal

da treliça - os valores são mostrados por treliça. ................................................ 65

Figura 4.2 - Esforços das cordas (por treliça)..................................................... 66

Figura 4.3 - Esforços na região do apoio da extremidade.................................... 67 
Figura 4.4 - Esforços na região do apoio central. .............................................. 67

Figura 4.5 - Comprimentos destravados da estrutura. ........................................ 69

Figura 4.6 - Falha por flambagem corda comprimida. ...................................... 70

Figura 4.7 - Perfis adotados para a treliça com perfis tubulares.......................... 72

Figura 4.8 - Regiões de discretização das diagonais e montantes. ....................... 72

Figura 5.1 - Flambagem global da treliça ST3 (Fator de escala: 50). .................. 76

Figura 5.2 - Comprimento de onda - Comparação da treliça com uma coluna

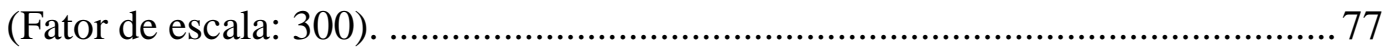

Figura 5.3 - Modo de flambagem apresentado na região dos apoios centrais

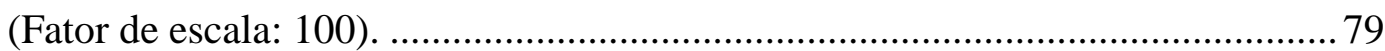

Figura 5.4 - Flambagem global da corda da treliça............................................. 79

Figura 5.5 - Nomenclatura das cordas da seção ST4 e ST3................................ 80

Figura 6.1 - Mapeamento das regiões com perfis mistos e tubulares.................. 122 


\section{Lista de tabelas}

Tabela 1.1 - Pontes pioneiras na construção em aço. .........................................2 21

Tabela 2.1 - Classificação do comprimento dos vãos (BELLEI, 1998). ............... 28

Tabela 2.2 - Classificação ajustada da classificação de galpões........................... 28

Tabela 3.1 - Carregamentos verticais aplicados na estrutura.............................. 48

Tabela 3.2 - Perfis utilizados para as estruturas secundárias................................55

Tabela 3.3 - Comprimento das chapas gusset utilizadas nas treliças.................... 61

Tabela 4.1 - Configurações geométricas da treliça principal................................64

Tabela 4.2 - Resumo das variações das configurações estudadas. .......................65 65

Tabela 4.3 - Forças axiais máximas nas cordas e reações de apoio por treliça. ... 66

Tabela 4.4 - Região crítica: apoio central (trecho de 6000mm). ......................... 70

Tabela 4.5 - Região crítica: centro do vão da extremidade (trecho de 6000mm).. 71

Tabela 4.6 - Perfis das diagonais e montantes das regiões discretizadas.............. 73

Tabela 4.7 - Resultados do estudo de caso. ……................................................ 73

Tabela 5.1 - Primeiros autovalores de flambagem da treliça com vão de $45 \mathrm{~m}$... 78

Tabela 5.2 - Perfis utilizados nas cordas das treliças - 32m - Seção ST4............. 81

Tabela 5.3 - Perfis utilizados nas estruturas com vão de 32m - Seção ST3.......... 81

Tabela 5.4 - Perfis utilizados nas treliças com vão de 45m - Seção ST4.............. 82

Tabela 5.5 - Perfis utilizados nas treliças com vão de 45m - Seção ST3.............. 82

Tabela 5.6 - Perfis utilizados nas treliças com vão de 60m - Seção ST4.............. 83

Tabela 5.7 - Perfis utilizados nas treliças com vão de 60m - Seção ST3.............. 83

Tabela 5.8 - Resultados encontrados para o vão de $32 \mathrm{~m}$ - altura de $0,80 \mathrm{~m}$. ........ 85

Tabela 5.9 - Resultados encontrados para o vão de $32 \mathrm{~m}$ - altura de $1,00 \mathrm{~m}$. ........ 86

Tabela 5.10 - Resultados encontrados para o vão de $32 \mathrm{~m}$ - altura de 1,20m........ 87

Tabela 5.11 - Resultados encontrados para o vão de $45 \mathrm{~m}$ - altura de 1,50m........ 88

Tabela 5.12 - Resultados encontrados para o vão de $45 \mathrm{~m}$ - altura de 1,80m........ 89

Tabela 5.13 - Resultados encontrados para o vão de $45 \mathrm{~m}$ - altura de 2,25m........ 90

Tabela 5.14 - Resultados encontrados para o vão de $60 \mathrm{~m}$ - altura de 1,50m........91

Tabela 5.15 - Resultados encontrados para o vão de $60 \mathrm{~m}$ - altura de 2,00m........92

Tabela 5.16 - Resultados encontrados para o vão de $60 \mathrm{~m}$ - altura de 2,50m........ 93 
Tabela 5.17 - Consumo de concreto nas treliças mistas de todos os vãos 94

Tabela 5.18 - (a): consumo de aço do vão de 60m; (b) análise $t$-Student ............. 99

Tabela 5.19 - (a): consumo de aço do vão de 32m; (b) análise t-Student ............ 100

Tabela 5.20 - (a): consumo de aço do vão de 45m; (b) análise t-Student............ 100

Tabela 5.21 - Resumo dos valores-p encontrados para a seções transversais. ... 102

Tabela 5.22 - Valores-p da comparação entre alturas.......................................... 103

Tabela 5.23 - Resumo dos testes $t$-Student analisando as inclinações das diagonais

Tabela 5.24 - Resumo dos testes $t$-Student para as flechas - Variação de perfis das cordas.

Tabela 5.25 - Resumo dos testes $t$-Student para comparação entre tipos

de seções para deslocamentos verticais

Tabela 5.26 - Resumo dos testes $t$-Student - avaliação das inclinações das

diagonais na flecha da estrutura.

Tabela 5.27 - Resumo dos testes $t$-Student para deslocamentos laterais.

Tabela 6.1 - Relação M/PL dos três vãos estudados.

Tabela 6.2 - Resultados estatísticos da relação M/PL para treliças com vão de $32 \mathrm{~m}$.

Tabela 6.3 - Resultados estatísticos da relação M/PL para treliças com vão de $45 \mathrm{~m}$.

Tabela 6.4 - Resultados estatísticos da relação M/PL para treliças com vão de $60 \mathrm{~m}$.

Tabela 6.5 - Comprimento médio das regiões de cada tipo de perfil, para as treliças mistas 


\section{Lista de gráficos}

Gráfico 2.1 - Relação carregamento e deformação axial de colunas

(HAN, 2016) 39

Gráfico 5.1 - Consumo de aço para o vão de $32 \mathrm{~m}: \mathrm{h}=0,80 \mathrm{~m}$. .85

Gráfico 5.2 - Consumo de aço para o vão de $32 \mathrm{~m}: \mathrm{h}=1,00 \mathrm{~m}$............................... 86

Gráfico 5.3 - Consumo de aço para o vão de $32 \mathrm{~m}: \mathrm{h}=1,20 \mathrm{~m}$............................ 87

Gráfico 5.4 - Consumo de aço para o vão de 45m: $\mathrm{h}=1,50 \mathrm{~m}$.............................. 88

Gráfico 5.5 - Consumo de aço para o vão de $45 \mathrm{~m}: \mathrm{h}=1,80 \mathrm{~m}$............................ 89

Gráfico 5.6 - Consumo de aço para o vão de $45 \mathrm{~m}: \mathrm{h}=2,25 \mathrm{~m}$.............................. 90

Gráfico 5.7 - Consumo de aço para o vão de $60 \mathrm{~m}: \mathrm{h}=1,50 \mathrm{~m}$............................. 91

Gráfico 5.8 - Consumo de aço para o vão de $60 \mathrm{~m}: \mathrm{h}=2,00 \mathrm{~m}$............................ 92

Gráfico 5.9 - Consumo de aço para o vão de $60 \mathrm{~m}: \mathrm{h}=2,50 \mathrm{~m}$............................. 93

Gráfico 5.10 - Consumo de aço - Vão de 60m - altura de 1,50m - Seção ST4. .. 98

Gráfico 5.11 - Consumo de aço - Vão de 60m - altura de 1,50m - Seção ST3 . .. 98

Gráfico 5.12 - Comparativo de seção transversal - Vão: 45m; Perfil misto. ..... 101

Gráfico 5.13 - Consumo de aço - Seção ST4 - Vão de 32m.............................. 104

Gráfico 5.14 - Flecha para as treliças com seção ST4, h1,50m e vão de 45m... 105

Gráfico 5.15 - Flecha para as treliças com seção ST3, h1,50m e vão de 45m. ... 106

Gráfico 5.16 - Deslocamentos verticais das treliças com perfis laminados

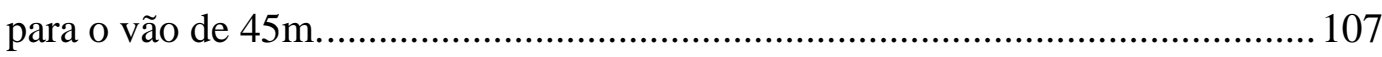

Gráfico 5.17 - Flechas para o vão de 60m para as treliças com perfis mistos.... 108

Gráfico 5.18 - Deslocamentos laterais para o vão de $32 \mathrm{~m}$ para a treliças com perfis mistos.

Gráfico 5.19 - Deslocamentos laterais para o vão de $45 \mathrm{~m}$ para as treliças com perfis mistos.

Gráfico 5.20 - Deslocamentos laterais para o vão de 60m para as treliças

com perfis mistos

Gráfico 5.21 - Deslocamentos laterais para o vão de 45m, altura de 1,50m.

Gráfico 5.22 - Melhores resultados encontrados para a seção ST4 
Gráfico 5.23 - Melhores resultados encontrados para a seção ST3.................... 112

Gráfico 5.24 - Evolução do consumo com o aumento do vão - seção ST4. ...... 113

Gráfico 5.25 - Evolução do consumo com o aumento do vão - seção ST3. ...... 114

Gráfico 6.1 - Intervalo de confiança - Relação M/PL - Vão de 32m. ................ 118

Gráfico 6.2 - Intervalo de confiança - Relação M/PL - Vão de 45m. ............... 119

Gráfico 6.3 - Intervalo de confiança - Relação M/PL - Vão de 60m. ............... 120 


\section{Lista de símbolos}

\section{Caracteres latinos:}

\begin{tabular}{|c|c|}
\hline$A_{c}$ & Área da seção transversal de concreto \\
\hline$A_{g}$ & Área total da seção \\
\hline$A_{s}$ & Área da seção transversal de aço \\
\hline$A_{s r}$ & Área da seção transversal das barras de reforço \\
\hline$B$ & Menor dimensão da peça \\
\hline$C_{1}$ & Coeficiente de da rigidez efetiva de membros CFST \\
\hline$C_{o} V$ & Coeficiente de variação \\
\hline$d$ & Diâmetro \\
\hline$E$ & Módulo de elasticidade \\
\hline$E_{c}$ & Módulo de elasticidade do concreto \\
\hline$E_{s}$ & Módulo de elasticidade do aço \\
\hline $\mathrm{F}$ & Força nas cordas da treliça \\
\hline$F_{y}$ & Tensão limite de escoamento do aço \\
\hline$f_{y s r}$ & Tensão limite de escoamento do aço de reforço \\
\hline$f_{c}^{\prime}$ & Resistência característica à compressão do concreto \\
\hline$f_{2 c r}$ & $\begin{array}{l}\text { Resistência da peça mista ao cisalhamento por ligação } \\
\text { direta }\end{array}$ \\
\hline$G$ & Ação permanente \\
\hline$h$ & Altura da treliça \\
\hline$I_{c}$ & Momento de inércia do concreto \\
\hline$I_{e f f}$ & Momento de inércia efetivo \\
\hline$I_{s}$ & Momento de inércia do aço \\
\hline$I_{s r}$ & Momento de inércia das barras de reforço \\
\hline$L$ & Comprimento do vão \\
\hline$L_{b}$ & Comprimento do módulo da treliça \\
\hline$l_{b}$ & Largura da chapa gusset da ligação \\
\hline$M_{r o}$ & Resistência à flexão solicitada no nó da corda \\
\hline$n$ & Número de elementos do conjunto \\
\hline$N_{c, R d}$ & Força axial de compressão resistente de cálculo \\
\hline$N_{c, S d}$ & Força axial de compressão solicitante de cálculo \\
\hline $\mathrm{P}$ & Força axial atuante na peça a ser travada \\
\hline$P_{e}$ & Carga crítica de flambagem elástica \\
\hline
\end{tabular}




$\begin{array}{ll}P_{n} & \text { Resistência à força compressiva } \\ P_{n o} & \text { Resistência nominal à força axial compressiva para se- } \\ P_{o} & \text { Ŗões duplamente simétricas } \\ P_{r o} & \text { Resistência à compressão da seção transversal } \\ \mathrm{Q} & \text { Ação variável } \\ Q_{f} & \text { Parâmetro de interação de tensão da corda } \\ r_{\min } & \text { Raio de giração mínimo } \\ S & \text { Desvio padrão } \\ S_{s} & \text { Módulo de resistência elástico da seção à flexão } \\ S_{x_{1} x_{2}} & \text { Desvio padrão agrupado } \\ t & \text { Espessura da parede do perfil } \\ U x & \text { Deslocamento horizontal / fora do plano da estrutura } \\ U z & \text { Deslocamento vertical/ no plano da estrutura } \\ x_{i} & \text { Ponto médio da classe } \\ \bar{x} & \text { Média aritmética amostral }\end{array}$

$\alpha$

$\gamma_{g}$

$\gamma_{q}$

$\xi$

$\xi_{o}$

$\lambda$

$\lambda_{1}$
Ângulo entre a diagonal e a corda da treliça Coeficiente de ponderação para carregamentos permanentes

Coeficiente de ponderação para carregamentos variáveis

Fator de confinamento

Fator crítico de confinamento

Autovalor de flambagem

Primeiro autovalor de flambagem 


\section{Lista de abreviaturas}

$\begin{array}{ll}\text { AISC } & \text { American Institute of Steel Construction } \\ \text { ASTM } & \text { American Society for Testing Materials } \\ \text { CEC } & \text { Concrete encased composite } \\ \text { CFST } & \text { Concrete filled steel tubular } \\ \text { CSA } & \text { Canadian Standarts Association } \\ \text { HSS } & \text { Hollow steel section } \\ \text { NBR } & \text { Norma brasileira } \\ \text { PCEC } & \text { Partially concrete encased composite }\end{array}$




\section{Introdução}

\section{1.}

\section{Contexto e motivação}

A necessidade de se obter estruturas que possam acomodar grande quantidade de pessoas ou de abrigar elementos de maior porte ou transpor grandes obstáculos fez com que ocorresse a evolução das tecnologias construtivas no decorrer dos anos.

Com a disseminação do uso do ferro e aço como materiais construtivos na Revolução Industrial, foi possível a execução de estruturas mais amplas e que fossem capazes de suprir as necessidades de edificações que abrangessem grandes áreas livres.

Em 1889, foi construída a Galeria das Máquinas, uma estrutura composta de arcos treliçados tri-rotulados de ferro fundido, com $115 \mathrm{~m}$ de vão livre, realizada na cidade de Paris, que representou todo o conhecimento adquirido ao longo do século XIX (FURTINI, 2005). A Figura 1.1 mostra uma imagem dessa edificação que representou um marco na engenharia estrutural da época.

A construção de pontes aprimorou o desenvolvimento das técnicas de construção de estruturas com vãos maiores. Observa-se o progresso do cálculo estrutural ao se analisar o aumento comprimento dos vãos dessas estruturas no decorrer dos anos, obviamente apoiada pela industrialização dos elementos estruturais em ferro. A Tabela 1.1 mostra as pontes consideradas pioneiras na construção em aço, seus anos de construção e o comprimento dos seus vãos enquanto que a Figura 1.2 mostra a Ponte de Coalbrookdale.

Como se pode notar, a utilização de estruturas metálicas e a padronização dos materiais utilizados são de fundamental importância para o desenvolvimento de estruturas de grande porte. Além disso, reduz de forma significativa o tempo de execução da obra, e simultaneamente, o custo final da obra.

A construção de edificações que necessitam de grandes áreas livres, utilizando a menor quantidade de pilares internos possível, tem aumentado de forma significativa. São arenas esportivas, hangares, depósitos, estacionamentos, centros 
de distribuição, supermercados, dentre outros, que cada vez mais necessitam de melhor rendimento estrutural para cumprirem com a distribuição de áreas exigida. A Figura 1.3 mostra o espaço livre entre pilares da cobertura do estacionamento de um centro de distribuição, em Pouso Alegre (MG).

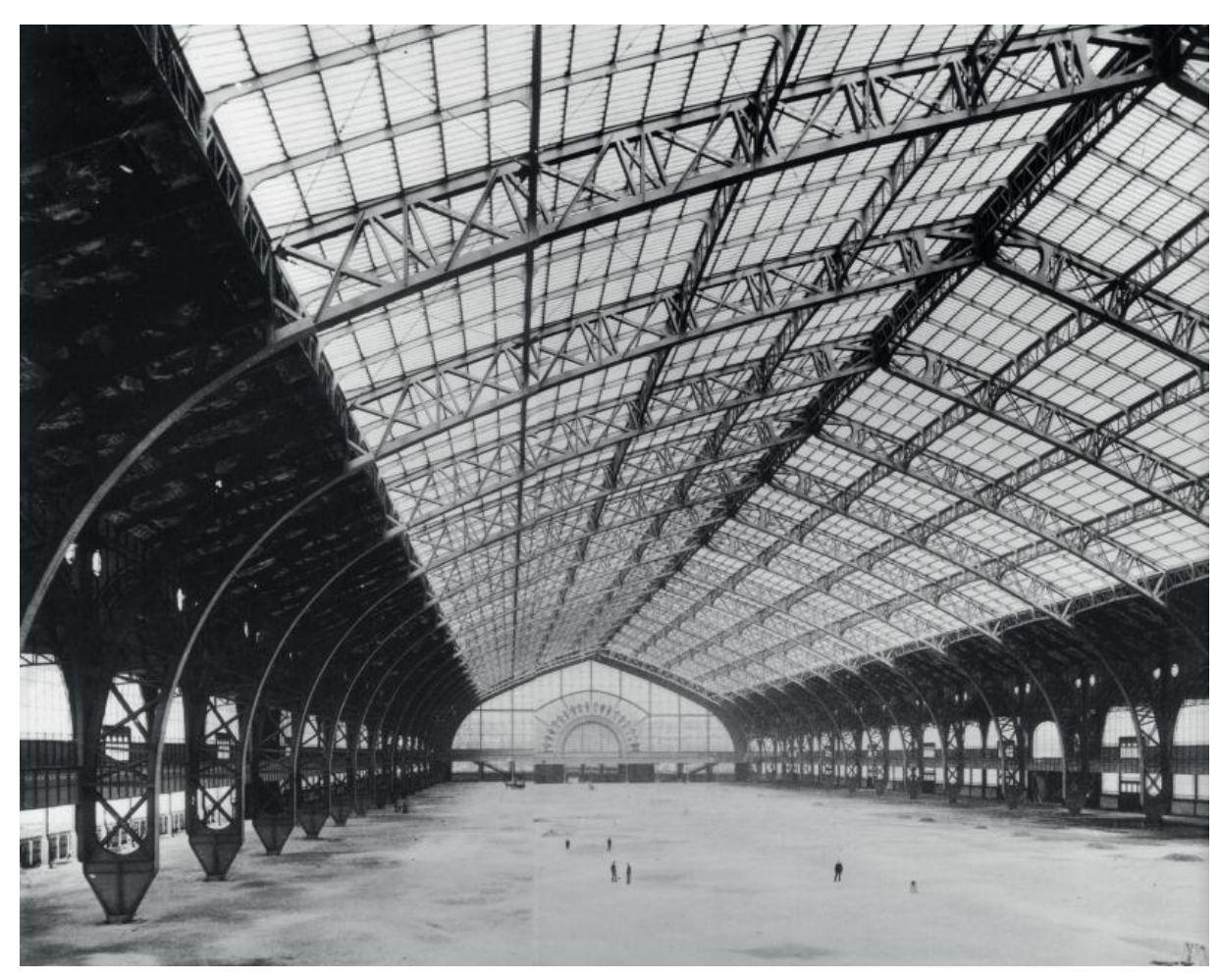

Figura 1.1 - Galeria das Máquinas - Paris, 1889.

\begin{tabular}{|c|c|c|}
\hline Obra & Ano de construção & Vão \\
\hline Ponte de Coalbrookdale & 1779 & $30 \mathrm{~m}$ \\
\hline Ponte de Wearmouth & 1796 & $70 \mathrm{~m}$ \\
\hline Ponte pênsil de Menai & 1826 & $177 \mathrm{~m}$ \\
\hline
\end{tabular}

Tabela 1.1 - Pontes pioneiras na construção em aço.

Centros de distribuição são bastante utilizados por grandes empresas de varejo que os constroem como ponto estratégico para a logística da empresa. Essas edificações apresentam-se como gigantescos galpões que são utilizados para a distribuição de mercadorias que são recebidas dos fabricantes para serem enviadas para pontos de vendas ou diretamente para os clientes, dependendo do tipo de atividade desenvolvida. 


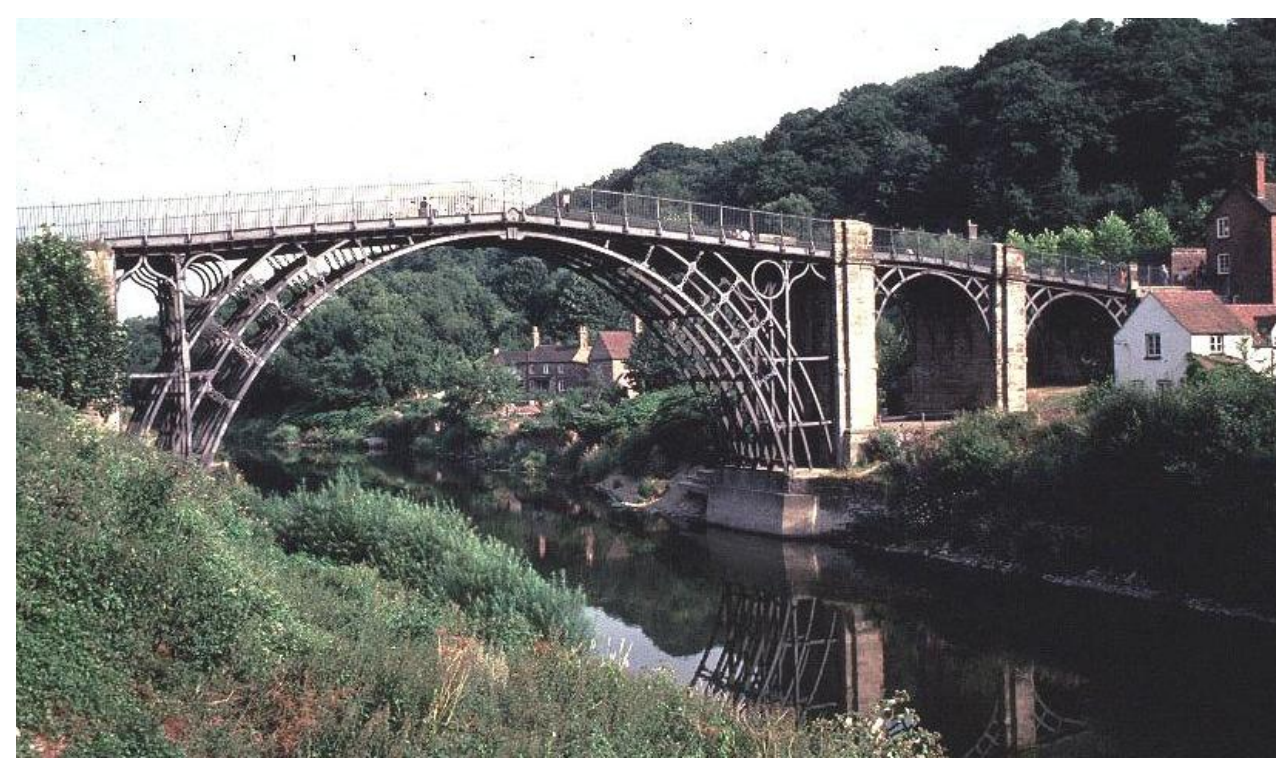

Figura 1.2 - Ponte de Coalbrookdale.

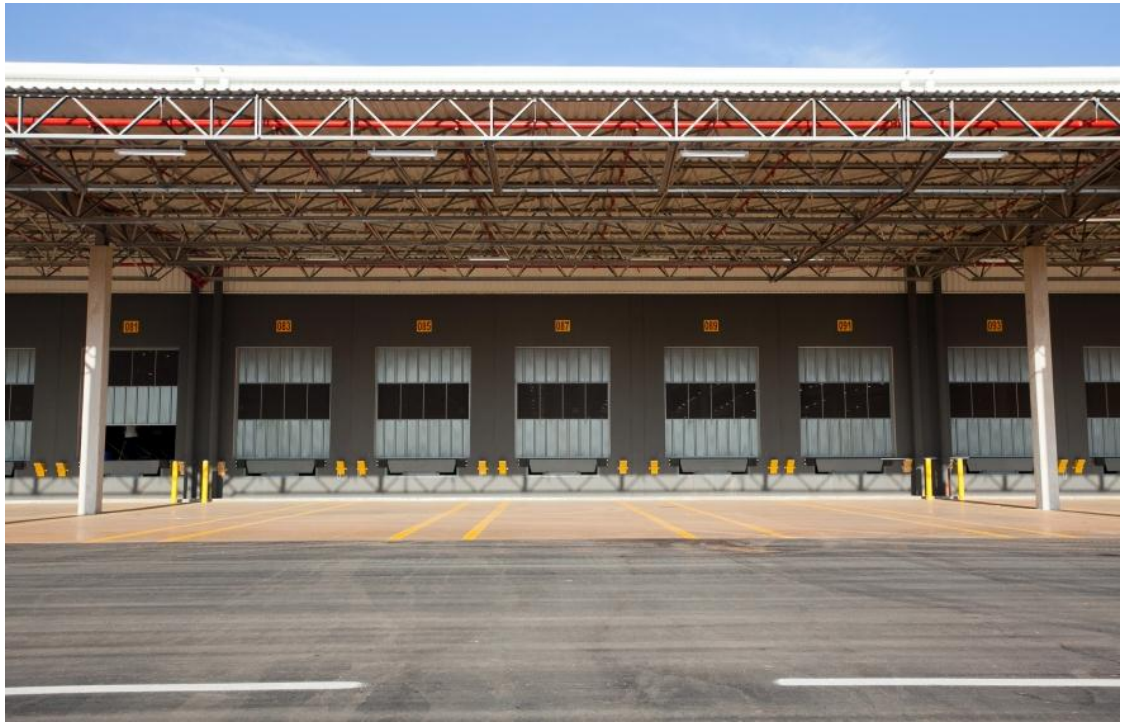

Figura 1.3 - Cobertura de estacionamento.

O centro de distribuição das Casas Bahia, em Jundiaí (SP), é, hoje em dia, um dos maiores da América Latina, mostrado na Figura 1.4. De acordo com Paduan (2008), tem uma área coberta de cerca de mais de $170.000 \mathrm{~m}^{2}$, onde cerca de 1,2 milhão de produtos comercializados mensalmente passam por essa edificação.

Esse tipo de construção, dentre outras citadas anteriormente, necessita de grandes espaços livres no seu interior, de forma a facilitar a montagem do espaço logístico dessas empresas. Dessa forma, fica evidente que se deseja que a edificação tenha a menor quantidade de pilares possível. 


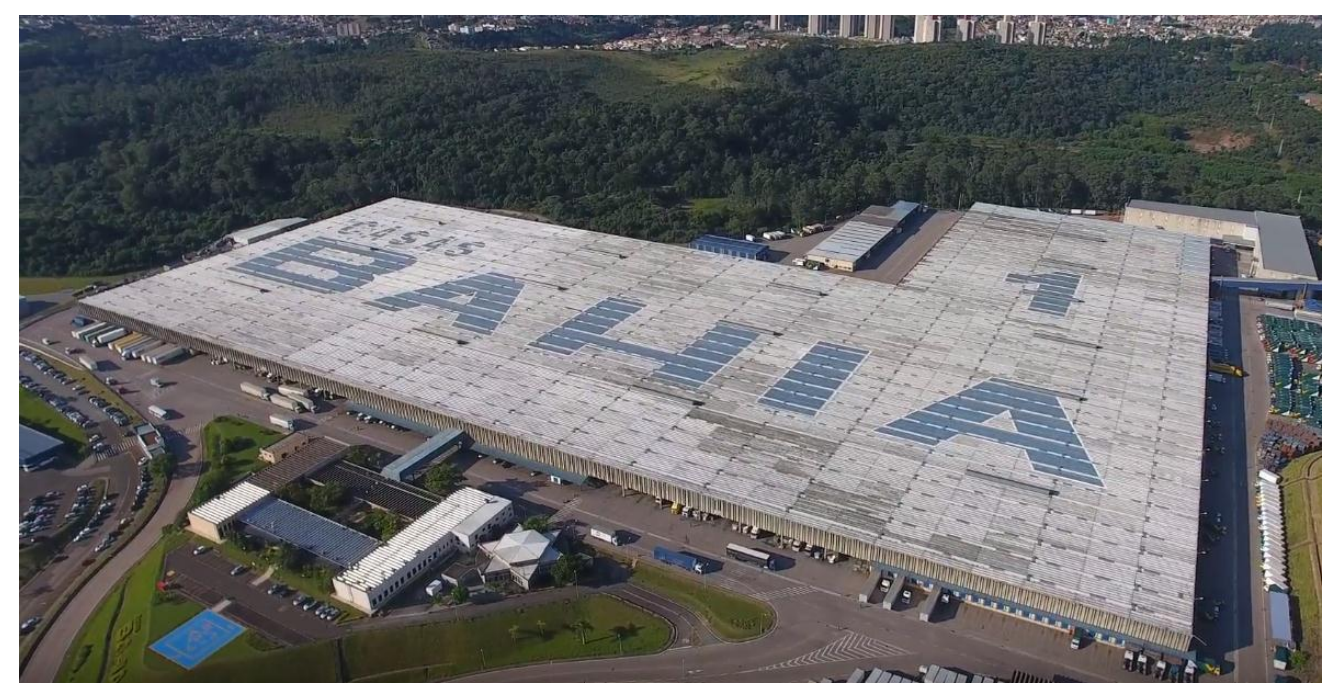

Figura 1.4 - Centro de distribuição das Casas Bahia - Jundiaí.

O ganho de espaços ao reduzir a quantidade de pilares exige que a edificação apresente um maior rendimento estrutural, visto que as cargas e deformações serão superiores com essa nova configuração de espaços.

Novas tecnologias têm sido desenvolvidas com o objetivo de vencer vãos cada vez maiores. Para sistemas de cobertura, a utilização de treliças leves padronizadas, conhecidas como steel joists, tem constituído uma solução eficiente para edificações industriais e comerciais.

Nesse tipo de estrutura, os elementos trabalham sob esforços axiais. Com isso, é possível utilizar a capacidade resistente máxima dos perfis utilizados, o que gera economia tanto para os perfis como para as fundações, já que se trata de redução de peso da estrutura. A Figura 1.5 mostra a cobertura de uma edificação industrial utilizando steel joists.

Estas treliças secundárias deverão ser apoiadas em vigamentos principais, que também apresentarão grandes vãos. Devido a essas grandes dimensões, é necessário projetar uma estrutura com deslocamentos reduzidos fora do plano.

Para estruturas como vigas laminadas ou treliças planas, podem ser utilizados sistemas de travamento, objetivando reduzir o comprimento destravado da estrutura, aumentando sua estabilidade lateral e capacidade de carga. Entretanto, em certos casos esse sistema pode encarecer bastante a obra, sendo desejável a redução de custos e a redução de elementos estruturais que prejudicam o aspecto estético da cobertura. 


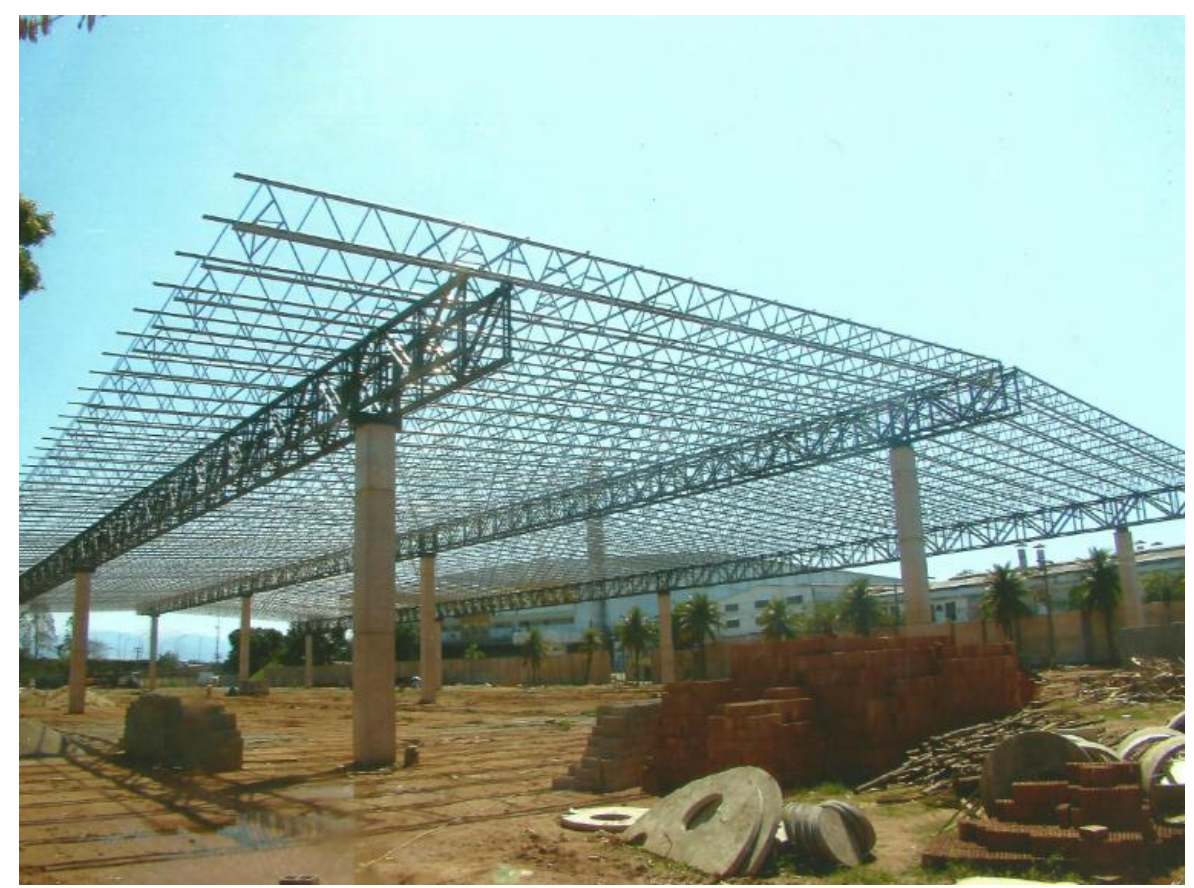

Figura 1.5 - Galpão em construção - Rio de Janeiro.

Como forma de evitar os custos com o sistema de travamentos entre essas treliças, pode-se utilizar outra configuração de treliça que dispensa esse tipo de travamento.

As treliças multiplanares apresentam-se como uma boa solução, pois possuem naturalmente uma boa estabilidade lateral. Com isso, a utilização desse tipo de estrutura para a ampliação dos tamanhos dos vãos dos galpões é uma boa solução, já que se reduz a quantidade de pilares e, consequentemente, aumenta-se a área da edificação livre de pilares.

Além da segurança e da eficiência da estrutura, outro ponto crucial para a qualidade de projeto estrutural é o custo. Atenção maior deve ser dada quando se trata de grandes edificações, pois há grande potencial de repetição de elementos a serem fabricados e montados.

A logística de execução da obra também tem papel fundamental no desenvolvimento e custo total da obra. Guindastes muitas vezes são necessários para a montagem da estrutura, principalmente as coberturas, e o custo do aluguel desse maquinário tem grande peso no orçamento da obra.

A substituição de um material mais oneroso por outro mais barato é sempre desejável, ainda mais quando essa substituição traz ganhos de resistência para a estrutura. Ganhos maiores são obtidos quando essa substituição não prejudica na logística de execução da obra. 
A literatura tem mostrado que a utilização de elementos compostos, ou mistos, constituídos por aço e concreto tem apresentado significativo aumento de resistência às solicitações de compressão e, além disso, mostra-se como solução economicamente viável, pois o custo do concreto é relativamente inferior ao do aço.

Assim, a possibilidade de aumentar o tamanho dos vãos aliada à possibilidade de reduzir custos com material, apresenta-se como uma solução bastante atrativa para a construção de edificações que necessitem de grandes áreas abertas, como centros de distribuição, supermercados, áreas de esportes, dentre outras.

\section{2.}

\section{Objetivos}

O objetivo desse trabalho é desenvolver projetos de treliças multiplanares, mistas ou não, para trabalhar adequadamente grandes vãos sem a necessidade de travamentos laterais, de forma a obter a solução de menor consumo de material.

Foram estudadas várias alternativas estruturais, projetadas com análises teóricas de segunda ordem do comportamento estrutural objetivando-se:

- Elaborar uma análise paramétrica das variáveis de projeto que influenciam no consumo de aço da estrutura, nas flechas e nos deslocamentos fora do plano;

- Avaliar os deslocamentos da estrutura dentro e fora do plano, verificando se a estabilidade lateral apresenta adequação, já que não serão utilizados travamentos laterais entre treliças;

- Identificar quais parâmetros constituem a solução que apresenta o menor consumo de aço;

- Avaliar o comportamento dos modos de ruína da estrutura. 


\section{3.}

\section{Apresentação e organização do trabalho}

Este trabalho contém sete capítulos, sendo que neste primeiro capítulo foi feita uma introdução ao tema proposto, além da motivação e dos objetivos para os quais este trabalho foi desenvolvido.

O capítulo 2 traz uma breve revisão teórica dos conceitos abordados no trabalho, desde a metodologia de construção de edificações industriais convencionais, partindo-se para os conceitos de coberturas de grandes vãos, apresentando os procedimentos adequados para o travamento dessas estruturas e, consequentemente, a ruína da mesma. São citadas, ainda, pesquisas relacionadas às treliças multiplanares, mostrando-se resultados encontrados na literatura, visando-se a sua aplicação em conjunto com elementos mistos de aço e concreto.

O capítulo 3 aborda as configurações estruturais e a metodologia de dimensionamento dos projetos de treliça, identificando-se os detalhes construtivos idealizados para a construção das estruturas em questão.

Exemplos de aplicação dessa metodologia são mostrados no capítulo 4, no qual são comparados os quatro tipos de perfis das cordas para uma mesma configuração geométrica.

O capítulo 5 apresenta os resultados dos projetos da treliça principal desenvolvida, além de abordar os mecanismos de falha que foram encontrados nas estruturas dimensionadas e as soluções adotadas para os mesmos.

Uma análise paramétrica dos resultados também é realizada neste capítulo. Nele, são comparadas as variações do comportamento estrutural e do consumo de aço com o efeito das alterações da geometria da treliça e do tipo de perfil das cordas.

Ainda será feito um levantamento de hipóteses quanto à influência dessas variáveis de projeto através de testes estatísticos, no qual será estudada a probabilidade destas hipóteses ocorrerem.

O capítulo 6 traz um estudo sobre qual é a solução de menor consumo de material, analisando qual solução é mais adequada para a estrutura, em função da geometria da treliça dos e tipos de perfis utilizados.

O capítulo 7 aborda as considerações finais, as conclusões obtidas e as recomendações para trabalhos futuros. 


\section{2 \\ Sistemas estruturais de cobertura}

Este capítulo traz de forma geral os principais tópicos relacionados com o desenvolvimento de edificações industriais, sistema de cobertura adequados para grandes vãos, aspectos de projeto das treliças leves padronizadas; e os mecanismos que controlam a ruína da estrutura, como os travamentos horizontais e verticais. São apresentadas também as treliças multiplanares, que possuem boa estabilidade fora do plano, característica fundamental para o desenvolvimento de estruturas de grandes vãos. Em seguida, é introduzido o sistema em estruturas mistas, mostrando suas características de viabilidade e comportamento da estrutura de seções compostas.

\section{1. \\ Edifícios industriais convencionais}

Geralmente, edifícios industriais são constituídos apenas por um pavimento, abrangendo uma grande área e são compostos por pórticos regularmente espaçados e com cobertura apoiada em sistemas de terças e vigas ou tesouras e treliças (CBCA, 2010). É utilizado para diversas atividades, como estoque do setor agropecuário, hangares de aeroportos, supermercados, dentre outros.

Para o desenvolvimento do projeto, é de fundamental importância que o proprietário defina claramente os objetivos e as necessidades da estrutura a ser construída. Dentre os fatores de que devem ser planejados estão: área livre, futuras expansões, altura da edificação, equipamentos específicos, dentre outros.

A configuração da geometria da edificação vai variar de acordo com a utilização desta. A partir dessas informações, poderá ser escolhida a tipologia do galpão, a altura, comprimento do vão e tipo de cobertura.

Para galpões convencionais, as telhas metálicas são apoiadas nas terças, que por sua vez são apoiadas nas tesouras treliçadas da estrutura de cobertura. A Figura 2.1 ilustra as partes principais de um galpão simples. 


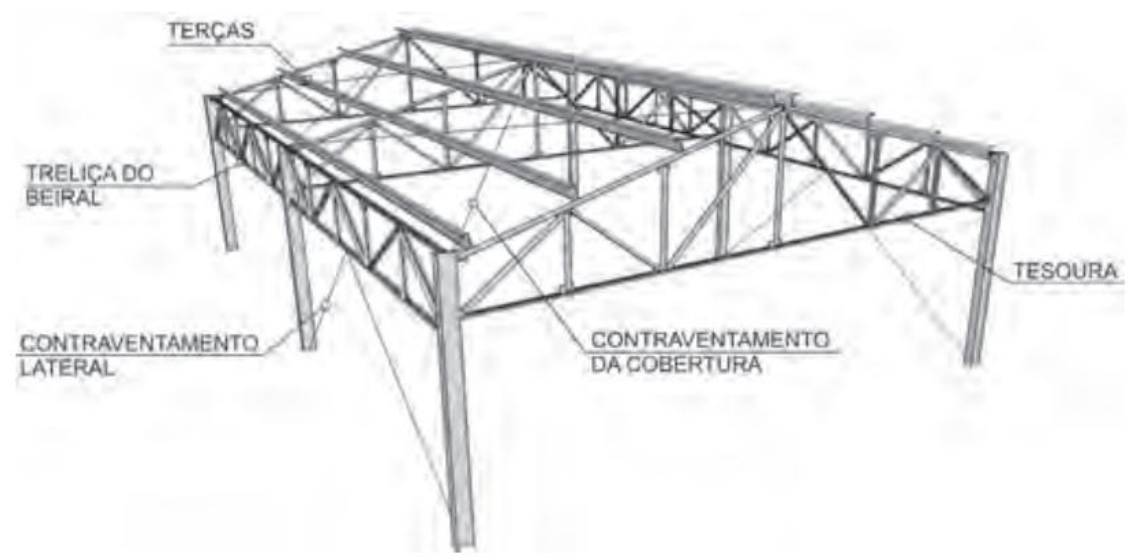

Figura 2.1 - Componentes de um galpão (CBCA, 2010).

Bellei (1998) classifica o comprimento dos vãos de edificações industriais de acordo com a Tabela 2.1.

\begin{tabular}{|c|c|}
\hline Classificação & Vão \\
\hline Pequeno & Até $15 \mathrm{~m}$ \\
\hline Médio & $16 \mathrm{~m}$ a 35m \\
\hline Grande & Maiores que 35m \\
\hline
\end{tabular}

Tabela 2.1 - Classificação do comprimento dos vãos (BELLEI, 1998).

Entretanto, esta classificação hoje em dia mudou bastante devido à melhora das características dos materiais empregados, podendo-se sugerir o ajuste mostrado na Tabela 2.2.

\begin{tabular}{|c|c|}
\hline Classificação & Vão \\
\hline Pequeno & Até $30 \mathrm{~m}$ \\
\hline Médio & $30 \mathrm{~m}$ a $60 \mathrm{~m}$ \\
\hline Grande & Maiores que $60 \mathrm{~m}$ \\
\hline
\end{tabular}

Tabela 2.2 - Classificação ajustada da classificação de galpões.

A tipologia da edificação também é alterada de acordo com a inclinação do telhado. A NBR 8800 (ABNT, 2008) recomenda que a inclinação das coberturas não seja inferior a 3\%, de modo a evitar o colapso estrutural ocasionado por empoçamento progressivo, este decorrente do peso próprio da água retida de chuva.

Para edificações em que a inclinação do telhado seja superior a $15^{\circ}$, a forma mais econômica para se construir a cobertura é utilizando uma tesoura apoiada em 
uma coluna simples e utilizando telhas metálicas apoiadas nas terças. Obviamente, esse tipo de estrutura é adotado para coberturas de vãos pequenos, podendo ser inapropriado para determinados usos.

Para vãos maiores, ou quando a inclinação da estrutura for de $15^{\circ}$ a $6^{\circ}$, recomenda-se a utilização de treliças para o sistema de cobertura. Esses dois tipos de cobertura podem ser vistos na Figura 2.2, respectivamente.
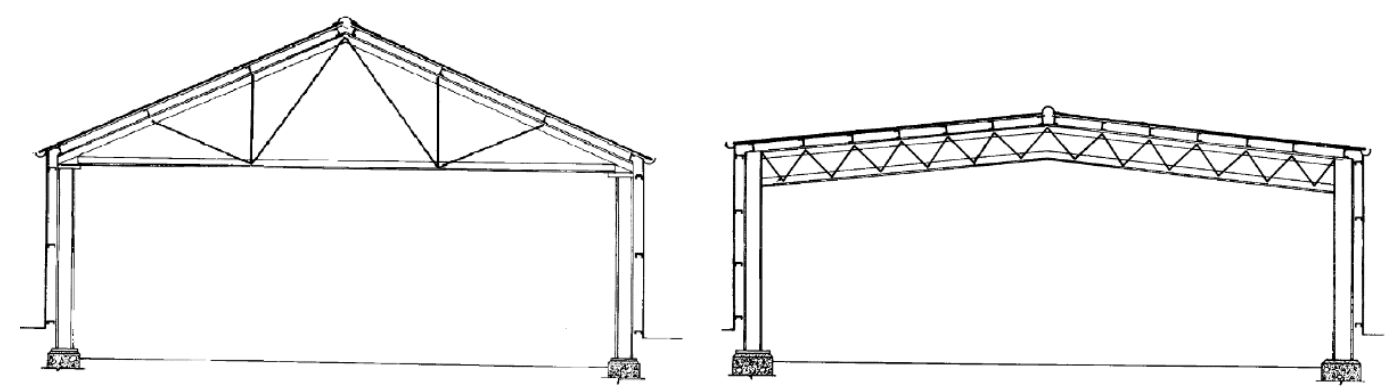

Figura 2.2 - Cobertura de galpões com tesoura e treliçado, respectivamente (Adaptado de BELLEI, 1998).

\section{2.}

\section{Sistema de travamento}

De acordo com Winter (1960), há muitas situações em que é necessário determinar características para o travamento lateral com o objetivo de redução do comprimento de flambagem de colunas e do trecho destravado de vigas. O sistema de travamento deve apresentar características de resistência e rigidez, impedindo deslocamentos excessivos que podem levar a estrutura à ruína.

Além disso, a capacidade resistente de elementos comprimidos, como colunas e cordas de treliças, é governada pela esbeltez da peça, diretamente relacionada com o seu comprimento destravado.

Quanto à força a ser resistida por essas estruturas, a norma AISC/16 afirma que os elementos devem ser capazes de resistir à um carregamento axial equivalente a $0,005 \mathrm{P}$, onde $\mathrm{P}$ representa a força axial atuante na peça a ser travada. Já para a rigidez dos elementos de travamento, esta deve ser igual ou superior a 4P/L, onde L é igual ao comprimento destravado. 
Galambos (2008) classificou o sistema de travamentos em quatro tipos: discreto, contínuo, relativo e lean-on. O sistema discreto constitui-se como um sistema pontual para impedir os deslocamentos, como o mostrado na Figura 2.3.

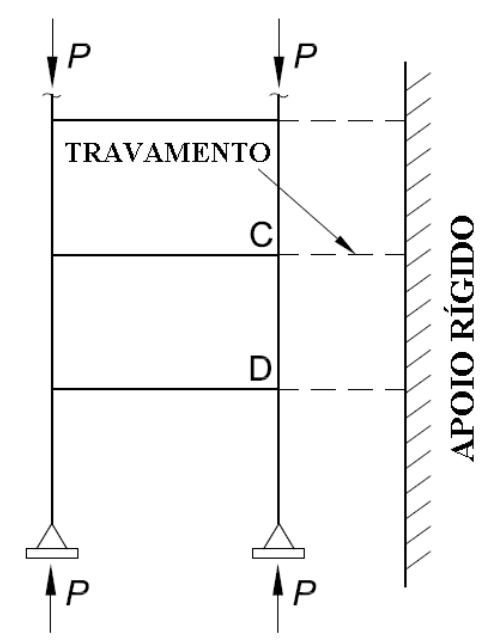

Figura 2.3 - Sistema discreto de travamento (Adaptado de: AISC, 2016).

O sistema contínuo, como o próprio nome explica, permite que se restrinja os deslocamentos de uma estrutura de forma continuada, como o sistema de lajes mistas. O sistema relativo é muito utilizado em treliças, controla o movimento relativo entre dois pontos de duas estruturas, como mostrado na Figura 2.4.

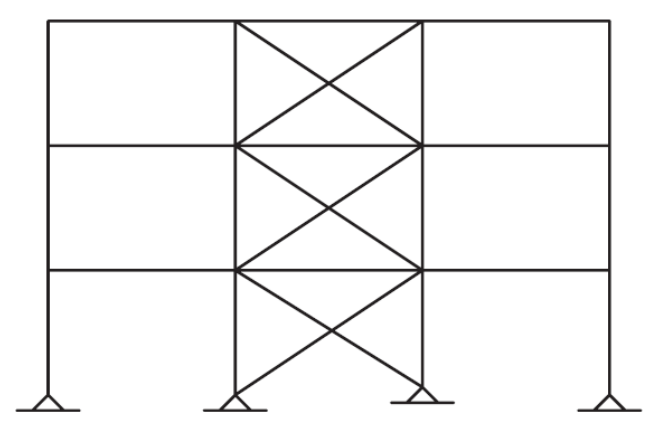

Figura 2.4 - Sistema de travamento relativo (Galambos, 2008).

O sistema de travamentos tipo lean-on é utilizado em pilares e ocorre quando um elemento obtém suporte aos deslocamentos laterais em um elemento adjacente de maior rigidez.

Em se tratando de treliças planas, o travamento em alguns pontos da estrutura é de fundamental importância para a estabilidade fora do plano de elementos comprimidos. 
As terças, que suportam as telhas metálicas, representam parte do sistema de travamento de forma natural, entretanto, não sendo suficiente para impedir deslocamentos laterais, podendo ocorrer a flambagem simultânea de diversas tesouras da estrutura, como é mostrado na Figura 2.5.
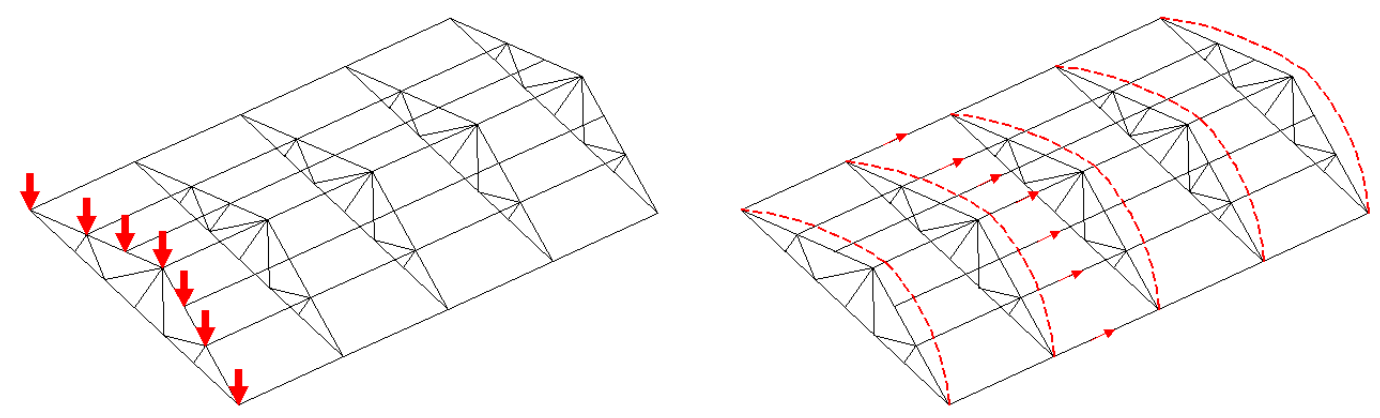

Figura 2.5 - Terças gerando flexão nas barras da tesoura e apresentando falta de travamento (CBCA, 2012).

Para evitar que isso ocorra, é necessário que se realize um tipo de travamento complementar, como elementos dispostos nas diagonais em forma de $\mathrm{X}$, como pode ser visto na Figura 2.6. Esses elementos têm a função de manter a estrutura sem grandes deslocamentos fora do plano e travando o sistema junto aos apoios.

Travamento em forma de $\mathrm{X}$ é sempre mais econômico pois evita que a estrutura venha a trabalhar com os efeitos de segunda ordem. A configuração em X permite que os elementos (normalmente cabos ou vergalhões) trabalhem sempre à tração, independentemente do sentido do carregamento (CBCA, 2012).

O travamento diagonal entre tesouras é uma outra opção para dar maior estabilidade global para a estrutura, formado por elementos diagonais em forma de $\mathrm{X}$ entre as tesouras da cobertura, como pode ser visto na Figura 2.7.

Além disso, deve ser dada uma atenção especial nos casos em que o vento provoca sucção na estrutura, o que inverte os esforços nos banzos inferiores, provocando nestes, compressão simples. Para isso, são utilizadas mãos-francesas, que transmitem os esforços para as terças e, por sua vez, transmitem para os travamentos horizontais. A Figura 2.8 mostra a configuração da mão-francesa. 


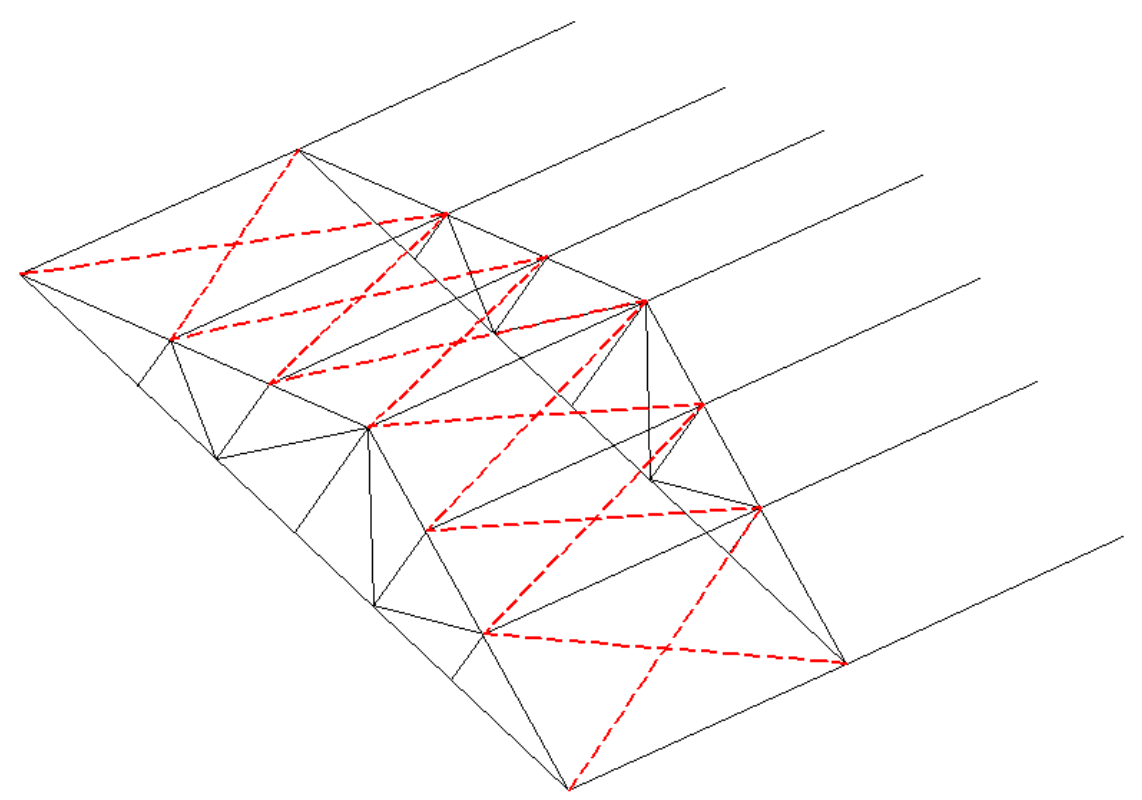

Figura 2.6 - Travamento relativo em X da cobertura (CBCA, 2012).

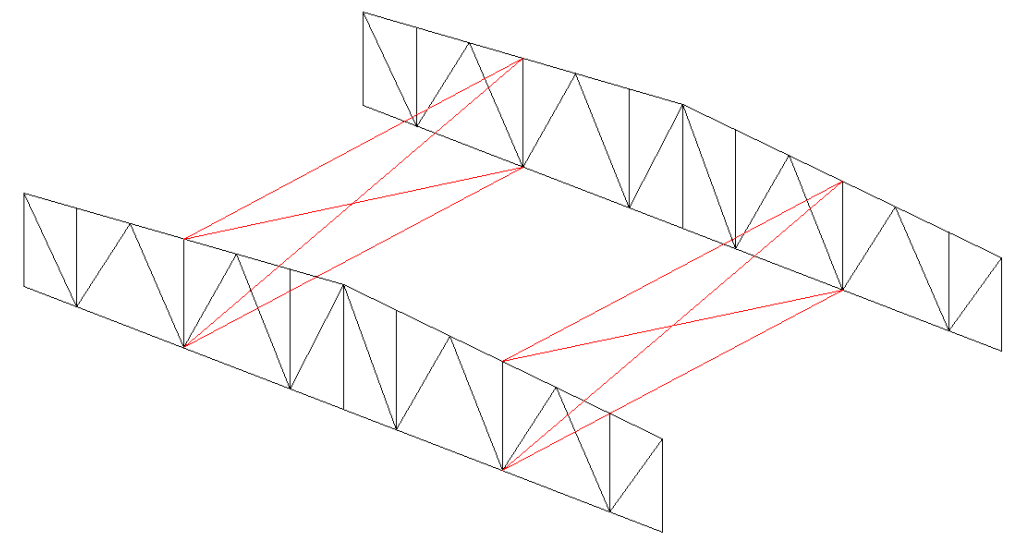

Figura 2.7 - Travamento diagonal entre tesouras.

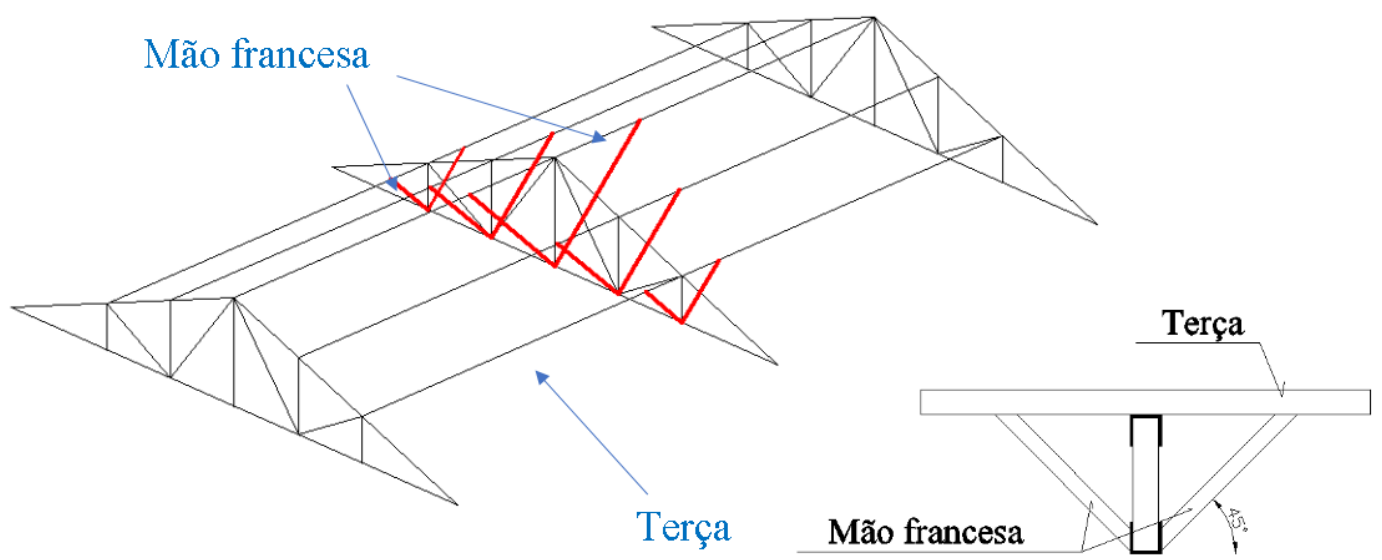

Figura 2.8 - Detalhe: mão francesa (Adaptado de CBCA, 2012). 


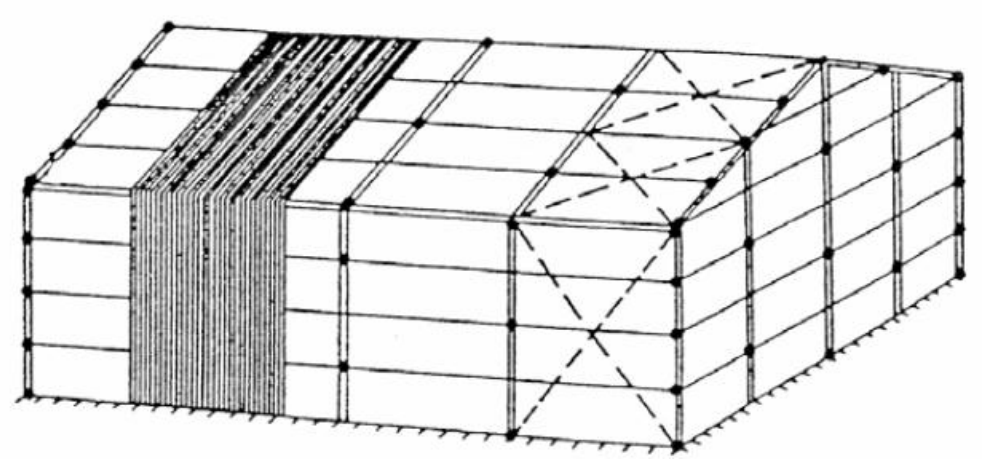

Figura 2.9 - Contraventamento em X (Carneiro e Martins, 2008).

\section{3.}

\section{Coberturas de grandes vãos}

De acordo com Samarra (2007), uma das características principais para um sistema de cobertura ser eficiente e econômico é a sua padronização, pois racionaliza o processo de fabricação devido às peças repetidas e pela simplificação de montagem.

Para estruturas de grandes vãos, é fundamental utilizar-se um sistema de cobertura mais eficiente e que mantenha um baixo peso de aço por metro quadrado. O steel joist é baseado em um sistema de vigas treliças leves e paralelas, travadas entre si, de fácil e rápida montagem. O mesmo é utilizado também para sistemas de vigamentos de pisos de concreto armado e fechamentos laterais. A Figura 2.10 apresenta uma ilustração esquemática de um módulo padrão deste sistema.

Com esse sistema construtivo, as solicitações provenientes de telhas, forros e instalações, dentre outros carregamentos construtivos são aplicados nos joists secundários, que estão simplesmente apoiados nos vigamentos principais. Por fim, este sistema de treliças leves pode se apoiar em pilares da estrutura ou, em casos de possuir maiores vãos, se apoiam em vigamentos principais.

As seções ilustradas na Figura 2.10 são padronizadas pela Steel Joist Institute. De acordo com Samarra (2007), em função da padronização, se utiliza o mesmo perfil para o banzo superior e inferior e o mesmo perfil para as diagonais, prescritos em tabelas fornecidos pelos fabricantes. A Figura 2.11 ilustra uma cobertura que utiliza steel joist. 


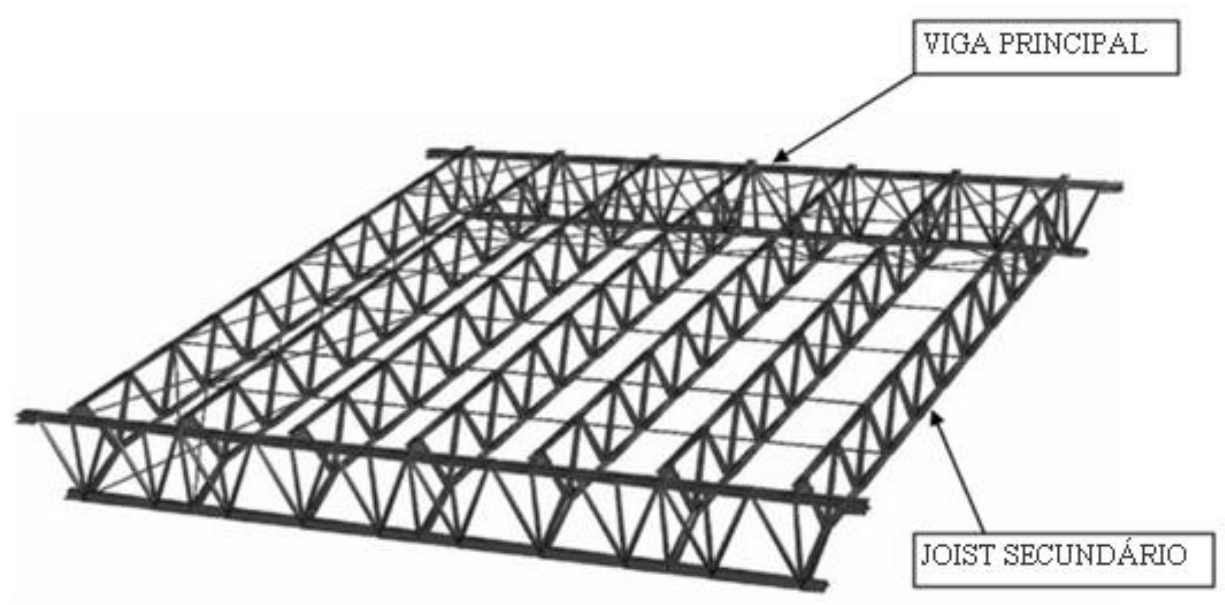

Figura 2.10 - Esquema do sistema steel joist (Adaptado de: CBCA, 2007).
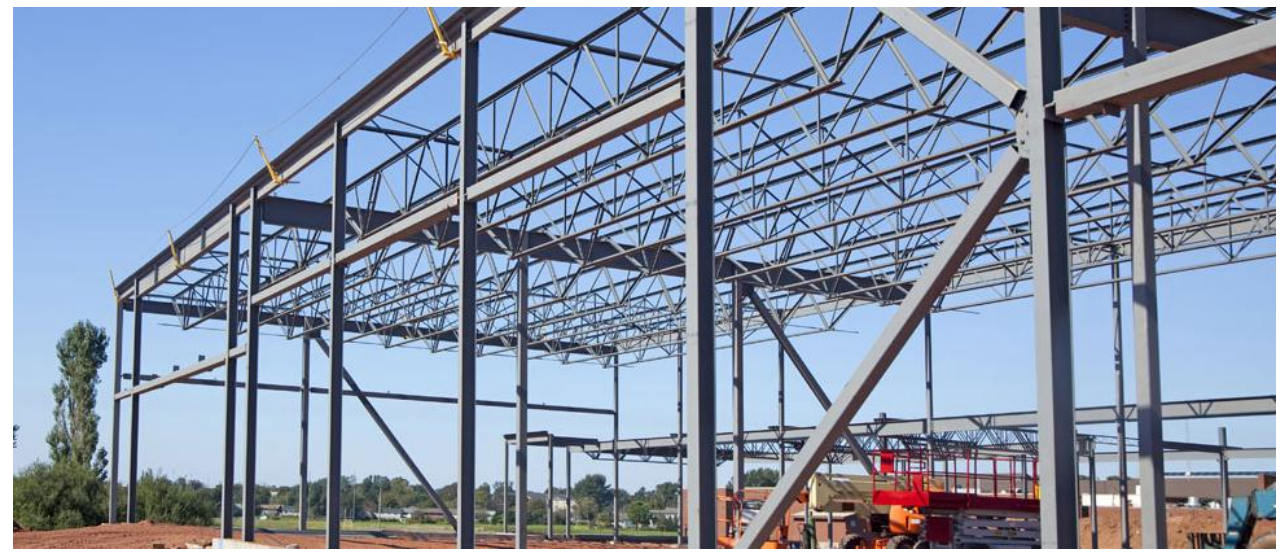

Figura 2.11 - Cobertura com steel joist.

Cabe notar que esse sistema é composto por elementos de grande esbeltez.

Dessa forma, devem ser previstos travamentos entre os joists para garantir a estabilidade lateral do conjunto, como mostrado na Figura 2.12. Já na ligação entre estruturas principais e secundárias, pode-se utilizar a extensão da corda inferior para travar a corda do sistema principal, como mostrado na Figura 2.13.

Para coberturas de edificações industriais convencionais, há a possibilidade de se utilizar três tipos diferentes de estruturas para trabalhar como vigas principais, são elas: vigas laminadas, treliças leves padronizadas (conhecidas como steel joists) ou treliças fabricadas para cada finalidade específica.

Fisher (2004) faz recomendações para as aplicações mais econômicas visando o comprimento do vão de galpões industriais. Para vãos de $9 \mathrm{~m}$ a $12 \mathrm{~m}$ de compri- 
mento, a solução mais viável é utilizar vigas com perfis laminados. Para comprimento de $12 \mathrm{~m}$ até $24 \mathrm{~m}$, é recomendado que sejam utilizados steel joist apoiados em treliças principais que se apoiam diretamente nos pilares da estrutura. Já para vãos maiores que os citados, recomenda-se a utilização de vigamentos principais formados por treliças de cobertura.

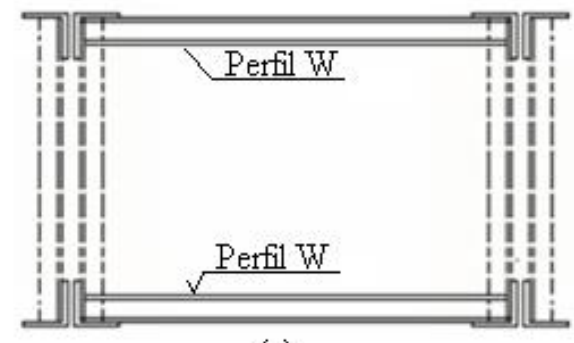

(a)

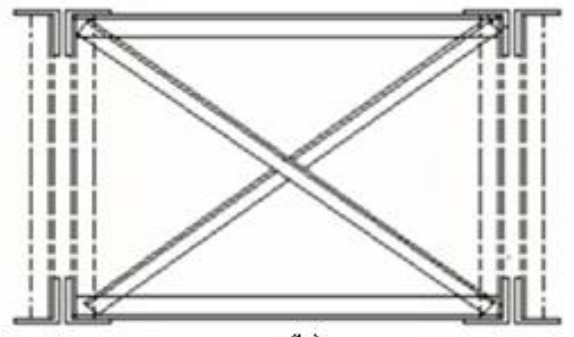

(b)

Figura 2.12 - Travamentos entre joists: em quadro (a) e em diagonal (b).

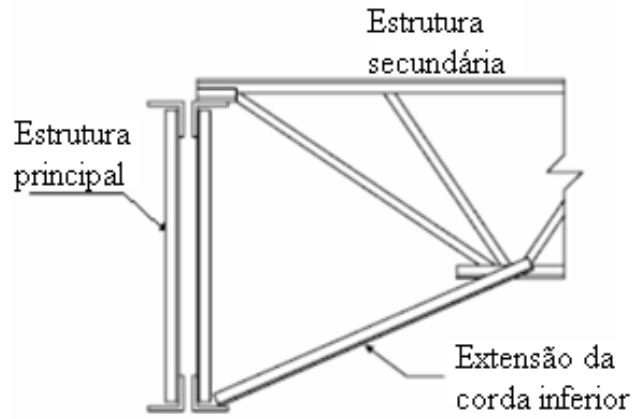

Figura 2.13 - Mão francesa da ligação do joist com a estrutura principal.

\section{4.}

\section{Treliças multiplanares}

Treliças multiplanares têm sido bastante utilizadas para vencer grandes vãos, pois sua geometria, diferentemente de treliças planas, apresenta grande resistência aos deslocamentos fora do plano.

Nesse tipo de estrutura, a rigidez aos deslocamentos laterais é dada por sua geometria: as cordas superiores, paralelas e interligadas pelas estruturas secundárias, trabalham em conjunto formando uma grande inércia para fora do plano. Assim, grandes vãos podem ser vencidos sem a necessidade de travamentos. A Figura 2.14 mostra a configuração geométrica deste tipo de estrutura. 


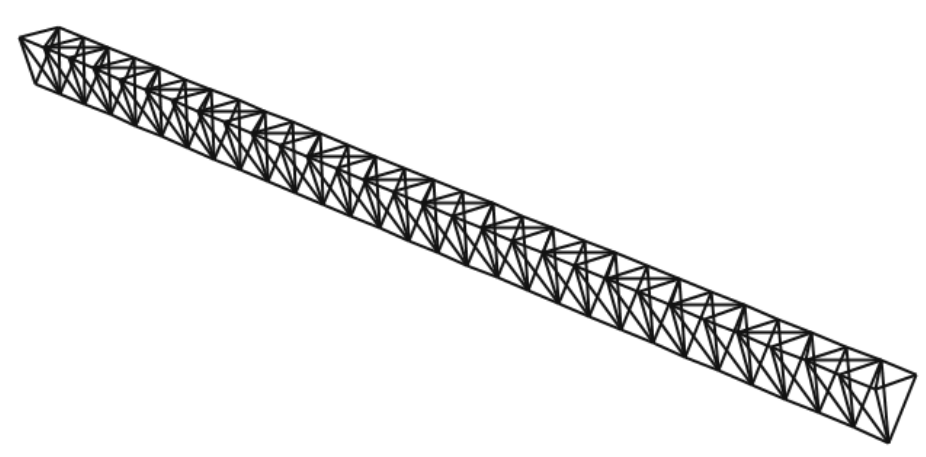

Figura 2.14 - Treliça multiplanar.

Por ter esse rendimento estrutural, as estruturas multiplanares têm sido cada vez mais utilizadas em estruturas que necessitam de grandes áreas livres, como de galpões, supermercados, dentre outros.

Para estudar o desempenho desse tipo de estrutura, Vieira (2010) realizou análises experimentais com duas treliças, com vãos de 30 metros, utilizando perfis tubulares para as cordas e para as diagonais.

Para seu trabalho, a combinação crítica de carregamento foi gerada pela sucção do vento. Para simular a aplicação dessas cargas, a geometria da treliça foi invertida e o carregamento foi aplicado nas cordas superiores da treliça, local este que ocasiona efeito mais desestabilizante na estrutura. A Figura 2.15 mostra a realização do ensaio, mostrando a inversão da geometria para a simulação dos efeitos de sucção do vento.

A partir dos ensaios, concluiu-se que esta configuração de treliça dispõe de uma ótima estabilidade lateral e um bom comportamento global, tornando-se ideal para estruturas de cobertura, pois tem a capacidade de cumprir bem grandes vãos. 


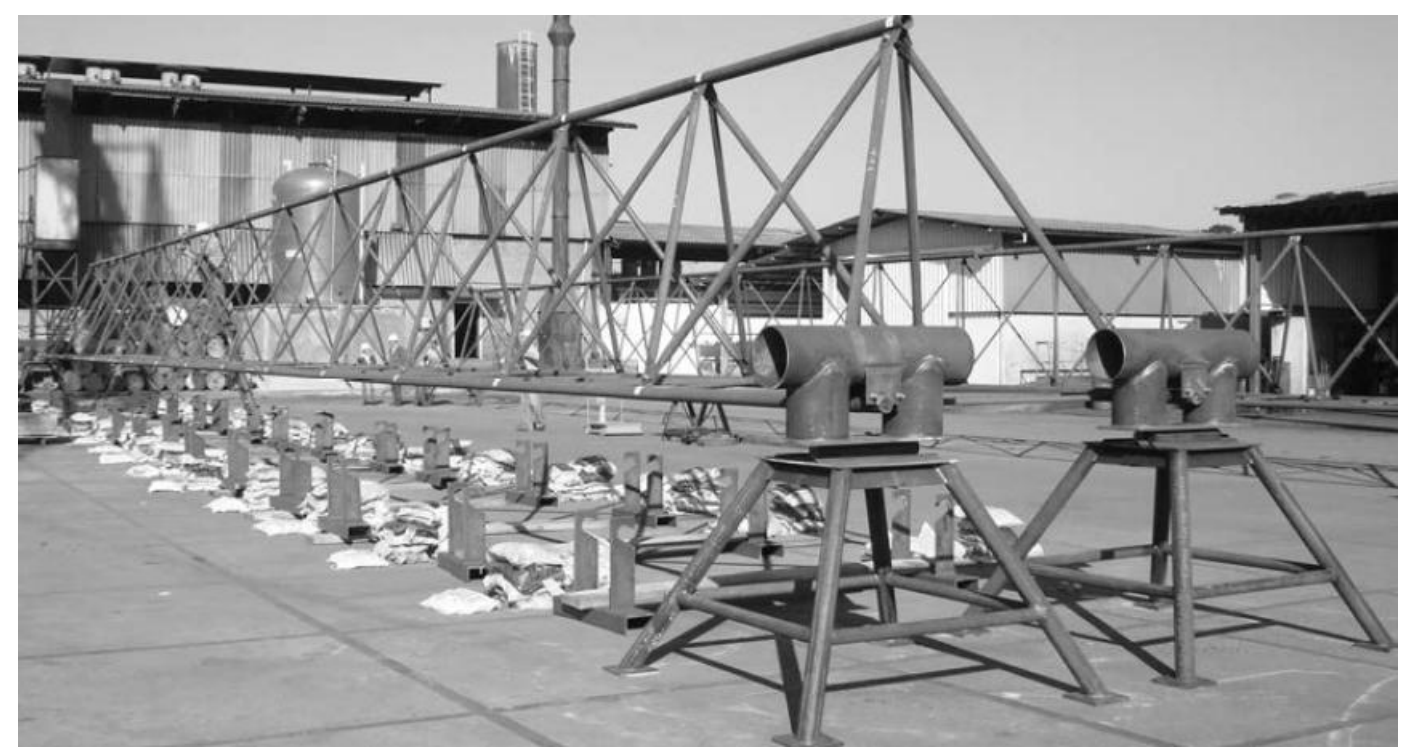

Figura 2.15 - Treliça multiplanar (VIEIRA et al, 2010).

\section{5. \\ Treliças com elementos mistos}

As cordas comprimidas das treliças trabalham predominantemente aos esforços axiais, independentemente do sentido das cargas atuantes, sejam elas gravitacionais ou variáveis. Assim, para o dimensionamento desses elementos utilizando seções mistas, pode-se fazer uso de colunas mistas, nos trechos de maiores solicitações de compressão.

De acordo com Liang (2015), as colunas mistas têm sido amplamente utilizadas em edificações de múltiplos pavimentos, estruturas off-shore e em pontes devido à sua alta performance estrutural, graças aos seguintes fatores: alta resistência, grande rigidez, grande capacidade de absorção de energia, grande ductilidade e resistência ao fogo.

Essas estruturas são recomendadas para grandes solicitações de compressão, como pilares centrais de arranha-céus ou de obras de infraestrutura. Entretanto, normalmente essas estruturas trabalham como viga-coluna, suportando carregamentos axiais e momentos fletores.

Como as cordas das treliças trabalham predominantemente sob esforços internos axiais, percebe-se que a utilização de elementos mistos nas regiões de compressão da treliça é muito vantajosa devido aos diversos benefícios citados acima. 
A adição de concreto no interior de tubos de aço também faz com que se aumente consideravelmente a resistência e rigidez dessas estruturas quando submetida a esforços de flexão. Elchalakani (2001) realizou ensaios experimentais com diversas seções de elementos CFST e comprovou que o efeito conjunto do aço e do concreto faz com que essas peças aumentem sua ductilidade e resistência a esse tipo de solicitação.

Os tipos mais comuns dessas estruturas utilizadas apresentam essas três configurações: envolvendo-se completamente o perfil metálico com concreto, chamados de CEC (concrete encased composite); envolvendo parcialmente um perfil metálico por concreto, chamados de PCEC (partially concrete encased composite); e preenchendo completamente o interior de um perfil tubular de aço por concreto, chamados de CFST (concrete filled steel tubular). Essas configurações podem ser vistas de forma simplificada na Figura 2.16.
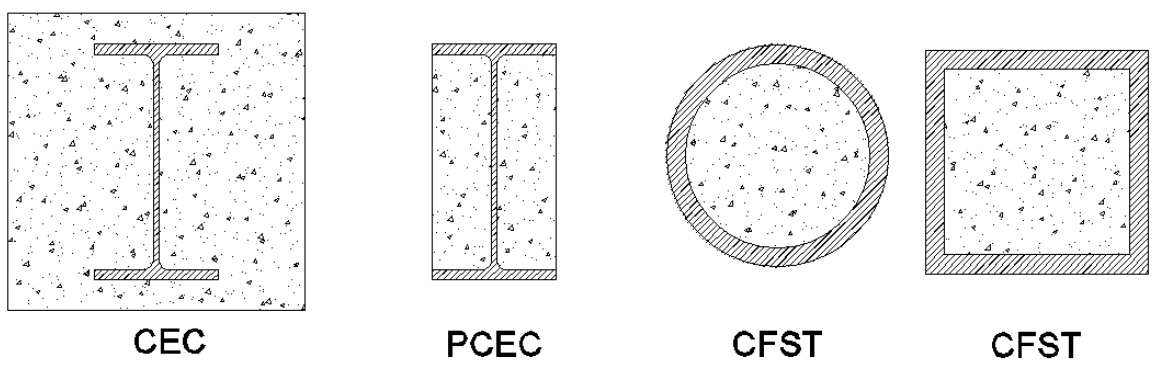

Figura 2.16 - Tipos de colunas mistas.

Outra vantagem de se utilizar estruturas CFST é que o próprio perfil de aço pode servir como fôrma para o concreto. Dessa forma, há uma economia de custos referentes a fase de construção, além da possibilidade de agilizar o desenvolvimento da obra.

\subsection{1.}

\section{Comportamento da estrutura CFST}

A grande capacidade de resistir às tensões de compressão se explica na ação conjunta dos dois materiais. Taranath (2012) afirmou que a ação composta desses materiais é sinérgica, ou seja, o comportamento da estrutura mista é superior à soma dos componentes separados. 
Han (2016) também demonstra isso no Gráfico 2.1 no qual compara diversas seções transversais, relacionando carregamento aplicado e deformação axial. Percebe-se que a ductilidade da estrutura CFST é relativamente superior que a soma dos materiais separadamente.

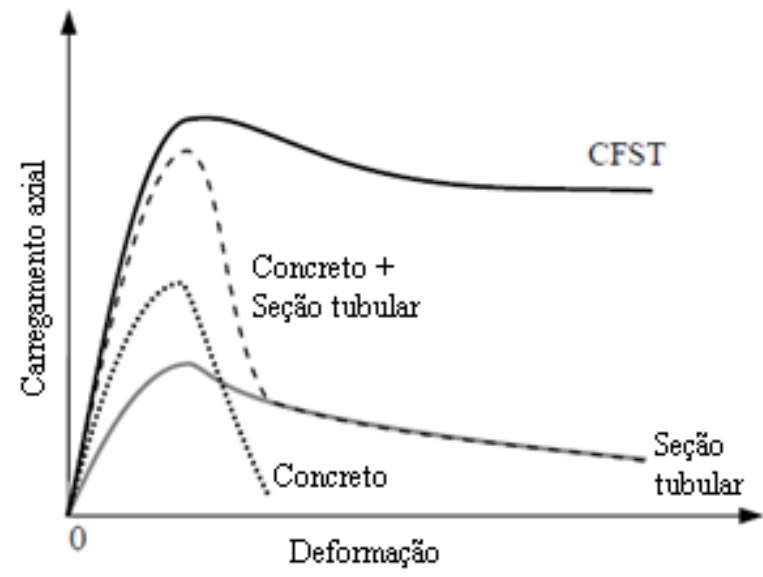

Gráfico 2.1 - Relação carregamento e deformação axial de colunas (HAN, 2016).

Muitos estudos comprovam que esse ganho de resistência está diretamente relacionado ao efeito de confinamento da peça, este que submete o concreto a tensões tri-axiais, situação na qual o material consegue resistir a maiores tensões de compressão.

Shantong (2007) explica o comportamento dos elementos CFST:

O comportamento de tubos circulares preenchidos por concreto é consideravelmente afetado pela diferença dos coeficientes de Poisson do concreto e do aço. No estágio inicial de carregamento, o coeficiente de Poisson do concreto é menor que o do aço. Assim, o tubo de aço não aplica efeitos de confinamento no núcleo de concreto. Com o aumento da deformação longitudinal, a expansão lateral do concreto gradualmente torna-se maior que a expansão do tubo de aço. Neste estágio, o concreto sofre tensões tri-axiais, enquanto que o aço sofre tensões biaxiais. $\mathrm{O}$ aço, ao atingir as tensões de escoamento, transfere o carregamento do tubo para o núcleo de concreto. $\mathrm{O}$ tubo apresenta um decréscimo do carregamento compartilhando o mesmo até que o concreto atinja o máximo de sua resistência à compressão. Após isso, o concreto devolve as tensões para o aço, este que irá apresentar comportamento plástico até a ruptura.

Com base nos em ensaios experimentais, Han (2002) introduziu o conceito de fator de confinamento descrito pelo fator $\xi$ : 


$$
\xi=\frac{A_{s} f_{y}}{A_{c} f_{c k}}
$$

Onde $A_{s}$ e $A_{c}$ são as áreas das seções transversais do aço e do concreto, respectivamente; $f_{y}$ é a tensão de escoamento do aço e $f_{c k}$ é a resistência característica do concreto.

Existe um limite para este fator, chamado de crítico, que serve como parâmetro para o efeito de confinamento da peça. Caso o fator crítico $\left(\xi_{o}\right)$ seja maior que o coeficiente na seção avaliada, tal peça irá apresentar menor resistência à compressão. De forma análoga ocorre quando o fator de confinamento é maior que o fator crítico.

Esse fator crítico é variável de acordo com o tipo de seção transversal: $\xi_{o} \approx$ 1.1 para seções circulares; e $\xi_{o} \approx 4.5$, para seções retangulares. Outro ponto importante a se notar é que quanto maior for o fator de confinamento, maior será a ductilidade do concreto confinado.

A Figura 2.17 ilustra os modos de falhas de três tipos de colunas submetidas a esforços de compressão: a primeira refere-se a um tubo metálico, desenvolvendo sua flambagem local nas regiões externa e interna; a segunda mostra uma coluna de concreto cuja falha ocorre por cisalhamento; a terceira configura-se por uma falha de uma coluna CFST, que apresenta apenas flambagem local externa (HAN, 2016).
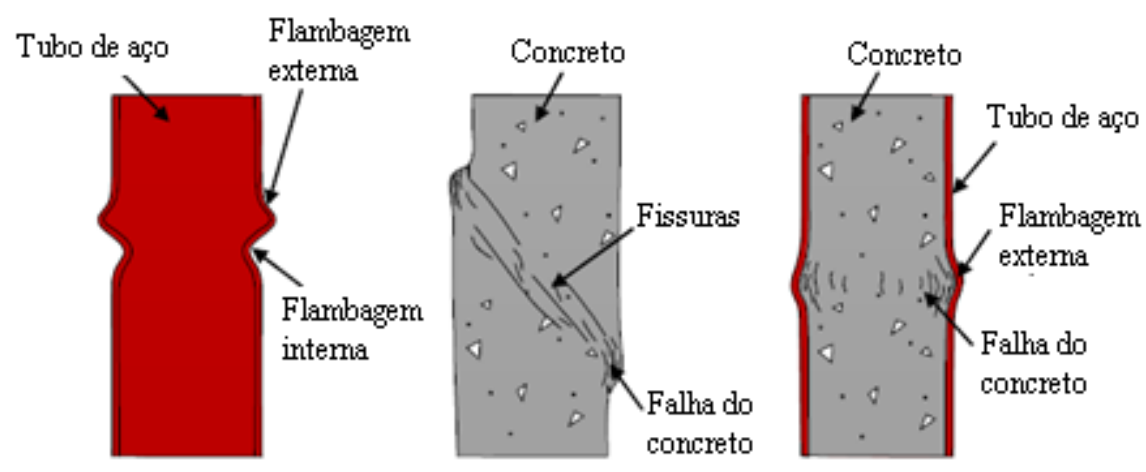

Figura 2.17 - Modos de falha das colunas (HAN, 2016).

Observa-se que o concreto no interior do perfil de aço impede que haja flambagem interna da seção. 


\subsection{2. \\ Dimensionamento de colunas CFST à força axial de compressão de acordo com a AISC}

A AISC (2016) utiliza três métodos para a determinação da resistência das seções transversais de colunas compostas dependendo da classificação da seção de acordo com sua esbeltez local. Para as seções compactas, são utilizados dois métodos: o da distribuição plástica das tensões e o da compatibilidade de deformações. Para as seções não compactas e/ou esbeltas, utiliza-se o método da tensão-deformação efetiva.

Pelo fato de ser mais simples e amplamente utilizado, a norma utiliza o método da distribuição plástica de tensões para o desenvolvimento das fórmulas a serem aplicadas para o dimensionamento das estruturas compostas.

Esse método é baseado na análise do limite plástico das seções transversais, no qual a seção composta forma uma rótula plástica ao atingir a ruína. Assim, considera-se que o concreto e o aço apresentam um comportamento uniaxial rígidoplástico, no qual o aço possui uma única tensão limite de escoamento $f_{y}$ para ambas as direções axiais e a tensão compressiva do concreto igual a $0,85 f^{\prime}{ }_{c}$. A resistência do concreto à tração é desconsiderada.

Será considerada uma rigidez efetiva reduzida na seção, pois objetiva-se levar em consideração perdas relativas de resistência, como fissuração do concreto e escoamento parcial do aço, retração e deformação lenta. Além disso, peças esbeltas sofrerão reduções maiores devido à possibilidade de falha por flambagem elástica global da estrutura.

Desta forma, para seções CFST, a rigidez efetiva da seção composta será dada por (2.2).

$$
E I_{\text {eff }}=E_{s} I_{s}+E_{s} I_{s r}+C_{1} E_{c} I_{c}
$$

onde $C_{1}$ corresponde ao coeficiente de cálculo da rigidez efetiva para membros CFST e é dado por (2.3).

$$
C_{1}=0,25+3\left(\frac{A_{s}+A_{s r}}{A_{g}}\right) \leq 0,7
$$

A AISC apresenta uma formulação conservadora para a resistência à compressão das estruturas CFST: equivale à soma das resistências dos materiais da seção composta separadamente. Já foi dito anteriormente que este resultado é inferior 
aos obtidos em estudos experimentais, ficando uma porcentagem da resistência última como margem de segurança. Para o cálculo da resistência à tração, esta equivale à soma da resistência do perfil tubular com as armaduras longitudinais, se estas existirem.

A resistência à compressão da seção transversal $\left(P_{o}\right)$ de acordo com a AISC para estruturas CFST é dada por (2.4).

$$
P_{o}=F_{y} A_{s}+F_{y s r} A_{s r}+0,85 f^{\prime}{ }_{c} A_{c}
$$

É interessante afirmar que o Eurocode considera que o coeficiente Rüsch aplicado nessa fórmula, ou seja, o valor 0,85 deve ser trocado pelo valor 1 , para as estruturas CFST.

Para se calcular a resistência à compressão de projeto, deve-se relacionar com o valor da carga crítica de flambagem elástica de Euler e, posteriormente, multiplicar pelo coeficiente de ponderação. Se o valor for maior que 2,25, deve ser utilizada a fórmula (2.5).

$$
P_{n}=0,877 P_{e}
$$

Caso seja menor ou igual a 2,25, deve-se. então, utilizar a fórmula (2.6).

$$
P_{n}=P_{n o}\left(0,658^{\frac{P_{n o}}{P_{e}}}\right)
$$

A introdução de forças externas aos membros mistos, como ligação de viga com o pilar ou a ligação de uma corda de treliça com as diagonais da mesma, exerce uma força de cisalhamento longitudinal no membro misto. Com isso, o concreto pode escorregar da parede de aço, prejudicando a seção da coluna.

Existem três mecanismos para o combate deste tipo de solicitação nas regiões de aplicação de carga: por ligação direta, por conectores de cisalhamento (stud bolts) e por placas que suportem essas cargas concentradas.

Roeder (1999), em seu trabalho que serviu de embasamento para a AISC, afirma que a transferência de carga da ligação direta entre o tubo de aço e o núcleo de concreto depende do deslocamento radial que é dado devido à pressão que o concreto fresco exerce na parede do tubo e devido à retração do concreto, obviamente aliado com a rugosidade da parede do tubo. 
Analisando os experimentos do tipo push-out de 20 colunas CFST circulares mistas, Roeder (1999) formulou uma expressão que fornece um resultado conservador para a determinação da resistência da peça ao cisalhamento por ligação direta de acordo com (2.7).

$$
f_{2 c r}[M P a]=2,109-0,026(d / t)
$$

A região de introdução de cargas adotada para a determinação da tensão de cisalhamento solicitante é dada como duas vezes a menor dimensão da peça acima e abaixo da região de transferência do carregamento, como é mostrado na Figura 2.18 .

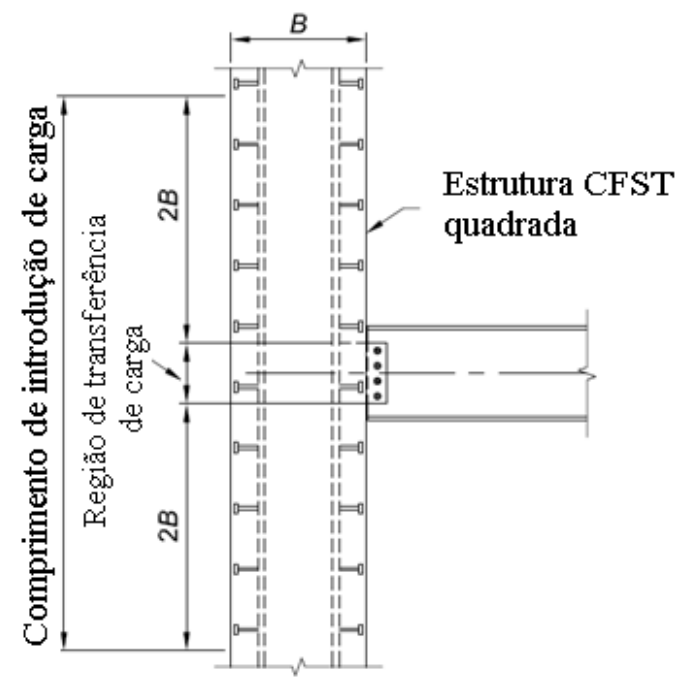

Figura 2.18 - Região de introdução de carregamentos (AISC, 2016).

\section{6.}

\section{Treliças multiplanares com elementos mistos}

Em busca de otimização dos sistemas construtivos, é possível aliar as características dos elementos mistos com as características da geometria das treliças multiplanares, gerando estruturas mais eficientes e de menor custo.

Fong (2011) realizou ensaios experimentais no qual ele comparou o comportamento de duas treliças simplesmente apoiadas: uma com todos os perfis metálicos tubulares e outra com as cordas comprimidas executadas com perfis tubulares preenchidos com concreto (CFST).

Seus resultados experimentais mostraram que a treliça com cordas CFST chegou a uma carga última $29 \%$ maior que a estrutura com membros completamente 
em aço, além de apresentar uma mesma flecha no meio do vão com maiores níveis de carregamento.

Chen (2015) desenvolveu experimentos nos quais estudou os modos de falha, a capacidade de carregamento, a rigidez a flexão e as deformações de quatro tipos diferentes de estruturas multiplanares com elementos CFST em suas cordas comprimidas. A Figura 2.19 mostram as seções transversais das regiões dos apoios utilizados nos ensaios das treliças triangulares enquanto a Figura 2.20 mostra as seções transversais para os testes das configurações de seção quadrada e trapezoidal utilizados por Chen.
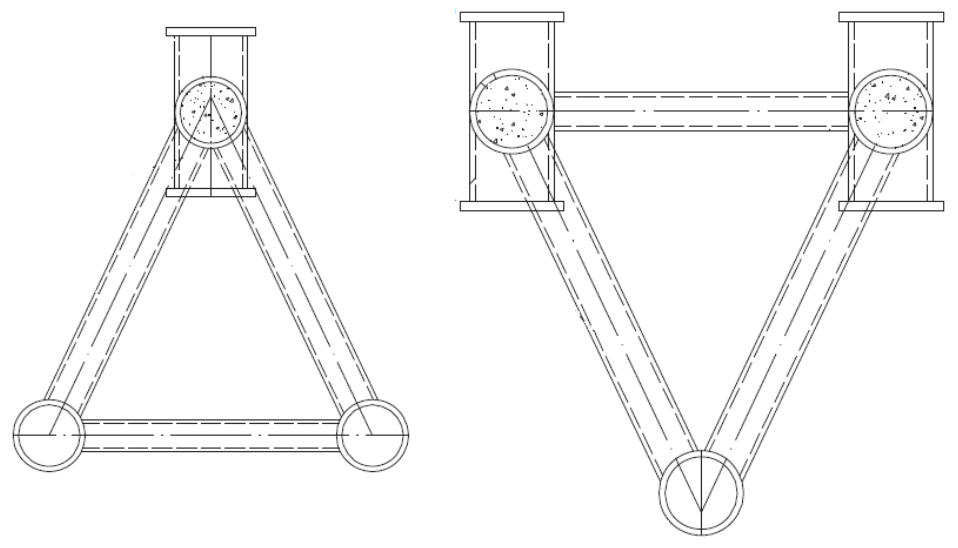

Figura 2.19 - Seções triangular e triangular inversa (CHEN, 2015).
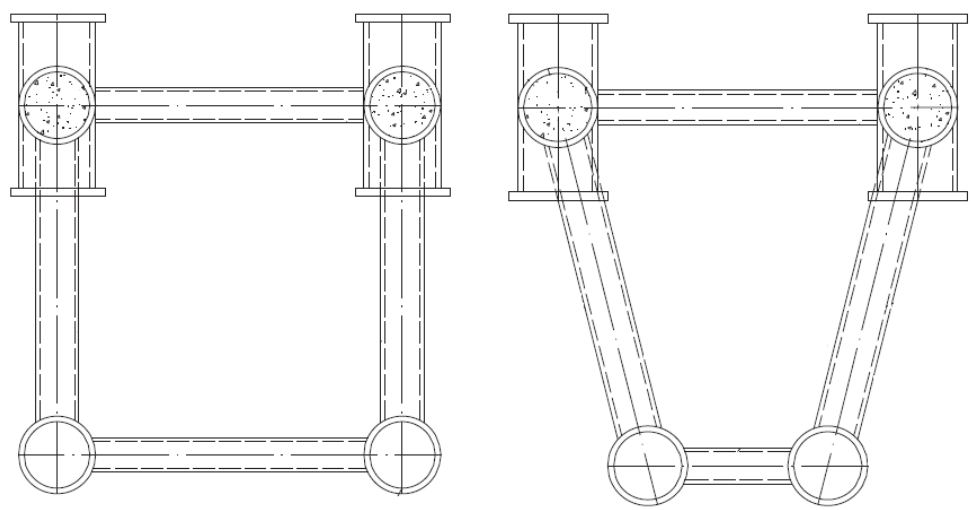

Figura 2.20 - Seções quadrada e trapezoidal (CHEN, 2015).

A partir dos resultados obtidos em seus experimentos e comparando com valores em sua bibliografia, Chen concluiu que as estruturas multiplanares apresentam valores de flecha menores que as estruturas convencionais, além de poderem suportar maiores cargas últimas. 
O modo de falha desenvolvido pelas estruturas normalmente ocorreu por plasticidade da parede do tubo ou perfuração por cisalhamento, ambos ocorrendo na corda superior. Já as estruturas preenchidas com concreto, o modo de falha foi por flambagem local das diagonais ou montantes da estrutura. 


\section{3 \\ Critérios de projeto estrutural}

Este capítulo descreve os procedimentos e as considerações de projeto empregados para o estudo das variações dos parâmetros de projeto. Foi utilizado o programa comercial SAP2000 para as análises de segunda ordem realizadas.

São mostradas as configurações estruturais das soluções abordadas e as premissas na escolha das diversas variáveis da análise paramétrica, sendo elas: a geometria da seção transversal da treliça, os perfis das cordas e a inclinação das diagonais. Além disso, serão descritos os detalhes construtivos mais importantes, as solicitações que a estrutura está submetida e suas restrições.

\section{1. \\ Projeto de estrutura exemplo}

A estrutura exemplo considera uma viga principal de um galpão que receberá os carregamentos gravitacionais e cargas variáveis provenientes do sistema de cobertura. Para isso, serão utilizadas treliças multiplanares para o dimensionamento da estrutura, de forma a identificar qual sistema construtivo apresenta o menor consumo de aço.

Será estudado apenas o vigamento entre as colunas internas do galpão, e, por simplificação, será adotada a mesma configuração geométrica para a estrutura exemplo. A edificação pode dispor de múltiplos de vãos transversais, aqui sendo utilizados apenas dois vãos de $25 \mathrm{~m}$ cada, também por simplificação.

Os vigamentos principais apresentam uma configuração longitudinal de três vãos (L) além de duas extremidades em balanço, com comprimentos fixos de 5 metros. A Figura 3.1 mostra o plano da cobertura do galpão que será utilizado como estrutura exemplo.

Os valores dos vãos (L) estudados neste trabalho irão variar em três comprimentos: $32 \mathrm{~m}, 45 \mathrm{~m}$ e $60 \mathrm{~m}$. Assim, como foram adotados três vãos para o vigamento principal, as dimensões máximas das vigas de cobertura serão, respectivamente: 
$106 \mathrm{~m}, 145 \mathrm{~m}$ e $190 \mathrm{~m}$. A Figura 3.2 ilustra a configuração dos vãos do vigamento principal da estrutura.

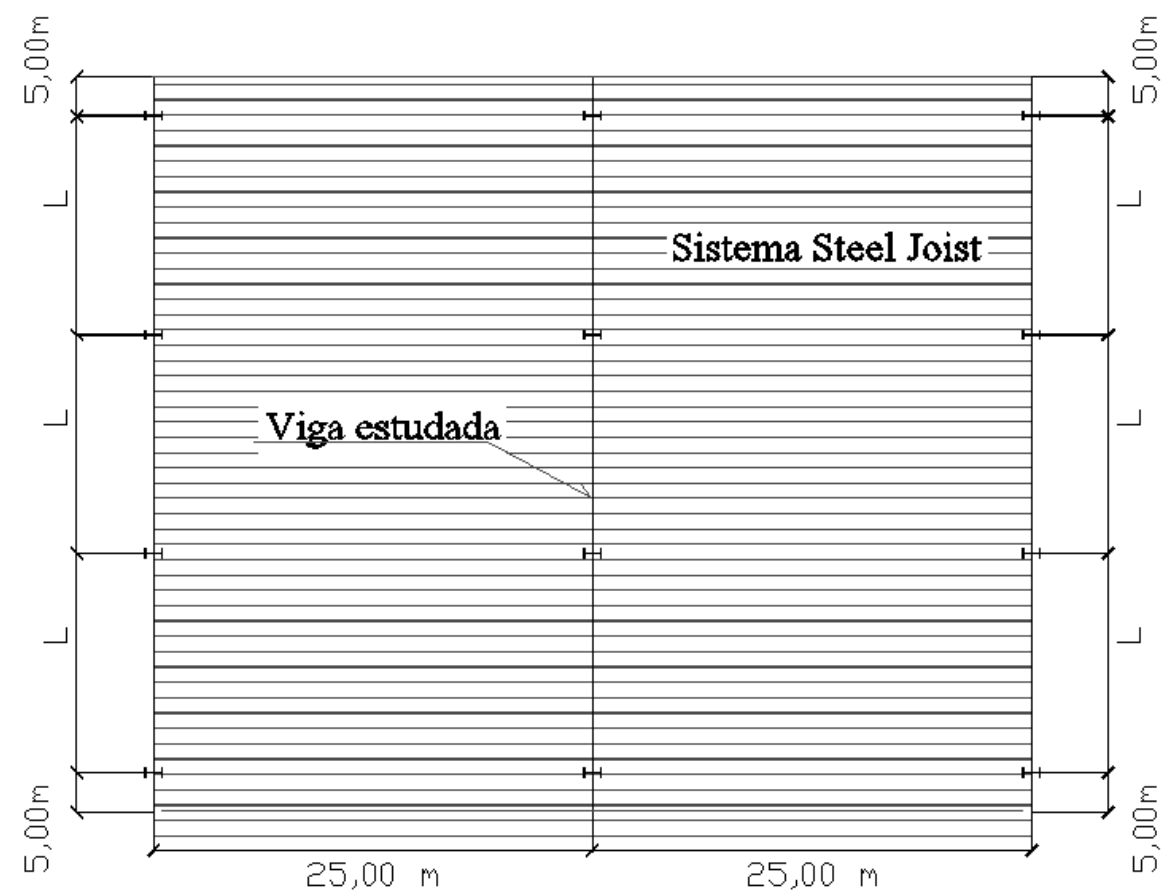

Figura 3.1 - Plano de cobertura da estrutura exemplo que será utilizada nesse estudo.

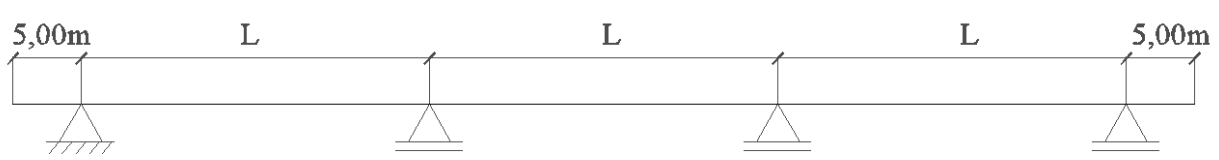

Figura 3.2 - Dimensões da viga de cobertura estudada.

Os carregamentos aplicados na estrutura estão dados na Tabela 3.1. Para coberturas comuns, na ausência de especificação mais rigorosa, foi previsto uma sobrecarga mínima atuante na cobertura, de acordo com as prescrições da NBR$8800 / 08$

Os carregamentos variáveis devido às forças de vento não foram contabilizados, já que, em estruturas de galpões, ocorre predominantemente sucção nos telhados. Essa sucção gera uma pressão interna positiva que tende a aliviar os esforços dos carregamentos permanentes, condição que não representa a situação mais desfavorável para a estrutura.

Serão utilizadas duas combinações de carregamentos, com o objetivo de dimensionar a estrutura para as eventuais ações que a estrutura pode ser solicitada. A 
primeira combinação de ações, ilustrada na Figura 3.3, é utilizada a combinação última normal com a aplicação dos carregamentos permanentes e variáveis em todo o comprimento da estrutura estudada.

\begin{tabular}{|c|c|}
\hline \multicolumn{2}{|c|}{ Ações permanentes } \\
\hline Steel joist e terças & $0,18 \mathrm{kN} / \mathrm{m}^{2}$ \\
\hline Telhas metálicas & $0,10 \mathrm{kN} / \mathrm{m}^{2}$ \\
\hline Peso próprio da treliça & $0,13 \mathrm{kN} / \mathrm{m}^{2}$ \\
\hline Ação variável & \\
\hline Sobrecarga & $0,25 \mathrm{kN} / \mathrm{m}^{2}$ \\
\hline Forro e serviços (proprietário) & $0,15 \mathrm{kN} / \mathrm{m}^{2}$ \\
\hline
\end{tabular}

Tabela 3.1 - Carregamentos verticais aplicados na estrutura.

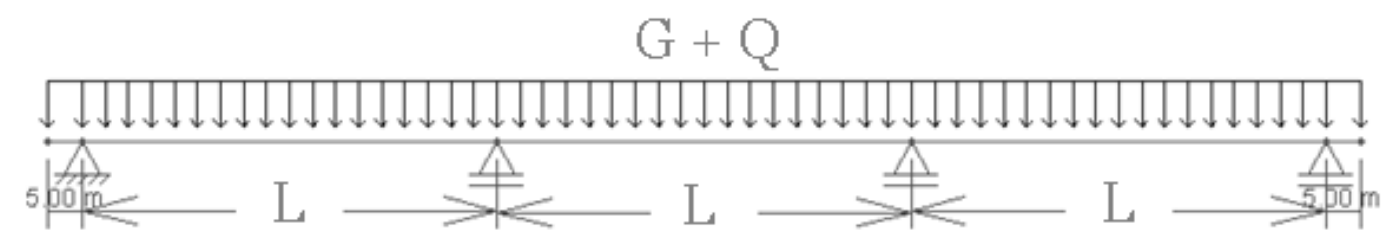

Figura 3.3 - Primeira combinação de ações.

A segunda combinação considera a soma dos carregamentos permanentes e variáveis apenas no centro do vão, enquanto que o resto da estrutura está sendo carregada apenas pelas ações permanentes, como mostrado na Figura 3.4.

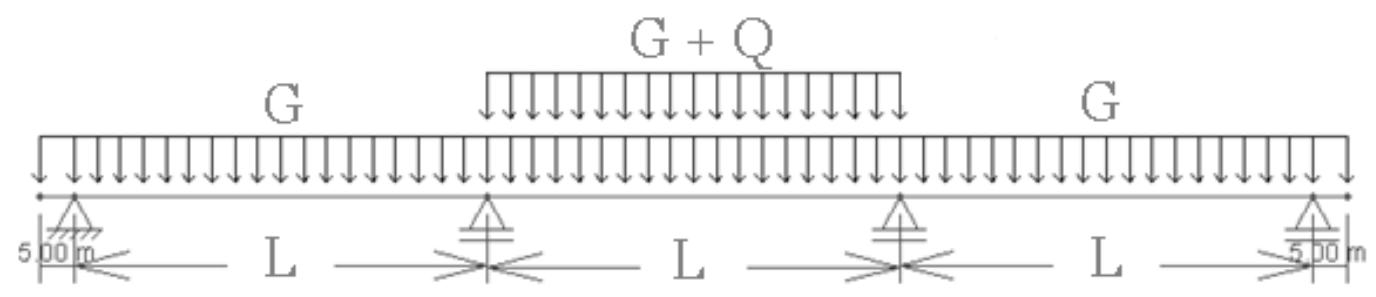

Figura 3.4 - Segunda combinação de ações.

A primeira combinação permite que se dimensione adequadamente a estrutura para a situação mais desfavorável para os vãos de extremidade, enquanto que a segunda combinação provoca uma configuração mais desfavorável para o vão central da estrutura. 
Para essas combinações, serão utilizados os coeficientes de ponderação da NBR 8800/08: carregamentos permanentes são multiplicados pelo coeficiente de ponderação $\left(\gamma_{\mathrm{g}}\right)$ igual a 1,30 e, para o carregamento variável, coeficiente $\left(\gamma_{\mathrm{q}}\right)$ 1,50.

\section{2.}

\section{Configurações estruturais}

\subsection{1.}

\section{Geometria da treliça}

Para a configuração longitudinal da treliça será utilizada o tipo Howe, como mostrado na Figura 3.5.

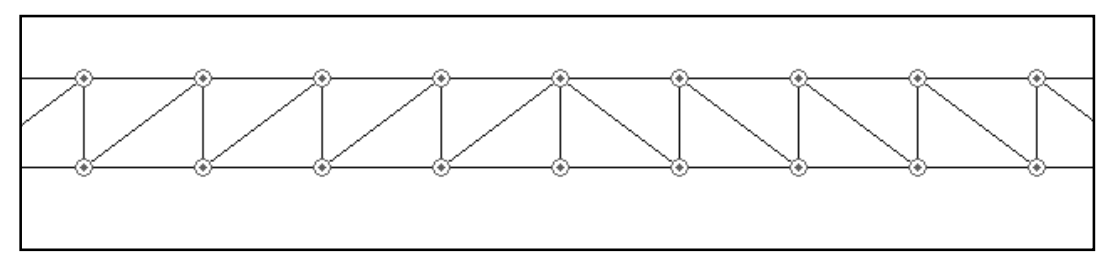

Figura 3.5 - Treliça tipo Howe (planos laterais).

Para o sistema de travamento das cordas da treliça, será utilizada uma configuração tipo Warren com montantes, como pode ser visto na Figura 3.6.

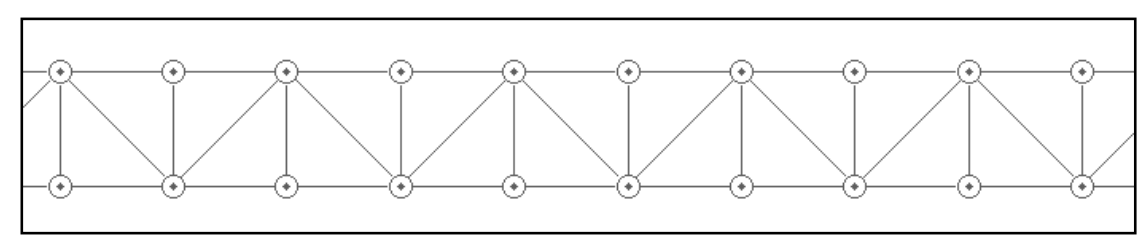

Figura 3.6 - Treliça tipo Warren com montantes (planos horizontais).

\subsection{2.}

\section{Seções transversais utilizadas}

Serão utilizadas duas variações para as seções transversais das treliças multiplanares: uma com quatro cordas (ST4), com seção transversal aproximadamente quadrada, ilustrada na Figura 3.7; e outra com três cordas (ST3), com a geometria triangular invertida, ilustrada na Figura 3.8. A distância adotada entre as cordas superiores das treliças com três cordas foi um valor aproximado à altura da estrutura. O comprimento de módulo será simbolizado por “Lb". 


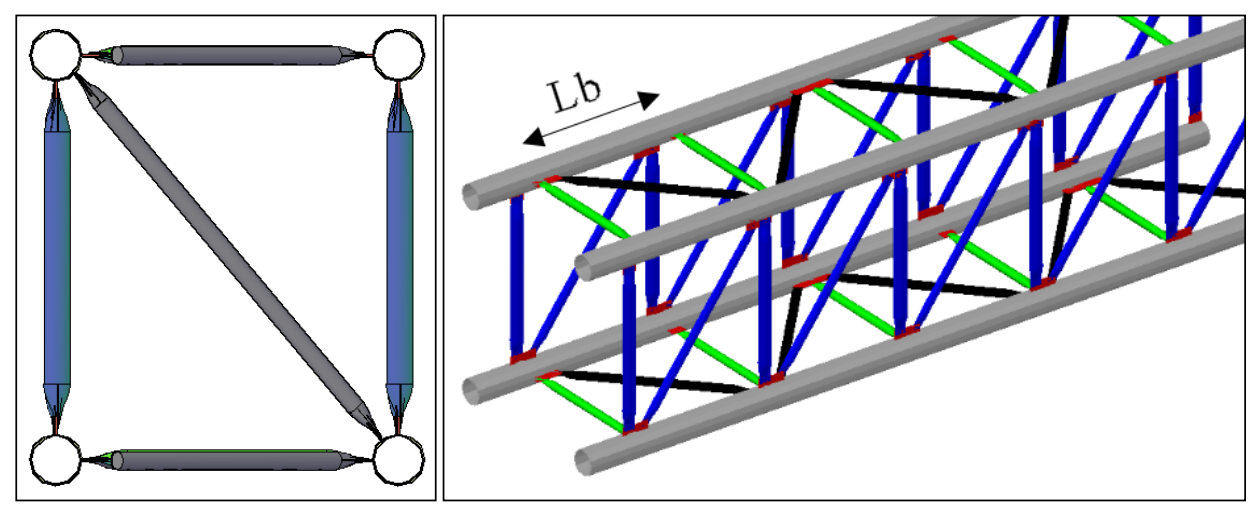

Figura 3.7 - Seção transversal ST4 nas regiões dos apoios e centros de vão.
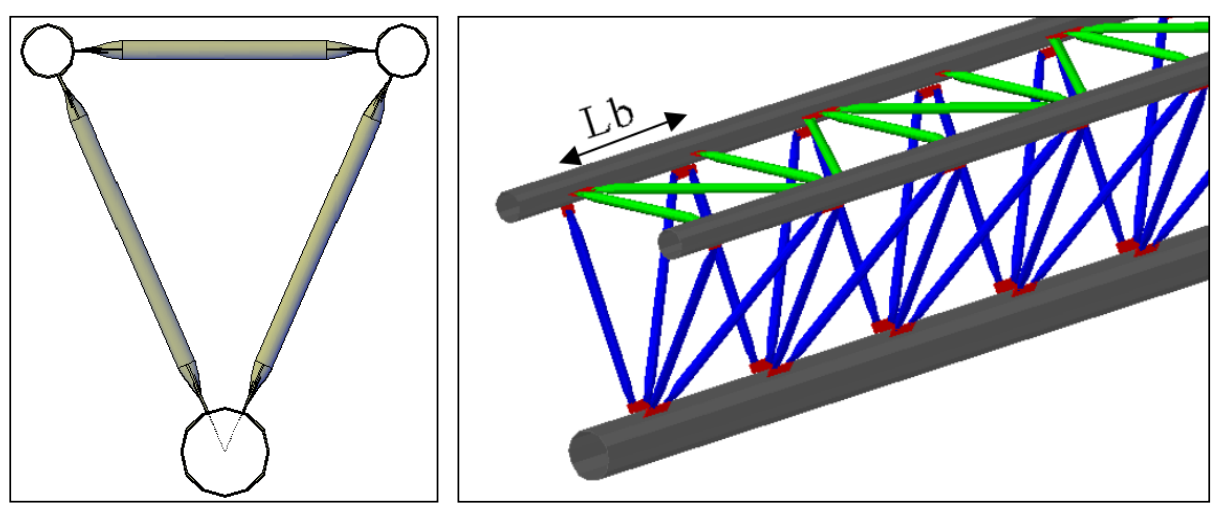

Figura 3.8 - Seção transversal ST3.

Para os projetos que serão desenvolvidos, foi considerado que as diagonais e montantes se interceptam num ponto comum que é o centro geométrico da seção transversal da corda. Assim, não serão consideradas excentricidades nas ligações dos nós.

\subsection{3.}

\section{Inclinação das diagonais}

As diagonais terão uma inclinação baseada nas alturas (h) e nos comprimentos dos módulos $(\mathrm{Lb})$ da estrutura em questão. Buscou-se utilizar valores de inclinações $(\alpha)$ próximos de $35^{\circ}, 45^{\circ}$ e $55^{\circ}$ para cada exemplo de aplicação. A configuração esquemática das inclinações de ambas as seções estudadas é ilustrada na Figura 3.9. 
Como a treliça principal trabalhará como uma viga de cobertura, a altura (h) representa o braço de alavanca da distribuição de forças $(\mathrm{F})$ para as cordas superiores e inferiores. Serão empregadas três alturas para as treliças principais definidas em aproximadamente Vão/40 a Vão/20. Foi tomado o valor de 2,50m como altura máxima das treliças nesse estudo.

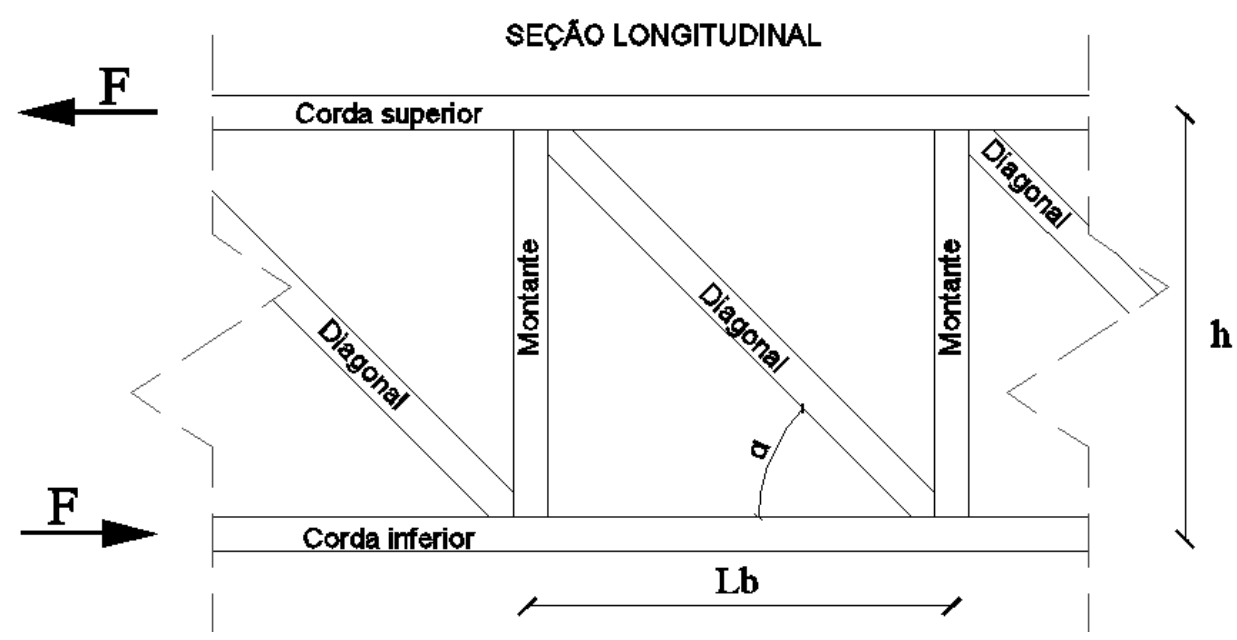

Figura 3.9 - Inclinação das diagonais da treliça.

Os comprimentos dos módulos ( $\mathrm{Lb}$ ) adotados foram influenciados pelos valores comerciais dos perfis brasileiros: 6 e 12 metros. O valor de 6 metros foi adotado pelo fato de poder usar uma maior variação dos perfis, evitando consumo de aço desnecessário em regiões menos carregadas da treliça, ou seja, evitando reduzir as taxas de utilização dos perfis dessas regiões.

Além disso, não foram utilizados valores de inclinações inferiores a $30^{\circ}$, pois dificulta a soldagem, montagem e inspeção da estrutura, como recomenda a norma americana AISC 360-16.

\subsection{4.}

\section{Restrições}

As ligações das diagonais, dos montantes e dos travamentos laterais das treliças espaciais foram idealizadas como nós típicos, interligados às cordas por meio de chapas soldadas. Dessa forma, foi considerado que essas estruturas secundárias da estrutura apresentam vinculações rotuladas em suas extremidades. 
A Figura 3.10 mostra as restrições dos apoios analisados nos projetos de treliça, onde os eixos X, Y e Z correspondem, respectivamente, a 1, 2 e 3. Essa configuração será utilizada para as seções ST3 e ST4.

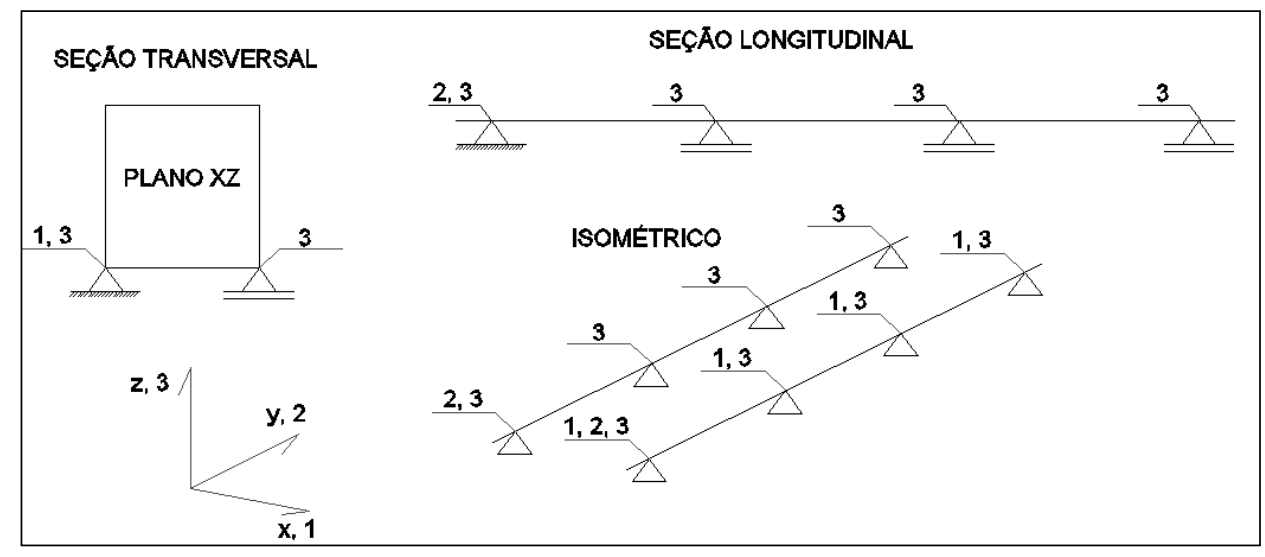

Figura 3.10 - Restrições dos apoios da estrutura.

\subsection{5. \\ Detalhes}

Nas regiões dos apoios e nos meios dos vãos das treliças com seção ST4 foram utilizados elementos que interligam uma corda inferior com uma corda superior, para dar mais estabilidade ao conjunto e para dar uma distribuição de forças melhor para a região do apoio.

Nos elementos citados acima, serão utilizados os mesmos tipos de perfis usados nas diagonais e montantes, repetidos por cerca de quatro módulos seguidos. A Figura 3.11 mostra a estrutura reticulada da região do apoio da treliça espacial, na qual as diagonais estão realçadas.

Com o objetivo de melhorar a estabilidade lateral da estrutura e de reduzir os esforços da região de apoio da seção ST3 com o pilar, foram dimensionadas diagonais interligando os apoios com as cordas superiores, como a mostrada na Figura 3.12 .

Para o desenvolvimento do nó das barras da região do apoio da estrutura na seção transversal ST3, foi idealizada a ligação ilustrada na Figura 3.13. A partir de uma chapa de gusset de maior diâmetro pode-se realizar a ligação das várias barras que a estrutura necessita. 
Para as treliças que trabalham com perfis laminados ou WT, haverá a necessidade de se utilizar uma chapa gusset soldada na mesa e na alma do perfil para executar a ligação das diagonais dos apoios e dos meios de vãos das seções transversais com quatro cordas. A Figura 3.14 mostra esse tipo de detalhe para uma treliça com cordas de perfis WT.

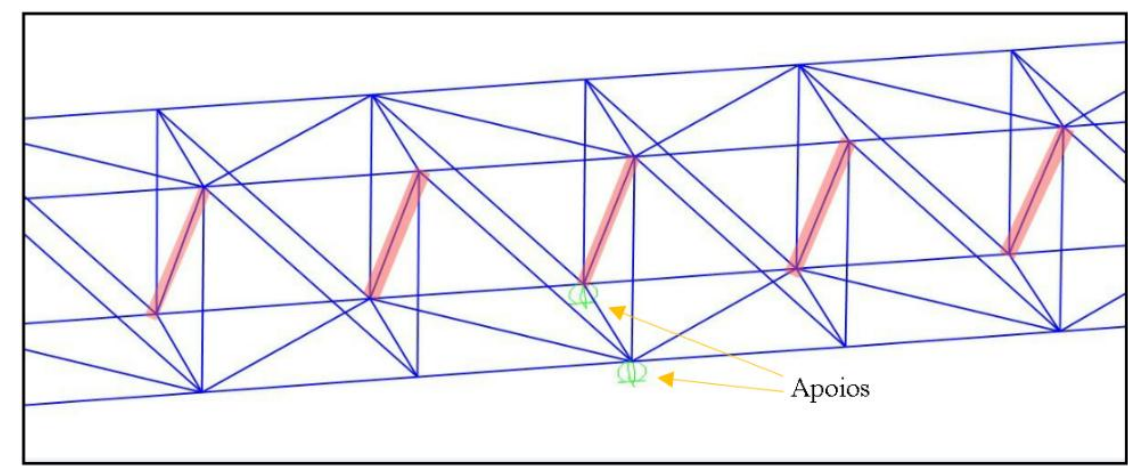

Figura 3.11 - Elementos diagonais na estrutura reticulada (em realce).

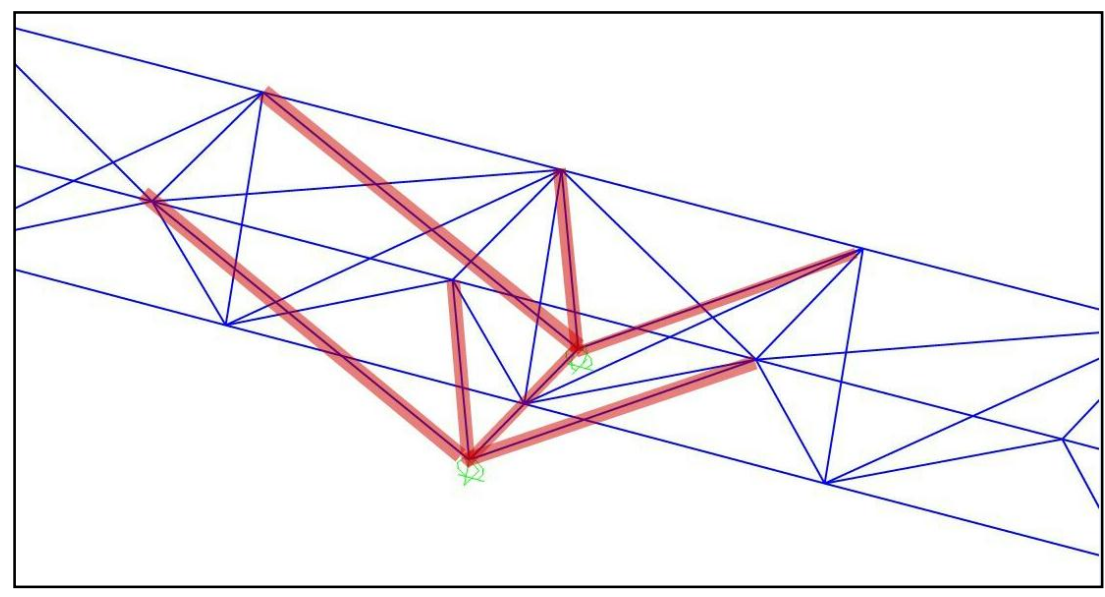

Figura 3.12 - Região dos apoios da estrutura ST3 (em realce).

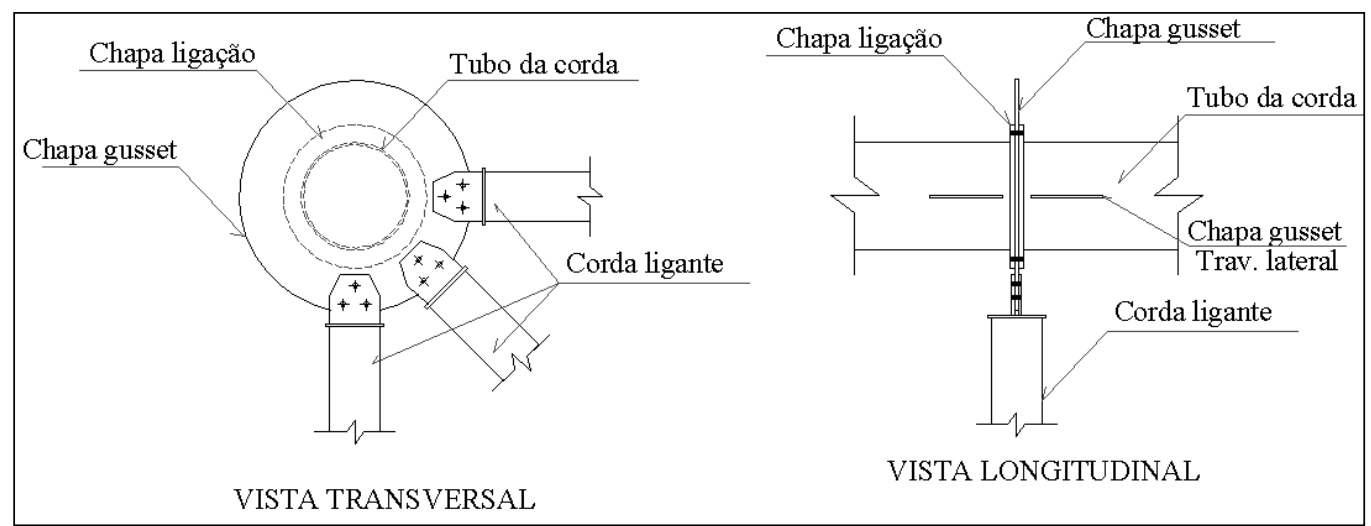

Figura 3.13 - Detalhe do nó do apoio da corda superior' da estrutura ST3. 
Configuração equivalente a essa ligação também será utilizada para as diagonais das cordas das regiões de apoio das estruturas com seção transversal tipo ST4 para os perfis tubulares e para os perfis mistos.

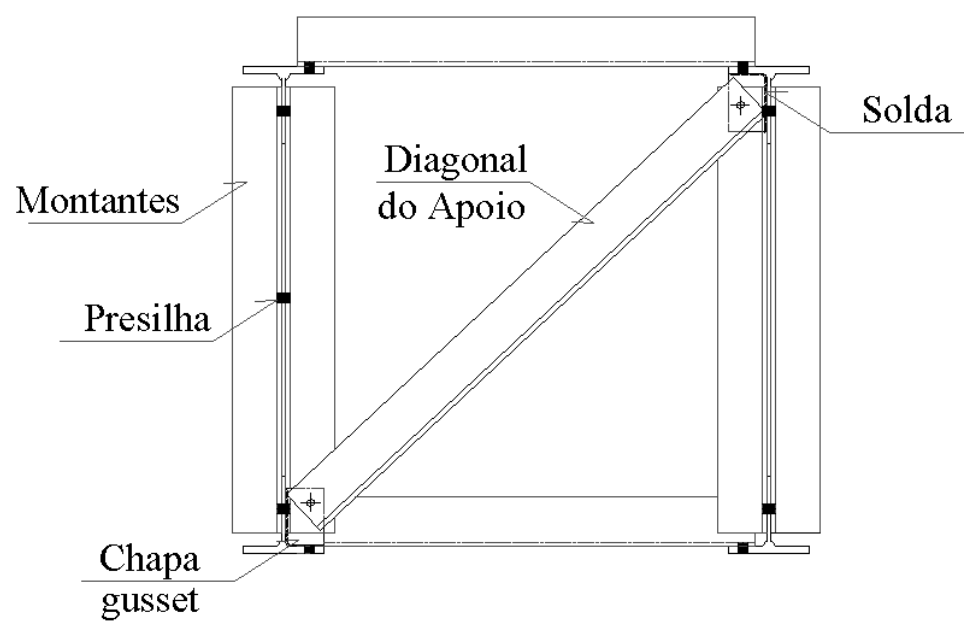

Figura 3.14 - Detalhe: perfis WT - Diagonal do apoio das seções ST4.

\subsection{6. \\ Perfis utilizados}

Para se obter a melhor solução, serão estudados quatro tipos de perfis para as cordas: perfis laminados (PL), perfis tubulares circulares (T), perfis WT (WT) e perfis tubulares preenchidos por concreto (M). Maiores detalhes serão apresentados posteriormente.

Para as diagonais, serão utilizados perfis tubulares circulares de pequeno diâmetro para as treliças com cordas que utilizam perfis laminados, perfis tubulares e mistos. Para as treliças com cordas constituídas por perfis WT, serão utilizadas cantoneiras duplas. A Tabela 3.2 resume os perfis que serão utilizados nas treliças, de acordo com a nomenclatura da AISC, sendo HSS a nomenclatura dada nesta norma aos tubos circulares.

Para as diagonais e montantes que utilizam tubos circulares, estes estarão conectados por meio de ligações aparafusadas do tipo nó típico (ponta amassada). Os tubos serão aparafusados em chapas gusset que deverão ser soldadas nas cordas.

Essa solução foi escolhida pelo fato de ser a mais econômica e de mais fácil execução e será adotada em todos os projetos de treliça deste trabalho. A Figura 3.15 ilustra a configuração da extremidade do tubo utilizado para as estruturas secundárias da treliça. 
Para as treliças com perfis WT, será considerada a utilização de presilhas para a composição dos elementos múltiplos com cantoneiras duplas, como mostra a Figura 3.16, presente na NBR 8800 (ABNT, 2008). O espaçamento adotado entre as cantoneiras será igual ao valor da espessura da alma dos perfis WT utilizado nas cordas.

\begin{tabular}{|c|c|}
\hline Tubos circulares [AISC] & Cantoneiras duplas \\
\hline HSS60,3×3,2 & $2 \mathrm{~L} 51 \times 51 \times 4,76$ \\
\hline HSS73 33,2 & $2 \mathrm{~L} 64 \times 64 \times 4,76$ \\
\hline HSS $88,9 \times 3,2$ & $2 \mathrm{~L} 76 \times 76 \times 4,76$ \\
\hline HSS101,6×3,2 & $2 \mathrm{~L} 76 \times 76 \times 6,35$ \\
\hline HSS127x3,2 & $2 L 89 \times 89 \times 6,35$ \\
\hline HSS140x3,8 & $2 \mathrm{~L} 102 \times 102 \times 6,35$ \\
\hline HSS168x3,2 & $2 \mathrm{~L} 102 \times 102 \times 7,94$ \\
\hline HSS168x4,8 & $2 \mathrm{~L} 127 \times 127 \times 6,35$ \\
\hline HSS168x6,4 & 2L127x127x9,52 \\
\hline
\end{tabular}

Tabela 3.2 - Perfis utilizados para as estruturas secundárias.

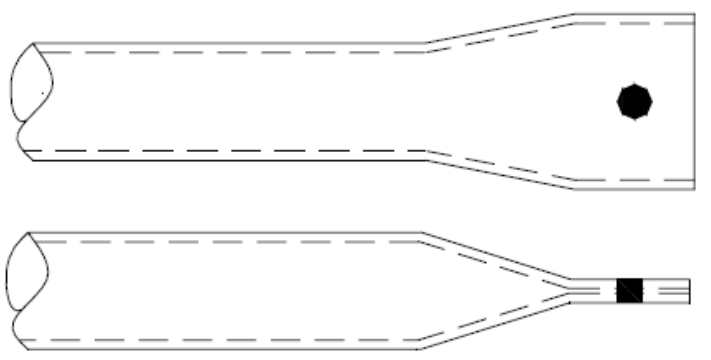

Figura 3.15 - Detalhe de nó típico (Adaptado de Souza, 2003).

Serão utilizadas cantoneiras duplas somente nas estruturas com perfil WT por se tratar de um método construtivo bastante utilizado nos sistemas de cobertura metálica. Devido à geometria dos perfis, não será possível a utilização deste tipo de seção para treliças com seção ST3.

Para facilitar a montagem da estrutura, foi idealizado que a variação da dimensão dos perfis das diagonais e montantes ocorresse dentro de um comprimento de $6 \mathrm{~m}$, de forma a coincidir com a variação das cordas.

Para as diagonais do plano horizontal das treliças multiplanares, será realizado da seguinte forma: um tipo de perfil será utilizado para as regiões onde se 
localizam os elementos que ligam uma corda inferior com uma superior; e outra dimensão de perfil será utilizado para o restante da estrutura.

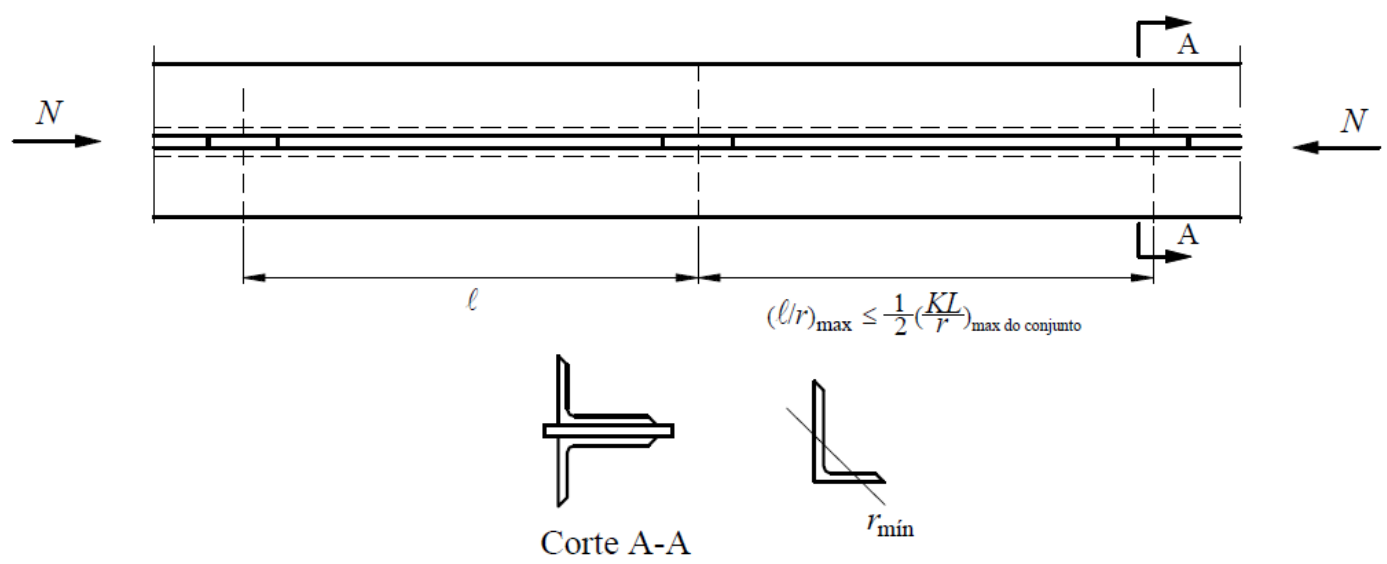

Figura 3.16 - Presilhas utilizadas nas diagonais e montantes das treliças (ABNT, 2008).

\subsubsection{1. Detalhe das cordas com perfis laminados}

A altura das treliças é o principal fator que controla o valor do momento de inércia em relação ao comportamento do plano da treliça. Assim, como a altura do perfil das cordas é bem inferior ao valor da altura total da treliça, a dimensão do perfil de pouco irá influenciar nos valores dos deslocamentos da estrutura, tanto no plano como fora do plano.

Por essa mesma razão, não haverá variação significativa nos deslocamentos da estrutura se o eixo de inércia principal do perfil das cordas for posicionado para trabalhar fora ou no mesmo plano da estrutura, como observado na Figura 3.17. Assim, para este trabalho foi escolhido o eixo fraco do perfil para trabalhar com o comportamento no plano da estrutura, como mostrado na Figura 3.17(b), de modo a facilitar a execução das ligações das diagonais diretamente nas cordas.

A escolha do perfil laminado ao invés do soldado é devido ao alto custo de produção do perfil soldado, além de que não há necessidade de se obter um perfil que tenha grande altura, já que as estruturas irão trabalhar primordialmente com tensões axiais de tração ou compressão. 
Para todos as treliças com cordas que utilizam perfis laminados, foram adotados a tipologia W310, esta especificamente por apresentar uma grande variabilidade de dimensões e pesos.

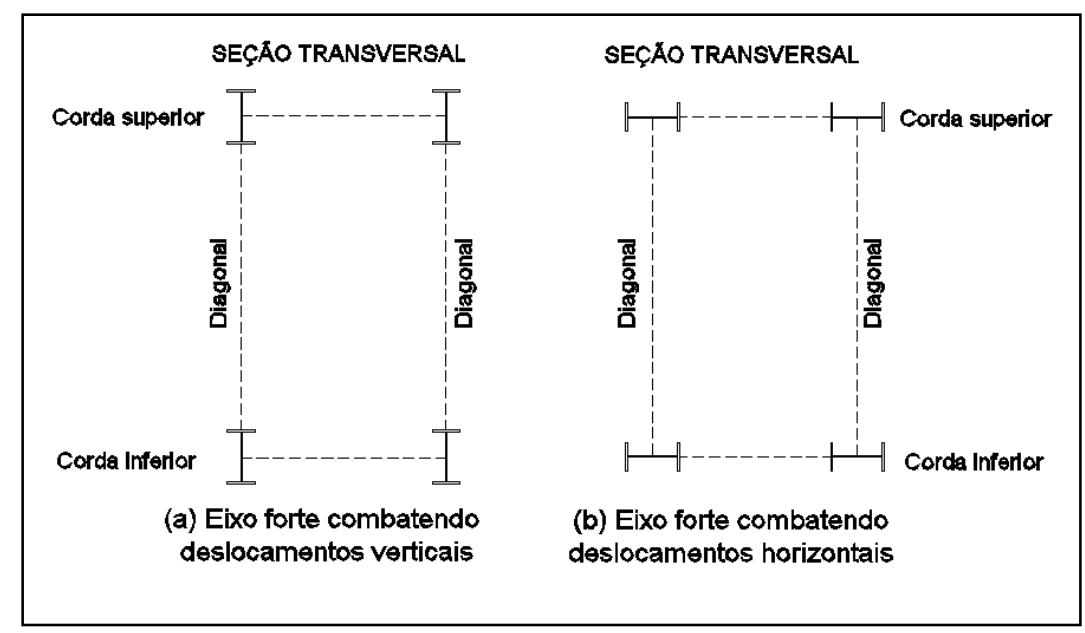

Figura 3.17 - Eixo de maior inércia do perfil trabalhando no plano (a) e fora do plano (b).

Placas serão soldadas nas mesas e alma dos perfis para as ligações com as diagonais e montantes da estrutura na seção ST4, como mostrado na Figura 3.18. Para as ligações com os travamentos laterais da estrutura, serão soldadas chapas na alma e entre as mesas dos perfis, ligação que servirá para ambas as seções transversais da treliça. A Figura 3.19 ilustra o primeiro tipo de ligação.

Para as seções ST3, as ligações entre as diagonais e montantes serão utilizadas também por meio de uma chapa soldada nas mesas dos perfis laminados, entretanto, apresentarão uma inclinação baseada na geometria da treliça, para permitir sua montagem. A Figura 3.20 mostra o detalhe desse tipo de ligação.

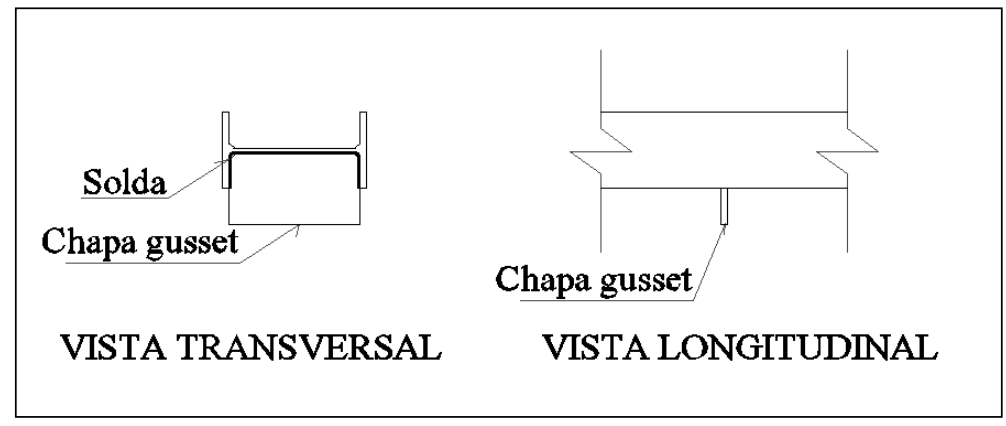

Figura 3.18 - Ligações com os elementos das diagonais e montantes para a seção ST4. 


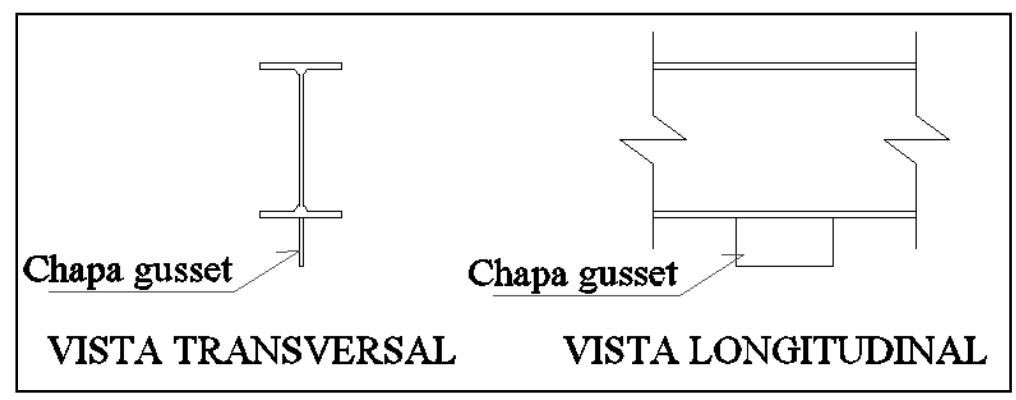

Figura 3.19 - Ligações com os elementos de travamento para a seção ST4.

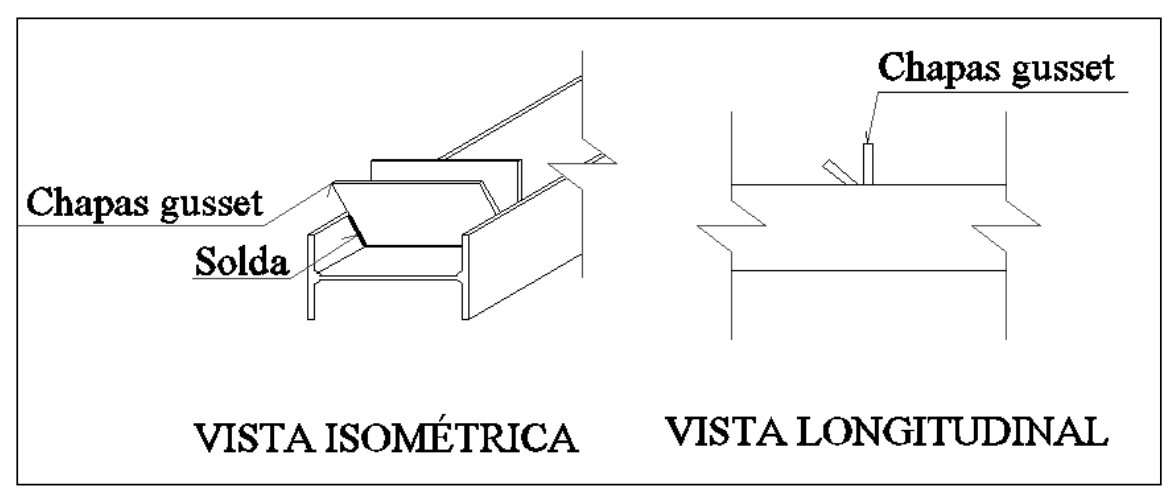

Figura 3.20 - Ligações com as diagonais para a seção ST3.

Também foi considerada a utilização de perfis duplos soldados nas mesas, como pode ser visto na Figura 3.21.

Também foi considerado que a emenda não fosse realizada na mesma região em que são feitas as ligações entre cordas e diagonais, para evitar ligações complexas. Para isso, foi considerado que os nós dos apoios estão localizados nas regiões centrais dos perfis de comprimento de seis metros.

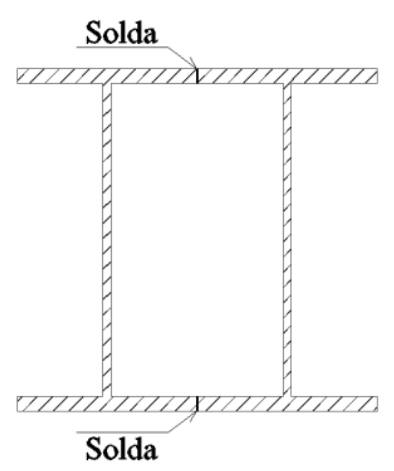

Figura 3.21 - Perfis duplos soldados nas mesas. 


\subsubsection{2.}

\section{Detalhe da solução com perfis WT}

Os perfis tipo WT serão obtidos a partir do corte de perfis W310 na metade da altura da alma, formando dois perfis T. Esses dois perfis $\mathrm{T}$ serão unidos por elementos secundários.

Em algumas regiões mais solicitadas, foi necessário soldar uma chapa na mesa do perfil WT, para que o mesmo ganhe em resistência, como pode ser visto na Figura 3.22. A largura da chapa é próxima da largura da mesa do perfil WT e a espessura da chapa é dimensionada de acordo com os esforços solicitantes.

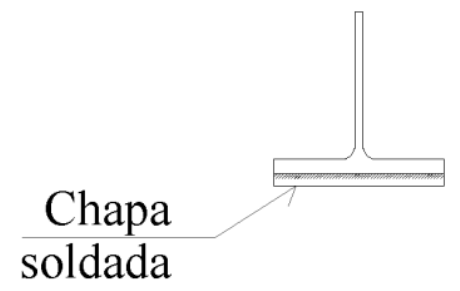

Figura 3.22 - Detalhe da chapa soldada na mesa do perfil WT.

\subsubsection{3. \\ Detalhe da corda com perfis tubulares}

Serão utilizados perfis com costura em todos os projetos com perfis tubulares nesse trabalho. As espessuras utilizadas estão fixadas de acordo com as dimensões de chapas de fabricação das usinas nacionais, adotando um valor mínimo de 3,8mm.

Os valores das resistências à compressão axial e as devidas verificações de flambagem local foram realizadas de acordo com as recomendações da AISC 36016.

Para a escolha das dimensões dos tubos, foram realizadas análises prévias considerando os esforços solicitantes nas cordas das treliças obtidos a partir da análise do programa comercial.

Após essa etapa, foram verificadas as taxas de utilização dos tubos, ou seja, a relação entre a solicitação de projeto e a resistência de projeto, para que possam ser utilizados os perfis que tragam o menor consumo de aço.

Para a escolha do diâmetro a ser utilizado na corda da seção ST4, foi estabelecido que devem ser atendidas as recomendações de esbeltez local máxima dos tubos. 
Para as treliças com três cordas (ST3), as cordas superiores apresentarão as mesmas dimensões, enquanto que a corda inferior será constituída por um tipo de perfil de dimensão superior às demais, por ser mais solicitada. Não foram realizadas variações de diâmetro dentro de uma mesma corda.

Para as treliças com cordas tubulares ou mistas, as ligações entre as cordas e as diagonais e montantes foram projetadas para serem executadas utilizando uma placa soldada longitudinalmente no tubo circular, como pode ser visto na Figura 3.23 .
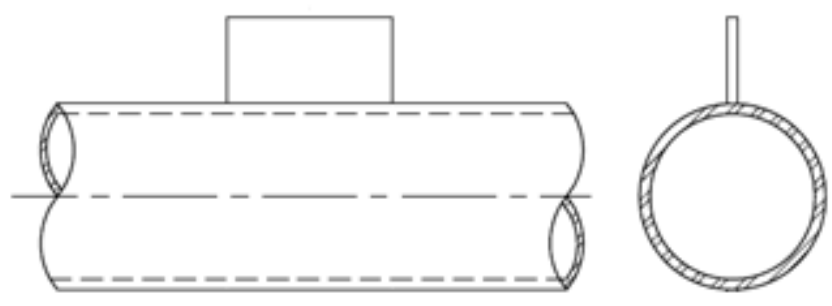

Figura 3.23 - Placa soldada no tubo circular para ligação com as diagonais (Adaptado de AISC, 2016).

As devidas verificações relacionadas à resistência dessas ligações também foram levadas em consideração na escolha dos perfis a serem adotados nas cordas. Essas verificações foram feitas de acordo com as recomendações da norma americana AISC 360-16, que utiliza a seguinte formulação para a resistência à plastificação da parede do tubo:

$$
R_{n} \sin \theta=5.5 F_{y} t^{2}\left(1+0.25 \frac{l_{b}}{D}\right) Q_{f} .
$$

Onde, t é a espessura da parede do perfil;

$l_{b}$ é o comprimento da chapa gusset;

$Q_{f}$ é o parâmetro de interação de tensão da corda .

A espessura da chapa gusset utilizada nas ligações é igual à espessura do tubo da corda da treliça.

O parâmetro de interação da tensão da corda apresenta valor 1 para os elementos secundários em tração e, para compressão, é utilizado a seguinte fórmula, para considerando o método dos estados limites:

$$
Q_{f}=1-0.3 U(1+U)
$$

Onde: 


$$
U=\left|\frac{P_{r o}}{F_{y} A_{g}}+\frac{M_{r o}}{F_{y} S_{s}}\right|
$$

A Tabela 3.3 apresenta os comprimentos das chapas de ligação adotados de modo a satisfazerem os requisitos de resistência dados pela equação (3.1).

\begin{tabular}{|c|c|}
\hline \multicolumn{2}{|c|}{ Comprimento das chapas de ligação } \\
\hline Vão [m] & Comprimento [mm] \\
\hline 32 & 150 \\
\hline 45 & 200 \\
\hline 60 & 300 \\
\hline
\end{tabular}

Tabela 3.3 - Comprimento das chapas gusset utilizadas nas treliças.

\subsubsection{4. \\ Detalhe da solução mista otimizada}

Quando se procura uma solução mista para uma edificação, sempre se idealiza uma forma de substituir o uso do aço por concreto, por ser um material mais barato. Para este trabalho, essas substituições serão realizadas para regiões de altas forças de compressão, devido ao bom desempenho do concreto sob esse tipo de solicitação.

Além dessas regiões, também serão utilizados perfis mistos nas regiões de aplicação de grandes forças externas nas paredes do tubo, devido às diagonais e montantes. Essa falha é mostrada na Figura 3.24. Essa utilização se deve à necessidade de se evitar que a parede do tubo plastifique e o núcleo de concreto aumenta a resistência dessa solicitação.

Estudos preliminares mostraram que a utilização de perfis mistos apresenta menor consumo de material quando comparada com a utilização de tubos mais espessos, quando se necessita evitar que a parede do tubo sofra plastificação devido à aplicação de forças externas.

Desta forma, serão utilizados perfis tubulares de aço nas regiões menos solicitadas e nas regiões de tração, já que o concreto não possui resistências significantes a estes tipos de ação.

Para as cordas superiores das regiões centrais dos vãos das extremidades e nas cordas inferiores dos apoios centrais, zonas de altas tensões de compressão, 
serão utilizadas as seções mistas. A Figura 3.25 mostra as regiões (realçadas) onde serão localizados os perfis mistos para um vão genérico.

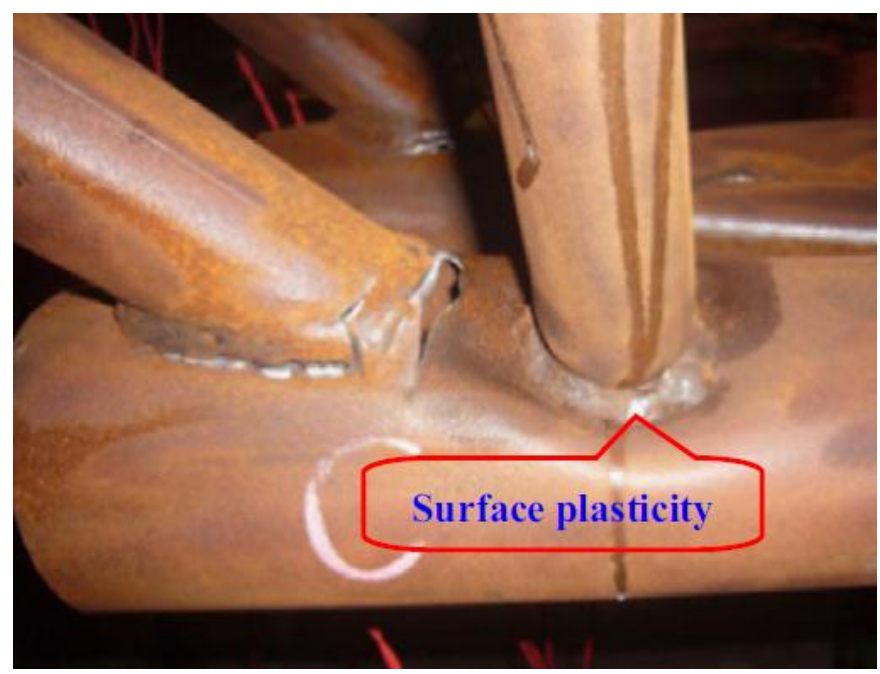

Figura 3.24 - Falha por plastificação da parede do tubo (CHEN, 2015).

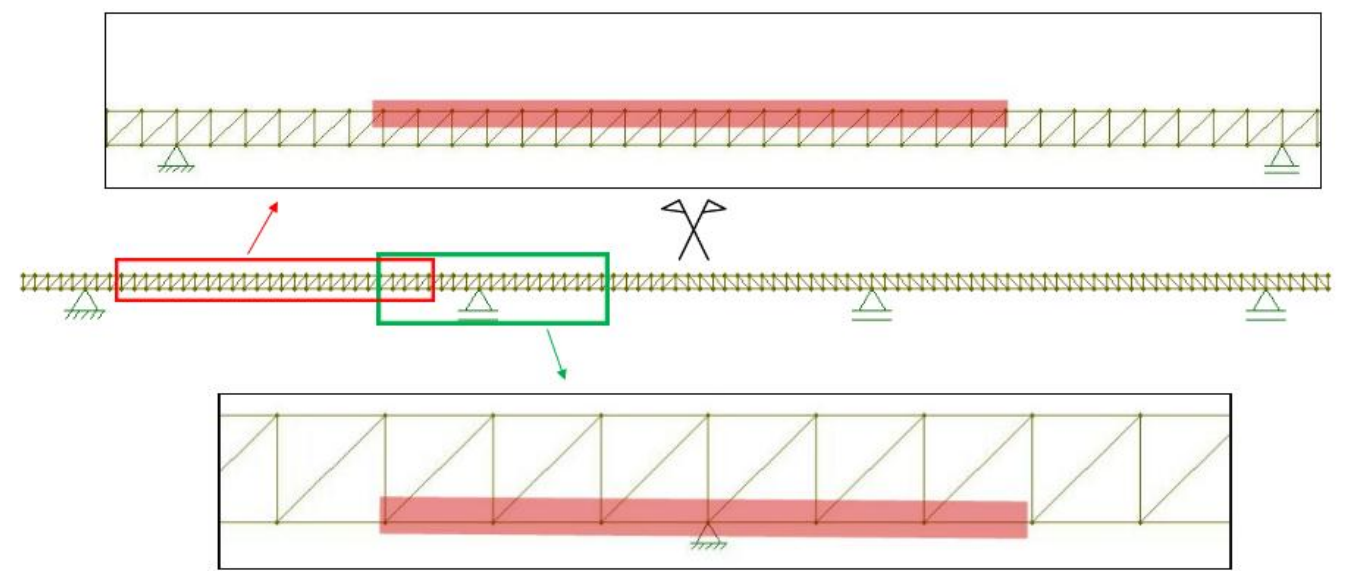

Figura 3.25 - Localização das seções mistas (realçadas) - vão genérico.

A Figura 3.26 mostra um diagrama de forças axiais das cordas da treliça estudada (as diagonais e montantes foram omitidas). As regiões citadas acima podem ser facilmente observadas, considerando que as forças de coloração azulada representam as forças de tração e as avermelhadas, de compressão.

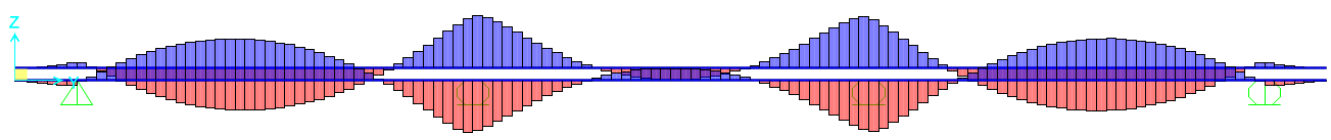

Figura 3.26 - Diagrama de forças axiais das cordas da treliça. 
O dimensionamento dos tubos mistos preenchidos com concreto foi feito de acordo com as recomendações da AISC 360-16 para elementos submetidos a carregamentos axiais.

Para os perfis mistos, foi considerada a utilização de uma chapa soldada nas extremidades, de forma a confinar o concreto no seu interior e contribuir para conter o deslizamento do mesmo no tubo, fenômeno que ocorre quando é submetido a carregamentos externos. Outra razão para o uso dessas chapas é a possibilidade de realizar as emendas com os outros perfis da mesma corda.

Foi idealizado que os tubos mistos fossem moldados no local da obra. Assim, para a produção do mesmo, será necessária a execução de aberturas do tubo para o bombeamento do concreto, como é mostrado na Figura 3.27.

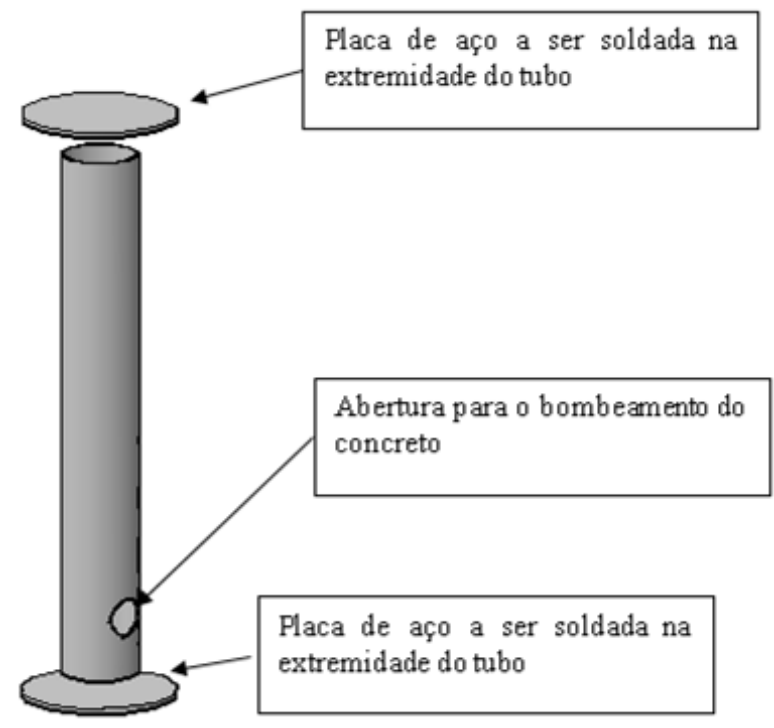

Figura 3.27 - Detalhe construtivo do tubo misto.

Foi considerado que as ligações das cordas mistas com as diagonais também fossem executadas com uma peça soldada diretamente à face externa do tubo misto. O dimensionamento dessa ligação foi realizado de acordo com os procedimentos da AISC-16, considerando o efeito de introdução de forças externas nos tubos. 


\section{Projeto de um galpão com 60 metros de vão e 190 m de comprimento}

Neste capítulo é apresentado um exemplo de aplicação prática do projeto de vigamento principal de uma cobertura para a edificação proposta no capítulo anterior.

O exemplo a ser analisado apresenta as seguintes características:

- Vão: 60m;

- Altura da treliça principal (h): 2,00m;

- Comprimento do módulo (Lb): 2,00m;

- Tipo de seção transversal: seção com quatro cordas (ST4).

O comportamento da estrutura sob as cargas será avaliado e as cordas serão dimensionadas para os quatro tipos de perfis: laminado, tubular, WT e misto.

Após a análise dos resultados deste exemplo, será ampliado este estudo de modo a serem considerados os efeitos da variação da altura da treliça principal e dos tipos de seção das cordas, gerando-se 189 diferentes configurações estruturais.

Os resultados dos 189 projetos estruturais servirão para a elaboração de conclusões a respeito de qual solução apresenta o menor peso da treliça principal. A Tabela 4.1 mostra as 27 configurações geométricas das treliças escolhidas para o estudo, ressaltando-se a configuração selecionada para ser estudada mais detalhadamente neste capítulo.

\begin{tabular}{|c|c|c|c|c|c|c|c|c|}
\hline \multicolumn{3}{|c|}{ Vão - 32m } & \multicolumn{3}{|c|}{ Vão - 45m } & \multicolumn{3}{|c|}{ Vão - 60m } \\
\hline $\mathrm{h}[\mathrm{m}]$ & $\mathrm{Lb}[\mathrm{m}]$ & $\alpha\left[^{\circ}\right]$ & $\mathrm{h}[\mathrm{m}]$ & Lb [m] & $\alpha\left[^{\circ}\right]$ & $\mathrm{h}[\mathrm{m}]$ & Lb [m] & $\alpha\left[^{\circ}\right]$ \\
\hline \multirow[b]{3}{*}{$=\mathrm{L} / 40,00$} & 0,50 & 57,99 & \multirow[b]{3}{*}{$=\mathrm{L} / 30,00$} & 1,25 & 50,19 & \multirow[b]{3}{*}{$=\mathrm{L} / 40,00$} & 1,20 & 51,34 \\
\hline & 0,80 & 45,00 & & 1,50 & 45,00 & & 1,50 & 45,00 \\
\hline & 1,00 & 38,66 & & 2,50 & 30,96 & & 2,50 & 30,96 \\
\hline $\mathrm{h}[\mathrm{m}]$ & $\mathrm{Lb}[\mathrm{m}]$ & $\alpha\left[^{\circ}\right]$ & $\mathrm{h}[\mathrm{m}]$ & Lb [m] & $\alpha\left[^{\circ}\right]$ & $\mathrm{h}[\mathrm{m}]$ & Lb [m] & $\alpha\left[^{\circ}\right]$ \\
\hline \multirow[b]{3}{*}{$=\mathrm{L} / 32,00$} & 0,80 & 51,34 & \multirow{2}{*}{1,80} & 1,50 & 50,19 & \multirow{2}{*}{2,00} & 1,50 & 53,13 \\
\hline & 1,00 & 45,00 & & 1,80 & 45,00 & & 2,00 & 45,00 \\
\hline & 1,60 & 32,01 & $=\mathrm{L} / 25,00$ & 3,00 & 30,96 & $=\mathrm{L} / 30,00$ & 3,00 & 33,69 \\
\hline $\mathrm{h}[\mathrm{m}]$ & $\mathrm{Lb}[\mathrm{m}]$ & $\alpha\left[^{\circ}\right]$ & $\mathrm{h}[\mathrm{m}]$ & $\mathrm{Lb}[\mathrm{m}]$ & $\alpha\left[^{\circ}\right]$ & $\mathrm{h}[\mathrm{m}]$ & Lb [m] & $\alpha\left[^{\circ}\right]$ \\
\hline \multirow{3}{*}{$\begin{array}{c}1,20 \\
=\mathrm{L} / 26,67\end{array}$} & 1,00 & 50,19 & \multirow{2}{*}{2,25} & 1,80 & 51,34 & \multirow{2}{*}{2,50} & 2,00 & 51,34 \\
\hline & 1,20 & 45,00 & & 2,25 & 45,00 & & 2,50 & 45,00 \\
\hline & 2,00 & 30,96 & $=\mathrm{L} / 20,00$ & 3,00 & 36,87 & $=\mathrm{L} / 24,00$ & 3,00 & 39,81 \\
\hline
\end{tabular}

Tabela 4.1 - Configurações geométricas da treliça principal. 
Cada uma das 27 configurações estruturais será estudada para quatro tipos de cordas (PL, T, WT e M) para o caso de treliças multiplanares de quatro cordas (ST4). Já para o caso de treliças de três cordas, serão estudados para três tipos de cordas (PL, T e M), resultando em 27x4+27x3 = 189 casos, apresentados de forma resumida na Tabela 4.2 .

\begin{tabular}{|c|c|}
\hline ST4 & ST3 \\
\hline 3 vãos (32m, 45m e 60m) & 3 vãos (32m, 45m e 60m) \\
\hline 9 configurações geométricas & 9 configurações geométricas \\
\hline 4 tipos de perfis (PL, T, WT e M) & 3 tipos de perfis ( $\mathrm{PL}$, T e $M$ ) \\
\hline 108 soluções & 81 soluções \\
\hline
\end{tabular}

Tabela 4.2 - Resumo das variações das configurações estudadas.

\section{1.}

\section{Carregamentos adotados}

Utilizando a combinação última de carregamentos, as cargas aplicadas por nó na estrutura estão apresentadas na equação (4.1), de acordo com os valores dados na Tabela 3.1. A Figura 4.1 mostra os carregamentos no centro da estrutura projetada.

$$
\begin{gathered}
25 m \times[1,3 \times(0,18+0,10+0,13)+1,5 \times(0,25+0,15)] k N / m^{2}= \\
28,33 k N / m \times 2 m=56,65 k N
\end{gathered}
$$$$
\text { Por treliça: } 56,65 k N / 2=28,33 k N
$$

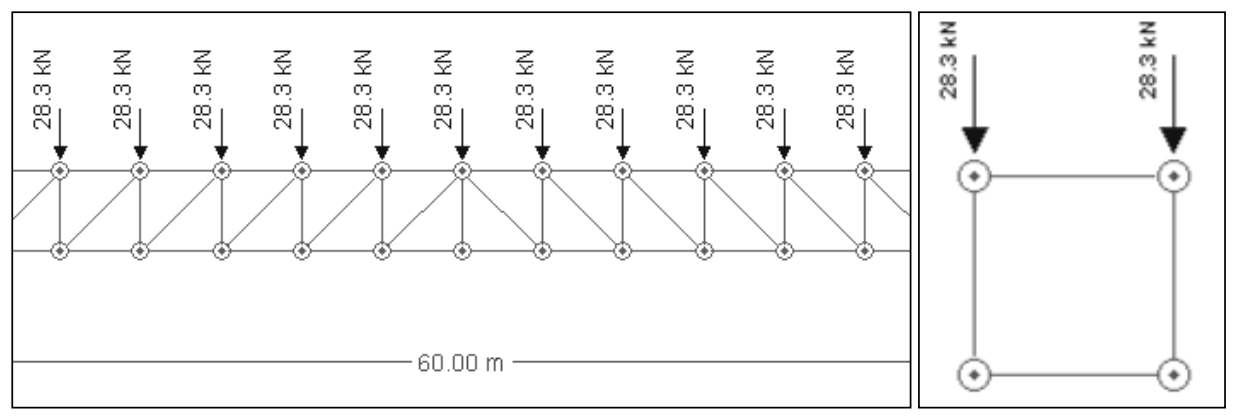

Figura 4.1 - (a) Aplicação do carregamento na estrutura; (b) seção transversal da treliça - os valores são mostrados por treliça. 


\subsection{1.}

\section{Esforços de projeto}

Com a aplicação desses carregamentos, serão obtidos os esforços de projeto nas cordas e as reações de apoio da estrutura. Na Figura 4.2, são mostrados os esforços mais desfavoráveis atuantes nas cordas. A Tabela 4.3 resume os valores dos esforços máximos encontrados na estrutura.

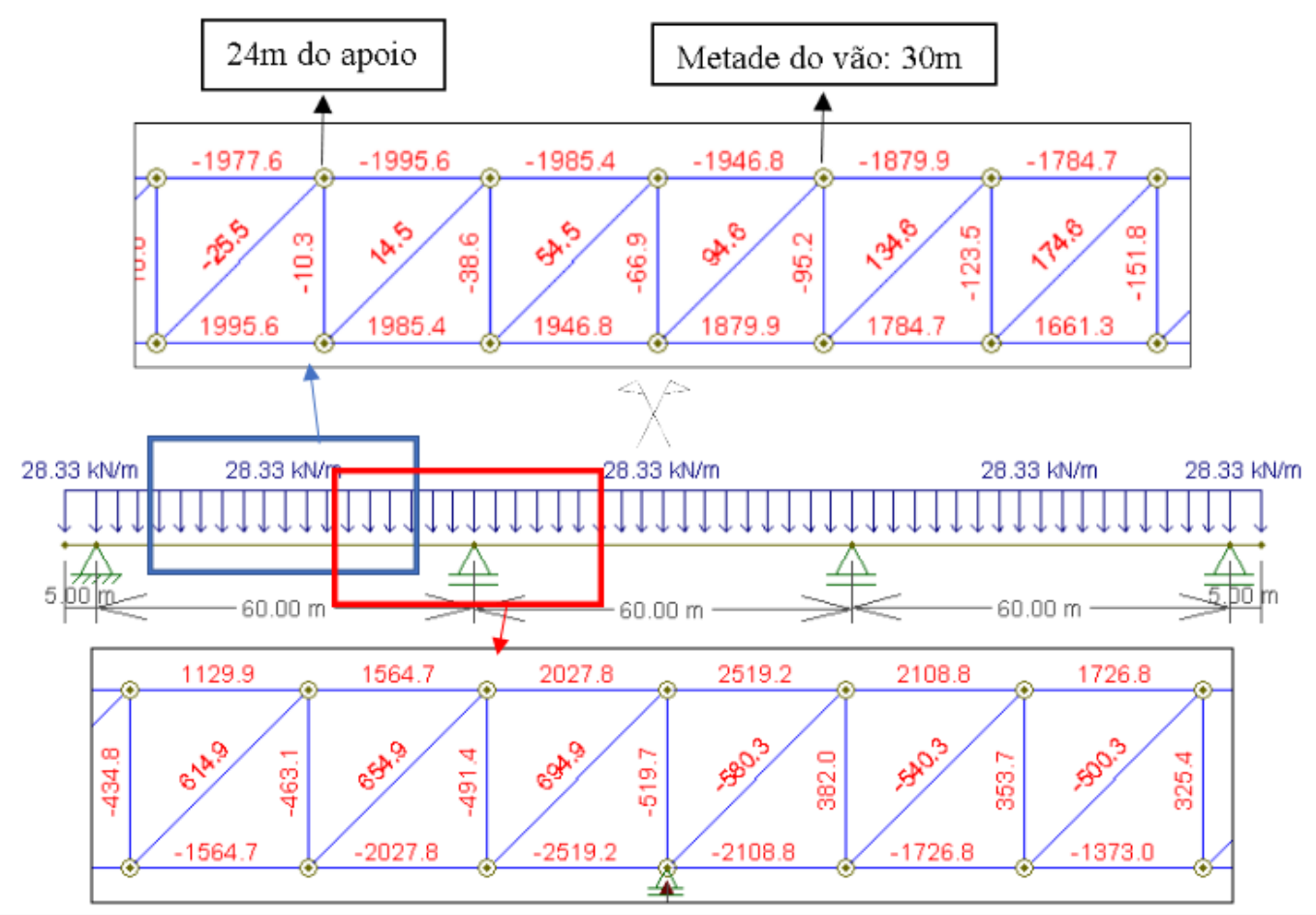

Figura 4.2 - Esforços das cordas (por treliça).

\begin{tabular}{|c|c|c|}
\hline \multirow{2}{*}{ Região } & \multicolumn{2}{|c|}{ Força axial máxima na corda } \\
\cline { 2 - 3 } & Compressão [kN] & Tração [kN] \\
\hline Meio do vão da extremidade & $-1995,60$ & 1995,60 \\
\hline Apoio & $-2519,20$ & 2519,20 \\
\hline Região & \multicolumn{2}{|c|}{ Reações de apoio [kN] } \\
\hline Apoios centrais & \multicolumn{2}{|c|}{930,00} \\
\hline Apoios das extremidades & \multicolumn{2}{|c|}{414,30} \\
\hline
\end{tabular}

Tabela 4.3 - Forças axiais máximas nas cordas e reações de apoio por treliça.

As diagonais que apresentaram maiores esforços são as que se localizam próximas dos apoios. A Figura 4.3 mostra os valores máximos de compressão por treliça das forças próximas do apoio da extremidade $(-465,70 \mathrm{kN})$ e a Figura 4.4 mostra os valores próximos dos apoios centrais da estrutura $(-580,30 \mathrm{kN})$. 


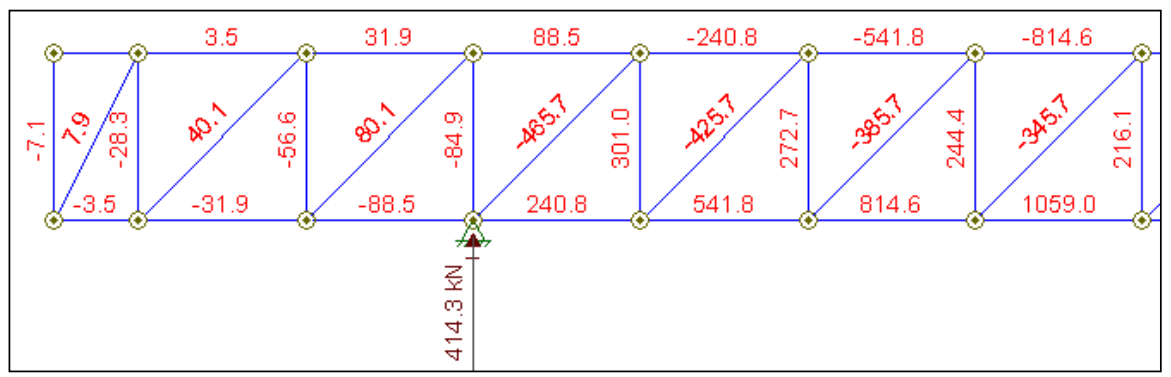

Figura 4.3 - Esforços na região do apoio da extremidade.

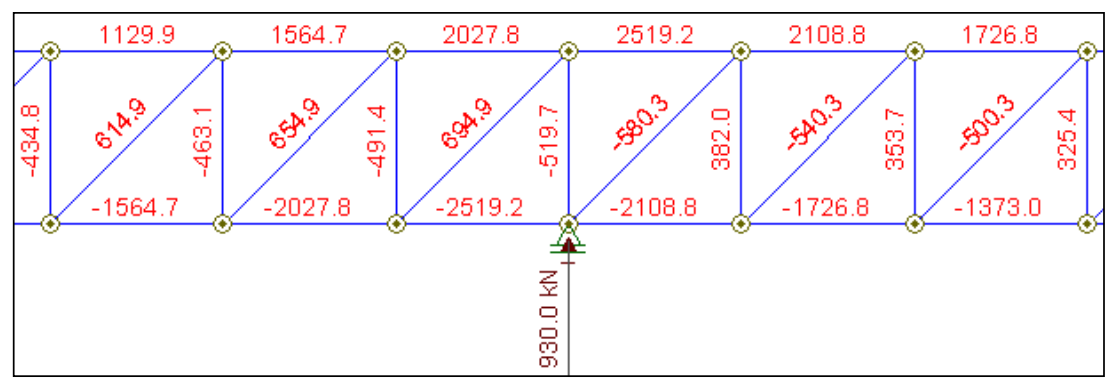

Figura 4.4 - Esforços na região do apoio central.

\section{2. \\ Materiais}

Será empregado para todos os perfis metálicos o aço ASTM 572 Grau 50, com módulo de elasticidade de $200000 \mathrm{MPa}$, tensão limite de escoamento de 345 MPa e tensão limite de ruptura de $450 \mathrm{MPa}$.

Para as estruturas com perfis mistos, foi utilizado um concreto com resistência característica à compressão de $40 \mathrm{MPa}$, com densidade de $2500 \mathrm{~kg} / \mathrm{m}^{3}$. Não foram dimensionadas armaduras de reforço em qualquer elemento misto neste trabalho, consideração permitida pela norma NBR8800/08.

Os dados de consumo de aço para as treliças com perfis mistos estão contabilizados com a consideração da conversão do valor do volume de concreto para uma quantidade equivalente de aço $\left(1 \mathrm{~m}^{3}\right.$ de concreto $=100 \mathrm{~kg}$ de aço $)$. Com essa conversão, os custos com o concreto referentes ao material em si, ao transporte e moldagem das peças mistas poderão ser contabilizados no consumo médio de aço da treliça.

As imperfeições geométricas iniciais da estrutura serão aplicadas no projeto reticulado por meio de forças equivalentes, denominadas de forças nocionais. Essas 
ações serão impostas lateralmente na corda superior das treliças, contribuindo para o deslocamento fora do plano da estrutura de forma mais desestabilizante.

As forças nocionais são calculadas a partir de uma parcela do somatório das forças verticais aplicadas. Serão adotadas as recomendações da norma canadense CSA S16-09, que utiliza 5\% do somatório dessas solicitações.

\section{3. \\ Considerações da análise estrutural}

O software comercial SAP2000 foi o programa de análise estrutural escolhido. A partir de sua interface gráfica tridimensional, foram realizados os procedimentos de modelagem dos elementos da estrutura.

Para o processamento das treliças, será realizado uma análise estática elástica aproximada de segunda ordem, com processo iterativo com base na resposta da estrutura sob sua geometria deformada.

Os efeitos decorrentes dos deslocamentos horizontais dos nós, ou seja, os efeitos globais de segunda ordem (P- $\Delta$ ) são calculados automaticamente utilizando o software SAP2000. Já para a consideração dos efeitos locais de segunda ordem decorrentes da não-retilineidade dos eixos das barras $(\mathrm{P}-\delta)$, será considerado o fator de majoração $B_{1}$.

Será necessário que o valor de rigidez de todos os elementos estruturais seja ajustado para contribuir com a estabilidade da estrutura. Isso se justifica para que os efeitos das imperfeições iniciais de material sejam considerados. Assim, os valores finais de rigidez à flexão e a rigidez axial são reduzidos para $80 \%$ dos valores iniciais, como especificado na NBR 8800/08.

A estrutura reticulada foi projetada no programa utilizando o elemento finito FRAME. O mesmo apresenta a formulação tridimensional de viga-coluna, ou seja, engloba os efeitos de flexão biaxial, torção, deformação axial e deformações biaxiais de cisalhamento (COMPUTERS AND STRUCTURES, 2011).

O dimensionamento dos perfis metálicos também foi realizado pelo software, este programado para a solução de acordo com as recomendações da norma AISC 360-10. Entretanto, o software não contém recursos para o dimensionamento para os elementos mistos, estes sendo, então, realizados externamente ao programa. 
As resistências das ligações também foram verificadas externamente ao software SAP2000, utilizando as recomendações da AISC 360-16. Quando necessário, novos dimensionamentos foram realizados para os elementos que não se adequaram a essas solicitações locais e atualizados dentro do software utilizado.

Para as seções dos perfis mistos, foi utilizada a ferramenta "Section Designer" do SAP2000. Ela é capaz de simular o comportamento de elementos com seções quaisquer, além de poder combinar diversos materiais.

As flechas obtidas nas treliças serão comparadas com os valores normativos estabelecidos pela NBR 8800/08 para vigas de cobertura, ou seja, L/250. Como orienta a NBR 8800, para treliças de vão igual ou superior a 24 metros devem ser aplicadas contraflechas aproximadamente iguais às flechas resultantes das ações permanentes diretas. Dessa forma, os resultados dos deslocamentos verticais das treliças estão relacionados apenas às solicitações variáveis.

Para a composição das cordas da estrutura, será considerado o fator de discretização: será utilizado um perfil de taxa de utilização mais próximo possível de $100 \%$, com o objetivo de evitar desperdício de material.

\section{4. \\ Dimensionamento estrutural}

Para o dimensionamento das cordas da treliça sob cargas de compressão axial, os comprimentos destravados nas três direções serão iguais ao comprimento do módulo. A Figura 4.5 mostra os valores dos comprimentos destravados.

As cordas comprimidas estarão travadas fora do plano de acordo com a configuração presente na Figura 4.5 (b), ou seja, será do tipo travamento relativo. Essa configuração geométrica dos travamentos é verificada ao se observar o comportamento da estrutura nos modos de flambagem, quando a estrutura falha localmente na peça, como pode ser visto na Figura 4.6.

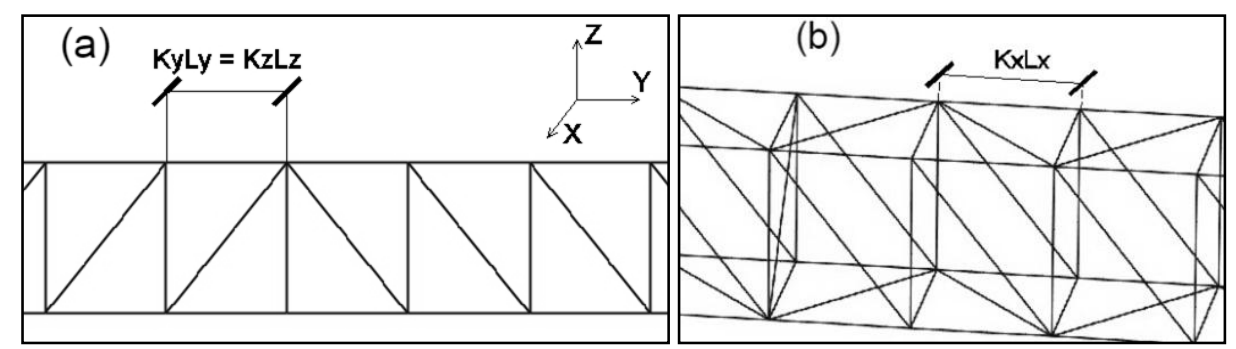

Figura 4.5 - Comprimentos destravados da estrutura. 


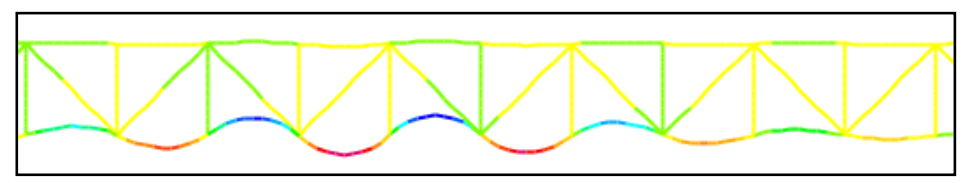

Figura 4.6 - Falha por flambagem corda comprimida.

\subsection{1. \\ Dimensionamento das regiões mais solicitadas}

Como já foram obtidos os valores das forças máximas nas cordas, a Tabela 4.4 foi montada para as regiões mais críticas. Nela, estão dispostos os quatro perfis escolhidos, as forças axiais resistente ( $\left.N_{c, R d}\right)$ e solicitação de projeto $\left(N_{c, S d}\right)$ encontradas para cada um desses perfis; a taxa de utilização; a taxa consumo médio de aço dessas peças nessa região crítica; e uma taxa comparativa que relaciona o peso dos perfis laminados com os outros, chamada de X/PL. Já a Tabela 4.5 mostra esses mesmos dados para a região central do vão da extremidade.

Para facilitar a leitura da tabela, foram utilizadas as seguintes nomenclaturas para os perfis nas cordas: para perfis laminados, será usado "PL"; para perfis tubulares, "T"; para perfis com seções WT, "WT"; e para perfis mistos, será usado o "M".

Para o consumo médio de aço da treliça, a nomenclatura será “CA”, cuja medida será em quilograma de aço por metro $[\mathrm{kg} / \mathrm{m}]$. Já para a taxa de utilização do perfil, a nomenclatura será "T.U.".

Os valores das treliças com perfis mistos já incluem a conversão dos custos com o concreto para aço equivalente.

A primeira observação a ser feita é que há proximidade de valores das forças solicitantes encontrados nas treliças, fato que ocorreu para todos as estruturas e nas duas regiões críticas.

\begin{tabular}{|c|c|c|c|c|c|c|}
\hline \multicolumn{7}{|c|}{ Região Crítica: Apoio } \\
\hline & Perfil & $N_{c, R d}$ & $N_{c, S d}$ & T.U. & $\mathrm{CA}$ & $\mathrm{X} / \mathrm{PL}$ \\
\hline $\mathrm{PL}$ & 2W310x38,7 & $-2958,84 k N$ & $-2596,50 \mathrm{kN}$ & $87,75 \%$ & 77,4 & $100 \%$ \\
\hline $\mathrm{T}$ & HSS200x17,46 & $-2897,83 \mathrm{kN}$ & $-2678,40 \mathrm{kN}$ & $92,43 \%$ & 78,6 & $101,55 \%$ \\
\hline WT & WT155x89,5 & $-2915,49 k N$ & $-2595,66 \mathrm{kN}$ & $89,03 \%$ & 89,5 & $115,63 \%$ \\
\hline $\mathrm{M}$ & CFST240×8 & $-2493,48 k N$ & $-2469,00 \mathrm{kN}$ & $99,02 \%$ & 53,63 & $69,29 \%$ \\
\hline
\end{tabular}

Tabela 4.4 - Região crítica: apoio central (trecho de 6000mm). 


\begin{tabular}{|c|c|c|c|c|c|c|}
\hline \multicolumn{7}{|c|}{ Meio do vão da extremidade } \\
\hline & Perfil & $N_{c, R d}$ & $N_{c, S d}$ & T.U. & CA & $\mathrm{X} / \mathrm{PL}$ \\
\hline $\mathrm{PL}$ & $2 W 310 \times 28,3$ & $-2023,31 \mathrm{kN}$ & $-1926,00 \mathrm{kN}$ & $95,19 \%$ & 56,6 & $100 \%$ \\
\hline $\mathrm{T}$ & HSS200x11,91 & $-2044,37 \mathrm{kN}$ & $-1900,20 \mathrm{kN}$ & $92,95 \%$ & 55,25 & $97,61 \%$ \\
\hline WT & WT155x62,5 & $-2068,93 \mathrm{kN}$ & $-1915,28 \mathrm{kN}$ & $92,57 \%$ & 62,5 & $110,42 \%$ \\
\hline$M$ & CFST240x4,8 & $-1982,59 \mathrm{kN}$ & $-1962,53 \mathrm{kN}$ & $98,99 \%$ & 32,01 & $56,55 \%$ \\
\hline
\end{tabular}

Tabela 4.5 - Região crítica: centro do vão da extremidade (trecho de $6000 \mathrm{~mm})$.

Outro ponto importante é que os valores das taxas de utilização apresentaramse bastante aceitáveis pela proximidade do valor unitário, fator que indica que a peça está sendo utilizada próximo da sua capacidade total, reduzindo desperdícios.

Para essas regiões, o perfil misto foi o que apresentou a solução mais leve, enquanto que o perfil WT apresentou a solução mais pesada. Houve proximidade de valores entre as estruturas com perfis laminados e perfis tubulares.

\subsection{2. \\ Perfis utilizados para a solução tubular}

De forma a exemplificar como foi realizado o dimensionamento dos perfis das seções tubulares, a Figura 4.7 mostra as seções tubulares utilizados no exemplo apresentado neste capítulo.

A figura mostra os perfis utilizados para as cordas superiores e inferiores das regiões de vão da extremidade (região $\mathrm{AB}$ e $\mathrm{CD}$ ) e para a região do vão central (região BC). Cada perfil apresenta um comprimento de $6,00 \mathrm{~m}$.

Observa-se que, para as regiões de maiores de esforços solicitantes, houve um aumento da espessura do tubo, como pode ser verificado ao se analisar as regiões centrais dos vãos das extremidades, onde ocorrem esforços de compressão para a corda superior e de tração para as cordas inferiores.

Já para as regiões de menores esforços solicitantes, como por exemplo a região central do vão intermediário e na região das extremidades em balanço, utilizouse espessuras menores para os perfis tubulares. 


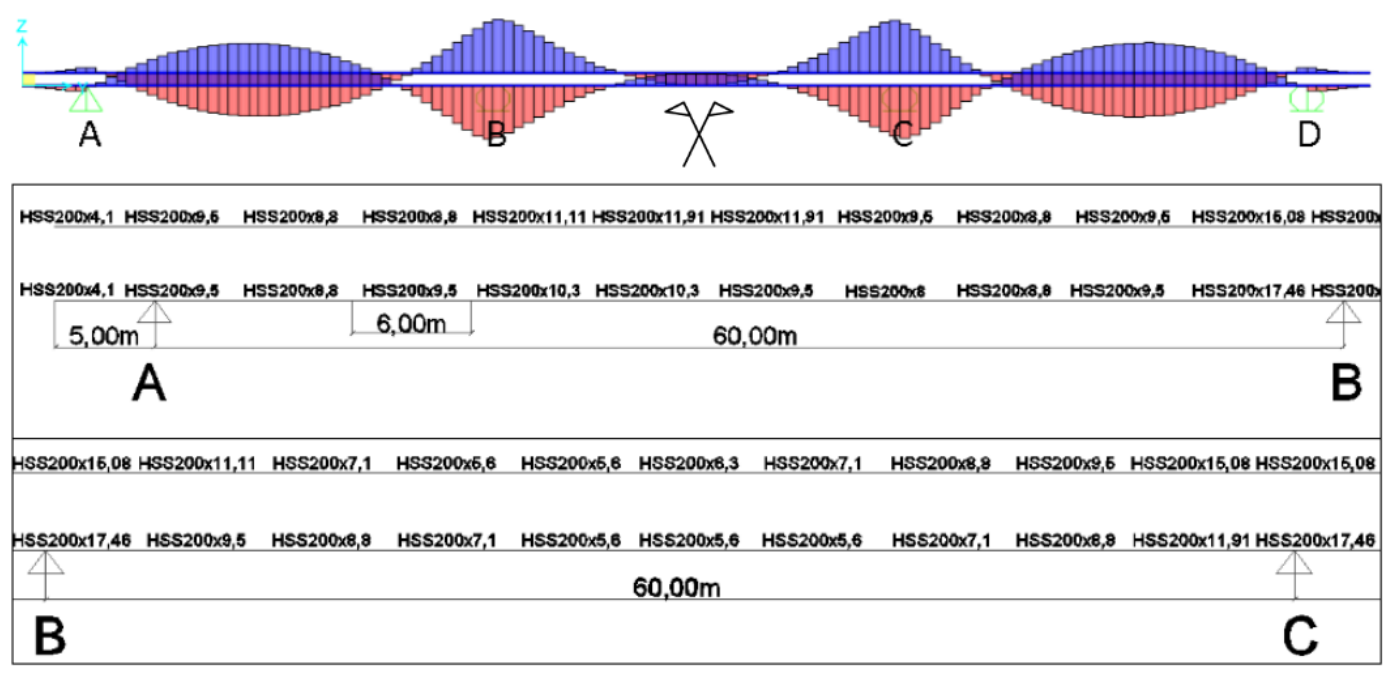

Figura 4.7 - Perfis adotados para a treliça com perfis tubulares.

\subsection{3. \\ Discretização das diagonais e montantes}

Para facilitar a execução das diagonais e montantes e objetivando buscar a solução de menor consumo de aço, foi feita uma variação de peças ao longo da treliça.

Sendo que as regiões dos apoios são as mais solicitadas, pode-se dividir a treliça em três partes: a região de centro de vão e extremidades (denominada regiões A); as regiões para os apoios extremos (regiões B); e as regiões dos apoios centrais (regiões C). O comprimento das regiões B e C (denominadas respectivamente de C1 e C2) irão variar de acordo com o comprimento do vão utilizado na estrutura. A Figura 4.8 mostra esquematicamente a discretização da treliça.

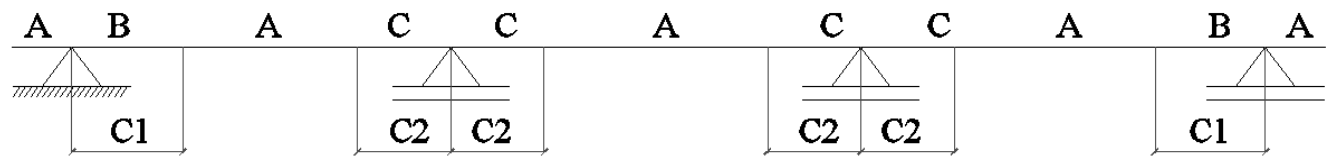

Figura 4.8 - Regiões de discretização das diagonais e montantes.

A Tabela 4.6 resume os perfis das estruturas secundárias utilizados nas treliças estudadas nesse capítulo. Os comprimentos das regiões B e C, ou seja, os valores de $\mathrm{C} 1$ e C2 são, respectivamente, $6 \mathrm{~m}$ e $12 \mathrm{~m}$. 


\begin{tabular}{|c|c|c|}
\hline Região & Tubos circulares [AISC] & Cantoneiras duplas \\
\hline A & HSS168×3,2 & $2 \mathrm{~L} 89 \times 89 \times 6,35$ \\
\hline B & HSS168x4,8 & $2 \mathrm{~L} 102 \times 102 \times 7,94$ \\
\hline C & HSS168x6,4 & $2 \mathrm{~L} 127 \times 127 \times 9,52$ \\
\hline
\end{tabular}

Tabela 4.6 - Perfis das diagonais e montantes das regiões discretizadas.

\section{5.}

\section{Resultados das treliças}

Após o dimensionamento da estrutura, foi possível montar a Tabela 4.7 com os principais resultados para as quatro treliças descritas acima. Nela são mostrados os valores de consumo médio de aço por metro e a relação X/PL entre as estruturas apresentadas; deslocamentos fora do plano (Ux) e no plano (Uz).

O primeiro autovalor de flambagem da estrutura será chamado nesse trabalho de $\lambda_{1}$, que representa intensidade do incremento a ser dado no carregamento aplicado na estrutura para produzir o fenômeno da instabilidade estrutural.

Os resultados das flechas (Uz) foram devidos apenas às ações variáveis, enquanto que os deslocamentos fora do plano (Ux) foram devidos às ações variáveis e permanentes.

\begin{tabular}{|c|c|c|c|c|c|}
\hline \multicolumn{6}{|c|}{ Resultados - V $=60 \mathrm{~m} ; \mathrm{h}=2,00 \mathrm{~m} ; \mathrm{Lb}=2,00 \mathrm{~m} ; \mathrm{ST4}$} \\
\hline Perfil & CA $[\mathrm{kg} / \mathrm{m}]$ & X/PL & Ux $[\mathrm{mm}]$ & $\mathrm{Uz}[\mathrm{mm}]$ & $\lambda_{1}$ \\
\hline PL & 296,56 & $100 \%$ & 6,60 & 343,80 & 1,485 \\
\hline T & 318,10 & $110,06 \%$ & 6,05 & 351,92 & 3,250 \\
\hline WT & 355,00 & $122,83 \%$ & 6,00 & 310,20 & 1,138 \\
\hline M & 264,87 & $91,65 \%$ & 7,80 & 229,90 & 3,947 \\
\hline
\end{tabular}

Tabela 4.7 - Resultados do estudo de caso.

A solução com perfis mistos foi a que apresentou menor quantidade de consumo de aço dentre os quatro, seguido da solução com perfis laminados. A solução que utilizou perfis WT foi a que apresentou maior consumo de aço.

Observando a relação X/PL, pode-se comparar as treliças de forma mais clara: a solução com perfis mistos consome $8,35 \%$ menos aço que a treliça com perfis laminados, enquanto que as outras duas trazem valores de consumo maiores que os encontrados na estrutura com perfil laminado. 
O perfil tubular apresentou um consumo de aço elevado, mesmo discretizando os valores das espessuras utilizadas nos tubos. Isso se justifica devido à necessidade de se utilizar tubos mais espessos de modo a evitar a plastificação da parede dos tubos devido às forças externas aplicadas pelas diagonais e montantes da treliça. Já para os perfis mistos, a plastificação é reforçada devido à presença do núcleo de concreto, que enrijece e fortalece a conexão.

Com o objetivo único de fortalecer a ligação e impedir a plastificação da parede do tubo de aço, foram utilizados perfis mistos nas regiões da treliça com esforços a tração. Mesmo havendo a necessidade de se utilizar o concreto em quase todas as regiões da treliça, esse método ainda se mostra como o de menor peso.

A norma NBR8800 aconselha que vigas de cobertura apresentem uma flecha máxima de L/250, que, para um vão de $60 \mathrm{~m}$, significa $240 \mathrm{~mm}$. Nota-se que apenas a treliça com perfis mistos está dentro dos valores normativos, enquanto que as outras não desenvolveram valores suficientes para estar de acordo com as prescrições normativas.

O preenchimento do interior dos tubos de aço com concreto faz com que a estrutura, que trabalha como uma viga, aumente sua resistência à flexão. Dessa forma, menores deslocamentos verticais são obtidos para as treliças que utilizam esse perfil em comparação com os outros estudados, como pôde ser exemplificado nos resultados acima.

A baixa altura que foi adotada para a treliça foi responsável pelos grandes valores das flechas obtidas pelas treliças que não utilizam perfis mistos. Dentre essas estruturas, a que foi dimensionada com perfis WT apresentou-se como a de menor flecha. Isso se dá devido à utilização de perfis de maior rigidez, o que levou essa estrutura a ser a que apresentou o maior peso por metro.

Ao se observar os valores de deslocamentos fora do plano, constata-se a boa estabilidade lateral das treliças multiplanares, já que o maior deslocamento encontrado (treliça com perfis laminados) representa um valor de $0,013 \%$ do total do vão.

O modo de falha encontrado para as quatro treliças acima foi o mesmo: flambagem global por flexão. Os autovalores de flambagem foram superiores ao valor unitário, significando que a estrutura é capaz de suportar os carregamentos aplicados sem apresentar falha em qualquer das treliças desenvolvidas. 


\section{5 Resultados da análise estrutural das treliças multiplanares}

Neste capítulo são abordados os resultados de variações de diversos parâmetros de configuração estrutural das treliças multiplanares, com ênfase nos modos de falha e nas resistências de projeto. Posteriormente será realizado um estudo paramétrico com o objetivo de comparar as variações de projeto e sua influência no comportamento e no consumo de aço da treliça.

\section{1. \\ Modos de falha}

Avaliar o comportamento da treliça após o dimensionamento e aplicação dos carregamentos é de fundamental importância para a garantia da segurança das estruturas projetadas.

Assim, é imprescindível que se atente quanto ao modo de falha que a estrutura irá manifestar, analisando se seus autovalores e sua configuração deformada mostram uma resposta adequada na etapa de dimensionamento.

Neste trabalho, os modos de flambagem da estrutura foram calculados automaticamente pelo software. Todos os resultados obtidos após a análise da estrutura apresentaram os primeiros autovalores de flambagem superiores a um $\left(\lambda_{1}>1,00\right)$, ou seja, para que aconteça falha na estrutura, deve-se aumentar o carregamento aplicado na mesma.

Foram verificados os primeiros autovalores de flambagem da estrutura de todos as treliças sob a matriz de rigidez computada na forma deformada, ou seja, considerando os efeitos de segunda ordem gerados a partir da deslocabilidade da estrutura nas análises globais $\mathrm{P}-\Delta$.

Após observar o comportamento dos projetos estruturais após o dimensionamento, viu-se que os primeiros modos de falha foram predominantemente relacionados à flambagem global da estrutura. $\mathrm{O}$ vão da extremidade da treliça principal, como um todo, sai do seu plano e tende a perder a estabilidade lateral associada a 
flexão da seção transversal. Esse fenômeno ocorre tanto para as seções com três como também com quatro cordas para todos os vãos estudados.

A Figura 5.1 mostra um caso de flambagem global de uma treliça com um vão de $60 \mathrm{~m}$ em três visualizações diferentes: vista superior, frontal inclinada e isométrica.

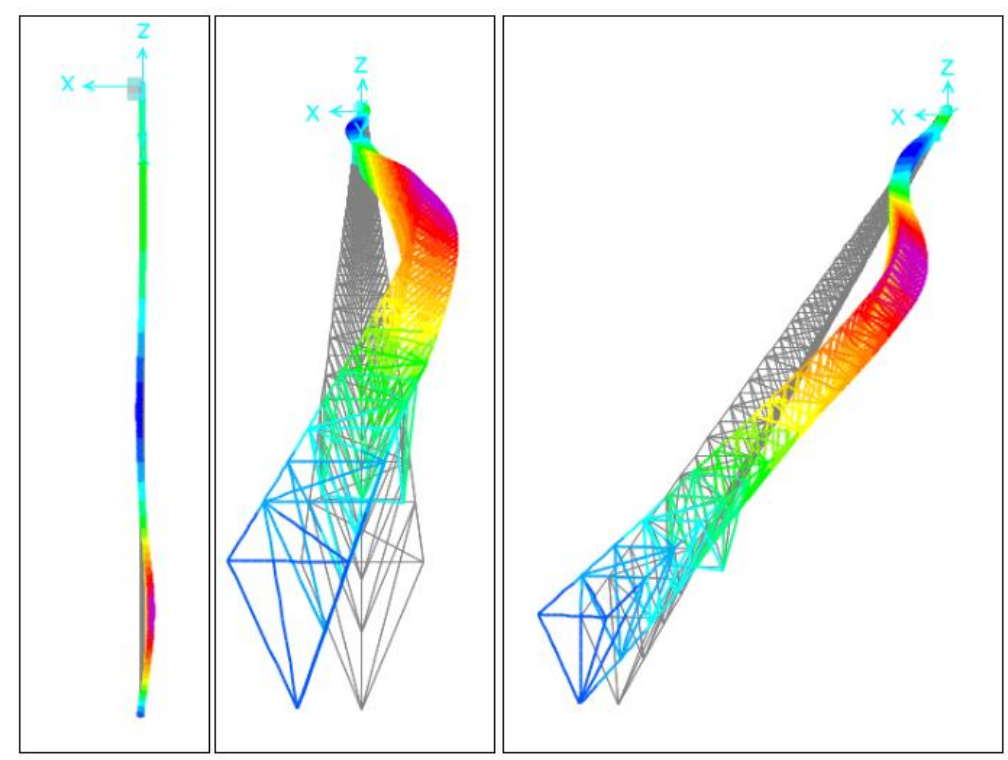

Figura 5.1 - Flambagem global da treliça ST3 (Fator de escala: 50).

Aumentando o fator de escala, vê-se claramente a formação das semi-ondas que representam os comprimentos de flambagem definidos entre as regiões dos apoios.

Pode-se observar que a treliça multiplanar trabalha de forma equivalente a uma coluna sob compressão axial, devido às suas cordas superiores estarem sofrendo predominantemente esforços de compressão. A Figura 5.2 mostra a treliça deformada com um grande fator de escala comparada com uma coluna com travamentos sob compressão axial.

A Tabela 5.1 resume os primeiros autovalores de flambagem $\left(\lambda_{1}\right)$ encontrados na treliça com vão de $45 \mathrm{~m}$. Todas essas estruturas projetadas desenvolveram o mesmo modo de falha: flambagem global por flexão.

Observando esses resultados, nota-se que as estruturas com seção transversal ST3 tem maior suscetibilidade a apresentar flambagem global por flexão, ao comparar com as treliças com seções ST4, principalmente nos casos de menor altura da treliça. 


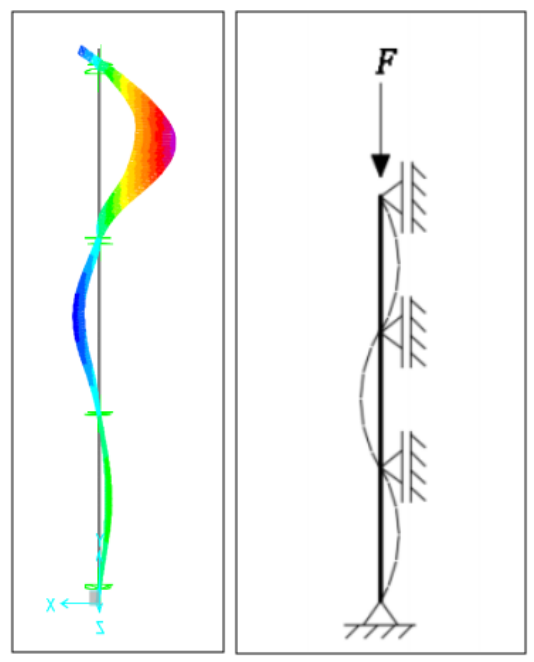

Figura 5.2 - Comprimento de onda - Comparação da treliça com uma coluna (Fator de escala: 300).

Durante a fase de projeto, observou-se que as barras diagonais que interligam cordas superiores com inferiores posicionadas no meio dos vãos são responsáveis por dar maior estabilidade lateral às estruturas de seção ST4.

A baixa altura da treliça, e consequente aumento das flechas, influencia diretamente na estabilidade da estrutura, devido aos efeitos de segunda ordem. Isso pode ser observado na Tabela 5.1, que mostra que os autovalores das treliças de altura 2,25m são bem maiores que os autovalores para as estruturas de altura 1,50m.

A mesma nomenclatura utilizada no capítulo 4 para determinar os tipos de perfil usados nas cordas será adotada nesse capítulo.

Analisando-se os autovalores das treliças com baixa altura, percebeu-se que os perfis escolhidos seguiam adequadamente às prescrições normativas para os esforços solicitantes locais, entretanto, o autovalor de flambagem global ainda era menor que o valor unitário $(1,00)$, significando que a estrutura não apresenta capacidade de carga adequada para as solicitações que lhe são impostas.

Como solução para isso, foi necessário enrijecer as estruturas secundárias das regiões próximas dos apoios. O modo de falha dessa seção é mostrado na Figura 5.3. Essas alterações propiciaram maior capacidade de carga para a estrutura de modo que ela pudesse suportar às solicitações de projeto. 


\begin{tabular}{|c|c|c|c|c|c|c|c|}
\hline \multicolumn{4}{|c|}{ Vão de 45m - ST4 } & \multicolumn{4}{|c|}{ Vão de $45 m$ - ST3 } \\
\hline$h[\mathrm{~m}]$ & $\alpha\left[^{\circ}\right]$ & Perfil & $\lambda_{1}$ & $\mathrm{~h}[\mathrm{~m}]$ & $\alpha\left[^{\circ}\right]$ & Perfil & $\lambda_{1}$ \\
\hline \multirow{12}{*}{1,50} & \multirow{4}{*}{30,96} & $\mathrm{PL}$ & 4,642 & \multirow{9}{*}{1,50} & \multirow{3}{*}{30,96} & $\mathrm{PL}$ & 1,25 \\
\hline & & $T$ & 4,458 & & & $T$ & 1,19 \\
\hline & & WT & 5,356 & & & $M$ & 1,587 \\
\hline & & $M$ & 5,213 & & \multirow{3}{*}{45,00} & $\mathrm{PL}$ & 1,03 \\
\hline & \multirow{4}{*}{45,00} & $\mathrm{PL}$ & 5,215 & & & $\mathrm{~T}$ & 1,1 \\
\hline & & $T$ & 4,987 & & & $M$ & 1,746 \\
\hline & & WT & 6,052 & & \multirow{3}{*}{50,19} & $\mathrm{PL}$ & 1,07 \\
\hline & & $M$ & 5,887 & & & $T$ & 1,01 \\
\hline & \multirow{4}{*}{50,19} & $\mathrm{PL}$ & 3,911 & & & $M$ & 1,551 \\
\hline & & $\mathrm{T}$ & 3,812 & $\mathrm{~h}[\mathrm{~m}]$ & $\alpha\left[^{\circ}\right]$ & Perfil & $\lambda_{1}$ \\
\hline & & WT & 4,988 & \multirow{9}{*}{1,80} & \multirow{3}{*}{30,96} & $\mathrm{PL}$ & 3,039 \\
\hline & & $M$ & 4,694 & & & $\mathrm{~T}$ & 2,736 \\
\hline $\mathrm{h}[\mathrm{m}]$ & $\alpha\left[^{\circ}\right]$ & Perfil & $\lambda_{1}$ & & & $M$ & 3,394 \\
\hline \multirow{12}{*}{1,80} & \multirow{4}{*}{30,96} & $\mathrm{PL}$ & 4,902 & & \multirow{3}{*}{45,00} & $\mathrm{PL}$ & 3,721 \\
\hline & & $\mathrm{T}$ & 4,547 & & & $\mathrm{~T}$ & 3,48 \\
\hline & & WT & 6,38 & & & $M$ & 4,48 \\
\hline & & $\mathrm{M}$ & 5,524 & & \multirow{3}{*}{50,19} & $\mathrm{PL}$ & 3,141 \\
\hline & \multirow{4}{*}{45,00} & $\mathrm{PL}$ & 5,871 & & & $\mathrm{~T}$ & 2,824 \\
\hline & & $\mathrm{T}$ & 5,72 & & & $M$ & 3,703 \\
\hline & & WT & 7,425 & $\mathrm{~h}[\mathrm{~m}]$ & $\alpha\left[^{\circ}\right]$ & Perfil & $\lambda_{1}$ \\
\hline & & $M$ & 6,788 & \multirow{9}{*}{2,25} & \multirow{3}{*}{36,87} & $\mathrm{PL}$ & 3,515 \\
\hline & \multirow{4}{*}{50,19} & $\mathrm{PL}$ & 5,397 & & & $T$ & 3,175 \\
\hline & & $\mathrm{T}$ & 5,226 & & & $M$ & 4,058 \\
\hline & & WT & 7,002 & & \multirow{3}{*}{45,00} & $\mathrm{PL}$ & 3,253 \\
\hline & & $M$ & 6,323 & & & $T$ & 2,969 \\
\hline $\mathrm{h}[\mathrm{m}]$ & $\alpha\left[^{\circ}\right]$ & Perfil & $\lambda_{1}$ & & & $M$ & 3,648 \\
\hline \multirow{12}{*}{2,25} & \multirow{4}{*}{36,87} & $\mathrm{PL}$ & 8,015 & & \multirow{3}{*}{51,34} & $\mathrm{PL}$ & 3,236 \\
\hline & & $T$ & 7,671 & & & $T$ & 2,947 \\
\hline & & WT & 12,176 & & & $M$ & 3,702 \\
\hline & & $M$ & 9,096 & & & & \\
\hline & \multirow{4}{*}{45,00} & $\mathrm{PL}$ & 8,427 & & & & \\
\hline & & $T$ & 7,787 & & & & \\
\hline & & WT & 5,276 & & & & \\
\hline & & $M$ & 9,237 & & & & \\
\hline & & $\mathrm{PL}$ & 7,349 & & & & \\
\hline & 5121 & $T$ & 6,798 & & & & \\
\hline & 51,34 & WT & 3,919 & & & & \\
\hline & & $M$ & 8,165 & & & & \\
\hline
\end{tabular}

Tabela 5.1 - Primeiros autovalores de flambagem da treliça com vão de $45 \mathrm{~m}$. 


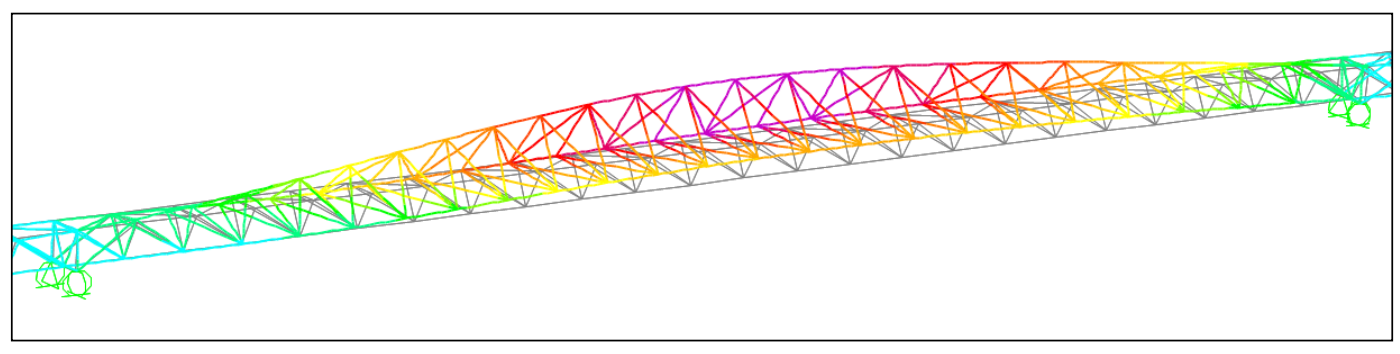

Figura 5.3 - Modo de flambagem apresentado na região dos apoios centrais (Fator de escala: 100).

A estrutura treliçada também apresentou flambagem da corda como modo de falha para maiores autovalores, valores observados para os três tipos de vãos. Este fenômeno é influenciado pelas propriedades do perfil que está sendo utilizado na corda, assim, caso se utilize um elemento mais rígido, o autovalor também irá aumentar.

Assim, caso essa flambagem ocorra num elemento secundário (diagonal, por exemplo), basta utilizar um perfil mais rígido para este sem que se necessite realizar alterações de maiores proporções. A Figura 5.4 mostra um caso de flambagem global das cordas da treliça.

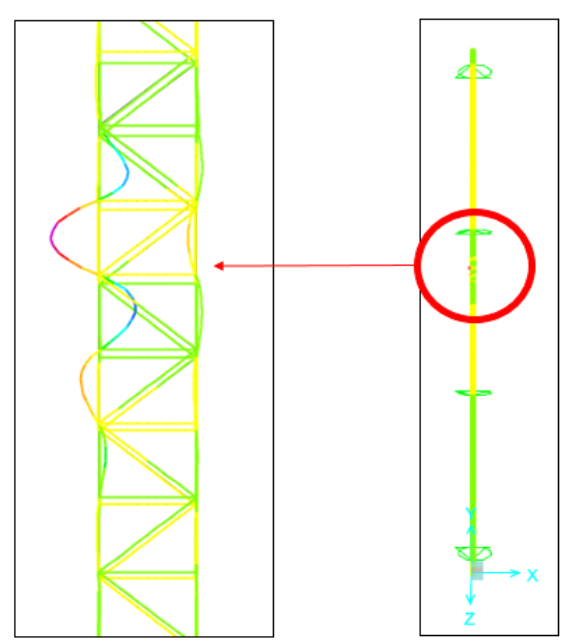

Figura 5.4 - Flambagem global da corda da treliça. 


\section{2.}

\section{Diâmetros adotados nas treliças com perfis tubulares e mistos}

A Tabela 5.2 apresenta os perfis utilizados nas treliças com vão de 32 metros para as seções ST4, onde "T" representa os perfis tubulares projetados para as quatro cordas; "M" representa os perfis mistos. A nomenclatura "cs" representa as cordas superiores, enquanto que "ci” representa as inferiores; já " $\alpha$ ” é o valor da inclinação das diagonais da treliça. A Figura 5.5 fornece a nomenclatura utilizada nessas tabelas para as seções ST4 e ST3.
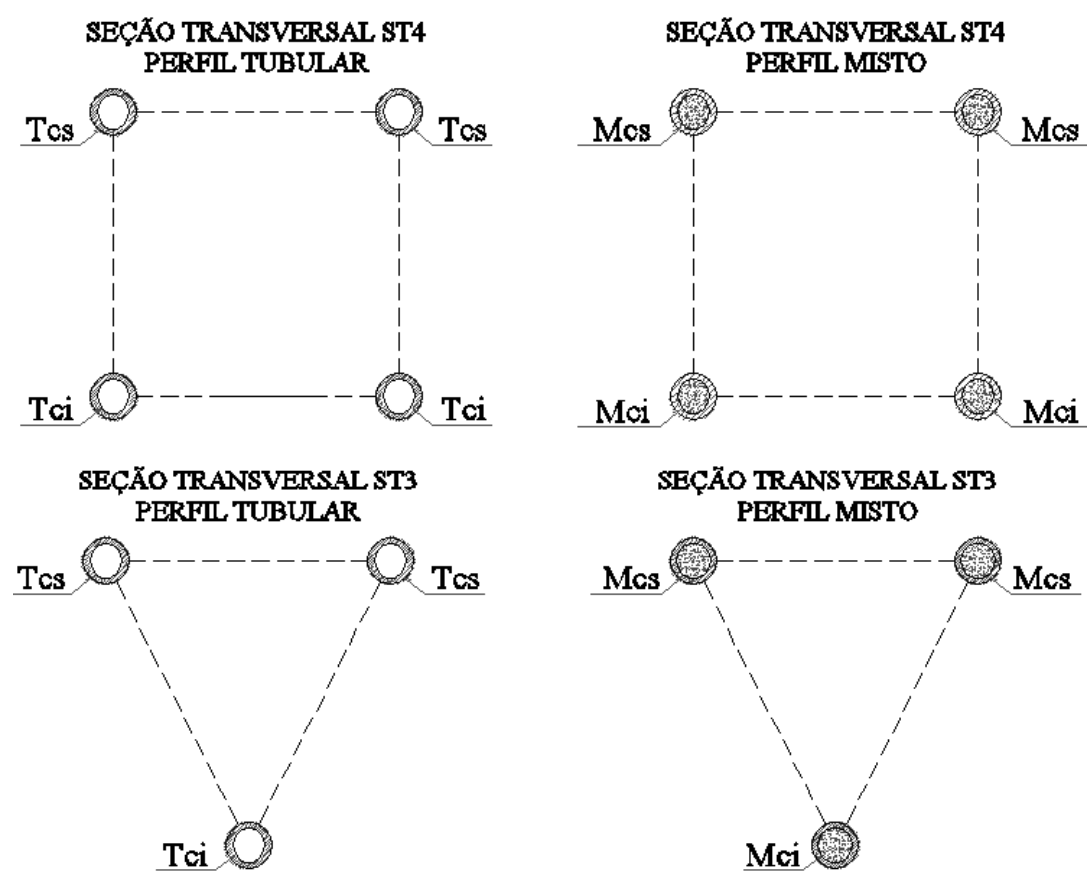

Figura 5.5 - Nomenclatura das cordas da seção ST4 e ST3.

Já a Tabela 5.3 apresenta os perfis utilizados nas treliças com vão de 32 metros para as seções ST3, na qual será utilizada a mesma nomenclatura.

As Tabelas 5.4 e 5.5 resumem os perfis tubulares e mistos utilizados para as seções ST4 e ST3, respectivamente, para treliças com vão de 45 metros. Já as Tabelas 5.6 e 5.7 se referem aos perfis utilizados nas seções ST4 e ST3 para treliças com vão de 60 metros. 


\begin{tabular}{|c|c|c|c|c|c|c|}
\hline \multicolumn{7}{|c|}{ Vão de 32m - ST4 } \\
\hline Altura & Comp. Destravado & Corda & $\mathrm{PL}$ & $T$ & WT & $\mathbf{M}$ \\
\hline \multirow{6}{*}{$\mathrm{h0,80m}$} & \multirow{2}{*}{ Lb1,00m } & CS & W310 & HSS 160 & WT155 & HSS 160 \\
\hline & & $\mathrm{Cl}$ & W310 & HSS 160 & WT155 & HSS 190 \\
\hline & \multirow{2}{*}{ Lb1,20m } & $\mathrm{CS}$ & W310 & HSS 160 & WT155 & HSS 160 \\
\hline & & $\mathrm{Cl}$ & W310 & HSS 160 & WT155 & HSS 190 \\
\hline & \multirow{2}{*}{$\mathrm{Lb} 2,00 \mathrm{~m}$} & CS & W310 & HSS 160 & WT155 & HSS 160 \\
\hline & & $\mathrm{Cl}$ & W310 & HSS 160 & WT155 & HSS 200 \\
\hline Altura & Comp. Destravado & Corda & PL & $T$ & WT & $\mathbf{M}$ \\
\hline \multirow{6}{*}{ h1,00m } & \multirow{2}{*}{ Lb0,80m } & CS & W310 & HSS 140 & WT155 & HSS 140 \\
\hline & & $\mathrm{Cl}$ & W310 & HSS 140 & WT155 & HSS 180 \\
\hline & \multirow{2}{*}{ Lb1,00m } & CS & W310 & HSS 140 & WT155 & HSS 150 \\
\hline & & $\mathrm{Cl}$ & W310 & HSS 140 & WT155 & HSS 180 \\
\hline & \multirow{2}{*}{ Lb1,60m } & CS & W310 & HSS 140 & WT155 & HSS 160 \\
\hline & & $\mathrm{Cl}$ & W310 & HSS 140 & WT155 & HSS 180 \\
\hline Altura & Comp. Destravado & Corda & PL & $T$ & WT & $\mathbf{M}$ \\
\hline \multirow{6}{*}{ h1,20m } & \multirow{2}{*}{ Lb0,50m } & $\mathrm{CS}$ & W310 & HSS 120 & WT155 & HSS 140 \\
\hline & & $\mathrm{Cl}$ & W310 & HSS 120 & WT155 & HSS 160 \\
\hline & \multirow{2}{*}{$\mathrm{Lb0}, 80 \mathrm{~m}$} & $\mathrm{CS}$ & W310 & HSS 120 & WT155 & HSS 140 \\
\hline & & $\mathrm{Cl}$ & W310 & HSS 120 & WT155 & HSS 170 \\
\hline & \multirow{2}{*}{ Lb1,00m } & CS & W310 & HSS 120 & WT155 & HSS 150 \\
\hline & & $\mathrm{Cl}$ & W310 & HSS 120 & WT155 & HSS 170 \\
\hline
\end{tabular}

Tabela 5.2 - Perfis utilizados nas cordas das treliças - 32m - Seção ST4.

\begin{tabular}{|c|c|c|c|c|c|}
\hline \multicolumn{6}{|c|}{ Vão de $32 m$ - ST3 } \\
\hline Altura & Comp. Destravado & Corda & PL & $T$ & $\mathbf{M}$ \\
\hline \multirow{6}{*}{ h0,80m } & \multirow{2}{*}{$\mathrm{Lb} 0,50 \mathrm{~m}$} & CS & W310 & HSS 130 & HSS 140 \\
\hline & & $\mathrm{Cl}$ & W310 & HSS 230 & HSS 210 \\
\hline & \multirow{2}{*}{$\mathrm{Lb} 0,80 \mathrm{~m}$} & $\mathrm{CS}$ & W310 & HSS 130 & HSS 140 \\
\hline & & $\mathrm{Cl}$ & W310 & HSS 230 & HSS 210 \\
\hline & \multirow{2}{*}{ Lb1,00m } & CS & W310 & HSS 130 & HSS 150 \\
\hline & & $\mathrm{Cl}$ & W310 & HSS 230 & HSS 210 \\
\hline Altura & Comp. Destravado & Corda & $\mathbf{P L}$ & $T$ & $\mathbf{M}$ \\
\hline \multirow{6}{*}{ h1,00m } & \multirow{2}{*}{ Lb0,80m } & $\mathrm{CS}$ & W310 & HSS 120 & HSS 150 \\
\hline & & $\mathrm{Cl}$ & W310 & HSS 200 & HSS 230 \\
\hline & \multirow{2}{*}{ Lb1,00m } & $\mathrm{CS}$ & W310 & HSS 120 & HSS 150 \\
\hline & & $\mathrm{Cl}$ & W310 & HSS 200 & HSS 230 \\
\hline & \multirow{2}{*}{ Lb1,60m } & $\mathrm{CS}$ & W310 & HSS 120 & HSS 160 \\
\hline & & $\mathrm{Cl}$ & W310 & HSS 200 & HSS 230 \\
\hline Altura & Comp. Destravado & Corda & PL & $\mathbf{T}$ & $M$ \\
\hline \multirow{6}{*}{ h1,20m } & \multirow{2}{*}{ Lb1,00m } & $\mathrm{CS}$ & W310 & HSS 100 & HSS 140 \\
\hline & & $\mathrm{Cl}$ & W310 & HSS 180 & HSS 210 \\
\hline & \multirow{2}{*}{ Lb1,20m } & $\mathrm{CS}$ & W310 & HSS 110 & HSS 140 \\
\hline & & $\mathrm{Cl}$ & W310 & HSS 180 & HSS 210 \\
\hline & \multirow{2}{*}{$\mathrm{Lb} 2,00 \mathrm{~m}$} & CS & W310 & HSS 120 & HSS 150 \\
\hline & & $\mathrm{Cl}$ & W310 & HSS 200 & HSS 210 \\
\hline
\end{tabular}

Tabela 5.3 - Perfis utilizados nas estruturas com vão de 32m - Seção ST3. 


\begin{tabular}{|c|c|c|c|c|c|c|}
\hline \multicolumn{7}{|c|}{ Vão de 45m - ST4 } \\
\hline Altura & Comp. Destravado & Corda & $\mathrm{PL}$ & $\mathbf{T}$ & WT & $\mathbf{M}$ \\
\hline \multirow{6}{*}{ h1,50m } & \multirow{2}{*}{ Lb1,25 } & CS & W310 & HSS 160 & WT155 & HSS 190 \\
\hline & & $\mathrm{Cl}$ & W310 & HSS 160 & WT155 & HSS 210 \\
\hline & \multirow{2}{*}{ Lb1,50 } & $\mathrm{CS}$ & W310 & HSS 160 & WT155 & HSS 190 \\
\hline & & $\mathrm{Cl}$ & W310 & HSS 160 & WT155 & HSS 210 \\
\hline & \multirow{2}{*}{$\mathrm{Lb} 2,50$} & CS & W310 & HSS 160 & WT155 & HSS 190 \\
\hline & & $\mathrm{Cl}$ & W310 & HSS 160 & WT155 & HSS 220 \\
\hline Altura & Comp. Destravado & Corda & PL & $\mathbf{T}$ & WT & $\mathbf{M}$ \\
\hline \multirow{6}{*}{ h1,80m } & \multirow{2}{*}{ Lb1,50 } & CS & W310 & HSS 160 & WT155 & HSS 170 \\
\hline & & $\mathrm{Cl}$ & W310 & HSS 160 & WT155 & HSS 190 \\
\hline & \multirow{2}{*}{ Lb1,80 } & $\mathrm{CS}$ & W310 & HSS 160 & WT155 & HSS 170 \\
\hline & & $\mathrm{Cl}$ & W310 & HSS 160 & WT155 & HSS 190 \\
\hline & \multirow{2}{*}{ Lb3,00 } & CS & W310 & HSS 180 & WT155 & HSS 190 \\
\hline & & $\mathrm{Cl}$ & W310 & HSS 180 & WT155 & HSS 220 \\
\hline Altura & Comp. Destravado & Corda & PL & $\mathbf{T}$ & WT & $\mathbf{M}$ \\
\hline \multirow{6}{*}{$\mathrm{h} 2,25 \mathrm{~m}$} & \multirow{2}{*}{ Lb1,80 } & CS & W310 & HSS 130 & WT155 & HSS 150 \\
\hline & & $\mathrm{Cl}$ & W310 & HSS 130 & WT155 & HSS 180 \\
\hline & \multirow{2}{*}{ Lb2,25 } & $\mathrm{CS}$ & W310 & HSS 130 & WT155 & HSS 160 \\
\hline & & $\mathrm{Cl}$ & W310 & HSS 130 & WT155 & HSS 180 \\
\hline & \multirow{2}{*}{ Lb3,00 } & $\mathrm{CS}$ & W310 & HSS 140 & WT155 & HSS 170 \\
\hline & & $\mathrm{Cl}$ & W310 & HSS 140 & WT155 & HSS 200 \\
\hline
\end{tabular}

Tabela 5.4 - Perfis utilizados nas treliças com vão de 45m - Seção ST4.

\begin{tabular}{|c|c|c|c|c|c|}
\hline \multicolumn{6}{|c|}{ Vão de 45m - ST3 } \\
\hline Altura & Comp. Destravado & Corda & PL & $T$ & $\mathbf{M}$ \\
\hline \multirow{6}{*}{$\mathrm{H} 1,50 \mathrm{~m}$} & \multirow{2}{*}{ Lb1,25 } & $\mathrm{CS}$ & W310 & HSS 140 & HSS 170 \\
\hline & & $\mathrm{Cl}$ & W310 & HSS 250 & HSS 270 \\
\hline & \multirow{2}{*}{ Lb1,50 } & $\mathrm{CS}$ & W310 & HSS 140 & HSS 180 \\
\hline & & $\mathrm{Cl}$ & W310 & HSS 250 & HSS 270 \\
\hline & \multirow{2}{*}{ Lb2,50 } & $\mathrm{CS}$ & W310 & HSS 170 & HSS 190 \\
\hline & & $\mathrm{Cl}$ & W310 & HSS 270 & HSS 270 \\
\hline Altura & Comp. Destravado & Corda & PL & $\mathbf{T}$ & $\mathbf{M}$ \\
\hline \multirow{6}{*}{$\mathrm{H} 1,80 \mathrm{~m}$} & \multirow{2}{*}{ Lb1,50 } & $\mathrm{CS}$ & W310 & HSS 130 & HSS 170 \\
\hline & & $\mathrm{Cl}$ & W310 & HSS 250 & HSS 230 \\
\hline & \multirow{2}{*}{ Lb1,80 } & CS & W310 & HSS 140 & HSS 180 \\
\hline & & $\mathrm{Cl}$ & W310 & HSS 250 & HSS 250 \\
\hline & \multirow{2}{*}{ Lb3,00 } & $\mathrm{CS}$ & W310 & HSS 160 & HSS 190 \\
\hline & & $\mathrm{Cl}$ & W310 & HSS 260 & HSS 260 \\
\hline Altura & Comp. Destravado & Corda & PL & $\mathbf{T}$ & $M$ \\
\hline \multirow{6}{*}{$\mathrm{H} 2,25 \mathrm{~m}$} & \multirow{2}{*}{ Lb1,80 } & CS & W310 & HSS 130 & HSS 160 \\
\hline & & $\mathrm{Cl}$ & W310 & HSS 230 & HSS 220 \\
\hline & \multirow{2}{*}{ Lb2,25 } & CS & W310 & HSS 130 & HSS 170 \\
\hline & & $\mathrm{Cl}$ & W310 & HSS 230 & HSS 220 \\
\hline & \multirow{2}{*}{ Lb3,00 } & $\mathrm{CS}$ & W310 & HSS 140 & HSS 180 \\
\hline & & $\mathrm{Cl}$ & W310 & HSS 240 & HSS 230 \\
\hline
\end{tabular}

Tabela 5.5 - Perfis utilizados nas treliças com vão de 45m - Seção ST3. 


\begin{tabular}{|c|c|c|c|c|c|c|}
\hline \multicolumn{7}{|c|}{ Vão de 60m - ST4 } \\
\hline Altura & Comp. Destravado & Corda & $\mathrm{PL}$ & $T$ & WT & $M$ \\
\hline \multirow{6}{*}{$\mathrm{H} 1,50 \mathrm{~m}$} & \multirow{2}{*}{ Lb1,20 } & CS & W310 & HSS 240 & WT155 & HSS 240 \\
\hline & & $\mathrm{Cl}$ & W310 & HSS 240 & WT155 & HSS 260 \\
\hline & \multirow{2}{*}{ Lb1,50 } & CS & W310 & HSS 240 & WT155 & HSS 240 \\
\hline & & $\mathrm{Cl}$ & W310 & HSS 240 & WT155 & HSS 270 \\
\hline & \multirow{2}{*}{ Lb2,50 } & CS & W310 & HSS 240 & WT155 & HSS 240 \\
\hline & & $\mathrm{Cl}$ & W310 & HSS 240 & WT155 & HSS 270 \\
\hline Altura & Comp. Destravado & Corda & PL & $T$ & WT & $M$ \\
\hline \multirow{6}{*}{$\mathrm{H} 2,00 \mathrm{~m}$} & \multirow{2}{*}{ Lb1,50 } & CS & W310 & HSS 200 & WT155 & HSS 240 \\
\hline & & $\mathrm{Cl}$ & W310 & HSS 200 & WT155 & HSS 240 \\
\hline & \multirow{2}{*}{ Lb2,00 } & CS & W310 & HSS 200 & WT155 & HSS 240 \\
\hline & & $\mathrm{Cl}$ & W310 & HSS 200 & WT155 & HSS 240 \\
\hline & \multirow{2}{*}{$\mathrm{Lb} 3,00$} & CS & W310 & HSS 200 & WT155 & HSS 240 \\
\hline & & $\mathrm{Cl}$ & W310 & HSS 200 & WT155 & HSS 240 \\
\hline Altura & Comp. Destravado & Corda & PL & $T$ & WT & $M$ \\
\hline \multirow{6}{*}{$\mathrm{H} 2,50 \mathrm{~m}$} & \multirow{2}{*}{ Lb2,00 } & CS & W310 & HSS 180 & WT155 & HSS 200 \\
\hline & & $\mathrm{Cl}$ & W310 & HSS 180 & WT155 & HSS 220 \\
\hline & \multirow{2}{*}{ Lb2,50 } & $\mathrm{CS}$ & W310 & HSS 180 & WT155 & HSS 200 \\
\hline & & $\mathrm{Cl}$ & W310 & HSS 180 & WT155 & HSS 230 \\
\hline & \multirow{2}{*}{$\mathrm{Lb} 3,00$} & CS & W310 & HSS 180 & WT155 & HSS 210 \\
\hline & & $\mathrm{Cl}$ & W310 & HSS 180 & WT155 & HSS 230 \\
\hline
\end{tabular}

Tabela 5.6 - Perfis utilizados nas treliças com vão de 60m - Seção ST4.

\begin{tabular}{|c|c|c|c|c|c|}
\hline \multicolumn{6}{|c|}{ Vão de 60m - ST3 } \\
\hline Altura & Comp. Destravado & Corda & PL & $T$ & $M$ \\
\hline \multirow{6}{*}{$\mathrm{H} 1,50 \mathrm{~m}$} & \multirow{2}{*}{ Lb1,20 } & CS & W310 & HSS 220 & HSS 230 \\
\hline & & $\mathrm{Cl}$ & W310 & HSS 350 & HSS 360 \\
\hline & \multirow{2}{*}{ Lb1,50 } & $\mathrm{CS}$ & W310 & HSS 220 & HSS 230 \\
\hline & & $\mathrm{Cl}$ & W310 & HSS 350 & HSS 360 \\
\hline & \multirow{2}{*}{$\mathrm{Lb} 2,50$} & $\mathrm{CS}$ & W310 & HSS 220 & HSS 240 \\
\hline & & $\mathrm{Cl}$ & W310 & HSS 350 & HSS 360 \\
\hline Altura & Comp. Destravado & Corda & $\mathrm{PL}$ & $T$ & $\mathbf{M}$ \\
\hline \multirow{6}{*}{$\mathrm{H} 2,0 \mathrm{~m}$} & \multirow{2}{*}{ Lb1,50 } & $\mathrm{CS}$ & W310 & HSS 180 & HSS 200 \\
\hline & & $\mathrm{Cl}$ & W310 & HSS 300 & $\mathrm{HSS} 310$ \\
\hline & \multirow{2}{*}{$\mathrm{Lb} 2,00$} & $\mathrm{CS}$ & W310 & HSS 190 & HSS 210 \\
\hline & & $\mathrm{Cl}$ & W310 & HSS 300 & HSS 310 \\
\hline & \multirow{2}{*}{$\mathrm{Lb} 3,00$} & $\mathrm{CS}$ & W310 & HSS 200 & HSS 230 \\
\hline & & $\mathrm{Cl}$ & W310 & HSS 300 & HSS 300 \\
\hline Altura & Comp. Destravado & Corda & PL & $T$ & $\mathbf{M}$ \\
\hline \multirow{6}{*}{$\mathrm{H} 2,50 \mathrm{~m}$} & \multirow{2}{*}{$\mathrm{Lb} 2,00$} & CS & W310 & HSS 170 & HSS 190 \\
\hline & & $\mathrm{Cl}$ & W310 & HSS 270 & HSS 280 \\
\hline & \multirow{2}{*}{$\mathrm{Lb} 2,50$} & $\mathrm{CS}$ & W310 & HSS 170 & HSS 200 \\
\hline & & $\mathrm{Cl}$ & W310 & HSS 270 & HSS 280 \\
\hline & \multirow{2}{*}{ Lb3,00 } & $\mathrm{CS}$ & W310 & HSS 180 & HSS 210 \\
\hline & & $\mathrm{Cl}$ & W310 & HSS 270 & HSS 280 \\
\hline
\end{tabular}

Tabela 5.7 - Perfis utilizados nas treliças com vão de 60m - Seção ST3. 
Nas treliças com seções ST4, foram utilizados perfis de maiores dimensões nas cordas inferiores devido aos grandes esforços internos de compressão que as regiões dos apoios centrais apresentam.

Também se observa que o diâmetro dos tubos é diretamente proporcional ao comprimento dos módulos. Quando se aumenta o comprimento destravado da estrutura, é necessário utilizar perfis com maiores raios de giração (maior diâmetro), de modo a evitar que essa peça sofra flambagem.

\section{3. \\ Resultados de consumo de aço e verificação das flechas}

Nesta seção serão resumidos todos os resultados referentes ao consumo de aço, ao volume de concreto utilizado nas soluções mistas e aos deslocamentos fora e dentro do plano. Os valores de consumo de aço serão apresentados sob a forma de uma relação entre a massa total da estrutura pela extensão total da treliça $(\mathrm{kg} / \mathrm{m})$.

Para efeitos de comparação, os custos referentes ao volume do concreto utilizado nos perfis mistos serão considerados a partir de uma taxa de equivalência, baseada em pesquisa de mercado. Assim, será considerado que um metro cúbico de concreto equivale em custo a cem quilogramas de aço, considerando o material em si, transporte e lançamento do mesmo.

Essa taxa de equivalência estará presente em todos os valores de consumo de aço dos perfis mistos. Assim, será possível identificar qual método é o de menor consumo de material simplesmente comparando o consumo de aço dos gráficos.

A norma NBR 8800 (2008) estipula que, para treliças de vão igual ou superior a $24 \mathrm{~m}$, devem ser aplicadas contraflechas aproximadamente iguais à flecha resultante das ações permanentes diretas características.

Dessa forma, para a apresentação dos resultados das flechas das treliças, serão utilizados apenas os deslocamentos devidos às ações variáveis.

Uma simplificação utilizada no estudo é a não contabilização do peso das chapas de gusset utilizadas nas estruturas. Estipulou-se que esses elementos equivalem a cerca de $10 \%$ do peso total da estrutura, sendo adicionados em todos resultados.

As Tabelas 5.8, 5.9 e 5.10 resumem os valores encontrados para os consumos de aço (CA), para os deslocamentos fora do plano (Ux) e para as flechas (Uz) das 
treliças com vão de 32 metros, para as duas seções transversais (ST4 e ST3) e alturas de $0,80 \mathrm{~m}, 1,00 \mathrm{~m}$ e $1,20 \mathrm{~m}$, respectivamente. Os Gráficos 5.1, 5.2 e 5.3 foram montados para uma melhor visualização desses resultados.

\begin{tabular}{|c|c|c|c|c|c|c|c|c|c|}
\hline \multicolumn{10}{|c|}{$32 m$} \\
\hline \multicolumn{5}{|c|}{ ST4 } & \multicolumn{5}{|c|}{ ST3 } \\
\hline \multirow{7}{*}{$\begin{array}{c}\mathrm{CA} \\
{[\mathrm{kg} / \mathrm{m}]}\end{array}$} & \multirow{3}{*}{$\mathrm{HO}, 80 \mathrm{~m}$} & \multicolumn{3}{|c|}{ Ângulo da diagonal } & \multirow{7}{*}{$\mathrm{CA}[\mathrm{kg} / \mathrm{m}]$} & \multirow{4}{*}{$\mathrm{H} 0,80 \mathrm{~m}$} & \multicolumn{3}{|c|}{ Ângulo da diagonal } \\
\hline & & Lb1,00 & Lb0,80 & Lb0,50 & & & Lb1,00 & Lb0,80 & Lb0,50 \\
\hline & & $38,66^{\circ}$ & $45,00^{\circ}$ & $57,99^{\circ}$ & & & \multirow{2}{*}{$38,66^{\circ}$} & \multirow{2}{*}{$45,00^{\circ}$} & \multirow{2}{*}{$57,9^{\circ}$} \\
\hline & $\mathrm{PL}$ & 207,04 & 212,06 & 225,69 & & & & & \\
\hline & $T$ & 203,51 & 206,35 & 223,73 & & PL & 190,19 & 189,30 & 215,24 \\
\hline & WT & 253,86 & 241,92 & 257,02 & & $T$ & 190,22 & 193,22 & 223,81 \\
\hline & $M$ & 182,05 & 186,42 & 201,24 & & $M$ & 178,04 & 177,51 & 202,94 \\
\hline \multicolumn{5}{|c|}{ ST4 } & \multicolumn{5}{|c|}{ ST3 } \\
\hline \multirow{7}{*}{$\mathrm{Ux}[\mathrm{mm}]$} & \multirow{3}{*}{$\mathrm{HO}, 80 \mathrm{~m}$} & \multicolumn{3}{|c|}{ Ângulo da diagonal } & \multirow{7}{*}{$\mathrm{Ux}[\mathrm{mm}]$} & \multirow{4}{*}{$\mathrm{H} 0,80 \mathrm{~m}$} & \multicolumn{3}{|c|}{ Ângulo da diagonal } \\
\hline & & Lb1,00 & Lb0,80 & Lb0,50 & & & Lb1,00 & Lb0,80 & Lb0,50 \\
\hline & & $38,66^{\circ}$ & $45,00^{\circ}$ & $57,99^{\circ}$ & & & \multirow{2}{*}{$38,66^{\circ}$} & \multirow{2}{*}{$45,00^{\circ}$} & \multirow{2}{*}{$57,99^{\circ}$} \\
\hline & PL & 2,70 & 3,50 & 3,00 & & & & & \\
\hline & $T$ & 3,50 & 3,50 & 3,50 & & PL & 5,00 & 5,00 & 5,50 \\
\hline & WT & 4,20 & 2,60 & 2,34 & & $\mathbf{T}$ & 5,50 & 5,50 & 5,40 \\
\hline & $M$ & 1,98 & 2,60 & 2,20 & & $M$ & 3,50 & 3,50 & 3,50 \\
\hline \multicolumn{5}{|c|}{ ST4 } & \multicolumn{5}{|c|}{ ST3 } \\
\hline \multirow{7}{*}{$\mathrm{Uz}[\mathrm{mm}]$} & \multirow{3}{*}{$\mathrm{HO}, 80 \mathrm{~m}$} & \multicolumn{3}{|c|}{ Ângulo da diagonal } & \multirow{7}{*}{ Uz [mm] } & \multirow{4}{*}{$\mathrm{HO}, 80 \mathrm{~m}$} & \multicolumn{3}{|c|}{ Ângulo da diagonal } \\
\hline & & Lb1,00 & Lb0,80 & Lb0,50 & & & Lb1,00 & Lb0,80 & Lb0,50 \\
\hline & & $38,66^{\circ}$ & $45,00^{\circ}$ & $57,99^{\circ}$ & & & \multirow{2}{*}{$38,66^{\circ}$} & $45.00^{\circ}$ & $57.99^{\circ}$ \\
\hline & $\mathbf{P L}$ & 214,60 & 216,50 & 222,86 & & & & & \\
\hline & $T$ & 225,00 & 235,80 & 246,22 & & PL & 225,90 & 236,78 & 236,30 \\
\hline & WT & 183,50 & 184,50 & 195,90 & & $T$ & 239,20 & 241,70 & 240,67 \\
\hline & $M$ & 168,13 & 166,55 & 172,90 & & $M$ & 169,50 & 168,30 & 179,50 \\
\hline
\end{tabular}

Tabela 5.8 - Resultados encontrados para o vão de $32 \mathrm{~m}$ - altura de $0,80 \mathrm{~m}$.

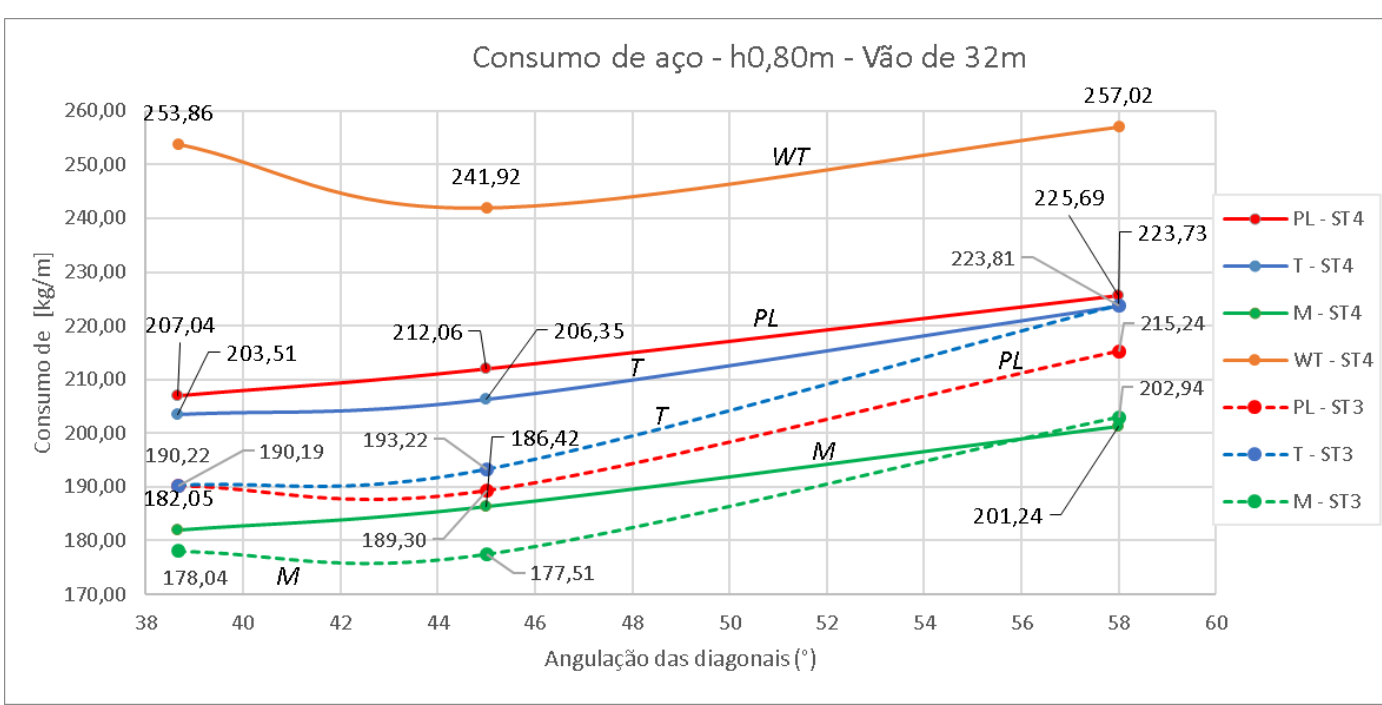

Gráfico 5.1 - Consumo de aço para o vão de $32 \mathrm{~m}: \mathrm{h}=0,80 \mathrm{~m}$. 


\begin{tabular}{|c|c|c|c|c|c|c|c|c|c|}
\hline \multicolumn{10}{|c|}{$32 m$} \\
\hline \multicolumn{5}{|c|}{ ST4 } & \multicolumn{5}{|c|}{ ST3 } \\
\hline \multirow{7}{*}{$\begin{array}{c}\mathrm{CA} \\
{[\mathrm{kg} / \mathrm{m}]}\end{array}$} & \multirow{3}{*}{$\mathrm{H} 1,00 \mathrm{~m}$} & \multicolumn{3}{|c|}{ Ângulo da diagonal } & \multirow{7}{*}{$\mathrm{CA}[\mathrm{kg} / \mathrm{m}]$} & \multirow{4}{*}{$\mathrm{H} 1,00 \mathrm{~m}$} & \multicolumn{3}{|c|}{ Ângulo da diagonal } \\
\hline & & Lb1,60 & Lb1,00 & Lb0,80 & & & Lb1,60 & Lb1,00 & Lb0,80 \\
\hline & & $32,01^{\circ}$ & $45,00^{\circ}$ & $51,34^{\circ}$ & & & \multirow{2}{*}{$32,01^{\circ}$} & \multirow{2}{*}{$45,00^{\circ}$} & \multirow{2}{*}{$51,34^{\circ}$} \\
\hline & $\mathbf{P L}$ & 189,51 & 190,43 & 198,55 & & & & & \\
\hline & $T$ & 173,65 & 184,10 & 190,69 & & PL & 158,38 & 163,09 & 177,82 \\
\hline & $M$ & 160,37 & 167,54 & 176,22 & & $T$ & 146,80 & 161,94 & 177,41 \\
\hline & WT & 214,96 & 229,60 & 226,23 & & $M$ & 135,16 & 145,84 & 157,75 \\
\hline \multicolumn{5}{|c|}{ ST4 } & \multicolumn{5}{|c|}{ ST3 } \\
\hline \multirow{7}{*}{$\mathrm{Ux}[\mathrm{mm}]$} & \multirow{3}{*}{$\mathrm{H} 1,00 \mathrm{~m}$} & \multicolumn{3}{|c|}{ Ângulo da diagonal } & \multirow{7}{*}{$\mathrm{Ux}[\mathrm{mm}]$} & \multirow{4}{*}{$\mathrm{H} 1,00 \mathrm{~m}$} & \multicolumn{3}{|c|}{ Ângulo da diagonal } \\
\hline & & Lb1,60 & Lb1,00 & Lb0,80 & & & Lb1,60 & Lb1,00 & Lb0,80 \\
\hline & & $32,01^{\circ}$ & $45,00^{\circ}$ & $51,34^{\circ}$ & & & \multirow{2}{*}{$32,01^{\circ}$} & \multirow{2}{*}{$45,00^{\circ}$} & \multirow{2}{*}{$51,34^{\circ}$} \\
\hline & PL & 3,60 & 3,12 & 2,42 & & & & & \\
\hline & $T$ & 4,40 & 3,08 & 2,42 & & PL & 5,50 & 4,00 & 4,00 \\
\hline & WT & 3,60 & 2,28 & 1,70 & & $T$ & 7,00 & 4,50 & 4,50 \\
\hline & $M$ & 3,15 & 2,40 & 1,76 & & $M$ & 4,40 & 3,85 & 2,80 \\
\hline \multicolumn{5}{|c|}{ ST4 } & \multicolumn{5}{|c|}{ ST3 } \\
\hline \multirow{7}{*}{$\mathrm{Uz}[\mathrm{mm}]$} & & \multicolumn{3}{|c|}{ Ângulo da diagonal } & \multirow{7}{*}{ Uz [mm] } & & \multicolumn{3}{|c|}{ Ângulo da diagonal } \\
\hline & $\mathrm{H} 1,00 \mathrm{~m}$ & Lb1,60 & Lb1,00 & Lb0,80 & & $\mathrm{H} 100 \mathrm{~m}$ & Lb1,60 & Lb1,00 & Lb0,80 \\
\hline & & $32,01^{\circ}$ & $45,00^{\circ}$ & $51,34^{\circ}$ & & $\mathrm{H} 1,00 \mathrm{~m}$ & $3201^{\circ}$ & $4500^{\circ}$ & $5134^{\circ}$ \\
\hline & PL & 168,75 & 177,41 & 180,73 & & & & & \\
\hline & $T$ & 194,50 & 191,74 & 200,07 & & $\mathrm{PL}$ & 190,20 & 189,40 & 192,44 \\
\hline & WT & 143,20 & 142,13 & 144,33 & & $T$ & 194,70 & 199,60 & 198,10 \\
\hline & $M$ & 127,10 & 159,80 & 136,44 & & $M$ & 141,00 & 143,00 & 161,10 \\
\hline
\end{tabular}

Tabela 5.9 - Resultados encontrados para o vão de 32m - altura de 1,00m.

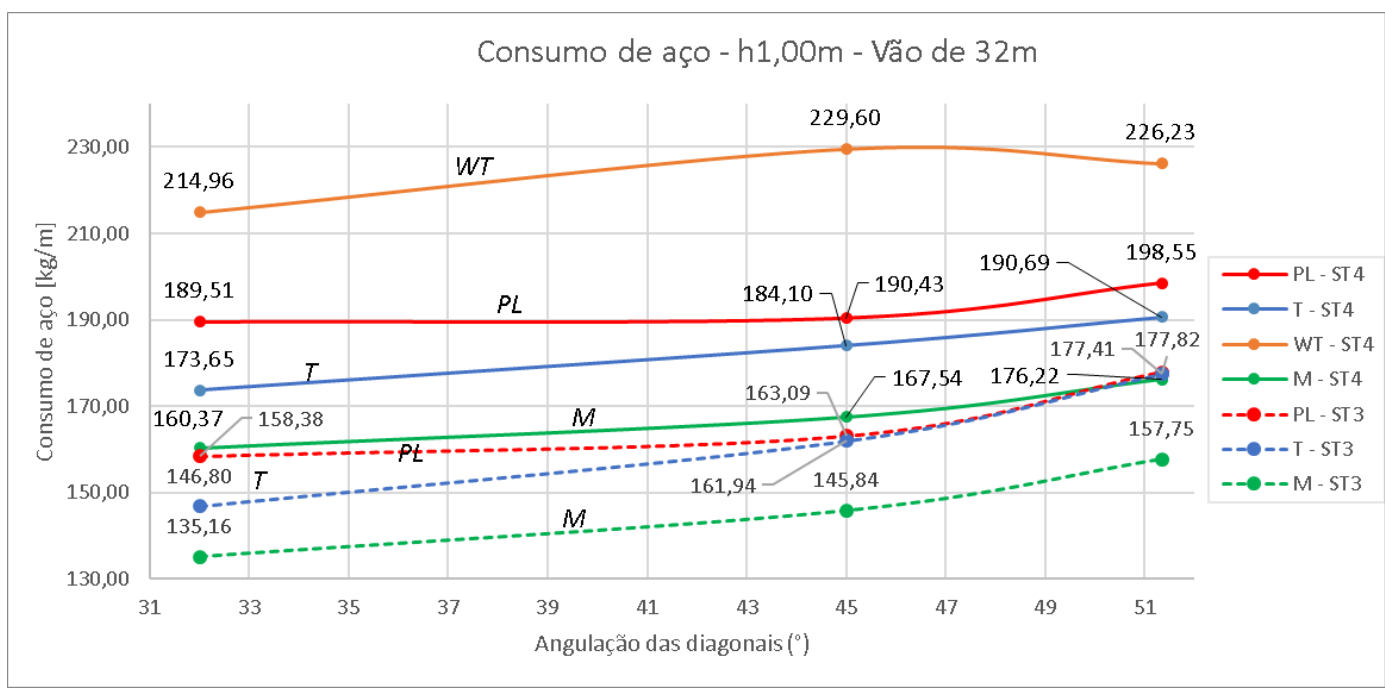

Gráfico 5.2 - Consumo de aço para o vão de $32 \mathrm{~m}: \mathrm{h}=1,00 \mathrm{~m}$. 


\begin{tabular}{|c|c|c|c|c|c|c|c|c|c|}
\hline \multicolumn{10}{|c|}{$32 m$} \\
\hline \multicolumn{5}{|c|}{ ST4 } & \multicolumn{5}{|c|}{ ST3 } \\
\hline \multirow{7}{*}{$\begin{array}{c}\mathrm{CA} \\
{[\mathrm{kg} / \mathrm{m}]}\end{array}$} & \multirow{3}{*}{$\mathrm{H1}$,20m } & \multicolumn{3}{|c|}{ Ângulo da diagonal } & \multirow{7}{*}{ CA $[\mathrm{kg} / \mathrm{m}]$} & \multirow{4}{*}{$\mathrm{H} 1,20 \mathrm{~m}$} & \multicolumn{3}{|c|}{ Ângulo da diagonal } \\
\hline & & Lb2,00 & Lb1,20 & Lb1,00 & & & Lb2,00 & Lb1,20 & Lb1,00 \\
\hline & & $30,96^{\circ}$ & $45,00^{\circ}$ & $50,19^{\circ}$ & & & \multirow{2}{*}{$30,96^{\circ}$} & \multirow{2}{*}{$45,00^{\circ}$} & \multirow{2}{*}{$50,19^{\circ}$} \\
\hline & PL & 188,71 & 184,69 & 184,89 & & & & & \\
\hline & $T$ & 156,60 & 166,99 & 171,06 & & PL & 155,09 & 156,88 & 153,99 \\
\hline & WT & 212,26 & 211,72 & 214,06 & & $T$ & 139,77 & 148,17 & 149,79 \\
\hline & $M$ & 151,10 & 158,58 & 159,60 & & $M$ & 123,76 & 134,09 & 137,23 \\
\hline \multicolumn{5}{|c|}{ ST4 } & \multicolumn{5}{|c|}{ ST3 } \\
\hline \multirow{7}{*}{ Ux $[\mathrm{mm}]$} & \multirow{3}{*}{$\mathrm{H1}$,20m } & \multicolumn{3}{|c|}{ Ângulo da diagonal } & \multirow{7}{*}{ Ux [mm] } & \multirow{4}{*}{$\mathrm{H} 1,20 \mathrm{~m}$} & \multicolumn{3}{|c|}{ Ângulo da diagonal } \\
\hline & & Lb2,00 & Lb1,20 & Lb1,00 & & & Lb2,00 & Lb1,20 & Lb1,00 \\
\hline & & $30,96^{\circ}$ & $45,00^{\circ}$ & $50,19^{\circ}$ & & & \multirow{2}{*}{$30,96^{\circ}$} & \multirow{2}{*}{$45,00^{\circ}$} & \multirow{2}{*}{$50,19^{\circ}$} \\
\hline & $\mathrm{PL}$ & 4,50 & 3,50 & 3,08 & & & & & \\
\hline & $T$ & 6,00 & 4,00 & 3,30 & & $\mathrm{PL}$ & 6,00 & 4,40 & 3,50 \\
\hline & WT & 4,00 & 3,30 & 2,64 & & $T$ & 9,35 & 5,50 & 4,40 \\
\hline & $M$ & 4,05 & 2,64 & 2,88 & & $M$ & 5,00 & 3,30 & 3,08 \\
\hline \multicolumn{5}{|c|}{ ST4 } & \multicolumn{5}{|c|}{ ST3 } \\
\hline \multirow{7}{*}{$\mathrm{Uz}[\mathrm{mm}]$} & \multirow{3}{*}{$\mathrm{H} 1,20 \mathrm{~m}$} & \multicolumn{3}{|c|}{ Ângulo da diagonal } & \multirow{7}{*}{ Uz [mm] } & \multirow{4}{*}{$\mathrm{H} 1,20 \mathrm{~m}$} & \multicolumn{3}{|c|}{ Ângulo da diagonal } \\
\hline & & Lb2,00 & Lb1,20 & Lb1,00 & & & Lb2,00 & Lb1,20 & Lb1,00 \\
\hline & & $30,96^{\circ}$ & $45,00^{\circ}$ & $50,19^{\circ}$ & & & $30.96^{\circ}$ & $4500^{\circ}$ & $50.19^{\circ}$ \\
\hline & $\mathbf{P L}$ & 126,50 & 146,41 & 149,50 & & & & & \\
\hline & $T$ & 150,80 & 162,90 & 163,80 & & $\mathrm{PL}$ & 141,80 & 158,40 & 166,22 \\
\hline & WT & 118,23 & 124,80 & 174,20 & & $\mathbf{T}$ & 162,70 & 173,60 & 176,30 \\
\hline & $M$ & 104,65 & 111,68 & 112,75 & & $M$ & 119,60 & 116,80 & 120,12 \\
\hline
\end{tabular}

Tabela 5.10 - Resultados encontrados para o vão de $32 \mathrm{~m}$ - altura de 1,20m.

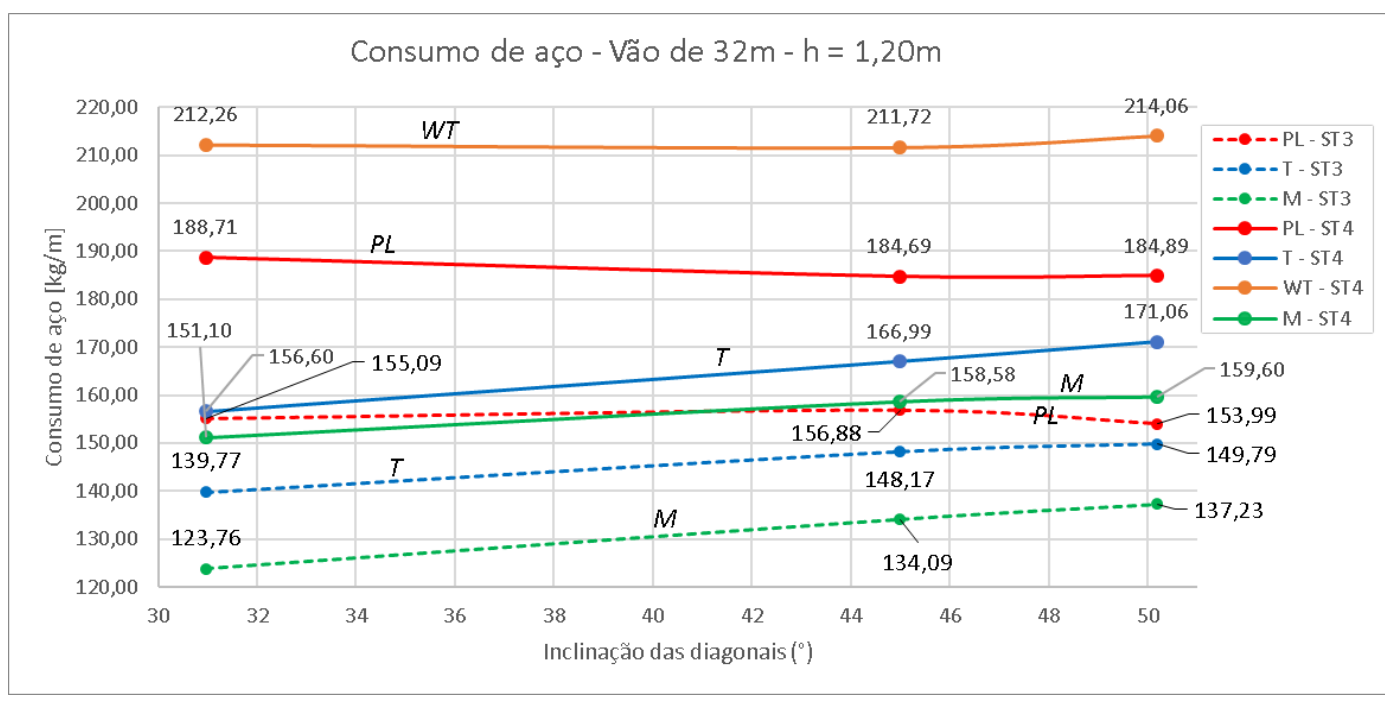

Gráfico 5.3 - Consumo de aço para o vão de 32m: $\mathrm{h}=1,20 \mathrm{~m}$.

Os mesmos resultados para as treliças com vão de 45 metros são encontrados para as alturas de, respectivamente, 1,50m, 1,80m e 2,25m nas Tabelas 5.11, 5.12 e 5.13, que são representados pelos Gráficos 5.4, 5.5 e 5.6, nesta ordem. 


\begin{tabular}{|c|c|c|c|c|c|c|c|c|c|}
\hline \multicolumn{10}{|c|}{$45 \mathrm{~m}$} \\
\hline \multicolumn{5}{|c|}{ ST4 } & \multicolumn{5}{|c|}{ ST3 } \\
\hline \multirow{7}{*}{$\begin{array}{c}\mathrm{CA} \\
{[\mathrm{kg} / \mathrm{m}]}\end{array}$} & \multirow{3}{*}{$\mathrm{H} 1,50 \mathrm{~m}$} & \multicolumn{3}{|c|}{ Ângulo da diagonal } & \multirow{7}{*}{$\mathrm{CA}[\mathrm{kg} / \mathrm{m}]$} & \multirow{4}{*}{$\mathrm{H} 1,50 \mathrm{~m}$} & \multicolumn{3}{|c|}{ Ângulo da diagonal } \\
\hline & & Lb2,50 & Lb0,80 & \multirow{2}{*}{$\begin{array}{l}\text { Lb0,50 } \\
50,19^{\circ}\end{array}$} & & & Lb2,50 & Lb0,80 & Lb0,50 \\
\hline & & $30,96^{\circ}$ & $45,00^{\circ}$ & & & & \multirow{2}{*}{$30,96^{\circ}$} & \multirow{2}{*}{$45,00^{\circ}$} & \multirow{2}{*}{$50,19^{\circ}$} \\
\hline & PL & 262,85 & 254,30 & 241,12 & & & & & \\
\hline & $T$ & 247,61 & 254,85 & 243,87 & & PL & 218,98 & 238,98 & 246,41 \\
\hline & WT & 289,95 & 281,26 & 293,95 & & $\mathbf{T}$ & 217,93 & 262,87 & 260,48 \\
\hline & $M$ & 224,89 & 228,34 & 218,70 & & $M$ & 185,76 & 229,73 & 230,59 \\
\hline \multicolumn{5}{|c|}{ ST4 } & \multicolumn{5}{|c|}{ ST3 } \\
\hline \multirow{7}{*}{$\mathrm{Ux}[\mathrm{mm}]$} & \multirow{3}{*}{$\mathrm{H} 1,50 \mathrm{~m}$} & \multicolumn{3}{|c|}{ Ângulo da diagonal } & \multirow{7}{*}{ Ux [mm] } & \multirow{4}{*}{$\mathrm{H} 1,50 \mathrm{~m}$} & \multicolumn{3}{|c|}{ Ângulo da diagonal } \\
\hline & & Lb2,50 & Lb0,80 & Lb0,50 & & & Lb2,50 & Lb0,80 & Lb0,50 \\
\hline & & $30,96^{\circ}$ & $45,00^{\circ}$ & $50,19^{\circ}$ & & & \multirow{2}{*}{$30,96^{\circ}$} & \multirow{2}{*}{$45,00^{\circ}$} & \multirow{2}{*}{$50,19^{\circ}$} \\
\hline & PL & 7,65 & 3,15 & 5,00 & & & & & \\
\hline & $T$ & 8,80 & 4,00 & 4,05 & & PL & 13,20 & 10,00 & 10,00 \\
\hline & WT & 9,00 & 4,50 & 4,00 & & $T$ & 14,30 & 16,00 & 12,00 \\
\hline & $\mathbf{M}$ & 6,50 & 3,30 & 3,85 & & $M$ & 6,30 & 8,00 & 8,25 \\
\hline \multicolumn{5}{|c|}{ ST4 } & \multicolumn{5}{|c|}{ ST3 } \\
\hline \multirow{7}{*}{$\mathrm{Uz}[\mathrm{mm}]$} & \multirow{3}{*}{$\mathrm{H} 1,50 \mathrm{~m}$} & \multicolumn{3}{|c|}{ Ângulo da diagonal } & & & \multicolumn{3}{|c|}{ Ângulo da diagonal } \\
\hline & & Lb2,50 & Lb0,80 & Lb0,50 & & $\mathrm{H} 1.50 \mathrm{~m}$ & Lb2,50 & Lb0,80 & Lb0,50 \\
\hline & & $30,96^{\circ}$ & $45,00^{\circ}$ & $50,19^{\circ}$ & & & $30.96^{\circ}$ & $45,00^{\circ}$ & $50.19^{\circ}$ \\
\hline & $\mathrm{PL}$ & 221,60 & 232,30 & 253,30 & $\mathrm{Uz}$ [mm] & & & & \\
\hline & $T$ & 250,31 & 254,40 & 264,50 & & $\mathrm{PL}$ & 244,70 & 245,20 & 243,70 \\
\hline & WT & 225,70 & 228,90 & 223,90 & & $\mathbf{T}$ & 255,40 & 247,80 & 258,40 \\
\hline & $M$ & 196,30 & 194,75 & 194,90 & & $M$ & 206,13 & 168,90 & 176,80 \\
\hline
\end{tabular}

Tabela 5.11 - Resultados encontrados para o vão de 45m - altura de 1,50m.

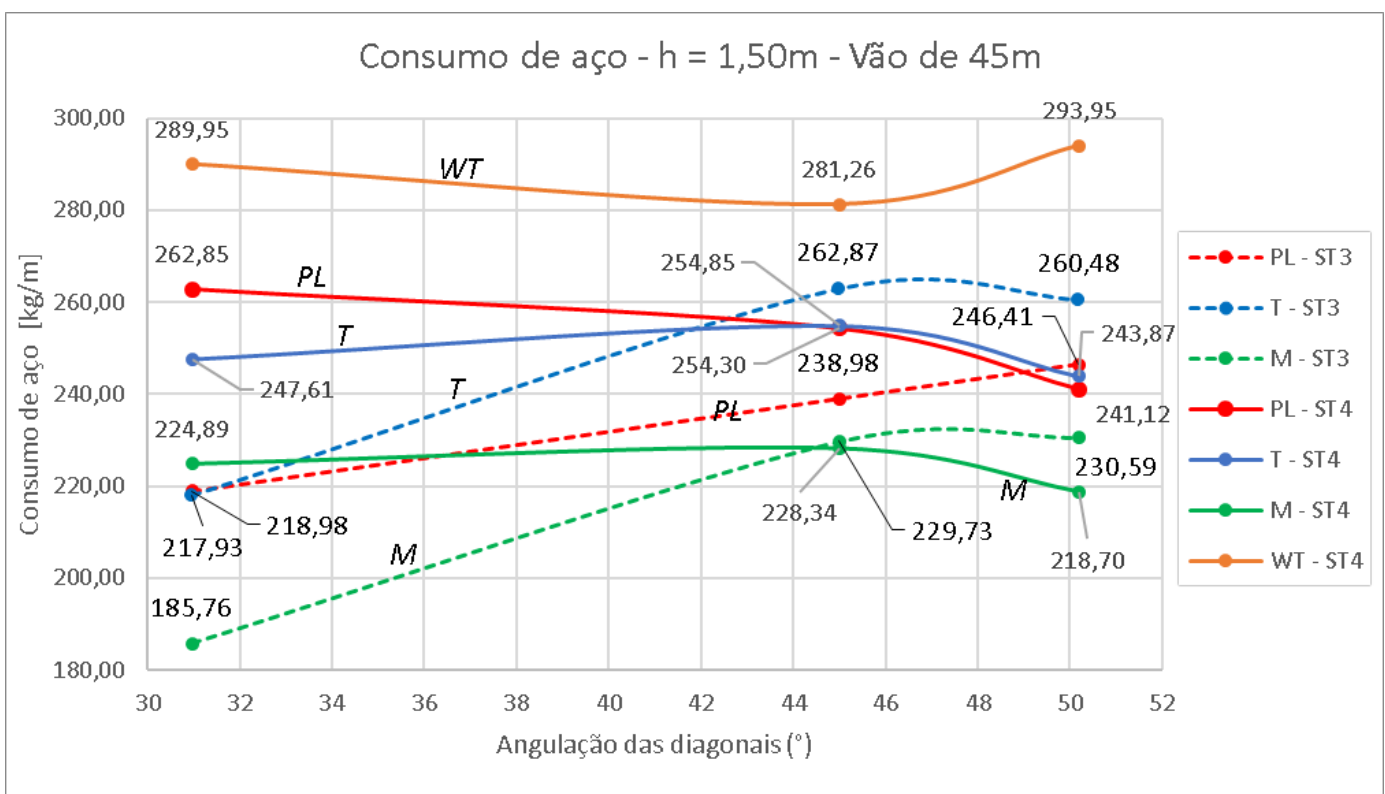

Gráfico 5.4 - Consumo de aço para o vão de 45m: $\mathrm{h}=1,50 \mathrm{~m}$. 


\begin{tabular}{|c|c|c|c|c|c|c|c|c|c|}
\hline \multicolumn{10}{|c|}{$45 m$} \\
\hline \multicolumn{5}{|c|}{ ST4 } & \multicolumn{5}{|c|}{ ST3 } \\
\hline \multirow{7}{*}{$\begin{array}{c}\mathrm{CA} \\
{[\mathrm{kg} / \mathrm{m}]}\end{array}$} & \multirow{3}{*}{$\mathrm{H} 1,80 \mathrm{~m}$} & \multicolumn{3}{|c|}{ Ângulo da diagonal } & \multirow{7}{*}{$\mathrm{CA}[\mathrm{kg} / \mathrm{m}]$} & \multirow{4}{*}{$\mathrm{H} 1,80 \mathrm{~m}$} & \multicolumn{3}{|c|}{ Ângulo da diagonal } \\
\hline & & Lb3,00 & Lb1,80 & Lb1,50 & & & Lb3,00 & Lb1,80 & Lb1,50 \\
\hline & & $30,96^{\circ}$ & $45,00^{\circ}$ & $50,19^{\circ}$ & & & \multirow{2}{*}{$30,96^{\circ}$} & \multirow{2}{*}{$45,00^{\circ}$} & \multirow{2}{*}{$50,19^{\circ}$} \\
\hline & PL & 244,16 & 223,70 & 229,54 & & & & & \\
\hline & $T$ & 219,07 & 214,07 & 222,59 & & PL & 219,47 & 214,76 & 205,89 \\
\hline & WT & 280,50 & 269,41 & 308,45 & & $\mathbf{T}$ & 208,59 & 209,96 & 222,95 \\
\hline & $M$ & 201,81 & 195,41 & 205,69 & & $M$ & 181,04 & 191,18 & 184,98 \\
\hline \multicolumn{5}{|c|}{ ST4 } & \multicolumn{5}{|c|}{ ST3 } \\
\hline \multirow{7}{*}{ Ux $[\mathrm{mm}]$} & \multirow{3}{*}{$\mathrm{H} 1,80 \mathrm{~m}$} & \multicolumn{3}{|c|}{ Ângulo da diagonal } & \multirow{7}{*}{ Ux [mm] } & \multirow{4}{*}{$\mathrm{H} 1,80 \mathrm{~m}$} & \multicolumn{3}{|c|}{ Ângulo da diagonal } \\
\hline & & $\mathrm{Lb} 3,00$ & Lb1,80 & Lb1,50 & & & Lb3,00 & Lb1,80 & Lb1,50 \\
\hline & & $30,96^{\circ}$ & $45,00^{\circ}$ & $50,19^{\circ}$ & & & \multirow{2}{*}{$30,96^{\circ}$} & \multirow{2}{*}{$45,00^{\circ}$} & \multirow{2}{*}{$50,19^{\circ}$} \\
\hline & $\mathrm{PL}$ & 7,20 & 4,00 & 5,00 & & & & & \\
\hline & $\mathbf{T}$ & 8,10 & 4,05 & 4,95 & & PL & 7,20 & 4,95 & 4,00 \\
\hline & WT & 12,00 & 4,00 & 3,30 & & $T$ & 9,00 & 5,50 & 6,05 \\
\hline & $M$ & 8,00 & 3,85 & 4,40 & & $M$ & 4,80 & 3,00 & 3,30 \\
\hline \multicolumn{5}{|c|}{ ST4 } & \multicolumn{5}{|c|}{ ST3 } \\
\hline \multirow{7}{*}{$\mathrm{Uz}[\mathrm{mm}]$} & \multirow{3}{*}{$\mathrm{H} 1,80 \mathrm{~m}$} & \multicolumn{3}{|c|}{ Ângulo da diagonal } & \multirow{7}{*}{ Uz [mm] } & \multirow{4}{*}{$\mathrm{H} 1,80 \mathrm{~m}$} & \multicolumn{3}{|c|}{ Ângulo da diagonal } \\
\hline & & Lb3,00 & Lb1,80 & Lb1,50 & & & Lb3,00 & Lb1,80 & Lb1,50 \\
\hline & & $30,96^{\circ}$ & $45,00^{\circ}$ & $50,19^{\circ}$ & & & \multirow{2}{*}{$30,96^{\circ}$} & $45.00^{\circ}$ & $50.19^{\circ}$ \\
\hline & $\mathrm{PL}$ & 181,00 & 202,80 & 215,90 & & & & & \\
\hline & $\mathbf{T}$ & 202,12 & 220,40 & 226,80 & & $\mathrm{PL}$ & 194,40 & 212,80 & 177,65 \\
\hline & WT & 175,30 & 173,40 & 149,00 & & $\mathbf{T}$ & 209,90 & 230,67 & 179,30 \\
\hline & $M$ & 146,13 & 148,90 & 160,80 & & $M$ & 150,14 & 158,00 & 129,40 \\
\hline
\end{tabular}

Tabela 5.12 - Resultados encontrados para o vão de 45m - altura de 1,80m.

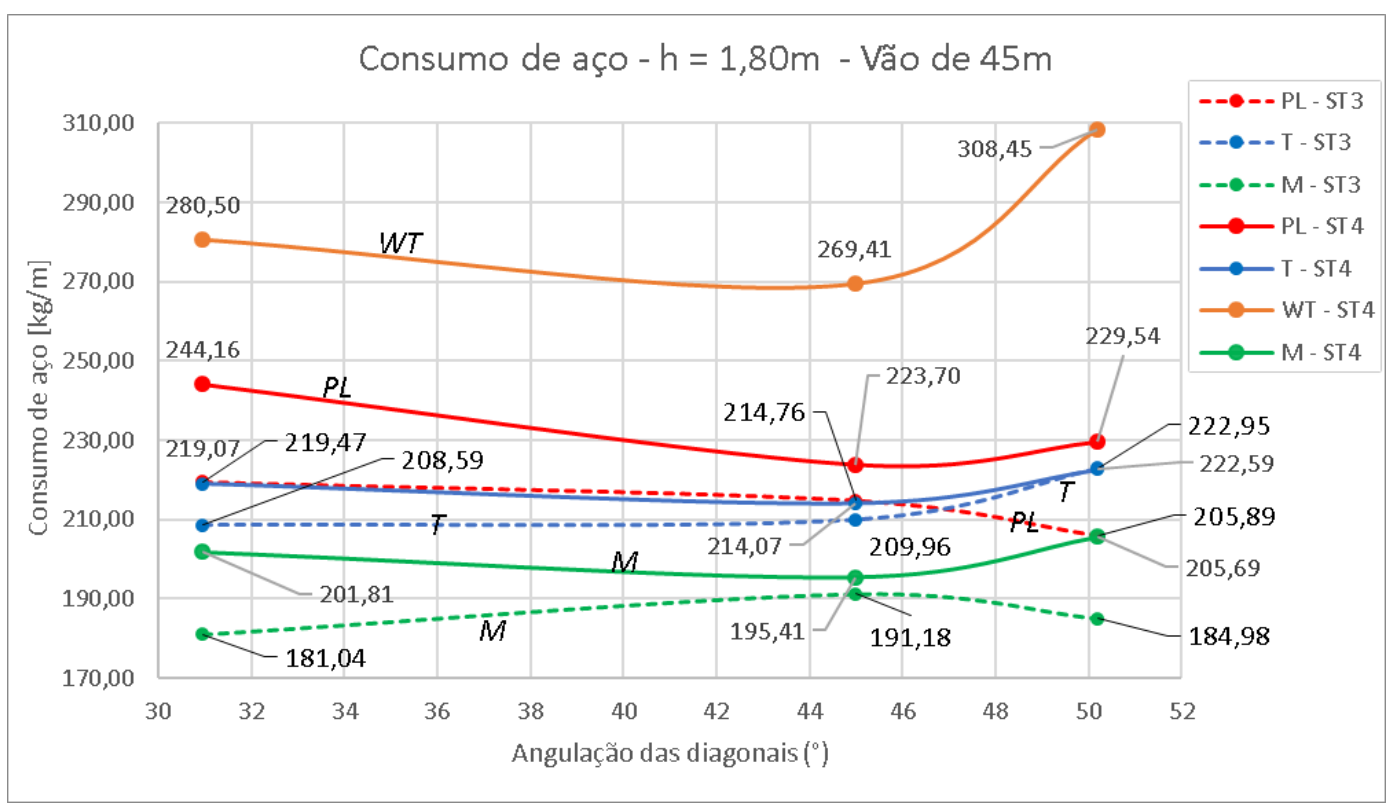

Gráfico 5.5 - Consumo de aço para o vão de 45m: $\mathrm{h}=1,80 \mathrm{~m}$. 


\begin{tabular}{|c|c|c|c|c|c|c|c|c|c|}
\hline \multicolumn{10}{|c|}{$45 m$} \\
\hline \multicolumn{5}{|c|}{ ST4 } & \multicolumn{5}{|c|}{ ST3 } \\
\hline \multirow{7}{*}{$\begin{array}{c}\text { CA } \\
{[\mathrm{kg} / \mathrm{m}]}\end{array}$} & \multirow{3}{*}{$\mathrm{H} 2,25 \mathrm{~m}$} & \multicolumn{3}{|c|}{ Ângulo da diagonal } & \multirow{7}{*}{$\mathrm{CA}[\mathrm{kg} / \mathrm{m}]$} & \multirow{4}{*}{$\mathrm{H} 2,25 \mathrm{~m}$} & \multicolumn{3}{|c|}{ Ângulo da diagonal } \\
\hline & & Lb3,00 & Lb2,25 & \multirow{2}{*}{$\begin{array}{r}\text { Lb1,80 } \\
51,34^{\circ}\end{array}$} & & & Lb3,00 & Lb2,25 & Lb1,80 \\
\hline & & $36,87^{\circ}$ & $45,00^{\circ}$ & & & & \multirow{2}{*}{$36,87^{\circ}$} & \multirow{2}{*}{$45,00^{\circ}$} & \multirow{2}{*}{$51,34^{\circ}$} \\
\hline & PL & 227,38 & 223,72 & 220,34 & & & & & \\
\hline & $T$ & 203,65 & 198,80 & 207,20 & & PL & 196,04 & 184,90 & 198,92 \\
\hline & WT & 282,56 & 268,02 & 258,58 & & $T$ & 193,91 & 191,72 & 196,64 \\
\hline & $M$ & 189,10 & 182,32 & 185,82 & & $M$ & 162,77 & 160,54 & 173,58 \\
\hline \multicolumn{5}{|c|}{ ST4 } & \multicolumn{5}{|c|}{ ST3 } \\
\hline \multirow{7}{*}{$\mathrm{Ux}[\mathrm{mm}]$} & \multirow{3}{*}{$\mathrm{H} 2,25 \mathrm{~m}$} & \multicolumn{3}{|c|}{ Ângulo da diagonal } & \multirow{7}{*}{ Ux $[\mathrm{mm}]$} & \multirow{4}{*}{$\mathrm{H} 2,25 \mathrm{~m}$} & \multicolumn{3}{|c|}{ Ângulo da diagonal } \\
\hline & & Lb3,00 & Lb2,25 & Lb1,80 & & & Lb3,00 & Lb2,25 & Lb1,80 \\
\hline & & $36,87^{\circ}$ & $45,00^{\circ}$ & $51,34^{\circ}$ & & & \multirow{2}{*}{$36,87^{\circ}$} & \multirow{2}{*}{$45,00^{\circ}$} & \multirow{2}{*}{$51,34^{\circ}$} \\
\hline & PL & 5,50 & 5,00 & 3,85 & & & & & \\
\hline & $\mathbf{T}$ & 5,85 & 4,50 & 4,00 & & PL & 6,75 & 4,50 & 5,50 \\
\hline & WT & 7,20 & 3,60 & 8,50 & & $T$ & 8,10 & 5,50 & 6,05 \\
\hline & $M$ & 6,60 & 3,85 & 3,85 & & $M$ & 4,95 & 4,80 & 4,00 \\
\hline \multicolumn{5}{|c|}{ ST4 } & \multicolumn{5}{|c|}{ ST3 } \\
\hline \multirow{7}{*}{$\mathrm{Uz}[\mathrm{mm}]$} & & \multicolumn{3}{|c|}{ Ângulo da diagonal } & \multirow{7}{*}{ Uz [mm] } & & \multicolumn{3}{|c|}{ Ângulo da diagonal } \\
\hline & $\mathrm{H} 2,25 \mathrm{~m}$ & Lb3,00 & Lb2,25 & Lb1,80 & & $\mathrm{H} 2.25 \mathrm{~m}$ & Lb3,00 & Lb2,25 & Lb1,80 \\
\hline & & $36,87^{\circ}$ & $45,00^{\circ}$ & $51,34^{\circ}$ & & & $36.87^{\circ}$ & $4500^{\circ}$ & $5134^{\circ}$ \\
\hline & $\mathrm{PL}$ & 149,83 & 157,87 & 158,90 & & & & & \\
\hline & $T$ & 164,90 & 179,40 & 173,60 & & $\mathrm{PL}$ & 162,40 & 167,27 & 174,89 \\
\hline & WT & 141,12 & 149,21 & 144,03 & & $T$ & 163,70 & 177,50 & 191,50 \\
\hline & $M$ & 109,53 & 121,52 & 123,67 & & $M$ & 119,30 & 127,35 & 157,00 \\
\hline
\end{tabular}

Tabela 5.13 - Resultados encontrados para o vão de $45 \mathrm{~m}$ - altura de 2,25m.

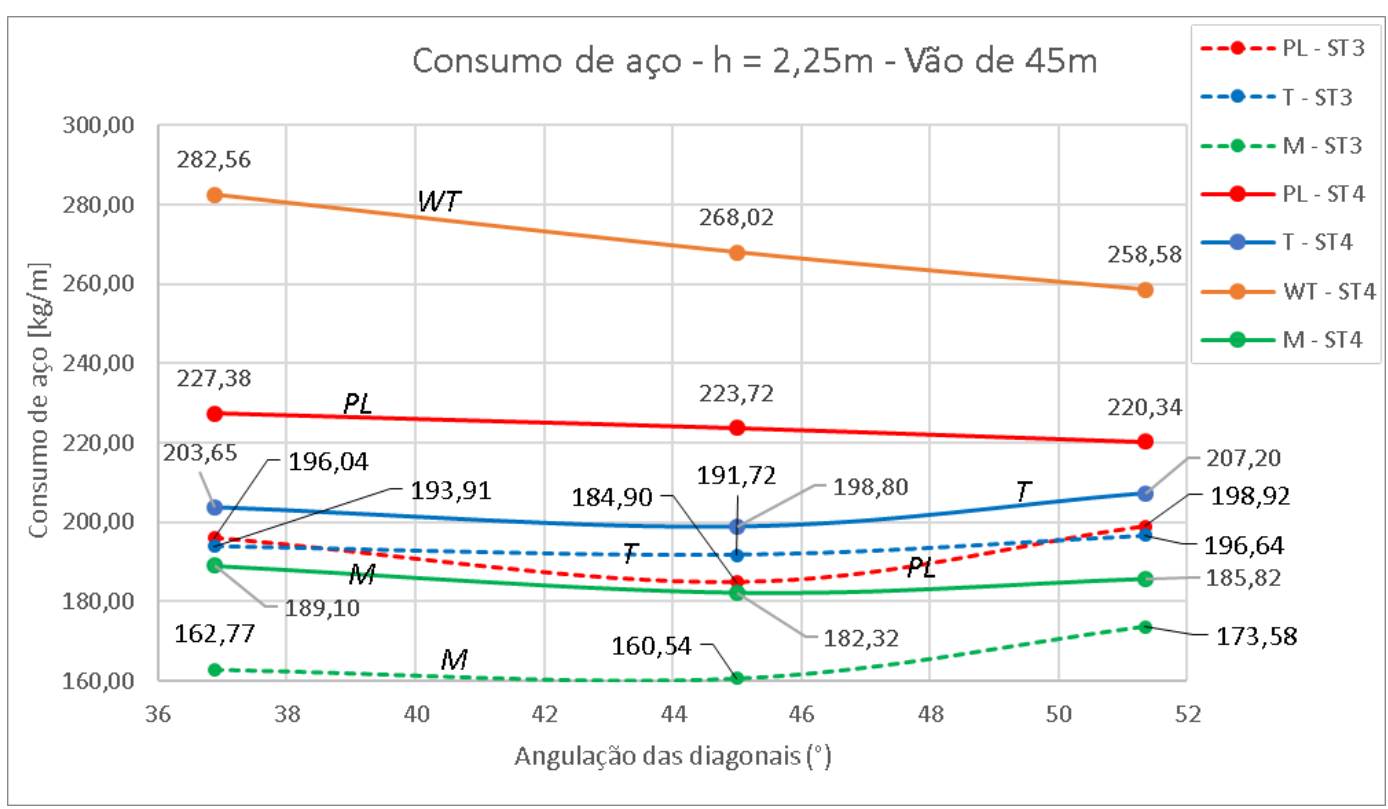

Gráfico 5.6 - Consumo de aço para o vão de 45m: $\mathrm{h}=2,25 \mathrm{~m}$. 
Já para o vão de 60 metros, as Tabelas $5.14,5.15$ e 5.16 resumem os valores para as alturas de $1,50 \mathrm{~m}, 2,00 \mathrm{~m}$ e $2,50 \mathrm{~m}$, respectivamente, para as duas seções estudadas, enquanto que os Gráficos 5.7, 5.8 e 5.9 ilustram esses resultados.

\begin{tabular}{|c|c|c|c|c|c|c|c|c|c|}
\hline \multicolumn{10}{|c|}{$60 \mathrm{~m}$} \\
\hline \multicolumn{5}{|c|}{ ST4 } & \multicolumn{5}{|c|}{ ST3 } \\
\hline \multirow{7}{*}{$\begin{array}{c}\mathrm{CA} \\
{[\mathrm{kg} / \mathrm{m}]}\end{array}$} & \multirow{3}{*}{$\mathrm{H} 1,50 \mathrm{~m}$} & \multicolumn{3}{|c|}{ Ângulo da diagonal } & \multirow{7}{*}{$\mathrm{CA}[\mathrm{kg} / \mathrm{m}]$} & \multirow{4}{*}{$\mathrm{H} 1,50 \mathrm{~m}$} & \multicolumn{3}{|c|}{ Ângulo da diagonal } \\
\hline & & Lb2,50 & Lb0,80 & Lb0,50 & & & $\mathrm{Lb} 2,50$ & Lb0,80 & Lb0,50 \\
\hline & & $30,96^{\circ}$ & $45,00^{\circ}$ & $51,34^{\circ}$ & & & \multirow{2}{*}{$30,96^{\circ}$} & \multirow{2}{*}{$45,00^{\circ}$} & \multirow{2}{*}{$51,34^{\circ}$} \\
\hline & PL & 356,99 & 360,06 & 373,95 & & & & & \\
\hline & $T$ & 395,38 & 385,73 & 404,20 & & PL & 363,22 & 411,73 & 436,54 \\
\hline & WT & 448,89 & 374,17 & 454,96 & & $T$ & 379,80 & 458,71 & 470,28 \\
\hline & $M$ & 322,08 & 334,70 & 301,57 & & $M$ & 298,08 & 301,69 & 341,59 \\
\hline \multicolumn{5}{|c|}{ ST4 } & \multicolumn{5}{|c|}{ ST3 } \\
\hline \multirow{7}{*}{$\mathrm{Ux}[\mathrm{mm}]$} & \multirow{3}{*}{$\mathrm{H} 1,50 \mathrm{~m}$} & \multicolumn{3}{|c|}{ Ângulo da diagonal } & \multirow{7}{*}{$\mathrm{Ux}[\mathrm{mm}]$} & \multirow{4}{*}{$\mathrm{H} 1,50 \mathrm{~m}$} & \multicolumn{3}{|c|}{ Ângulo da diagonal } \\
\hline & & Lb2,50 & Lb0,80 & Lb0,50 & & & Lb2,50 & Lb0,80 & Lb0,50 \\
\hline & & $30,96^{\circ}$ & $45,00^{\circ}$ & $51,34^{\circ}$ & & & \multirow{2}{*}{$30,96^{\circ}$} & \multirow{2}{*}{$45,00^{\circ}$} & \multirow{2}{*}{$51,34^{\circ}$} \\
\hline & PL & 9,60 & 5,50 & 7,15 & & & & & \\
\hline & $T$ & 8,80 & 7,00 & 7,15 & & PL & 6,40 & 19,80 & 14,00 \\
\hline & WT & 9,90 & 7,70 & 6,05 & & $\mathbf{T}$ & 8,10 & 17,60 & 16,50 \\
\hline & $M$ & 8,50 & 5,00 & 7,20 & & $M$ & 8,50 & 7,15 & 7,70 \\
\hline \multicolumn{5}{|c|}{ ST4 } & \multicolumn{5}{|c|}{ ST3 } \\
\hline \multirow{7}{*}{$\mathrm{Uz}[\mathrm{mm}]$} & \multirow{3}{*}{$\mathrm{H} 1,50 \mathrm{~m}$} & \multicolumn{3}{|c|}{ Ângulo da diagonal } & \multirow{7}{*}{ Uz [mm] } & \multirow{4}{*}{$\mathrm{H} 1,50 \mathrm{~m}$} & \multicolumn{3}{|c|}{ Ângulo da diagonal } \\
\hline & & $\mathrm{Lb} 2,50$ & Lb0,80 & Lb0,50 & & & Lb2,50 & Lb0,80 & Lb0,50 \\
\hline & & $30,96^{\circ}$ & $45,00^{\circ}$ & $51,34^{\circ}$ & & & \multirow{2}{*}{$30,96^{\circ}$} & $45.00^{\circ}$ & $5134^{\circ}$ \\
\hline & $\mathrm{PL}$ & 445,30 & 431,80 & 426,11 & & & & & \\
\hline & $T$ & 455,25 & 469,10 & 476,40 & & $\mathrm{PL}$ & 453,11 & 412,30 & 432,91 \\
\hline & WT & 406,70 & 536,70 & 439,30 & & $T$ & 465,90 & 450,71 & 450,21 \\
\hline & $M$ & 368,10 & 352,40 & 379,24 & & $M$ & 275,21 & 386,30 & 415,24 \\
\hline
\end{tabular}

Tabela 5.14 - Resultados encontrados para o vão de $60 \mathrm{~m}$ - altura de 1,50m.

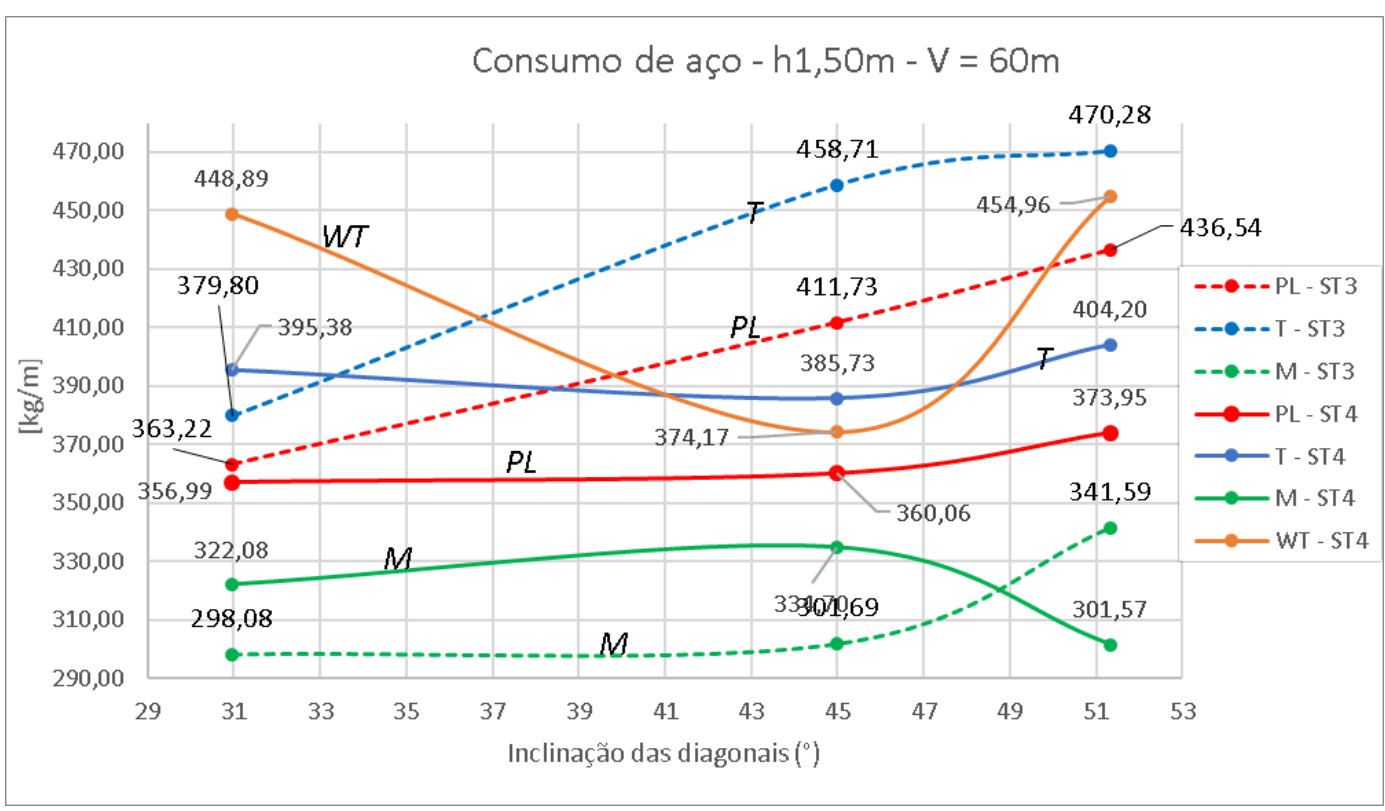

Gráfico 5.7 - Consumo de aço para o vão de $60 \mathrm{~m}: \mathrm{h}=1,50 \mathrm{~m}$. 


\begin{tabular}{|c|c|c|c|c|c|c|c|c|c|}
\hline \multicolumn{10}{|c|}{$60 \mathrm{~m}$} \\
\hline \multicolumn{5}{|c|}{ ST4 } & \multicolumn{5}{|c|}{ ST3 } \\
\hline \multirow{7}{*}{$\begin{array}{c}\text { CA } \\
{[\mathrm{kg} / \mathrm{m}]}\end{array}$} & \multirow{3}{*}{$\mathrm{H} 2,00 \mathrm{~m}$} & \multicolumn{3}{|c|}{ Ângulo da diagonal } & \multirow{7}{*}{$\mathrm{CA}[\mathrm{kg} / \mathrm{m}]$} & \multirow{4}{*}{$\mathrm{H} 2,00 \mathrm{~m}$} & \multicolumn{3}{|c|}{ Ângulo da diagonal } \\
\hline & & Lb3,00 & Lb2,00 & \multirow{2}{*}{$\begin{array}{l}\mathrm{Lb1} 1,50 \\
53,13^{\circ}\end{array}$} & & & Lb3,00 & Lb2,00 & Lb1,50 \\
\hline & & $33,69^{\circ}$ & $45,00^{\circ}$ & & & & \multirow{2}{*}{$33,69^{\circ}$} & \multirow{2}{*}{$45,00^{\circ}$} & \multirow{2}{*}{$53,13^{\circ}$} \\
\hline & PL & 331,24 & 296,56 & 359,74 & & & & & \\
\hline & $\mathbf{T}$ & 326,06 & 318,10 & 359,91 & & PL & 291,70 & 280,27 & 298,38 \\
\hline & WT & 390,46 & 355,00 & 404,60 & & $\mathbf{T}$ & 292,97 & 304,94 & 328,99 \\
\hline & $M$ & 287,84 & 264,87 & 331,32 & & $M$ & 253,07 & 243,36 & 263,58 \\
\hline \multicolumn{5}{|c|}{ ST4 } & \multicolumn{5}{|c|}{ ST3 } \\
\hline \multirow{7}{*}{$\mathrm{Ux}[\mathrm{mm}]$} & \multirow{3}{*}{$\mathrm{H} 2,00 \mathrm{~m}$} & \multicolumn{3}{|c|}{ Ângulo da diagonal } & \multirow{7}{*}{ Ux $[\mathrm{mm}]$} & \multirow{4}{*}{$\mathrm{H} 2,00 \mathrm{~m}$} & \multicolumn{3}{|c|}{ Ângulo da diagonal } \\
\hline & & Lb3,00 & Lb2,00 & Lb1,50 & & & Lb3,00 & Lb2,00 & Lb1,50 \\
\hline & & $33,69^{\circ}$ & $45,00^{\circ}$ & $53,13^{\circ}$ & & & \multirow{2}{*}{$33,69^{\circ}$} & \multirow{2}{*}{$45,00^{\circ}$} & \multirow{2}{*}{$53,13^{\circ}$} \\
\hline & PL & 9,90 & 6,60 & 5,50 & & & & & \\
\hline & $\mathbf{T}$ & 11,00 & 6,05 & 5,00 & & PL & 8,00 & 9,90 & 11,00 \\
\hline & WT & 8,00 & 6,00 & 5,00 & & $T$ & 9,00 & 11,00 & 11,00 \\
\hline & $\mathbf{M}$ & 9,00 & 7,80 & 4,40 & & M & 7,50 & 7,15 & 7,50 \\
\hline \multicolumn{5}{|c|}{ ST4 } & \multicolumn{5}{|c|}{ ST3 } \\
\hline \multirow{7}{*}{$\mathrm{Uz}[\mathrm{mm}]$} & & \multicolumn{3}{|c|}{ Ângulo da diagonal } & \multirow{7}{*}{ Uz [mm] } & & \multicolumn{3}{|c|}{ Ângulo da diagonal } \\
\hline & $\mathrm{H} 2,00 \mathrm{~m}$ & Lb3,00 & Lb2,00 & Lb1,50 & & & Lb3,00 & Lb2,00 & Lb1,50 \\
\hline & & $33,69^{\circ}$ & $45,00^{\circ}$ & $53,13^{\circ}$ & & $\mathrm{H} \mathbf{R}, \mathbf{0 u m}$ & $33.69^{\circ}$ & $4500^{\circ}$ & $53.13^{\circ}$ \\
\hline & PL & 303,24 & 343,80 & 337,11 & & & כט,נת & טס, & בגובנ \\
\hline & $\mathbf{T}$ & 334,30 & 351,92 & 353,40 & & PL & 332,44 & 286,87 & 362,48 \\
\hline & WT & 284,50 & 310,20 & 315,14 & & $T$ & 356,67 & 360,80 & 372,10 \\
\hline & $M$ & 248,70 & 229,90 & 245,70 & & $M$ & 250,86 & 292,61 & 297,43 \\
\hline
\end{tabular}

Tabela 5.15 - Resultados encontrados para o vão de $60 \mathrm{~m}$ - altura de 2,00m.

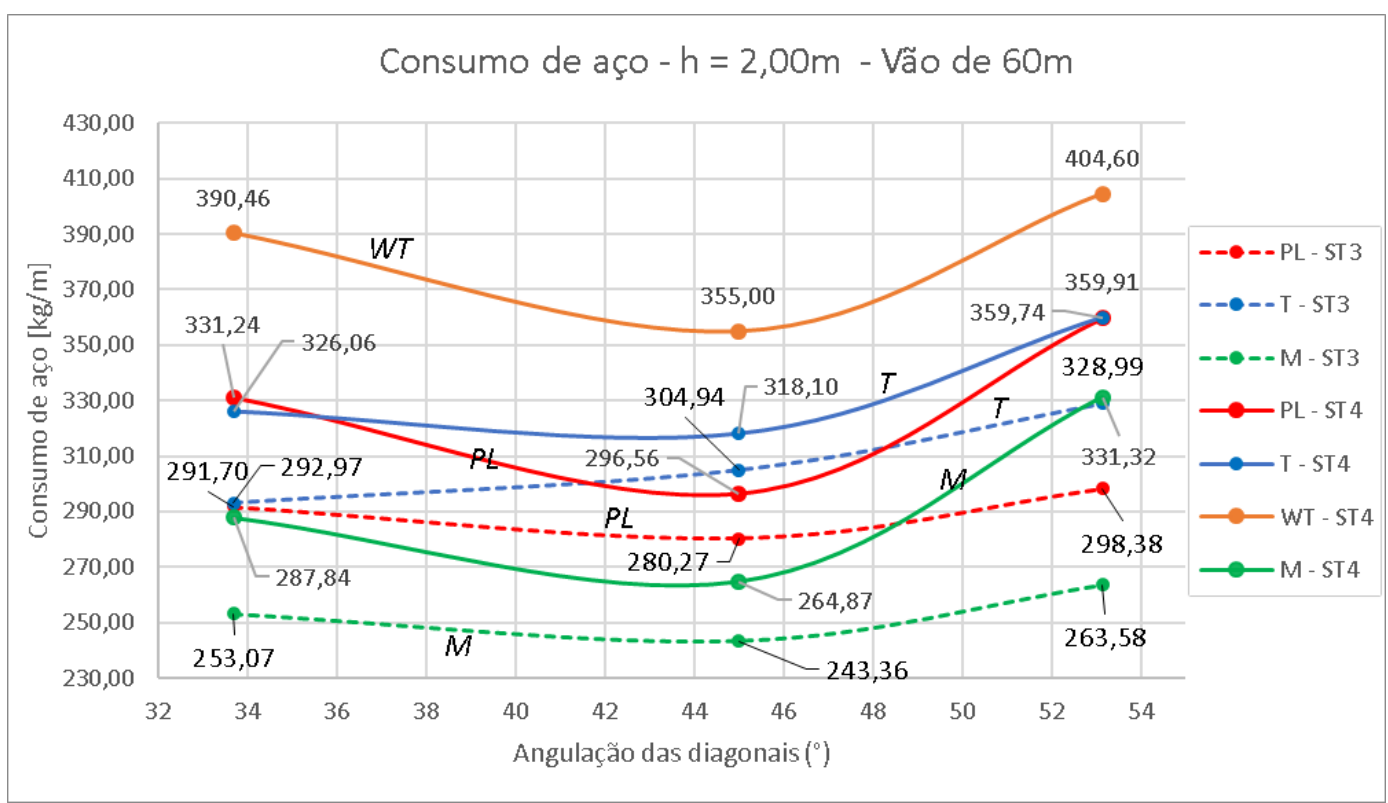

Gráfico 5.8 - Consumo de aço para o vão de 60m: $\mathrm{h}=2,00 \mathrm{~m}$. 


\begin{tabular}{|c|c|c|c|c|c|c|c|c|c|}
\hline \multicolumn{10}{|c|}{$60 \mathrm{~m}$} \\
\hline \multicolumn{5}{|c|}{ ST4 } & \multicolumn{5}{|c|}{ ST3 } \\
\hline \multirow{7}{*}{$\begin{array}{c}\text { CA } \\
{[\mathrm{kg} / \mathrm{m}]}\end{array}$} & \multirow{3}{*}{$\mathrm{H} 2,50 \mathrm{~m}$} & \multicolumn{3}{|c|}{ Ângulo da diagonal } & \multirow{7}{*}{$\mathrm{CA}[\mathrm{kg} / \mathrm{m}]$} & \multirow{4}{*}{$\mathrm{H} 2,50 \mathrm{~m}$} & \multicolumn{3}{|c|}{ Ângulo da diagonal } \\
\hline & & Lb3,00 & Lb2,50 & Lb2,00 & & & Lb3,00 & Lb2,50 & Lb2,00 \\
\hline & & $39,81^{\circ}$ & $45,00^{\circ}$ & $51,34^{\circ}$ & & & & & \\
\hline & PL & 295,59 & 272,48 & 288,32 & & & 39,81 & 45,00 & 51,34 \\
\hline & $T$ & 290,81 & 331,17 & 272,48 & & PL & 261,84 & 262,74 & 256,37 \\
\hline & WT & 363,37 & 364,12 & 390,37 & & $\mathbf{T}$ & 268,18 & 274,05 & 286,21 \\
\hline & $M$ & 252,70 & 238,86 & 258,91 & & $M$ & 228,39 & 230,94 & 246,93 \\
\hline \multicolumn{5}{|c|}{ ST4 } & \multicolumn{5}{|c|}{ ST3 } \\
\hline \multirow{7}{*}{$\mathrm{Ux}[\mathrm{mm}]$} & \multirow{3}{*}{$\mathrm{H} 2,50 \mathrm{~m}$} & \multicolumn{3}{|c|}{ Ângulo da diagonal } & \multirow{7}{*}{ Ux $[\mathrm{mm}]$} & \multirow{4}{*}{$\mathrm{H} 2,50 \mathrm{~m}$} & \multicolumn{3}{|c|}{ Ângulo da diagonal } \\
\hline & & Lb3,00 & Lb2,50 & Lb2,00 & & & Lb3,00 & Lb2,50 & Lb2,00 \\
\hline & & $39,81^{\circ}$ & $45,00^{\circ}$ & $51,34^{\circ}$ & & & \multirow{2}{*}{$39,81^{\circ}$} & \multirow{2}{*}{$45,00^{\circ}$} & \multirow{2}{*}{$51,34^{\circ}$} \\
\hline & $\mathbf{P L}$ & 8,10 & 6,50 & 4,80 & & & & & \\
\hline & $T$ & 8,00 & 6,50 & 5,50 & & PL & 9,00 & 8,80 & 7,70 \\
\hline & WT & 6,75 & 6,50 & 4,00 & & $T$ & 12,10 & 12,00 & 12,10 \\
\hline & $M$ & 6,75 & 5,50 & 4,80 & & $M$ & 9,00 & 8,40 & 11,00 \\
\hline \multicolumn{5}{|c|}{ ST4 } & \multicolumn{5}{|c|}{ ST3 } \\
\hline \multirow{7}{*}{$\mathrm{Uz}[\mathrm{mm}]$} & \multirow{3}{*}{$\mathrm{H} 2,50 \mathrm{~m}$} & \multicolumn{3}{|c|}{ Ângulo da diagonal } & \multirow{7}{*}{ Uz [mm] } & \multirow{4}{*}{$\mathrm{H} 2,50 \mathrm{~m}$} & \multicolumn{3}{|c|}{ Ângulo da diagonal } \\
\hline & & Lb3,00 & Lb2,50 & Lb2,00 & & & Lb3,00 & Lb2,50 & Lb2,00 \\
\hline & & $39,81^{\circ}$ & $45,00^{\circ}$ & $51,34^{\circ}$ & & & \multirow{2}{*}{$39,81^{\circ}$} & \multirow{2}{*}{$45,00^{\circ}$} & \multirow{2}{*}{$51,34^{\circ}$} \\
\hline & PL & 253,40 & 270,30 & 269,40 & & & & & \\
\hline & $T$ & 265,10 & 270,00 & 238,80 & & PL & 270,60 & 274,10 & 295,85 \\
\hline & WT & 228,60 & 243,30 & 244,80 & & $T$ & 279,50 & 286,60 & 291,60 \\
\hline & $M$ & 198,30 & 190,70 & 208,70 & & $M$ & 211,38 & 204,45 & 248,45 \\
\hline
\end{tabular}

Tabela 5.16 - Resultados encontrados para o vão de 60m - altura de 2,50m.

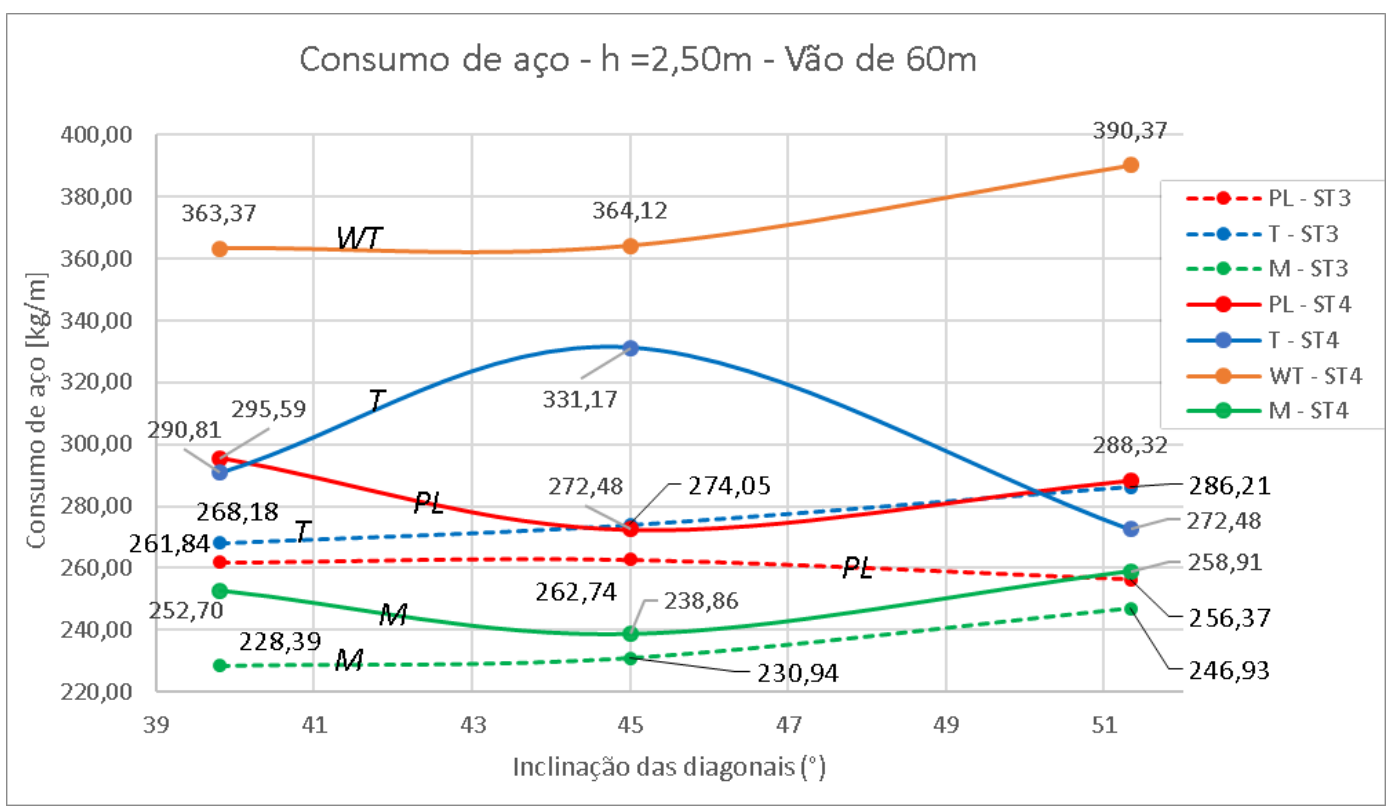

Gráfico 5.9 - Consumo de aço para o vão de 60m: $\mathrm{h}=2,50 \mathrm{~m}$.

O valor do consumo de concreto para as treliças mistos de cada vão e seções utilizados estão resumidos na Tabela 5.17. 


\begin{tabular}{|c|c|c|c|c|c|c|c|c|c|}
\hline \multicolumn{5}{|c|}{$32 m$ - ST4 } & \multicolumn{5}{|c|}{$32 m-S T 3$} \\
\hline \multirow{9}{*}{$\begin{array}{c}\text { Volume } \\
\text { de } \\
\text { concreto } \\
{\left[\mathrm{m}^{3}\right]}\end{array}$} & \multirow{3}{*}{$\mathrm{H} 0,80 \mathrm{~m}$} & Lb1,00 & Lb0,80 & Lb0,50 & \multirow{9}{*}{$\begin{array}{c}\text { Volume } \\
\text { de } \\
\text { concreto } \\
{\left[\mathrm{m}^{3}\right]}\end{array}$} & \multirow{3}{*}{$\mathrm{HO}, 80 \mathrm{~m}$} & Lb1,00 & Lb0,80 & Lb0,50 \\
\hline & & $38,66^{\circ}$ & $45,00^{\circ}$ & $57,99^{\circ}$ & & & $38,66^{\circ}$ & $45,00^{\circ}$ & $57,99^{\circ}$ \\
\hline & & $5,96 \mathrm{~m}^{3}$ & $6,19 \mathrm{~m}^{3}$ & $6,29 \mathrm{~m}^{3}$ & & & $5,64 m^{3}$ & $6,77 \mathrm{~m}^{3}$ & $5,94 \mathrm{~m}^{3}$ \\
\hline & \multirow{3}{*}{$\mathrm{H} 1,00 \mathrm{~m}$} & Lb1,60 & Lb1,00 & Lb0,80 & & \multirow{3}{*}{$\mathrm{H} 1,00 \mathrm{~m}$} & Lb1,60 & Lb1,00 & Lb0,80 \\
\hline & & $32,01^{\circ}$ & $45,00^{\circ}$ & $51,34^{\circ}$ & & & $32,01^{\circ}$ & $45,00^{\circ}$ & $51,34^{\circ}$ \\
\hline & & $6,31 \mathrm{~m}^{3}$ & $5,37 \mathrm{~m}^{3}$ & $5,69 \mathrm{~m}^{3}$ & & & $5,45 \mathrm{~m}^{3}$ & $5,10 \mathrm{~m}^{3}$ & $5,34 \mathrm{~m}^{3}$ \\
\hline & \multirow{3}{*}{$\mathrm{H} 1,20 \mathrm{~m}$} & Lb2,00 & Lb1,20 & Lb1,00 & & \multirow{3}{*}{$\mathrm{H} 1,20 \mathrm{~m}$} & Lb2,00 & Lb1,20 & Lb1,00 \\
\hline & & $30,96^{\circ}$ & $45,00^{\circ}$ & $50,19^{\circ}$ & & & $30,96^{\circ}$ & $45,00^{\circ}$ & $50,19^{\circ}$ \\
\hline & & $5,18 m^{3}$ & $4,98 \mathrm{~m}^{3}$ & $4,54 \mathrm{~m}^{3}$ & & & $4,74 \mathrm{~m}^{3}$ & $4,64 \mathrm{~m}^{3}$ & $4,72 \mathrm{~m}^{3}$ \\
\hline \multicolumn{5}{|c|}{$45 m$ - ST4 } & \multicolumn{5}{|c|}{$45 m$ - ST3 } \\
\hline \multirow{9}{*}{$\begin{array}{c}\text { Volume } \\
\text { de } \\
\text { concreto } \\
{\left[\mathrm{m}^{3}\right]}\end{array}$} & \multirow{3}{*}{$\mathrm{H} 1,50 \mathrm{~m}$} & Lb2,50 & Lb0,80 & Lb0,50 & \multirow{9}{*}{$\begin{array}{c}\text { Volume } \\
\text { de } \\
\text { concreto } \\
{\left[\mathrm{m}^{3}\right]}\end{array}$} & \multirow{3}{*}{$\mathrm{H} 1,50 \mathrm{~m}$} & Lb2,50 & Lb0,80 & Lb0,50 \\
\hline & & $30,96^{\circ}$ & $45,00^{\circ}$ & $50,19^{\circ}$ & & & $30,96^{\circ}$ & $45,00^{\circ}$ & $50,19^{\circ}$ \\
\hline & & $13,10 \mathrm{~m}^{3}$ & $11,61 \mathrm{~m}^{3}$ & $18,04 \mathrm{~m}^{3}$ & & & $10,84 \mathrm{~m}^{3}$ & $10,15 \mathrm{~m}^{3}$ & $10,19 \mathrm{~m}^{3}$ \\
\hline & \multirow{3}{*}{$\mathrm{H} 1,80 \mathrm{~m}$} & Lb3,00 & Lb1,80 & Lb1,50 & & \multirow{3}{*}{$\mathrm{H} 1,80 \mathrm{~m}$} & Lb3,00 & Lb1,80 & Lb1,50 \\
\hline & & $30,96^{\circ}$ & $45,00^{\circ}$ & $50,19^{\circ}$ & & & $30,96^{\circ}$ & $45,00^{\circ}$ & $50,19^{\circ}$ \\
\hline & & $13,19 \mathrm{~m}^{3}$ & $11,53 \mathrm{~m}^{3}$ & $10,07 \mathrm{~m}^{3}$ & & & $11,10 \mathrm{~m}^{3}$ & $10,92 \mathrm{~m}^{3}$ & $9,39 \mathrm{~m}^{3}$ \\
\hline & \multirow{3}{*}{$\mathrm{H} 2,25 \mathrm{~m}$} & Lb3,00 & Lb2,25 & Lb1,80 & & \multirow{3}{*}{$\mathrm{H} 2,25 \mathrm{~m}$} & Lb3,00 & Lb2,25 & Lb1,80 \\
\hline & & $36,87^{\circ}$ & $45,00^{\circ}$ & $51,34^{\circ}$ & & & $36,87^{\circ}$ & $45,00^{\circ}$ & $51,34^{\circ}$ \\
\hline & & $12,19 \mathrm{~m}^{3}$ & $9,53 \mathrm{~m}^{3}$ & $9,38 m^{3}$ & & & $9,91 \mathrm{~m}^{3}$ & $9,18 m^{3}$ & $7,53 \mathrm{~m}^{3}$ \\
\hline \multicolumn{5}{|c|}{$60 \mathrm{~m}$ - ST4 } & \multicolumn{5}{|c|}{$60 m$ - ST3 } \\
\hline \multirow{9}{*}{$\begin{array}{c}\text { Volume } \\
\text { de } \\
\text { concreto } \\
{\left[\mathrm{m}^{3}\right]}\end{array}$} & \multirow{3}{*}{$\mathrm{H} 1,50 \mathrm{~m}$} & Lb2,50 & Lb0,80 & Lb0,50 & \multirow{9}{*}{$\begin{array}{c}\text { Volume } \\
\text { de } \\
\text { concreto } \\
{\left[\mathrm{m}^{3}\right]}\end{array}$} & \multirow{3}{*}{$\mathrm{H} 1,50 \mathrm{~m}$} & Lb2,50 & Lb0,80 & Lb0,50 \\
\hline & & $30,96^{\circ}$ & $45,00^{\circ}$ & $51,34^{\circ}$ & & & $30,96^{\circ}$ & $45,00^{\circ}$ & $51,34^{\circ}$ \\
\hline & & $23,50 \mathrm{~m}^{3}$ & $22,95 \mathrm{~m}^{3}$ & $22,11 \mathrm{~m}^{3}$ & & & $22,25 \mathrm{~m}^{3}$ & $22,49 \mathrm{~m}^{3}$ & $21,65 \mathrm{~m}^{3}$ \\
\hline & \multirow{3}{*}{$\mathrm{H} 2,00 \mathrm{~m}$} & Lb3,00 & Lb2,00 & Lb1,50 & & \multirow{3}{*}{$\mathrm{H} 2,00 \mathrm{~m}$} & Lb3,00 & Lb2,00 & Lb1,50 \\
\hline & & $33,69^{\circ}$ & $45,00^{\circ}$ & $53,13^{\circ}$ & & & $33,69^{\circ}$ & $45,00^{\circ}$ & $53,13^{\circ}$ \\
\hline & & $20,45 \mathrm{~m}^{3}$ & $18,98 \mathrm{~m}^{3}$ & $18,84 \mathrm{~m}^{3}$ & & & $19,99 \mathrm{~m}^{3}$ & $18,60 \mathrm{~m}^{3}$ & $18,49 \mathrm{~m}^{3}$ \\
\hline & \multirow{3}{*}{$\mathrm{H} 2,50 \mathrm{~m}$} & Lb3,00 & Lb2,50 & Lb2,00 & & & Lb3,00 & Lb2,50 & Lb2,00 \\
\hline & & $39,81^{\circ}$ & $45,00^{\circ}$ & $51,34^{\circ}$ & & $\mathrm{H} 2,50 \mathrm{~m}$ & $39,81^{\circ}$ & $45,00^{\circ}$ & $51,34^{\circ}$ \\
\hline & & $18,88 \mathrm{~m}^{3}$ & $17,10 \mathrm{~m}^{3}$ & $15,48 \mathrm{~m}^{3}$ & & & $18,50 \mathrm{~m}^{3}$ & $16,81 \mathrm{~m}^{3}$ & $15,16 \mathrm{~m}^{3}$ \\
\hline
\end{tabular}

Tabela 5.17 - Consumo de concreto nas treliças mistas de todos os vãos.

Pode-se observar previamente que os projetos que utilizaram os perfis mistos são os que apresentam o menor consumo de aço e que os que apresentam os maiores valores de altura.

Além disso, quando se compara os vãos por altura, nota-se que há semelhanças no consumo de aço. Por exemplo, observando os valores de consumo das estruturas com perfis laminados para as maiores alturas dos três vãos, há uma redução no consumo de aço com o aumento do ângulo da diagonal.

Quanto ao consumo de concreto, de forma óbvia, nota-se que o consumo de concreto aumenta quando se aumenta o comprimento dos módulos, devido ao aumento do diâmetro dos tubos. 
Para realizar um estudo paramétrico de forma mais detalhada será realizada uma abordagem determinística com os resultados obtidos acima, de forma a estabelecer a influência das diversas variáveis de projeto e, assim, determinar qual solução apresenta o menor consumo de aço.

Para esse estudo determinístico, será realizada uma breve revisão bibliográfica sobre testes de hipóteses e intervalos de confiança, conceitos utilizados ao longo deste trabalho para embasar as conclusões obtidas. Após isso, serão estudadas as influências de cada variável de projeto no consumo de aço, flechas e deslocamentos fora do plano da treliça.

\section{4 . \\ Testes de hipótese e intervalo de confiança}

Diante de tantas variáveis em tantos problemas de engenharia, frequentemente há a necessidade de se aceitar ou não determinada afirmação hipotética acerca de um determinado parâmetro analisado. Para tal, é necessário realizar testes de hipóteses estatísticos para o procedimento de tomada de decisões.

De acordo com Spiegel (1977), formula-se uma hipótese estatística com a finalidade de rejeitá-la ou não. Para decidir se determinado processo é melhor do que outro, formula-se uma hipótese de que não há diferença entre dois processos (quaisquer diferenças são devidas a meras flutuações de amostragem da mesma população). Essa hipótese é chamada de nula $\left(\mathrm{H}_{0}\right)$.

Também é formulada a hipótese alternativa $\left(\mathrm{H}_{1}\right)$, que afirma que as alterações entre as médias das distribuições são causadas após a variação do parâmetro analisado. Dessa forma, quando se rejeita a hipótese nula, significa dizer que a hipótese alternativa deve ser aceita.

Os processos que permitem que hipóteses sejam aceitas ou rejeitadas, ou determinar se amostras observadas diferem significativamente dos resultados esperados são chamados de testes de hipóteses.

A partir de testes de hipóteses, é possível afirmar, com um nível de significância pré-estabelecido, se um parâmetro é capaz de influenciar um resultado comparando médias de duas distribuições normais independentes.

A probabilidade de realizar uma escolha errada é chamada de nível de significância. Spiegel (1977) afirma que comumente se adota um nível de significância 
de 0,05 ou de 0,01 , embora outros valores possam ser utilizados. $\mathrm{O}$ valor de 0,05 significa que há uma possibilidade de se rejeitar 5\% das hipóteses quando esta deveria ser aceita.

Os erros quanto às escolhas de hipóteses são dois: erro tipo I, que é quando se rejeita uma hipótese quando deveria ter sido aceita; e erro tipo II, que é quando se aceita uma hipótese quando deveria ter sido recusada.

Esse levantamento de hipóteses pode ser realizado para grandes ou pequenas amostras, para uma ou mais populações, dependendo da necessidade. Para pequenas amostras, o teste $t$-Student é mais recomendável para realizar essa análise.

De acordo com Silva (2014), o teste $t$-Student é um teste de hipótese que usa conceitos estatísticos para rejeitar ou não uma hipótese nula quando a estatística de teste segue uma distribuição $t$-Student. É utilizado quando se deseja realizar comparações entre as médias de uma variável quantitativa em dois grupos diferentes, nos quais se desconhece suas respectivas variâncias. Para duas amostras, o valor de t é calculado pela fórmula (4.2) e o desvio padrão agrupado $\left(S_{x_{1} x_{2}}\right)$ será calculado pela fórmula (4.3). O número de graus de liberdade (gl) do problema é dado pela fórmula (4.4).

$$
\begin{gathered}
t=\frac{\bar{x}_{1}-\bar{x}_{2}}{S_{x_{1} x_{2}} \cdot \sqrt{\frac{2}{n}}} \\
S_{x_{1} x_{2}}=\sqrt{\frac{S_{x_{1}}{ }^{2}+S_{x 2}^{2}}{2}} \\
g l=2 n-2
\end{gathered}
$$

Onde:

$S_{x_{1}}:$ desvio padrão da amostra $1 ;$

$S_{x 2}:$ desvio padrão da amostra 2 ;

$\bar{x}:$ média da amostra;

n: tamanho da amostra.

De acordo com Spiegel (1977), após conhecidos o valor-t e a quantidade de graus de liberdade, procura-se o valor da densidade de probabilidade da distribuição t de Student em uma tabela de distribuição (obter o valor-P), para que seja comparado com o valor do nível de significância. 
Assim, se o valor encontrado for menor que o nível de significância, a hipótese nula é rejeitada; caso seja maior, a hipótese é aceita.

Já o intervalo de confiança (IC) é o intervalo de médias da população. Ou seja, a média da amostra acrescida ou reduzida do intervalo de confiança equivalerá ao intervalo de médias da população, usando qualquer outra amostragem. De acordo com Montgomery (2009), ele é construído de modo que se tenha alta confiança de que ele contém o parâmetro desconhecido da população.

O intervalo de confiança (IC) é calculado após verificar se o nível de confiança está adequado, ou seja, realizando o teste t de Student. Com isso, para um nível de confiança de $95 \%$ (valor adotado nesse trabalho), calcula-se o intervalo de confiança de acordo com a fórmula seguinte:

$$
I C= \pm 1,96 \frac{s}{\sqrt{n}} .
$$

\section{5. \\ Influência das variáveis de projeto no consumo de aço}

Nessa seção será realizado um estudo no qual serão comparados os principais parâmetros analisados nesse trabalho. Para isso, serão isoladas as variáveis a serem estudadas e o restante dos parâmetros serão mantidos fixos, de forma a identificar a resposta da estrutura somente devido à mudança da variável escolhida.

Inicialmente, serão levantadas duas hipóteses acerca de qual solução é mais eficiente: a hipótese nula $\left(\mathrm{H}_{0}\right)$ e a hipótese alternativa $\left(\mathrm{H}_{1}\right)$. A hipótese nula indica que a variação foi motivada por acaso, enquanto que a hipótese alternativa indica que a evolução do resultado é devido à variação do parâmetro.

Após isso, será realizado um teste t-Student, com o objetivo de aceitar ou rejeitar a hipótese nula. Como foi escolhido o nível de confiança em 95\%, caso o valor-p encontrado seja maior que 5\%, deve-se aceitar a hipótese nula. Caso contrário, se o valor-p for menor que 5\%, deve-se rejeitar a hipótese nula, ou seja, aceita-se a hipótese alternativa (Montgomery, 2009). 


\subsection{1.}

\section{Tipo de perfil das cordas}

Ao se fixar os parâmetros de altura e a geometria da seção transversal da treliça, pode-se analisar a influência do tipo de perfil da corda na variação do consumo de aço. Para efeito comparativo, o perfil laminado será adotado como referencial.

O Gráfico 5.10 mostra o consumo de aço para uma treliça de altura de 1,50m, nos vãos de 60 metros de comprimento e seção transversal tipo ST4. O Gráfico 5.11 mostra a mesma configuração, entretanto para uma seção transversal do tipo ST3.

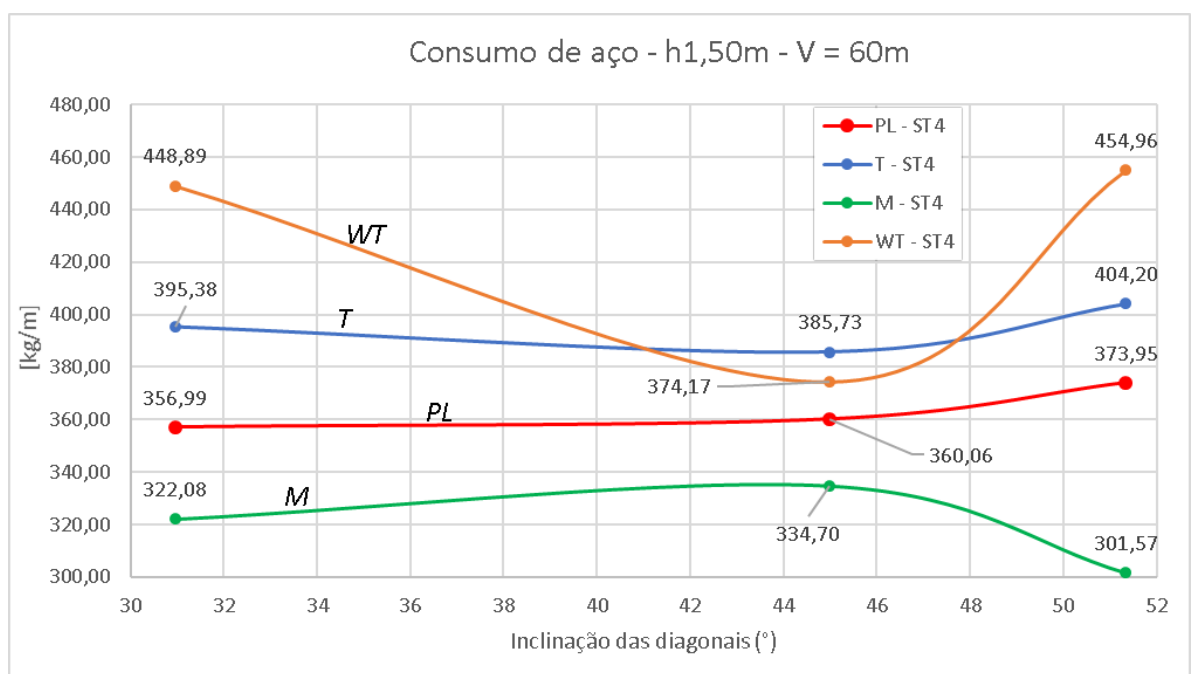

Gráfico 5.10 - Consumo de aço - Vão de 60m - altura de 1,50m - Seção ST4.

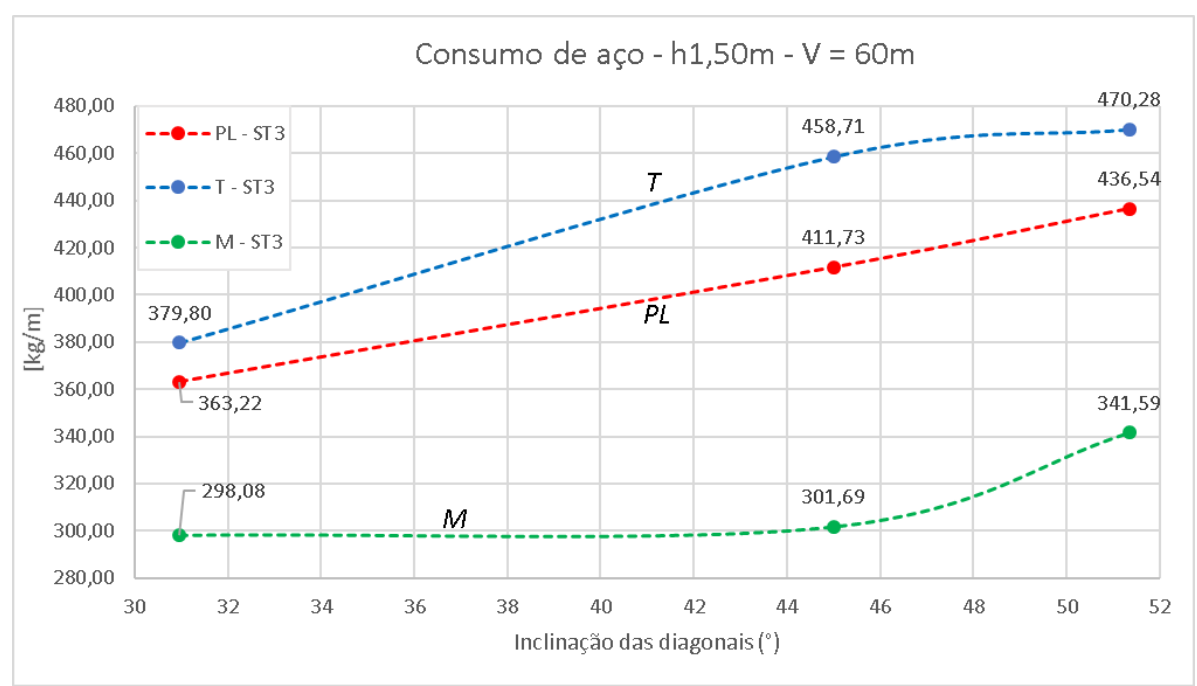

Gráfico 5.11 - Consumo de aço - Vão de 60m - altura de 1,50m - Seção ST3. 
Ao visualizar esses valores, é possível levantar a hipótese de que o consumo de aço nas estruturas com cordas mistas é inferior às estruturas com outros perfis.

Entretanto, é necessário verificar a probabilidade dessa hipótese ocorrer e para isso será realizado um teste t-Student. Para isso, serão comparados os valores de consumo de aço para as estruturas com perfis mistos e perfis laminados.

A hipótese nula é a de que a variável "Perfil da corda" é igual para ambos os casos (laminado e misto) e não influencia no resultado obtido, enquanto que a hipótese alternativa é a de que os valores serão diferentes devido à variação do perfil.

Para esses testes, a amostra de cada grupo (com perfis laminados e mistos) foi de 18: são dois tipos de seção transversal, três alturas diferentes e três valores de comprimento destravado para cada altura. Esse teste será utilizado para os três comprimentos de vão estudados.

A Tabela 5.18(a) mostra os resultados de consumo de aço agrupados das estruturas com perfis laminados e perfis mistos para o vão de $60 \mathrm{~m}$. A partir desses valores, realizou-se o teste $t$-Student para a verificação da hipótese nula.

\begin{tabular}{|c|c|c|c|c|c|}
\hline Seção & $\mathrm{h}[\mathrm{m}]$ & $\mathrm{Lb}[\mathrm{m}]$ & $\alpha\left[^{\circ}\right]$ & $\mathrm{PL}[\mathrm{kg} / \mathrm{m}]$ & $\mathrm{M}[\mathrm{kg} / \mathrm{m}]$ \\
\hline ST4 & 1,50 & 1,20 & 51,34 & 373,95 & 301,57 \\
\hline ST4 & 1,50 & 1,50 & 45,00 & 360,06 & 334,70 \\
\hline ST4 & 1,50 & 2,50 & 30,96 & 356,99 & 322,08 \\
\hline ST4 & 2,00 & 1,50 & 53,13 & 359,74 & 331,32 \\
\hline ST4 & 2,00 & 2,00 & 45,00 & 296,56 & 264,87 \\
\hline ST4 & 2,00 & 3,00 & 33,69 & 331,24 & 287,84 \\
\hline ST4 & 2,50 & 2,00 & 51,35 & 288,32 & 258,91 \\
\hline ST4 & 2,50 & 2,50 & 45,00 & 272,48 & 238,86 \\
\hline ST4 & 2,50 & 3,00 & 39,81 & 295,59 & 252,70 \\
\hline ST3 & 1,50 & 1,20 & 51,34 & 436,54 & 341,59 \\
\hline ST3 & 1,50 & 1,50 & 45,00 & 411,73 & 301,69 \\
\hline ST3 & 1,50 & 2,50 & 30,96 & 363,22 & 298,08 \\
\hline ST3 & 2,00 & 1,50 & 53,13 & 298,38 & 263,58 \\
\hline ST3 & 2,00 & 2,00 & 45,00 & 280,27 & 243,36 \\
\hline ST3 & 2,00 & 3,00 & 33,69 & 291,70 & 253,07 \\
\hline ST3 & 2,50 & 2,00 & 51,35 & 256,37 & 246,93 \\
\hline ST3 & 2,50 & 2,50 & 45,00 & 262,74 & 230,94 \\
\hline ST3 & 2,50 & 3,00 & 39,81 & 261,84 & 228,39 \\
\hline
\end{tabular}

\begin{tabular}{|c|c|c|}
\hline & $P L[\mathrm{~kg} / \mathrm{m}]$ & $M[\mathrm{~kg} / \mathrm{m}]$ \\
\hline Média & 322,10 & 277,81 \\
\hline Variância & 2902,24 & 1414,18 \\
\hline Amostra & 18 & 18 \\
\hline Graus de liberdade & 30 & \\
\hline Valor-P & $0,36 \%$ & \\
\hline Valort & 1,691 & \\
\hline
\end{tabular}

Tabela 5.18 - (a): consumo de aço do vão de 60m; (b) análise $t$-Student

Como se pode observar, o valor-p obtido no teste é igual a $0,36 \%$, inferior aos 5\% do valor de significância, devendo ser rejeitada a hipótese nula. Dessa forma, há a probabilidade de $95 \%$ de que a escolha por utilizar perfis mistos nas cordas resulta em um menor consumo de material comparado com perfis laminados.

As Tabelas 5.19 e 5.20 mostram os mesmos testes para os vãos de $32 \mathrm{~m}$ e $45 \mathrm{~m}$. 
Vê-se que a mesma conclusão obtida com o vão de $60 \mathrm{~m}$ pode ser encontrada nos vãos de $32 \mathrm{~m}$ e $45 \mathrm{~m}$, ou seja, a probabilidade de encontrar economia no consumo de aço ao trocar os perfis laminados por perfis mistos nas cordas é de $95 \%$.

\begin{tabular}{|c|c|c|c|c|c|}
\hline \multicolumn{5}{|c|}{ Geometria da treliça } & \multicolumn{2}{c|}{ CA $[\mathrm{kg} / \mathrm{m}]$} \\
\hline Seção & $\mathrm{h}[\mathrm{m}]$ & Lb $[\mathrm{m}]$ & $\left.\alpha{ }^{\circ}\right]$ & $\mathrm{PL}[\mathrm{kg} / \mathrm{m}]$ & $\mathrm{M}[\mathrm{kg} / \mathrm{m}]$ \\
\hline ST4 & 0,80 & 0,50 & 57,99 & 225,69 & 201,24 \\
\hline ST4 & 0,80 & 0,80 & 45,00 & 212,06 & 186,42 \\
\hline ST4 & 0,80 & 1,00 & 38,66 & 207,04 & 182,05 \\
\hline ST4 & 1,00 & 0,80 & 51,34 & 198,55 & 176,22 \\
\hline ST4 & 1,00 & 1,00 & 45,00 & 190,43 & 167,54 \\
\hline ST4 & 1,00 & 1,60 & 32,01 & 189,51 & 160,37 \\
\hline ST4 & 1,20 & 1,00 & 50,19 & 184,89 & 159,60 \\
\hline ST4 & 1,20 & 1,20 & 45,00 & 184,69 & 158,58 \\
\hline ST4 & 1,20 & 2,00 & 30,96 & 188,71 & 151,10 \\
\hline ST3 & 0,80 & 0,50 & 57,99 & 215,24 & 202,94 \\
\hline ST3 & 0,80 & 0,80 & 45,00 & 189,30 & 177,51 \\
\hline ST3 & 0,80 & 1,00 & 38,66 & 190,19 & 178,04 \\
\hline ST3 & 1,00 & 0,80 & 51,34 & 177,82 & 157,75 \\
\hline ST3 & 1,00 & 1,00 & 45,00 & 163,09 & 145,84 \\
\hline ST3 & 1,00 & 1,60 & 32,01 & 158,38 & 135,16 \\
\hline ST3 & 1,20 & 1,00 & 50,19 & 153,99 & 137,23 \\
\hline ST3 & 1,20 & 1,20 & 45,00 & 156,88 & 134,09 \\
\hline ST3 & 1,20 & 2,00 & 30,96 & 155,09 & 123,76 \\
\hline
\end{tabular}

Teste t-Student: 32m - [PL x M]

\begin{tabular}{lrr}
\hline & $P L[\mathrm{~kg} / \mathrm{m}]$ & \multicolumn{1}{c}{$M[\mathrm{~kg} / \mathrm{m}]$} \\
\hline Média & $\mathbf{1 8 5 , 6 4}$ & $\mathbf{1 6 3 , 0 8}$ \\
Variância & 468,27 & 524,54 \\
Observações & 18 & 18 \\
Graus de liberdade & 34 & \\
Valor-p & $\mathbf{0 , 2 3 \%}$ & \\
Valor t & 1,691 & \\
\hline
\end{tabular}

Tabela 5.19 - (a): consumo de aço do vão de 32m; (b) análise t-Student

\begin{tabular}{|c|c|c|c|c|c|}
\hline \multicolumn{5}{|c|}{ Geometria da treliça } & \multicolumn{2}{c|}{ CA [ kg/m] } \\
\hline Seção & $\mathrm{h}[\mathrm{m}]$ & $\mathrm{Lb}[\mathrm{m}]$ & $\alpha\left[^{\circ}\right]$ & $\mathrm{PL}[\mathrm{kg} / \mathrm{m}]$ & $\mathrm{M}[\mathrm{kg} / \mathrm{m}]$ \\
\hline ST4 & 1,50 & 1,25 & 50,19 & 241,12 & 218,70 \\
\hline ST4 & 1,50 & 1,50 & 45,00 & 254,30 & 228,34 \\
\hline ST4 & 1,50 & 2,50 & 30,96 & 262,85 & 224,89 \\
\hline ST4 & 1,80 & 1,50 & 50,19 & 229,54 & 205,69 \\
\hline ST4 & 1,80 & 1,80 & 45,00 & 223,70 & 195,41 \\
\hline ST4 & 1,80 & 3,00 & 30,96 & 244,16 & 201,81 \\
\hline ST4 & 2,25 & 1,80 & 51,34 & 220,34 & 185,82 \\
\hline ST4 & 2,25 & 2,25 & 45,00 & 223,72 & 182,32 \\
\hline ST4 & 2,25 & 3,00 & 36,87 & 227,38 & 189,10 \\
\hline ST3 & 1,50 & 1,25 & 50,19 & 246,41 & 230,59 \\
\hline ST3 & 1,50 & 1,50 & 45,00 & 238,98 & 229,73 \\
\hline ST3 & 1,50 & 2,50 & 30,96 & 218,98 & 185,76 \\
\hline ST3 & 1,80 & 1,50 & 50,19 & 205,89 & 184,98 \\
\hline ST3 & 1,80 & 1,80 & 45,00 & 214,76 & 191,18 \\
\hline ST3 & 1,80 & 3,00 & 30,96 & 219,47 & 181,04 \\
\hline ST3 & 2,25 & 1,80 & 51,34 & 198,92 & 173,58 \\
\hline ST3 & 2,25 & 2,25 & 45,00 & 184,90 & 160,54 \\
\hline ST3 & 2,25 & 3,00 & 36,87 & 196,04 & 162,77 \\
\hline
\end{tabular}

Teste t-Student: 45m - [PL x M]

\begin{tabular}{lrr}
\hline & $P L[\mathrm{~kg} / \mathrm{m}]$ & $M[\mathrm{~kg} / \mathrm{m}]$ \\
\hline Média & $\mathbf{2 2 5 , 0 8}$ & $\mathbf{1 9 6 , 2 4}$ \\
Variância & 428,58 & 501,91 \\
Observações & 18 & 18 \\
Graus de liberdade & 34 & \\
Valor-P & $\mathbf{0 , 0 1 6 \%}$ & \\
Valor t & 1,691 & \\
\hline
\end{tabular}

Tabela 5.20 - (a): consumo de aço do vão de 45m; (b) análise t-Student. 


\subsection{2.}

\section{Variação da seção transversal da treliça}

Outra importante questão a ser analisada é a determinação de qual seção transversal da treliça multiplanar é mais recomendada para a estrutura. Para esse trabalho, foram consideradas duas tipologias de seção transversal, uma com quatro cordas e outra com apenas três. A altura da treliça foi variada em três valores diferentes para cada vão estudado.

O Gráfico 5.12 mostra um comparativo entre valores de consumo de aço para seções transversais de treliças que utilizam a solução mista em suas cordas, para um vão de $45 \mathrm{~m}$. Nele, são demonstradas as curvas referentes aos valores encontrados para as três alturas e para os dois tipos de seções transversais.

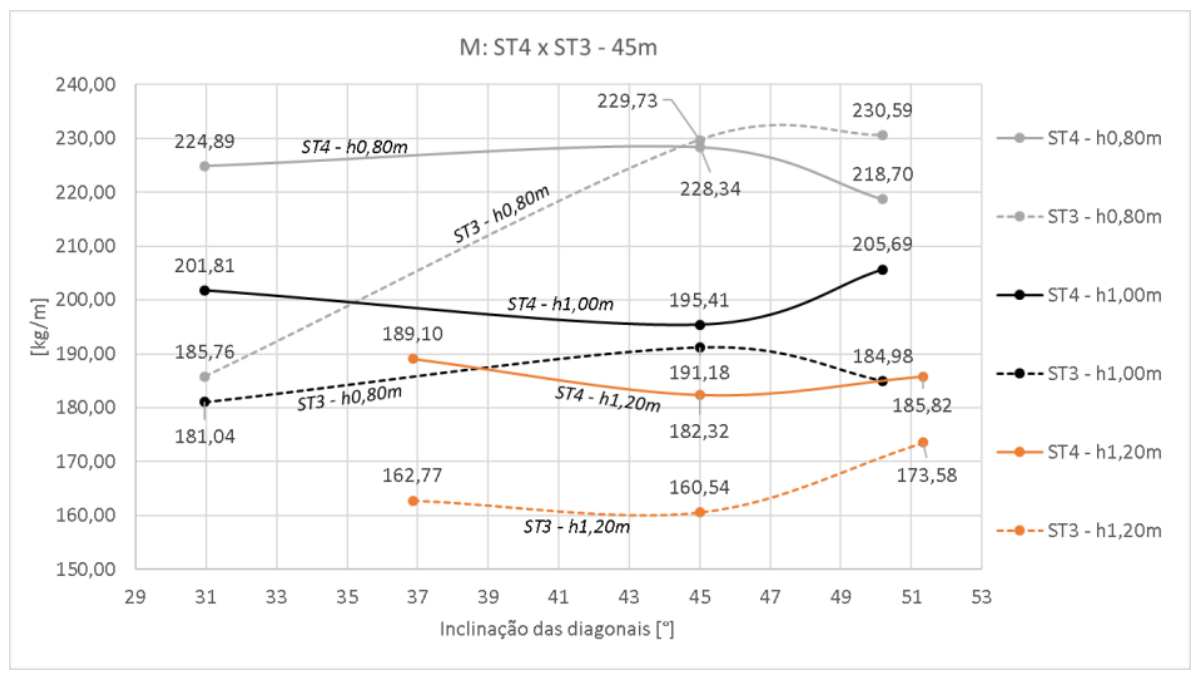

Gráfico 5.12 - Comparativo de seção transversal - Vão: 45m; Perfil misto.

Com a visualização das curvas apresentadas, pode-se levantar duas hipóteses. A primeira hipótese é a de que os valores de consumo de aço das estruturas ST3 são mais baixos em comparação com os valores da seção ST4. Já a segunda hipótese é a de que quanto maior for a altura da estrutura, menor será o consumo de aço utilizada para a mesma.

Dessa forma, será necessário verificar se essas hipóteses estão corretas através de testes t. A primeira hipótese nula será: não há diferença entre valores com seções transversais diferentes; enquanto que a hipótese alternativa será: os valores são influenciados pela modificação do tipo de seção transversal. 
A segunda hipótese nula afirma que os valores de altura não interferem no consumo de aço das treliças; já a hipótese alternativa afirma que o menor consumo de aço é devido à variação do parâmetro "Altura".

Para o primeiro teste, os valores de amostragem utilizados para os três vãos foram agrupados por altura, dessa forma, serão realizados 3 testes por vão. Para o segundo teste, os valores extremos de alturas dos vãos serão utilizados na comparação. Assim, será analisado se essa variação influi estatisticamente no consumo de aço da treliça.

Os valores-p encontrados para o primeiro teste, ou seja, o teste que analisa a influência do tipo de seção transversal, foram resumidos na Tabela 5.21.

\begin{tabular}{|c|c|c|c|c|c|}
\hline \multicolumn{6}{|c|}{ Comparação: ST4 x ST3 } \\
\hline \multicolumn{2}{|c|}{$V=32 m$} & \multicolumn{4}{|c|}{ Média } \\
\hline Altura & Valor-p & $\mathrm{ST} 4[\mathrm{~kg} / \mathrm{m}]$ & $\mathrm{ST} 3[\mathrm{~kg} / \mathrm{m}]$ & ST3/ST4 & Diferença média \\
\hline $\mathrm{H} 0,80 \mathrm{~m}$ & $9,65 \%$ & 205,340 & 195,610 & $95,26 \%$ & \multirow{3}{*}{$10,70 \%$} \\
\hline $\mathrm{H} 1,00 \mathrm{~m}$ & $0,11 \%$ & 181,230 & 158,240 & $87,31 \%$ & \\
\hline $\mathrm{H} 1,20 \mathrm{~m}$ & $0,04 \%$ & 169,140 & 144,310 & $85,32 \%$ & \\
\hline \multicolumn{2}{|c|}{$V=45 m$} & \multicolumn{4}{|c|}{ Média } \\
\hline Altura & Valor-p & $\mathrm{ST} 4[\mathrm{~kg} / \mathrm{m}]$ & $\mathrm{ST} 3[\mathrm{~kg} / \mathrm{m}]$ & ST3/ST4 & Diferença média \\
\hline $\mathrm{H} 1,50 \mathrm{~m}$ & $16,52 \%$ & 241,840 & 232,410 & $96,10 \%$ & \multirow{3}{*}{$6,55 \%$} \\
\hline $\mathrm{H} 1,80 \mathrm{~m}$ & $4,27 \%$ & 217,340 & 204,310 & $94,00 \%$ & \\
\hline $\mathrm{H} 2,25 \mathrm{~m}$ & $0,87 \%$ & 204,260 & 184,340 & $90,25 \%$ & \\
\hline \multicolumn{2}{|c|}{$V=60 m$} & \multicolumn{4}{|c|}{ Média } \\
\hline Altura & Valor-p & $\mathrm{ST} 4[\mathrm{~kg} / \mathrm{m}]$ & $\mathrm{ST} 3[\mathrm{~kg} / \mathrm{m}]$ & ST3/ST4 & Diferença média \\
\hline $\mathrm{H} 1,50 \mathrm{~m}$ & $15,74 \%$ & 359,410 & 384,630 & $107,02 \%$ & \multirow{3}{*}{$3,83 \%$} \\
\hline $\mathrm{H} 2,00 \mathrm{~m}$ & $1,09 \%$ & 319,520 & 284,140 & $88,93 \%$ & \\
\hline $\mathrm{H} 2,50 \mathrm{~m}$ & $4,12 \%$ & 277,920 & 257,290 & $92,58 \%$ & \\
\hline
\end{tabular}

Tabela 5.21 - Resumo dos valores-p encontrados para a seções transversais.

Pode-se perceber que apenas os valores-p das menores alturas dos três vãos resultam em valores superiores a 5\%, enquanto que os outros valores estão abaixo do nível de significância.

Isso significa dizer que a influência do tipo de seção transversal no consumo de aço da estrutura é diretamente proporcional à altura da treliça principal.

Observa-se também que a diferença entre as médias das seções vai diminuindo quando se aumenta o comprimento do vão. Essa diferença foi de 10,70\% para o vão de $32 \mathrm{~m}$, enquanto que o vão de $60 \mathrm{~m}$ apresentou uma diferença de $3,83 \%$. 
Ao se realizar os testes $t$-Student para avaliar o efeito da variação da altura, pode-se montar a Tabela 5.22, que resume os valores-p obtidos. Nesse segundo teste hipotético, foram utilizados os resultados das alturas extremas de cada vão da treliça.

\begin{tabular}{|c|c|c|c|c|c|c|}
\hline \multicolumn{3}{|c|}{ Comparação entre alturas } & \multicolumn{4}{|c|}{ Média } \\
\hline Vão & Altura & Valor-p & Menor altura $[\mathrm{kg} / \mathrm{m}]$ & Maior altura $[\mathrm{kg} / \mathrm{m}]$ & Maior/Menor & Diferença média \\
\hline $32 m$ & $\mathrm{H} 0,80 \mathrm{~m} \times \mathrm{H} 1,20 \mathrm{~m}$ & $0,01 \%$ & 204,07 & 168,48 & $82,56 \%$ & \\
\hline $45 \mathrm{~m}$ & $\mathrm{H} 1,50 \mathrm{~m} \times \mathrm{H} 2,25 \mathrm{~m}$ & $0,01 \%$ & 238,99 & 202,47 & $84,72 \%$ & $17,73 \%$ \\
\hline $60 \mathrm{~m}$ & $\mathrm{H} 1,50 \mathrm{~m} \times \mathrm{H} 2,50 \mathrm{~m}$ & $0,03 \%$ & 355,61 & 282,82 & $79,53 \%$ & \\
\hline
\end{tabular}

Tabela 5.22 - Valores-p da comparação entre alturas.

Observa-se que os valores-p estão abaixo do nível de significância adotado no trabalho. Isso indica que a probabilidade que a variação do parâmetro "Altura da treliça" tenha influência no consumo de aço total da estrutura é assegurada pelo nível de confiança de $95 \%$.

Verifica-se, a partir da diferença média entre os valores da maior altura em comparação com os de menor altura, a vantagem em redução de consumo de material quando se adota alturas maiores para esse tipo de estrutura.

\subsection{3. \\ Análise do efeito das inclinações das diagonais}

Foi estudada a variação da inclinação das diagonais em função dos diferentes tipos de perfis e o Gráfico 5.13 mostra os resultados para a altura de 1,20m, no vão de $32 \mathrm{~m}$. Percebe-se que não há variação acentuada nas curvas de consumo de aço ao se alterar a inclinação das diagonais. Para analisar esse efeito com mais detalhes serão realizados testes $t$-Student.

Para essa verificação, os dados foram agrupados por altura para cada vão, de modo a evitar que o efeito desse parâmetro interfira no resultado. Foram utilizados os dados que foram obtidos com as inclinações extremas, para acentuar o efeito comparativo. A Tabela 5.23 resume os testes $t$-Student realizados.

Mais uma vez a hipótese nula afirma que não haverá modificação devido à variação do parâmetro “inclinação das diagonais", enquanto que a hipótese alternativa implica o contrário.

Como todos os valores-p obtido na tabela foram superiores a 5\%, não se pode rejeitar a hipótese nula, ou seja, não se pode afirmar que a variável estudada foi 
responsável pela variação do consumo de aço, para todas as configurações analisadas.

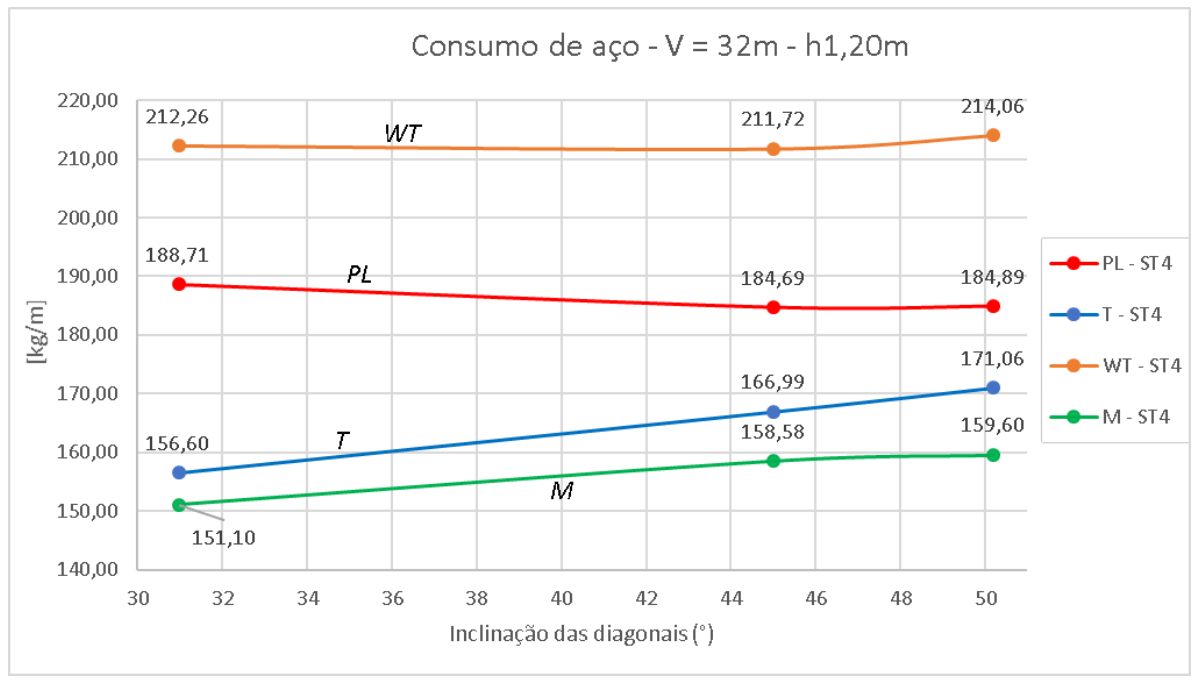

Gráfico 5.13 - Consumo de aço - Seção ST4 - Vão de 32m.

\begin{tabular}{|c|c|c|c|c|c|c|c|c|}
\hline \multicolumn{9}{|c|}{ Comparação: Inclinação das diagonais - Consumo de aço } \\
\hline \multicolumn{3}{|c|}{ V $=32 \mathrm{~m}$} & \multicolumn{3}{|c|}{ V =45m } & \multicolumn{3}{c|}{$\mathrm{V}=60 \mathrm{~m}$} \\
\hline Altura & Ângulos & Valor-p & Altura & Ângulos & Valor-p & Altura & Ângulos & Valor-p \\
\hline $\mathrm{H} 0,80 \mathrm{~m}$ & $38,66^{\circ} \times 57,99^{\circ}$ & $5,51 \%$ & $\mathrm{H} 1,50 \mathrm{~m}$ & $30,96^{\circ} \times 50,19^{\circ}$ & $22,34 \%$ & $\mathrm{H} 1,50 \mathrm{~m}$ & $30,96^{\circ} \times 51,34^{\circ}$ & $15,86 \%$ \\
\hline $\mathrm{H} 1,00 \mathrm{~m}$ & $32,01^{\circ} \times 51,34^{\circ}$ & $9,76 \%$ & $\mathrm{H} 1,80 \mathrm{~m}$ & $30,96^{\circ} \times 50,19^{\circ}$ & $42,66 \%$ & $\mathrm{H} 2,00 \mathrm{~m}$ & $33,69^{\circ} \times 53,13^{\circ}$ & $16,11 \%$ \\
\hline $\mathrm{H} 1,20 \mathrm{~m}$ & $30,96^{\circ} \times 50,19^{\circ}$ & $34,27 \%$ & $\mathrm{H} 2,25 \mathrm{~m}$ & $36,87^{\circ} \times 51,34^{\circ}$ & $45,51 \%$ & $\mathrm{H} 2,50 \mathrm{~m}$ & $30,96^{\circ} \times 50,19^{\circ}$ & $41,30 \%$ \\
\hline
\end{tabular}

Tabela 5.23 - Resumo dos testes $t$-Student analisando as inclinações das diagonais.

\section{6 .}

\section{Comportamento estrutural em serviço}

\subsection{1.}

\section{Deslocamentos verticais}

Nesta seção serão analisados os efeitos da variação do tipo de perfil da corda, do tipo de seção transversal e dos valores de inclinação das diagonais no desenvolvimento das flechas na treliça principal. Não será avaliado o efeito da variação da altura da estrutura nos deslocamentos verticais da estrutura, por ser um conceito já bastante difundido na literatura. 


\subsubsection{1.}

\section{Tipo de perfil das cordas}

O Gráfico 5.14 mostra as flechas máximas para uma treliça de seção ST4, vão de 45 metros e altura de 1,50 metros. Já o Gráfico 5.15 mostra esses resultados para a seção ST3.

As estruturas com perfis mistos são as que desenvolveram as menores flechas, atingindo até valores abaixo do limite estabelecido pela NBR8800 para vigas de cobertura (L/250). Enquanto isso, os valores obtidos pelas treliças com perfis tubulares mostraram os piores resultados.

Pode-se levantar a hipótese de que as treliças com perfis mistos são as que apresentam os menores deslocamentos verticais. Para a realização dos testes $t$-Student, as estruturas com perfis laminados serão utilizadas como referenciais.

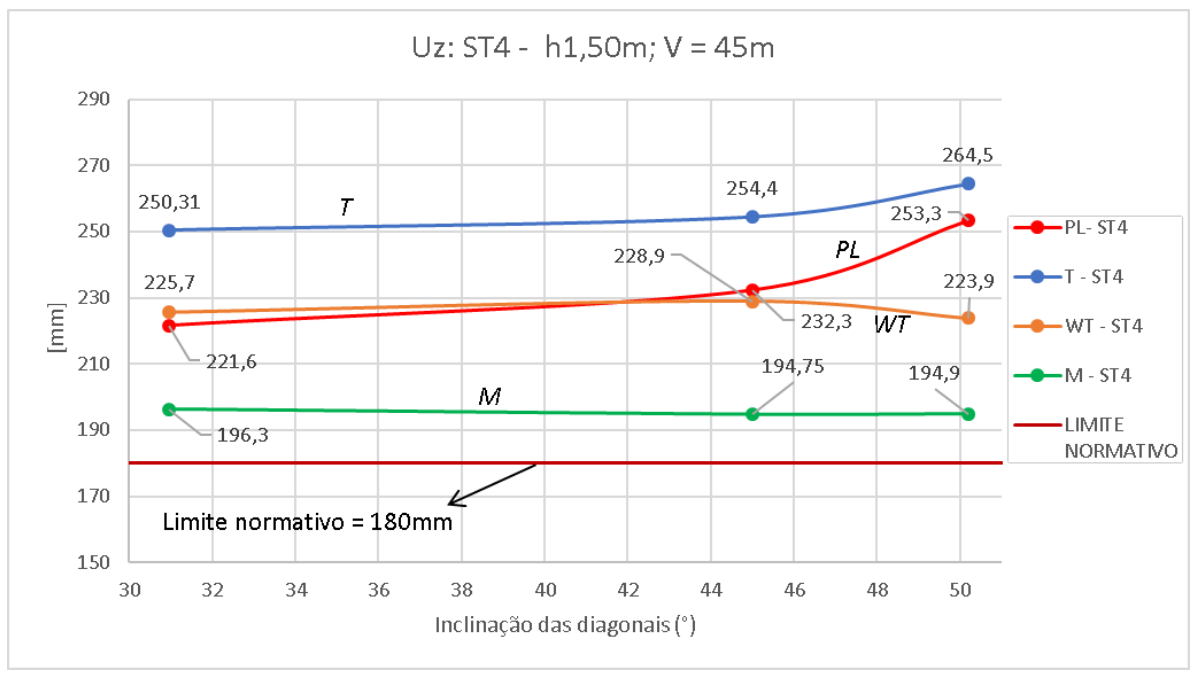

Gráfico 5.14 - Flecha para as treliças com seção ST4, h1,50m e vão de 45m.

Para avaliar o efeito da alteração da variável "tipo de perfil da corda", os resultados serão agrupados de acordo com as alturas de cada vão estudado. A Tabela 5.24 resume os valores-p encontrados nos testes realizados.

Observa-se que a influência do tipo de perfil se deu apenas para as menores alturas de treliças, em ambos os comprimentos de vão. Logo, para treliças de maior altura, há a probabilidade de $95 \%$ de que a alteração do tipo de perfil não irá influenciar nas flechas. 


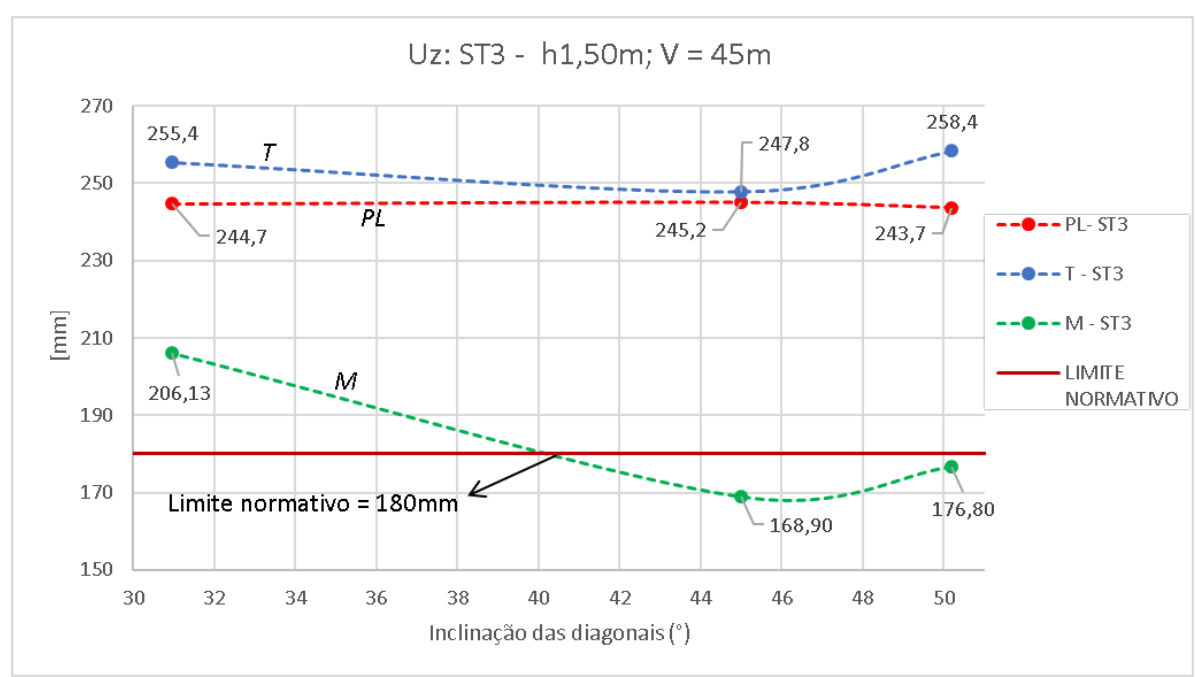

Gráfico 5.15 - Flecha para as treliças com seção ST3, h1,50m e vão de 45m.

\begin{tabular}{|c|c|c|c|c|c|c|c|c|}
\hline \multicolumn{9}{|c|}{ Flechas: Variação de perfil da corda } \\
\hline Vão & Altura & Valor-p & Vão & Altura & Valor-p & Vão & Altura & Valor-p \\
\hline \multirow{3}{*}{$32 \mathrm{~m}$} & $\mathrm{H} 0,80 \mathrm{~m}$ & $0,05 \%$ & \multirow{3}{*}{$45 \mathrm{~m}$} & $\mathrm{H} 1,50 \mathrm{~m}$ & $0,004 \%$ & \multirow{3}{*}{$60 \mathrm{~m}$} & $\mathrm{H} 1,50 \mathrm{~m}$ & $1,31 \%$ \\
\hline & $\mathrm{H} 1,00 \mathrm{~m}$ & $0,39 \%$ & & $\mathrm{H} 1,80 \mathrm{~m}$ & $0,05 \%$ & & $\mathrm{H} 2,00 \mathrm{~m}$ & $0,31 \%$ \\
\hline & $\mathrm{H} 1,20 \mathrm{~m}$ & $61,53 \%$ & & $\mathrm{H} 2,25 \mathrm{~m}$ & $22,64 \%$ & & $\mathrm{H} 2,50 \mathrm{~m}$ & $19,48 \%$ \\
\hline
\end{tabular}

Tabela 5.24 - Resumo dos testes $t$-Student para as flechas - Variação de perfis das cordas.

\subsubsection{2.}

\section{Variação no tipo de seção transversal da treliça}

Nessa seção será analisada se a alteração do tipo de seção transversal da treliça multiplanar influencia na flecha que a estrutura irá desenvolver.

O Gráfico 5.16 mostra as curvas relativas às flechas das estruturas com perfis laminados para o vão de 45m. A partir dele, é possível levantar a hipótese de que a seção ST3 apresenta maiores deslocamentos verticais quando se compara com os valores obtidos com a seção ST4. O limite normativo para este comprimento de vão é de $180 \mathrm{~mm}$, de acordo com a NBR 8800.

Para essa análise, será necessário agrupar os dados de acordo com a altura das treliças, de forma que se possa comparar a seção ST4 com a seção tipo ST3 de forma adequada. 
Após isso, testes $t$-Student foram realizados para analisar a hipótese nula, que será a igualdade de comportamento entre as seções avaliadas. A Tabela 5.25 resume os valores-p encontrados nos testes.

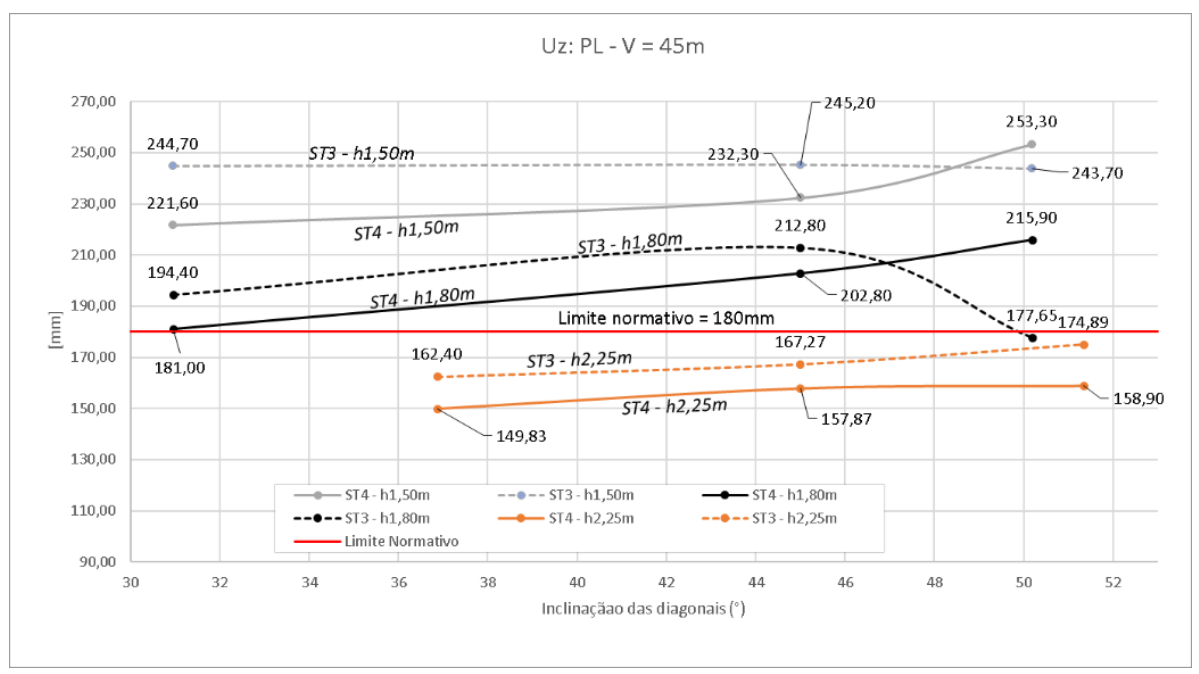

Gráfico 5.16 - Deslocamentos verticais das treliças com perfis laminados para o vão de $45 \mathrm{~m}$.

\begin{tabular}{|c|c|c|c|c|c|c|c|c|}
\hline \multicolumn{9}{|c|}{ Flechas: ST4 x ST3 } \\
\hline Vão & Altura & Valor-p & Vão & Altura & Valor-p & Vão & Altura & Valor-p \\
\hline \multirow{3}{*}{$32 \mathrm{~m}$} & $\mathrm{H} 0,80 \mathrm{~m}$ & $61,16 \%$ & \multirow{3}{*}{$45 \mathrm{~m}$} & $\mathrm{H} 1,50 \mathrm{~m}$ & $91,03 \%$ & \multirow{3}{*}{$60 \mathrm{~m}$} & $\mathrm{H} 1,50 \mathrm{~m}$ & $78,44 \%$ \\
\hline & $\mathrm{H} 1,00 \mathrm{~m}$ & $49,52 \%$ & & $\mathrm{H} 1,80 \mathrm{~m}$ & $64,66 \%$ & & $\mathrm{H} 2,00 \mathrm{~m}$ & $42,00 \%$ \\
\hline & $\mathrm{H} 1,20 \mathrm{~m}$ & $30,32 \%$ & & $\mathrm{H} 2,25 \mathrm{~m}$ & $20,74 \%$ & & $\mathrm{H} 2,50 \mathrm{~m}$ & $18,18 \%$ \\
\hline
\end{tabular}

Tabela 5.25 - Resumo dos testes $t$-Student para comparação entre tipos de seções para deslocamentos verticais.

Observa-se que todos os dados resultam em valores acima de 5\%, significando que a hipótese nula não pode ser rejeitada e que o tipo de seção transversal da estrutura tem a probabilidade de $95 \%$ de não influenciar nas flechas da treliça.

\subsubsection{3.}

\section{Análise das inclinações das diagonais}

O Gráfico 5.17 mostra os valores das flechas para o vão de $60 \mathrm{~m}$. A partir do mesmo, não é possível determinar se a variação do ângulo da diagonal influencia na evolução da flecha. 


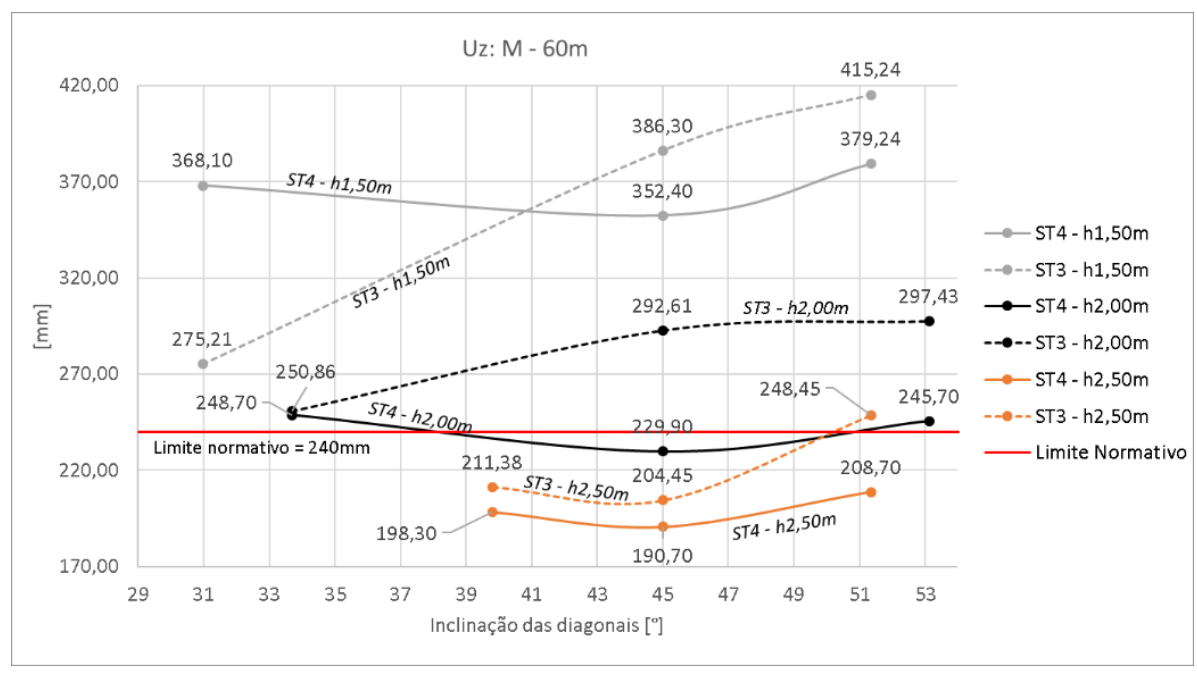

Gráfico 5.17 - Flechas para o vão de 60m para as treliças com perfis mistos.

Para analisar de forma mais precisa, foram agrupados os valores de flecha dos vãos de acordo com a altura. Testes $t$-Student foram novamente realizados para determinar se o parâmetro "Inclinação da diagonal" influencia nos deslocamentos verticais. A hipótese nula é a de que não há influencia na flecha da estrutura com a variação da inclinação das diagonais da treliça. A Tabela 5.26 resume os resultados obtidos com os testes $t$-Student realizados.

\begin{tabular}{|c|c|c|c|c|c|c|c|c|}
\hline \multicolumn{8}{|c|}{ Comparação: Inclinação das diagonais - Flechas } \\
\hline Altura & Ângulos & Valor-p & Altura & Ângulos & Valor-p & Altura & Ângulos & Valor-p \\
\hline $\mathrm{H} 0,80 \mathrm{~m}$ & $38,66^{\circ} \times 57,99^{\circ}$ & $61,72 \%$ & $\mathrm{H} 1,50 \mathrm{~m}$ & $30,96^{\circ} \times 50,19^{\circ}$ & $87,78 \%$ & $\mathrm{H} 1,50 \mathrm{~m}$ & $30,96^{\circ} \times 51,34^{\circ}$ & $57,75 \%$ \\
\hline $\mathrm{H} 1,00 \mathrm{~m}$ & $32,01^{\circ} \times 51,34^{\circ}$ & $58,93 \%$ & $\mathrm{H} 1,80 \mathrm{~m}$ & $30,96^{\circ} \times 50,19^{\circ}$ & $95,64 \%$ & $\mathrm{H} 2,00 \mathrm{~m}$ & $33,69^{\circ} \times 53,13^{\circ}$ & $40,21 \%$ \\
\hline $\mathrm{H} 1,20 \mathrm{~m}$ & $30,96^{\circ} \times 50,19^{\circ}$ & $34,11 \%$ & $\mathrm{H} 2,25 \mathrm{~m}$ & $36,87^{\circ} \times 51,34^{\circ}$ & $21,18 \%$ & $\mathrm{H} 2,50 \mathrm{~m}$ & $30,96^{\circ} \times 50,19^{\circ}$ & $53,48 \%$ \\
\hline
\end{tabular}

Tabela 5.26 - Resumo dos testes $t$-Student - avaliação das inclinações das diagonais na flecha da estrutura.

Como pode ser visto, para todos os grupos de alturas dos vãos, os valores-p estão acima do nível de significância, devendo, então, ter-se a proposta nula aceita. Dessa forma, há $95 \%$ de chance de que a evolução do deslocamento não seja em função da inclinação das diagonais. 


\subsection{2.}

\section{Deslocamentos horizontais da treliça}

O Gráfico 5.18 mostra os valores de deslocamentos laterais da estrutura para o vão de 32m; o Gráfico 5.19, para o de 45m; e, por último, o Gráfico 5.20 para o vão de $60 \mathrm{~m}$.

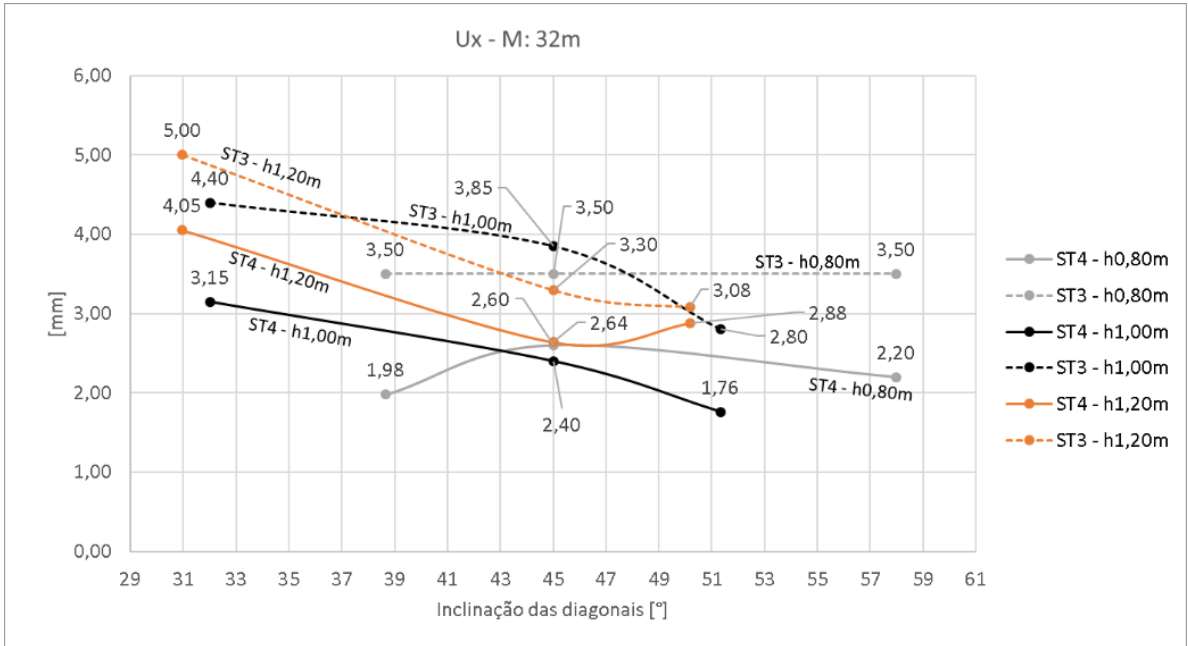

Gráfico 5.18 - Deslocamentos laterais para o vão de 32m para a treliças com perfis mistos.

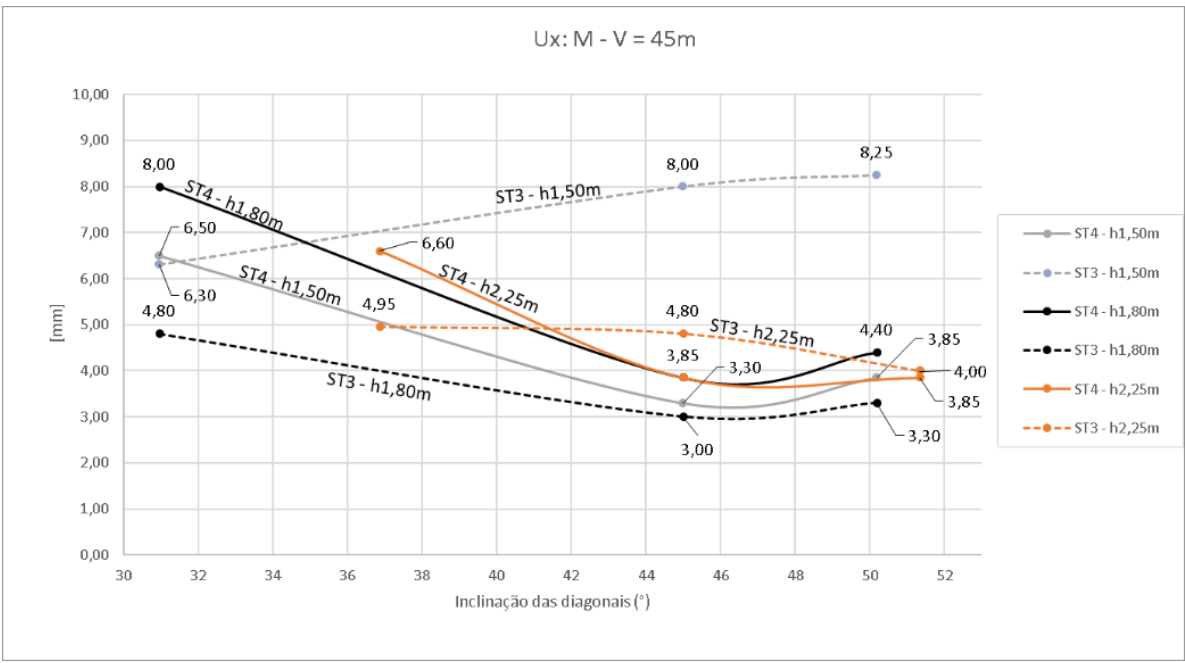

Gráfico 5.19 - Deslocamentos laterais para o vão de 45m para as treliças com perfis mistos. 


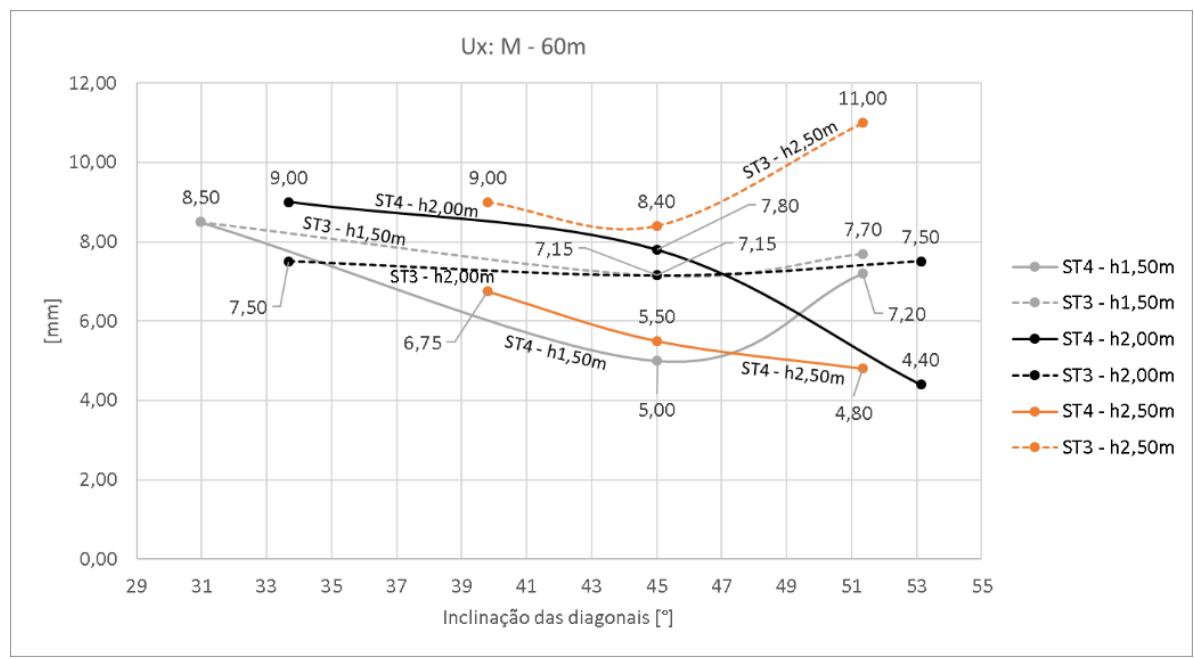

Gráfico 5.20 - Deslocamentos laterais para o vão de 60m para as treliças com perfis mistos.

Observa-se que os valores encontrados para deslocamentos laterais são muito pequenos e próximos, visto que não se pode obter considerações conclusivas da significância da variação da altura das treliças.

Isso fortalece as conclusões encontradas por Vieira (2010) em seu trabalho sobre treliças multiplanares, no qual ele afirma que esse tipo de estrutura tem ótima estabilidade lateral.

Nota-se também que, de forma óbvia, os valores de deslocamentos laterais são diretamente proporcionais com o comprimento dos vãos.

Quando se trata de variação do tipo de perfil, os valores também se encontram muito próximos e de pequenos valores, como pode ser exemplificado no Gráfico 5.21, que apresenta os valores dos deslocamentos laterais para o vão de $45 \mathrm{~m}$ e altura de $1,50 \mathrm{~m}$.

Entretanto, ao se analisar os gráficos acima, pode-se levantar a hipótese de que a variação do tipo de seção transversal pode influenciar nos deslocamentos laterais da estrutura, de forma que a seção tipo ST3 apresenta maiores deslocamentos.

Assim, serão realizados testes de hipóteses para analisar essa possibilidade, cujos resultados estão resumidos na Tabela 5.27, juntamente com os valores das médias dos deslocamentos laterais encontradas para cada tipo de seção.

Observa-se que os valores-p obtidos estão abaixo do nível de significância, o que significa dizer que há 95\% de chance de que a seção tipo ST3 desenvolva maiores deslocamentos laterais, como pode ser visto pelas médias das duas seções presentes na tabela acima. 


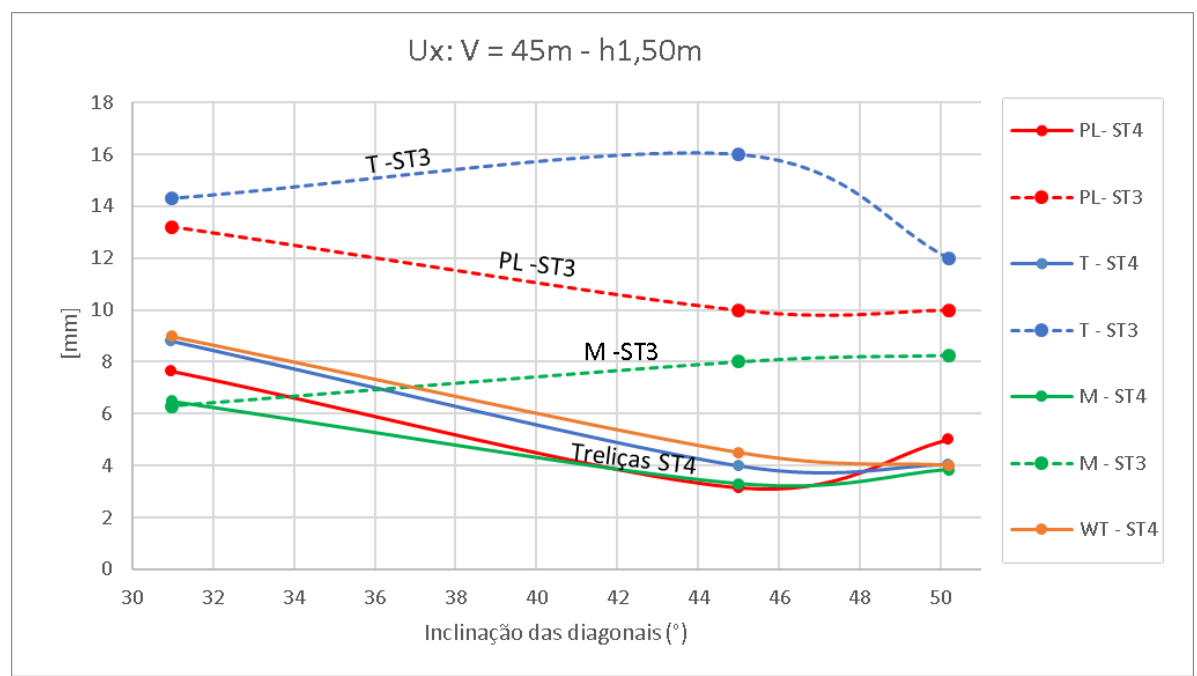

Gráfico 5.21 - Deslocamentos laterais para o vão de 45m, altura de 1,50m.

\begin{tabular}{|c|c|c|c|}
\hline \multicolumn{4}{|c|}{ Ux - ST4 x ST3 } \\
\hline Vão & Valor-p & Média - ST4 & Média - ST3 \\
\hline $32 \mathrm{~m}$ & $1,74 \mathrm{E}-05$ & $3,21 \mathrm{~mm}$ & $4,72 \mathrm{~mm}$ \\
\hline $45 \mathrm{~m}$ & $0,61 \%$ & $5,14 \mathrm{~mm}$ & $7,26 \mathrm{~mm}$ \\
\hline $60 \mathrm{~m}$ & $0,01 \%$ & $6,94 \mathrm{~mm}$ & $10,15 \mathrm{~mm}$ \\
\hline
\end{tabular}

Tabela 5.27 - Resumo dos testes $t$-Student para deslocamentos laterais.

\section{7. \\ Resumo dos melhores resultados encontrados}

A partir dos resultados encontrados nos projetos desenvolvidos, foi possível montar gráficos com os melhores resultados encontrados para os três vãos estudados. O Gráfico 5.22 mostra esses resultados para a seção ST4, enquanto que o Gráfico 5.23 apresenta esses valores para a seção ST3.

As soluções que apresentaram o menor consumo de aço para a estrutura foram aquelas projetadas com perfis mistos, com a seção ST3 e para os maiores valores de altura estudados.

Para o vão de $32 \mathrm{~m}$ o menor valor de consumo foi de $123,76 \mathrm{~kg} / \mathrm{m}$, para a solução com altura de $1,20 \mathrm{~m}$ e comprimento de módulo de $1,00 \mathrm{~m}$, o que gerou uma inclinação de $30,96^{\circ}$ para a diagonal. Enquanto isso, a melhor solução para a seção com quatro cordas foi a que apresentou consumo de $151,10 \mathrm{~kg} / \mathrm{m}$. 


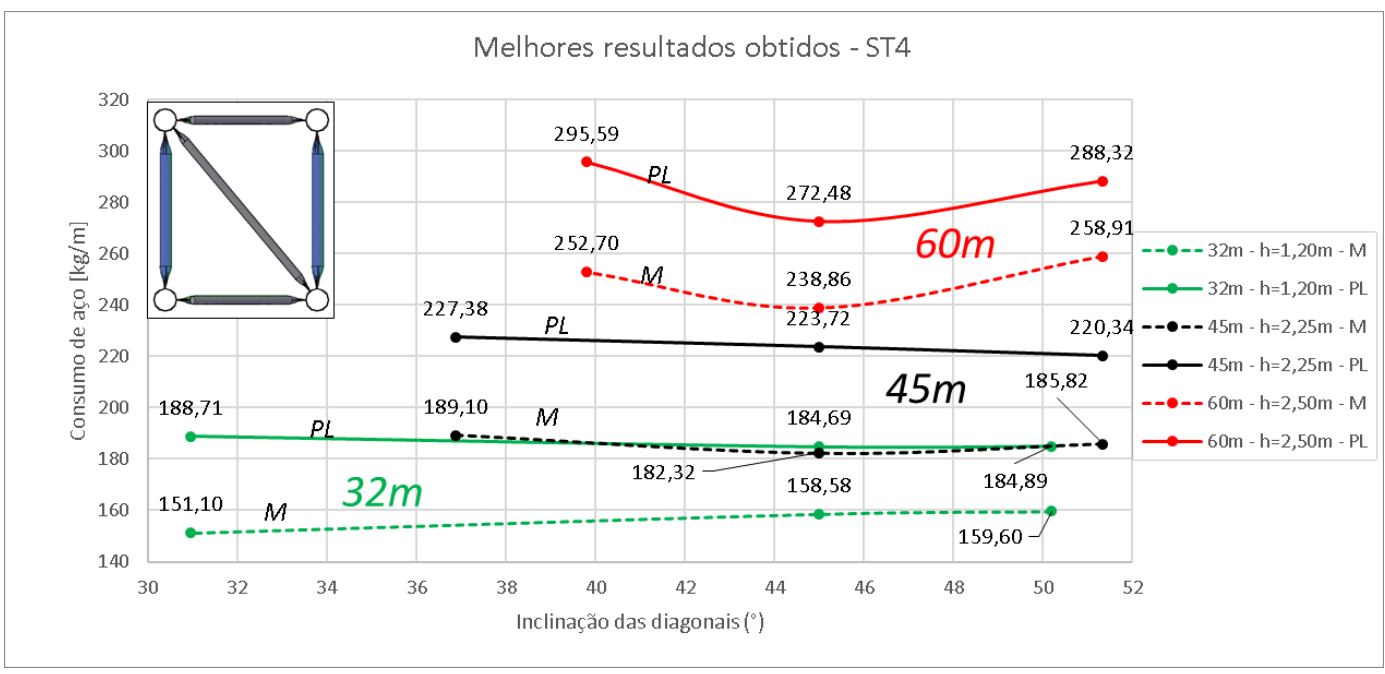

Gráfico 5.22 - Melhores resultados encontrados para a seção ST4

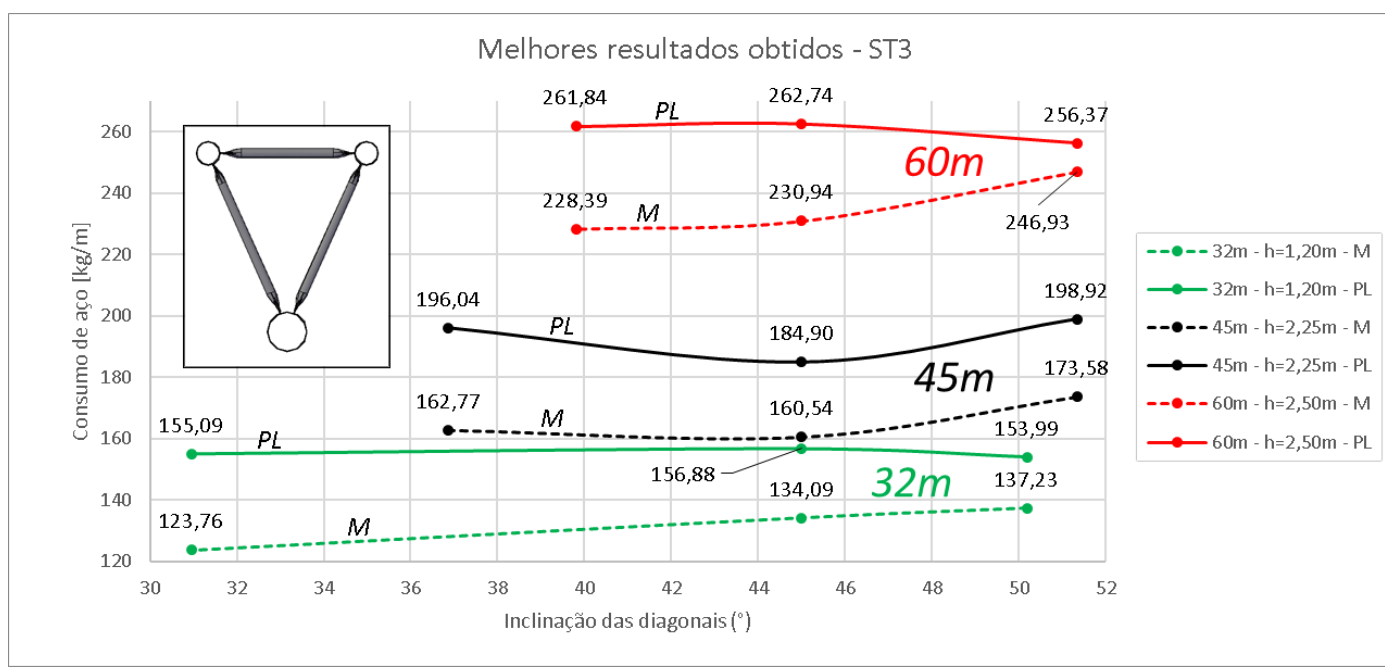

Gráfico 5.23 - Melhores resultados encontrados para a seção ST3.

Para o vão de $45 \mathrm{~m}$, o menor consumo encontrado foi de $160,54 \mathrm{~kg} / \mathrm{m}$ para a seção ST3, enquanto que a seção ST4 apresentou o valor de $184,69 \mathrm{~kg} / \mathrm{m}$. A configuração geométrica do melhor resultado é a de altura e comprimento de módulo de 2,25m, tanto para a seção ST3 como para a ST4.

Já para o vão de 60m, a seção ST3 apresentou o valor de $228,39 \mathrm{~kg} / \mathrm{m}$ como melhor resultado, enquanto que a seção ST4, 238,86kg/m. A geometria da treliça para a melhor solução foi a de altura de 2,50m e comprimento de módulo de 3,00m, o que gera uma inclinação de $39,81^{\circ}$.

Observa-se que a diferença de resultados entre as duas seções varia de acordo com o comprimento do vão, como foi mostrado anteriormente na seção 5.5.2. A 
diferença entre valores para o vão de $32 \mathrm{~m}$ é maior que a diferença entre valores para o vão de $60 \mathrm{~m}$.

\subsection{1.}

\section{Evolução dos resultados com o comprimento do vão}

Para sistemas de cobertura, o consumo de aço é diretamente proporcional ao comprimento de vão escolhido. Isso se deve às maiores solicitações que os componentes estruturais devem resistir, situação que exige elementos mais rígidos.

O Gráfico 5.24 mostra a esse comportamento para as treliças dimensionadas neste trabalho, considerando-se os melhores resultados de cada vão para a seção ST4 com diagonais a $45^{\circ}$. Já o Gráfico 5.25, mostra esse mesmo comportamento para as treliças com seção ST3.

Nota-se que a solução ST3 sempre apresenta o menor consumo de aço para o intervalo de vão estudados.

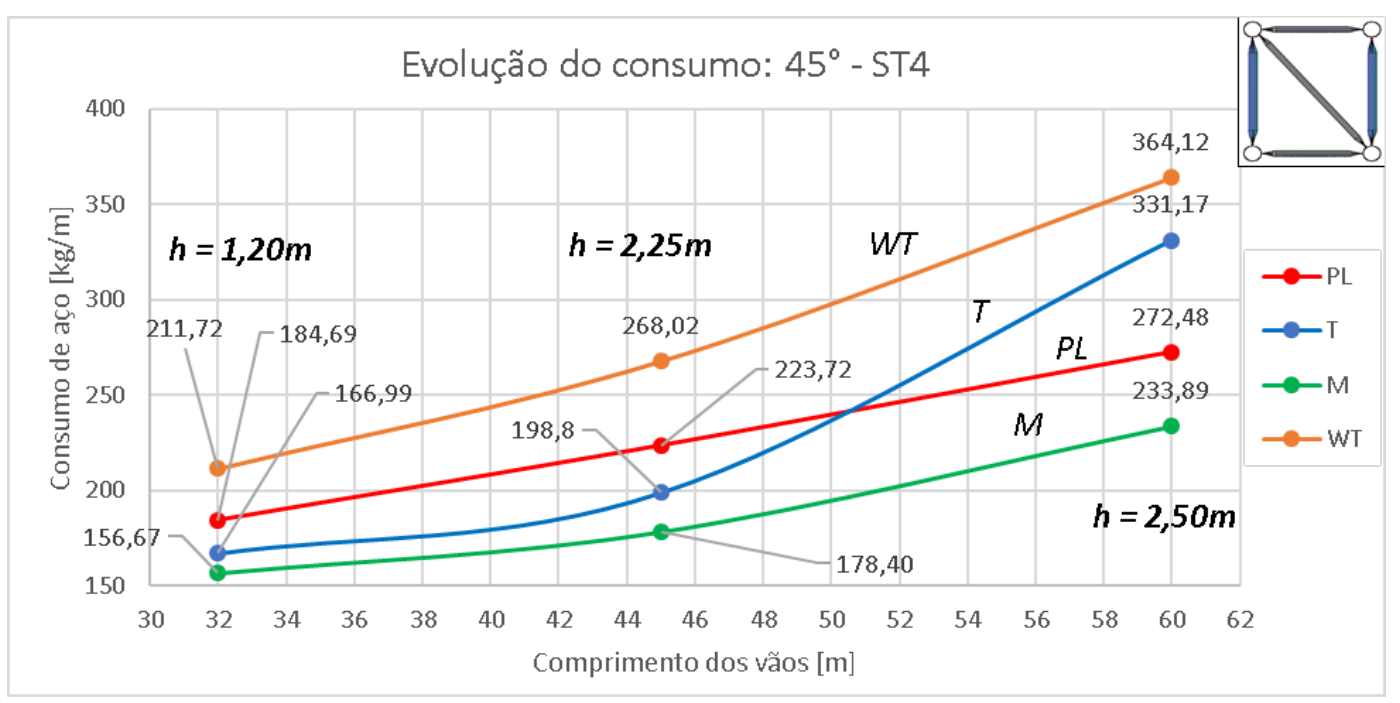

Gráfico 5.24 - Evolução do consumo com o aumento do vão - seção ST4. 


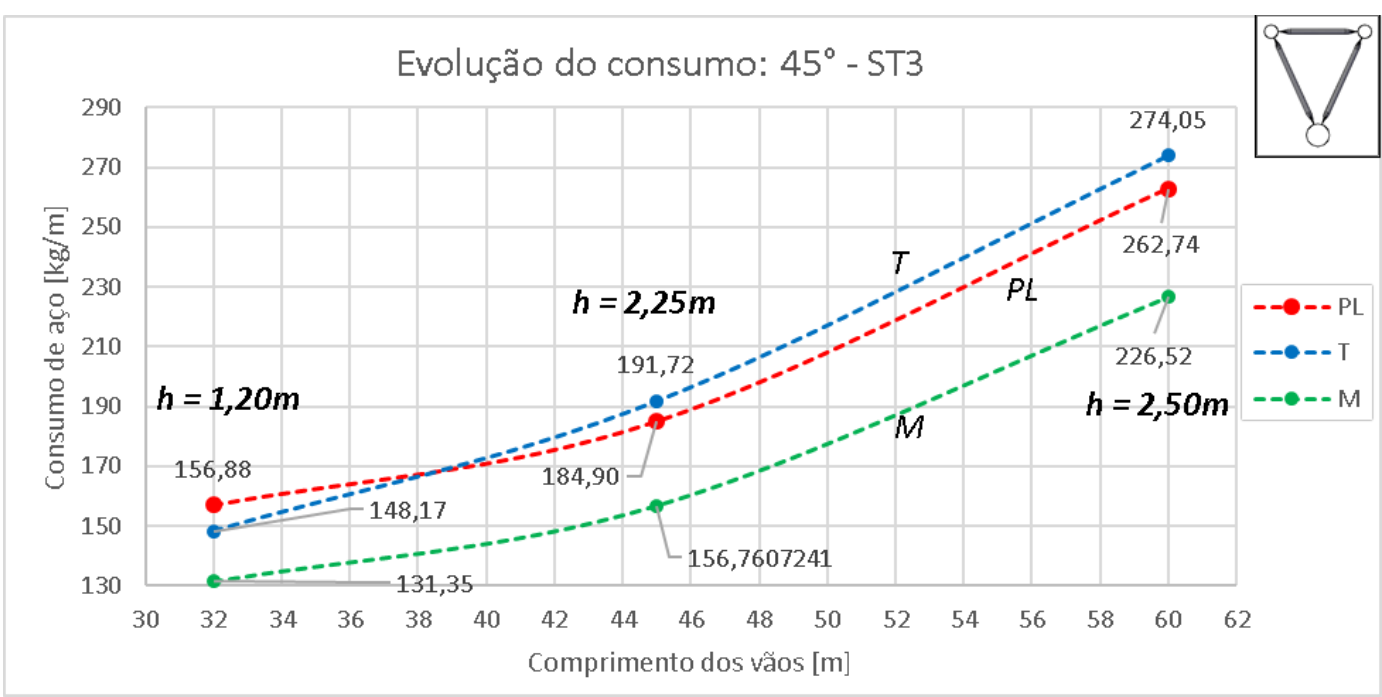

Gráfico 5.25 - Evolução do consumo com o aumento do vão - seção ST3. 


\section{6 Estudo da solução de menor consumo de material da es- trutura}

Neste capítulo serão abordadas as recomendações de projeto para a construção de forma mais viável em termos de consumo de material das treliças multiplanares para a cobertura de edificações industriais de grandes vãos, com base nos resultados obtidos no capítulo anterior. Serão identificadas as variáveis que obtiveram as melhores soluções, e será verificado se o comportamento estrutural das mesmas apresenta desempenho adequado quanto às prescrições normativas.

\section{1.}

Seleção dos perfis das cordas

Como foi mostrado no capítulo anterior, os perfis das cordas têm grande probabilidade de influenciar no consumo de aço da estrutura, sendo fundamental que se escolha um tipo de perfil que seja adequado para as condições de projeto.

Viu-se que o perfil misto apresenta menor consumo de material em comparação com os outros três tipos de perfis utilizados nessa análise comparativa. Isso se deve aos variados benefícios obtidos ao se preencher o interior de um tubo de aço com concreto.

Embora esse tipo de construção possa prejudicar uma das principais vantagens da estrutura metálica que é a rápida e fácil montagem de seus elementos, a solução mista pode ser idealizada com elementos pré-moldados, sendo simplesmente içada e montada in loco.

O fato de se facilitar a ligação entre elementos, ao se utilizar uma chapa nas extremidades do tubo misto, otimiza ainda mais a montagem já que não será realizada nenhum tipo de ligação entre concreto e aço na obra. Ligações desse tipo requerem tempo para serem realizadas, o que encarece a construção.

Outro fator que simplifica esse tipo de solução mista é o fato de que o elemento idealizado não necessita de armaduras longitudinais, facilitando o processo de fabricação dessas estruturas. 
Outro fator que reduziu o consumo de aço foi o fato de que o núcleo de concreto otimiza a resistência à plastificação do tubo de aço, efeito esse que ocorre quando se há forças externas aplicadas nas paredes do tubo, como é o caso das diagonais e montantes da treliça.

Assim, como a resistência à essa plastificação local é ampliada, existe a possibilidade de se utilizar uma menor espessura de aço para o perfil misto quando se comparado com o perfil tubular. Essa verificação foi realizada para todos as treliças estudadas nesse trabalho.

Em se tratando de flechas, foi visto que as treliças com perfis mistos apresentaram 95\% de chance de desenvolver menores deslocamentos verticais quando comparada com outros perfis. Entretanto, isso só foi observado para as duas menores alturas analisadas nesse trabalho em ambos os vãos.

Mesmo que, para os valores de maior altura dos vãos, o parâmetro "perfil da corda" não seja o responsável pela variação das flechas, pode-se recomendar esse tipo de perfil como mais rígido. Obviamente, é necessário que se aplique adequadamente as devidas contraflechas, pois elas combatem os efeitos de grandes cargas permanentes do perfil misto, devido ao elevado peso do núcleo de concreto.

\subsection{1. \\ Relação M/PL: Economia e intervalos de confiança}

Ao se relacionar os valores de consumo de aço obtidos nas estruturas com perfis laminados com as treliças com perfis mistos, pode-se montar a Tabela 6.1.

Percebe-se que todos os valores obtidos são menores que $100 \%$, significando dizer que, em todas as treliças projetadas nesse trabalho, as que utilizaram perfis mistos em suas cordas sempre consumiram menos aço que as estruturas com perfis laminados.

Percebe-se que todos os valores obtidos são menores que $100 \%$, significando dizer que, em todas as treliças projetadas nesse trabalho, as que utilizaram perfis mistos em suas cordas sempre consumiram menos aço que as estruturas com perfis laminados.

Dessa forma, pode-se trabalhar esses dados de forma a estimar a redução de consumo de material obtida ao se utilizar perfis mistos ao invés de laminados. Para 
isso, será utilizado intervalos de confiança, cujos valores serão agrupados por vão. Será utilizado um nível de confiabilidade de $95 \%$.

As Tabelas 6.2, 6.3 e 6.4 mostram os principais resultados estatísticos referentes aos dados obtidos na relação M/PL, e gráficos, com os valores da média e o intervalo de confiança obtidos, para os vãos de $32 \mathrm{~m}, 45 \mathrm{~m}$ e $60 \mathrm{~m}$, respectivamente. Já os Gráficos 6.1, 6.2 e 6.3 mostram a construção dos intervalos de confiança para essa mesma relação e para os mesmos vãos.

\begin{tabular}{|c|c|c|c|c|c|c|c|}
\hline \multicolumn{8}{|c|}{ Relação M/PL } \\
\hline \multicolumn{2}{|c|}{ Geometria } & \multicolumn{6}{|c|}{ Ângulos } \\
\hline \multirow{9}{*}{$32 m$} & \multirow{3}{*}{$\mathrm{HO}, 80 \mathrm{~m}$} & \multicolumn{3}{|c|}{ ST4 - $\alpha\left[^{\circ}\right]$} & \multicolumn{3}{|c|}{ ST3 - $\alpha\left[^{\circ}\right]$} \\
\hline & & 38,66 & 45,00 & 57,99 & 38,66 & 45,00 & 57,99 \\
\hline & & $87,93 \%$ & $87,91 \%$ & $89,17 \%$ & $93,61 \%$ & $93,77 \%$ & $94,29 \%$ \\
\hline & \multirow{3}{*}{$\mathrm{H} 1,00 \mathrm{~m}$} & \multicolumn{3}{|c|}{ ST4 - $\alpha\left[^{\circ}\right]$} & \multicolumn{3}{|c|}{ ST3 $-\alpha\left[^{\circ}\right]$} \\
\hline & & 32,01 & 45,00 & 51,34 & 32,01 & 45,00 & 51,34 \\
\hline & & $84,63 \%$ & $87,98 \%$ & $88,75 \%$ & $85,34 \%$ & $89,42 \%$ & $88,71 \%$ \\
\hline & \multirow{3}{*}{$\mathrm{H} 1,20 \mathrm{~m}$} & \multicolumn{3}{|c|}{ ST4 - $\alpha\left[^{\circ}\right]$} & \multicolumn{3}{|c|}{ ST3 - $\alpha\left[^{\circ}\right]$} \\
\hline & & 30,96 & 45,00 & 50,19 & 30,96 & 45,00 & 50,19 \\
\hline & & $80,07 \%$ & $85,87 \%$ & $86,32 \%$ & $79,80 \%$ & $85,47 \%$ & $89,12 \%$ \\
\hline \multirow{9}{*}{$45 m$} & \multirow{3}{*}{$\mathrm{H} 1,50 \mathrm{~m}$} & \multicolumn{3}{|c|}{ ST4 - $\alpha\left[^{\circ}\right]$} & \multicolumn{3}{|c|}{ ST3 $-\alpha\left[^{\circ}\right]$} \\
\hline & & 30,96 & 45,00 & 50,19 & 30,96 & 45,00 & 50,19 \\
\hline & & $85,56 \%$ & $89,79 \%$ & $90,70 \%$ & $84,83 \%$ & $96,13 \%$ & $93,58 \%$ \\
\hline & \multirow{3}{*}{$\mathrm{H} 1,80 \mathrm{~m}$} & \multicolumn{3}{|c|}{ ST4 - $\alpha\left[^{\circ}\right]$} & \multicolumn{3}{|c|}{ ST3 - $\alpha\left[^{\circ}\right]$} \\
\hline & & 30,96 & 45,00 & 50,19 & 30,96 & 45,00 & 50,19 \\
\hline & & $82,65 \%$ & $87,36 \%$ & $89,61 \%$ & $82,49 \%$ & $89,02 \%$ & $89,85 \%$ \\
\hline & \multirow{3}{*}{$H 2,25 m$} & \multicolumn{3}{|c|}{ ST4 - $\alpha\left[^{\circ}\right]$} & \multicolumn{3}{|c|}{ ST3 - $\alpha\left[^{\circ}\right]$} \\
\hline & & 36,87 & 45,00 & 51,34 & 36,87 & 45,00 & 51,34 \\
\hline & & $83,17 \%$ & $81,50 \%$ & $84,33 \%$ & $83,03 \%$ & $86,83 \%$ & $87,26 \%$ \\
\hline \multirow{9}{*}{$60 m$} & \multirow{3}{*}{$\mathrm{H} 1,50 \mathrm{~m}$} & \multicolumn{3}{|c|}{ ST4 - $\alpha\left[^{\circ}\right]$} & \multicolumn{3}{|c|}{ ST3 $-\alpha\left[^{\circ}\right]$} \\
\hline & & 30,96 & 45,00 & 51,34 & 30,96 & 45,00 & 51,34 \\
\hline & & $90,22 \%$ & $92,96 \%$ & $80,65 \%$ & $82,07 \%$ & $73,27 \%$ & $78,25 \%$ \\
\hline & \multirow{3}{*}{$\mathrm{H} 2,00 \mathrm{~m}$} & \multicolumn{3}{|c|}{ ST4 - $\alpha\left[^{\circ}\right]$} & \multicolumn{3}{|c|}{ ST3 - $\alpha\left[^{\circ}\right]$} \\
\hline & & 33,69 & 45,00 & 53,13 & 33,69 & 45,00 & 53,13 \\
\hline & & $86,90 \%$ & $89,31 \%$ & $92,10 \%$ & $86,76 \%$ & $86,83 \%$ & $88,34 \%$ \\
\hline & \multirow{3}{*}{$\mathrm{H} 2,50 \mathrm{~m}$} & & $\mathrm{T4}-\alpha\left[^{\circ}\right]$ & & & $\mathrm{TT} 3-\alpha\left[^{\circ}\right]$ & \\
\hline & & 39,81 & 45,00 & 51,34 & 39,81 & 45,00 & 51,34 \\
\hline & & $85,49 \%$ & $87,66 \%$ & $89,80 \%$ & $87,23 \%$ & $87,90 \%$ & $96,32 \%$ \\
\hline
\end{tabular}

Tabela 6.1 - Relação M/PL dos três vãos estudados. 


\begin{tabular}{lr}
\hline \multicolumn{2}{c}{ Relação M/PL - 32m } \\
\hline Média & $87,68 \%$ \\
Mediana & $87,95 \%$ \\
Desvio padrão & $3,99 \%$ \\
Variância da amostra & $0,0016 \%{ }^{2}$ \\
Coeficiente de Variação (CV) & $4,55 \%$ \\
Amplitude & $14,49 \%$ \\
Mínimo & $79,80 \%$ \\
Máximo & $94,29 \%$ \\
Contagem & 18 \\
Nível de confiança (95,0\%) & $\pm 1,98 \%$ \\
Intervalo de confiança & $85,70 \%$ a 89,66\% \\
\hline
\end{tabular}

Tabela 6.2 - Resultados estatísticos da relação M/PL para treliças com vão de $32 \mathrm{~m}$.

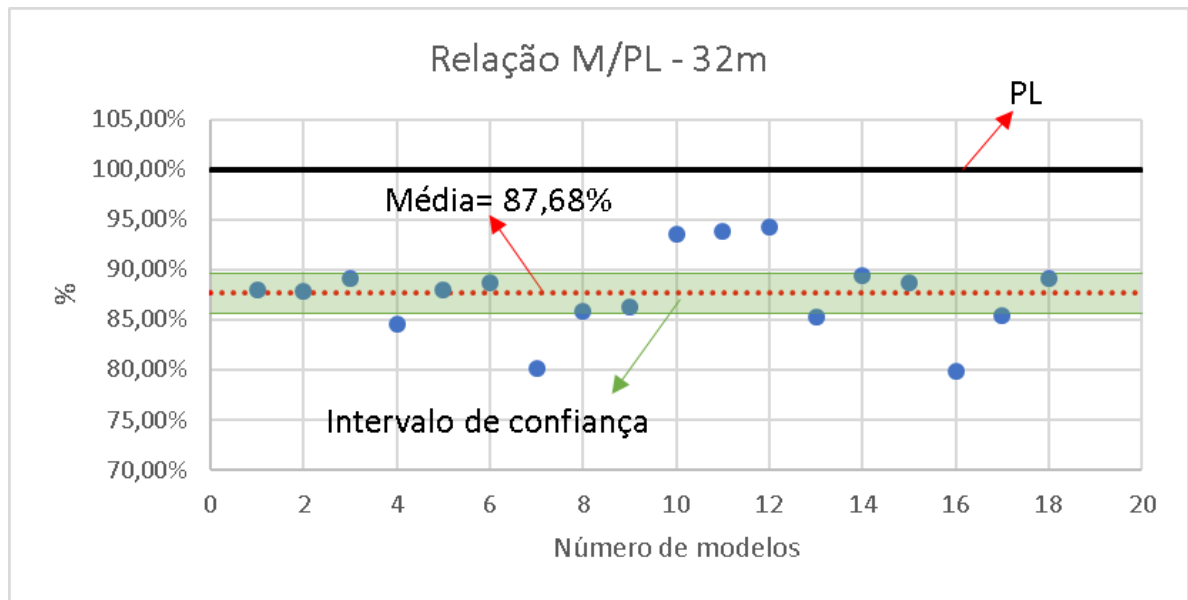

Gráfico 6.1 - Intervalo de confiança - Relação M/PL - Vão de 32m.

Observa-se que a média da diferença de consumo de material ao se utilizar treliças com perfis mistos gira em torno de $12 \%$ em todos os vãos estudados. Esse valor é bastante considerável quando se trata de estruturas de grande porte, como centros de distribuições e indústrias.

Como já foi visto, o intervalo de confiança é o intervalo no qual se encontra a média da população. Como os resultados dos IC's obtidos na relação M/PL desse trabalho estão aproximadamente entre $84 \%$ e $89 \%$, o que significa que as treliças com perfis mistos consomem menos aço que as com perfis laminados. 


\begin{tabular}{lr}
\hline \multicolumn{2}{c}{ Relação - M/PL - 45m } \\
\hline \\
Média & $87,09 \%$ \\
Mediana & $87,04 \%$ \\
Desvio padrão & $4,07 \%$ \\
Variância da amostra & $0,0017 \%^{2}$ \\
Coeficiente de Variação (CV) & $4,67 \%$ \\
Intervalo & $14,64 \%$ \\
Mínimo & $81,50 \%$ \\
Máximo & $96,13 \%$ \\
Contagem & 18 \\
Nível de confiança(95,0\%) & $\pm 2,02 \%$ \\
Intervalo de confiança & $85,07 \%$ a $89,11 \%$ \\
\hline
\end{tabular}

Tabela 6.3 - Resultados estatísticos da relação M/PL para treliças com vão de $45 \mathrm{~m}$.

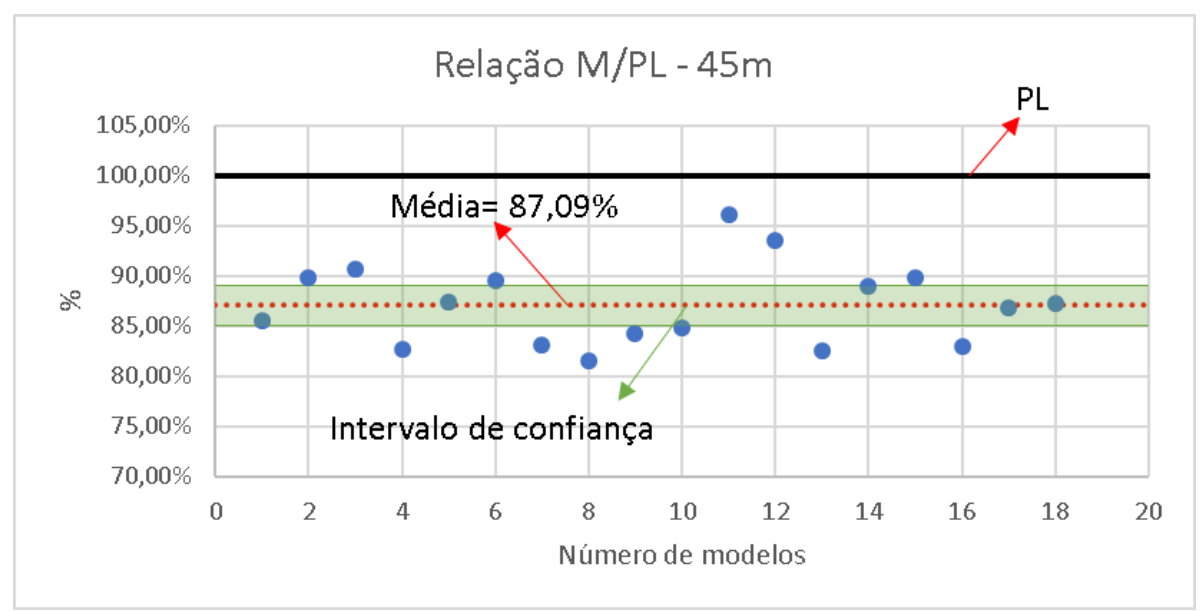

Gráfico 6.2 - Intervalo de confiança - Relação M/PL - Vão de 45m.

Dessa forma, se forem realizados novos estudos comparativos de consumo de aço para treliças com cordas mistas e laminadas, a média dos novos resultados estará dentro dos intervalos de confiança encontrados nesse trabalho, ou seja, apontará que o perfil misto é o que fornece a solução com menor consumo de aço.

A ideia acima é fortalecida ao se analisar os valores dos coeficientes de variação obtidos na amostra. Vê-se que para os três vãos adotados, esse coeficiente está com valores inferiores a $10 \%$, o que é considerado como uma dispersão baixa de valores. 


\section{Relação - M/PL - 60m}

Média

$86,78 \%$

Mediana

$87,44 \%$

Desvio padrão

$5,46 \%$

Variância da amostra

$0,0030 \%^{2}$

Coeficiente de Variação ( $\mathrm{Cl}$

$6,29 \%$

Amplitude

$23,05 \%$

Mínimo

$73,27 \%$

Máximo

$96,32 \%$

Contagem

Nível de confiança(95,0\%)

Intervalo de confiança

$84,07 \%$ a $89,49 \%$

Tabela 6.4 - Resultados estatísticos da relação M/PL para treliças com vão de $60 \mathrm{~m}$.

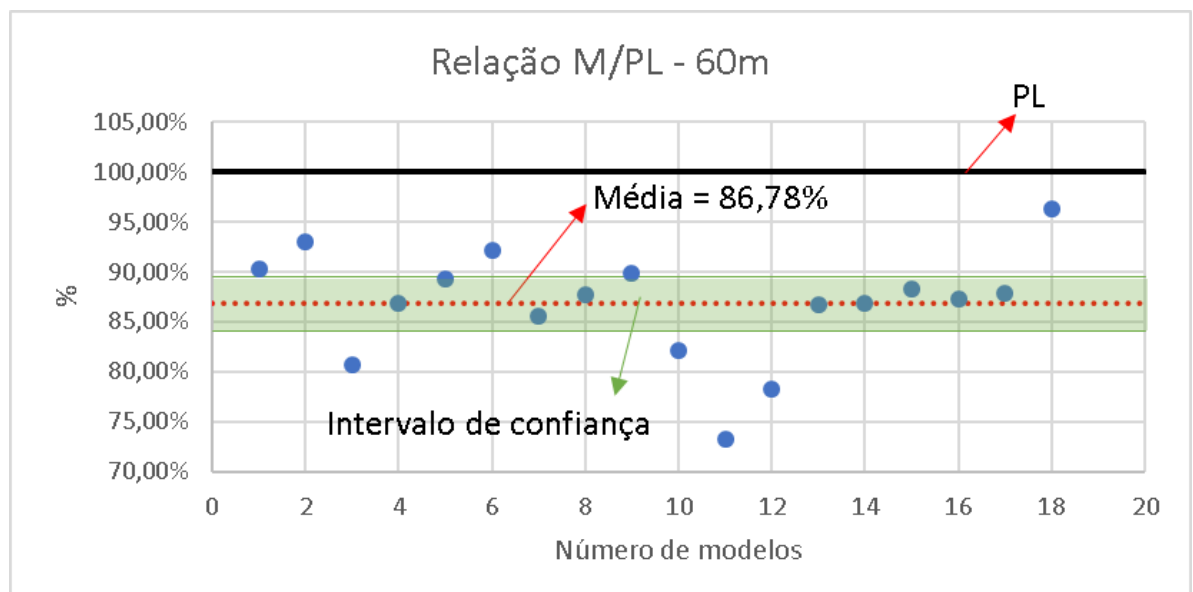

Gráfico 6.3 - Intervalo de confiança - Relação M/PL - Vão de 60m.

É bastante significativa a utilização de perfis mistos nas treliças multiplanares quando se objetiva obter a melhor solução. Observando as relações feitas entre os tipos de perfis, observou-se que essa diferença de consumo de aço apresentou uma baixa dispersão de valores, ou seja, há uma grande probabilidade de se obter uma solução de menor consumo de aço, que é uma característica muito interessante para estruturas de grandes vãos, já que normalmente se trata de construções bastante onerosas. 


\subsection{2. Mapeamento das regiões mistas dentro da treliça}

Ao se dimensionar as treliças com perfis mistos, observou-se que as estruturas apresentavam uma configuração padrão de regiões onde era necessário utilizar ora perfis mistos, ora perfis tubulares.

Isso é importante para se ter ideia de quais regiões da treliça necessitam da utilização de perfis mistos e quais regiões necessitam somente da utilização de perfis tubulares.

Os perfis mistos foram utilizados por duas razões: devido às grandes solicitações axiais de compressão e devido às grandes forças externas aplicadas pelas diagonais e montantes nas paredes dos tubos de aço.

Para as regiões com grandes solicitações axiais foram utilizados perfis mistos nas cordas superiores nos centros dos vãos da extremidade; enquanto que nas cordas inferiores foram utilizados nas regiões dos apoios centrais.

Quando se necessitou evitar que o tubo metálico sofresse plastificação da parede, foram utilizados tubos mistos nas regiões próximos aos apoios, tanto nos centrais como os das extremidades.

Para o mapeamento dos tipos de perfis, a estrutura será dividida em nove regiões, tanto para as cordas superiores como para as inferiores, já que apenas o comprimento de cada região é que irá variar. As seções ST4 e ST3 obtiveram as mesmas variações de perfis, ou seja, o mapeamento independe do tipo de seção transversal.

A Figura 6.1 ilustra a divisão da treliça em função do tipo de perfil a ser utilizado nas cordas, de acordo com o dimensionamento realizado nas treliças com perfis mistos desenvolvidas nesse trabalho.

A Tabela 6.5 resume os valores médios dos comprimentos dessas regiões para cada vão, obtidos com a análise de cada treliça. Os valores são apresentados tanto para as cordas superiores como para as inferiores, e estão expressos em porcentagem do comprimento do respectivo vão. Ao final foi calculado o valor médio de cada região para os três vãos estudados.

Observa-se que as regiões A e I, ou seja, nos balanços da estrutura, não se necessitou preencher o interior dos perfis com concreto devido às baixas solicitações axiais de compressão e das pequenas forças externas aplicadas diretamente à parede do tubo. 
CORDA SUPERIOR

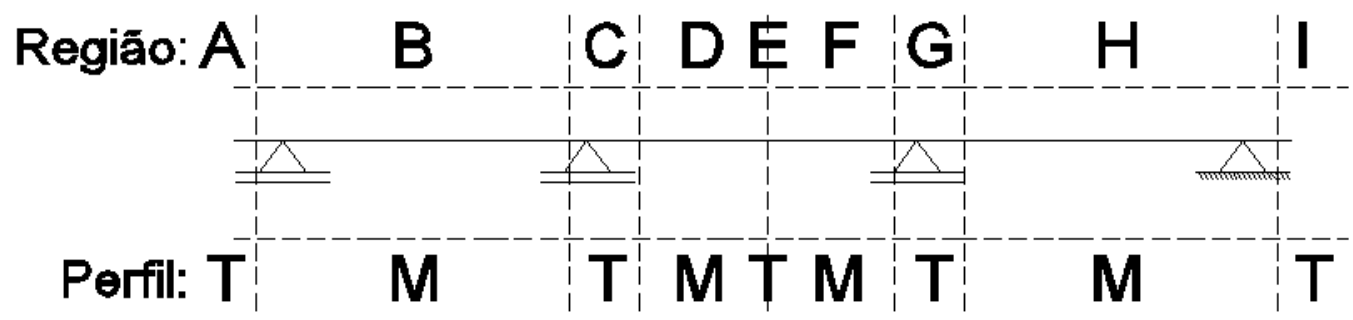

\section{CORDA INFERIOR}

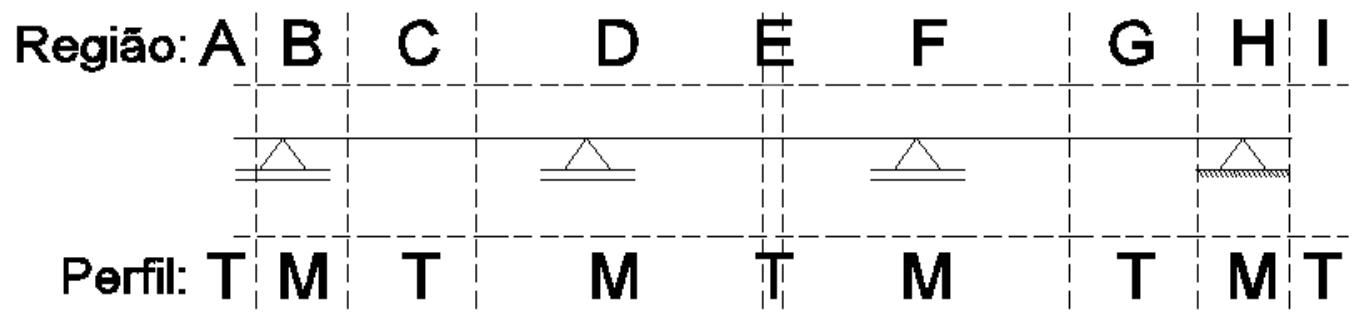

Figura 6.1 - Mapeamento das regiões com perfis mistos e tubulares.

Ao se somar os valores médios das regiões mistas da treliça, obtém-se que: cerca de $84,45 \%$ das cordas superiores são compostas por perfis mistos, já para as cordas inferiores, esse valor cai para $71,83 \%$. Essa diferença de valores é coerente, já que as os maiores esforços de compressão na treliça estão localizados nas cordas superiores.

\begin{tabular}{|c|c|c|c|c|c|c|c|c|c|}
\hline \multicolumn{10}{|c|}{ CORDAS SUPERIORES } \\
\hline Região & A & B & C & D & E & F & G & H & I \\
\hline Perfil & TUB & M & TUB & M & TUB & M & TUB & M & TUB \\
\hline $\mathbf{3 2 m}$ & $1,82 \%$ & $28,22 \%$ & $10,90 \%$ & $8,99 \%$ & $0,00 \%$ & $8,99 \%$ & $10,90 \%$ & $27,71 \%$ & $2,45 \%$ \\
\hline $\mathbf{4 5 m}$ & $1,54 \%$ & $30,87 \%$ & $4,24 \%$ & $13,08 \%$ & $0,00 \%$ & $14,52 \%$ & $4,65 \%$ & $29,37 \%$ & $1,74 \%$ \\
\hline $\mathbf{6 0 m}$ & $1,20 \%$ & $30,35 \%$ & $4,68 \%$ & $15,26 \%$ & $0,00 \%$ & $15,26 \%$ & $4,68 \%$ & $30,70 \%$ & $1,02 \%$ \\
\hline Média & $1,52 \%$ & $29,81 \%$ & $6,61 \%$ & $12,45 \%$ & $0,00 \%$ & $12,92 \%$ & $6,74 \%$ & $29,26 \%$ & $1,74 \%$ \\
\hline \multicolumn{8}{|c|}{ CORDAS INFERIORES } \\
\hline Região & A & B & $\mathbf{C}$ & $\mathbf{D}$ & $\mathbf{E}$ & $\mathbf{F}$ & $\mathbf{G}$ & $\mathbf{H}$ & $\mathbf{I}$ \\
\hline Perfil & TUB & $\mathbf{M}$ & TUB & $\mathbf{M}$ & TUB & $\mathbf{M}$ & TUB & M & TUB \\
\hline $\mathbf{3 2 m}$ & $1,82 \%$ & $9,01 \%$ & $12,62 \%$ & $25,66 \%$ & $1,76 \%$ & $26,16 \%$ & $11,36 \%$ & $9,14 \%$ & $2,45 \%$ \\
\hline $\mathbf{4 5 m}$ & $1,54 \%$ & $9,57 \%$ & $9,97 \%$ & $27,58 \%$ & $2,18 \%$ & $27,58 \%$ & $10,38 \%$ & $9,08 \%$ & $2,12 \%$ \\
\hline $\mathbf{6 0 m}$ & $1,20 \%$ & $7,72 \%$ & $13,86 \%$ & $27,95 \%$ & $3,39 \%$ & $27,95 \%$ & $11,75 \%$ & $8,07 \%$ & $1,02 \%$ \\
\hline Média & $1,52 \%$ & $8,77 \%$ & $12,15 \%$ & $27,06 \%$ & $2,45 \%$ & $27,23 \%$ & $11,17 \%$ & $8,76 \%$ & $1,86 \%$ \\
\hline
\end{tabular}

Tabela 6.5 - Comprimento médio das regiões de cada tipo de perfil, para as treliças mistas. 


\section{2.}

\section{Variação na geometria da seção transversal da treliça}

Como foi visto no capítulo anterior, a variação do tipo de seção transversal (ST4 ou ST3) tem grande probabilidade de influenciar no consumo de aço, tendo a seção ST3 como a de menor consumo de material. Entretanto, essa economia encontrada devido à alteração do parâmetro "tipo de seção transversal”" surgiu apenas para os dois maiores vãos estudados.

Para as treliças que utilizam perfis laminados, para vãos menores que $45 \mathrm{~m}$ é recomendado que se utilize a seção ST4. Pois, além de não garantir que esse tipo de seção possa trazer um menor consumo de aço, a seção ST3 exige ligações de execução mais complexas.

Em se tratando das flechas, não se pôde afirmar, com 5\% de chance de errar, que o tipo de seção transversal influencia no desenvolvimento das flechas totais da estrutura, já que ambos os testes apresentaram valores-p superiores ao nível de significância.

O mesmo não pode ser dito para os deslocamentos laterais. Os testes realizados no capítulo anterior mostram que há uma grande probabilidade de que essa troca de seção influencie nesses deslocamentos, tendo a seção ST4 como mais rígida. Entretanto, é importante dizer que a diferença de deslocamentos entre os tipos de seções é irrisória, visto o comprimento dos vãos.

Quando se trata da altura total da treliça, é importante frisar que quanto menor for a altura da mesma, maiores deslocamentos fora do plano ela apresentará, o que gera maiores esforços de segunda ordem. Isso foi visto quando se analisou os coeficientes de flambagem discutidos no capítulo 5.

Além disso, é imprescindível também que a altura da treliça esteja de acordo com os limites do projeto de arquitetura, considerando todas as especificações técnicas que a estrutura necessitará, tanto para sua construção como para sua utilização.

O teste de hipóteses realizado para determinar se o consumo de aço era influenciado pelo parâmetro "Altura da treliça", mostrou que há grande probabilidade de que encontre economia nessa variação, sendo positivo para treliças de maiores alturas. 
Ou seja, dentro dos valores estabelecidos pela arquitetura, a treliça que apresenta a melhor solução é a que apresenta a maior altura. Nos cálculos determinísticos realizados nesse trabalho, há a possibilidade de $95 \%$ de que a solução com uma treliça mais alta consuma menos aço que as de menores alturas.

Mesmo que o valor em peso das estruturas secundárias da treliça aumente quando se aumenta a altura da estrutura, o peso total da estrutura tende a diminuir. Isso se dá porque, é necessário utilizar perfis mais robustos, para combater os efeitos de segunda ordem, que são maiores em estruturas de menor altura. Dessa forma, as taxas de utilização da estrutura tendem a ser menores, pois as regiões menos solicitadas ficarão superdimensionadas, o que encarece a construção.

Não só se reduz o consumo de material como também há a redução das flechas quando se opta por utilizar uma estrutura de maior altura. Isso é essencial para que as construções possam estar dentro dos limites normativos, condição que não foi respeitada em várias treliças propostas, principalmente as de menores alturas.

A recomendação a ser feita para a altura das treliças, em razão do comprimento do vão, é que esteja dentro do intervalo de L/20 e L/30. Esses valores foram obtidos após uma análise dos deslocamentos da estrutura, buscando evitar que as treliças apresentem flechas superiores às estabelecidas por norma.

Uma dificuldade a ser ressaltada ao se utilizar treliças de grandes alturas é que, caso elas não sejam montadas na obra, o transporte dessas estruturas pode ser dificultado ou até mesmo inviabilizado.

\section{3.}

\section{Análise das inclinações das diagonais das treliças}

Os testes $t$-Student realizados no capítulo anterior para avaliar a hipótese de que a variação do parâmetro "Inclinação das diagonais" influenciava no consumo de aço apresentou, para todos os valores de alturas e para vãos, que há a probabilidade de $95 \%$ de não provocar qualquer alteração.

Entretanto, quando se utiliza maiores comprimentos destravados, as diagonais apresentarão maiores solicitações axiais. Essas solicitações irão exercer maiores forças externas nas cordas, necessitando de perfis mais robustos para evitar o surgimento de falhas locais por plastificação da parede do tubo metálico. 
Ao se optar por menores comprimentos destravados, a quantidade de barras para as estruturas secundárias também aumentará. Entretanto, esses elementos também terão suas solicitações diminuídas, havendo uma compensação quantitativa em peso nessas estruturas.

Dessa forma, é recomendável que se projete estruturas com ângulos em torno de $45^{\circ}$ a $55^{\circ}$, para que as forças externas aplicadas nas cordas sejam distribuídas. Assim, pode ser utilizado perfis mais leves para suportar essas solicitações sem sofrer falhas locais.

A norma AISC 360/16, também recomenda que não se utilize ligações com inclinações inferiores a $30^{\circ}$ por dificultar a soldagem e inspeção.

As inclinações das diagonais apresentam uma pequena probabilidade de influenciar na evolução dos deslocamentos verticais, como pôde ser verificado após as realizações dos testes $t$-Student no capítulo passado.

Já os deslocamentos laterais, haverá insignificantes valores de diferença dos dados obtidos na variação do parâmetro "inclinação das diagonais", considerando o comprimento do vão adotado. 


\section{7 \\ Considerações finais e conclusões}

Este trabalho avalia o comportamento e projeto de vigamentos principais de grandes coberturas e galpões industriais sobre as diversas variáveis de projeto para determinar qual configuração apresenta o menor consumo.

Assim, foram desenvolvidos 189 projetos de treliça de um galpão exemplo com o objetivo de analisar a influência e os efeitos da variação das configurações estruturais. Foram analisadas estruturas com três comprimentos de vãos diferentes (32m, 45m e 60m) e foram verificados os seguintes parâmetros: tipo e geometria da seção transversal, perfis das cordas e inclinação das diagonais, inclusive com a consideração de cordas mistas (aço/concreto).

Uma análise paramétrica foi realizada com o objetivo de identificar as variáveis que influenciam tanto no consumo de aço da estrutura como em seu comportamento. Com isso, verificou-se qual sistema construtivo é o que traz os maiores benefícios.

O emprego de um sistema misto apresenta uma boa redução no consumo de aço para a estrutura, ao se comparar com as outras soluções. A redução de consumo de material obtida ao utilizar esse tipo de perfil ficou, em média, 10\% menor quando comparado com as treliças com perfis laminados, resultados encontrados em todos os comprimentos de vãos estudados.

A utilização de perfis mistos também é uma estratégia eficiente para evitar desperdício de material, além da redução do tempo de execução das estruturas.

A partir dos resultados, confirmou-se que o sistema de treliças multiplanares promove grande estabilidade lateral para a estrutura quando comparado com o sistema de treliças planas. Com isso, reduz-se os custos associados a travamentos, já que a estrutura apresenta maior capacidade de carga.

Além disso, o sistema misto não prejudica a logística da execução da obra pois as estruturas utilizadas podem ser pré-moldadas, sendo necessário apenas transportá-las para o local da obra e montá-las. 
Tanto o sistema de treliças multiplanares como a utilização otimizada dos perfis mistos apresentaram-se como uma boa solução estrutural independentemente do comprimento dos vãos estudados neste trabalho.

\section{1.}

\section{Considerações finais}

Após a análise paramétrica dos resultados obtidos nos projetos de treliça principal de uma cobertura de uma edificação industrial exemplo, este trabalho permite concluir que:

- O sistema misto apresentou-se como a melhor solução, consumindo uma quantidade de aço cerca de $12 \%$ menor quando comparado com as treliças com perfis laminados. Além disso, ao se analisar estatisticamente as relações M/PL, observa-se que essa redução de consumo apresenta uma média com baixa dispersão de valores;

- A causa da falha estrutural equivalente ao primeiro modo de flambagem das treliças foi por perda da estabilidade lateral, associada à flexo-torção da seção transversal da estrutura, como pode ser visto na Figura 5.1;

- A altura recomendada para a estrutura está, em razão do comprimento do vão, dentro do intervalo L/20 e L/30;

- Nas regiões das cordas onde há a aplicação de grandes forças externas que podem ocasionar falha por plastificação da parede do tubo de aço, consome-se menos aço se utilizar um sistema misto ao invés de utilizar tubos de paredes mais espessas;

- Treliças de maiores alturas apresentaram menores consumos de aço e menores flechas;

- São necessárias estruturas secundárias mais rígidas para combater a instabilidade das cordas em treliças de menores alturas, de modo que 
a estrutura possa suportar as cargas que lhe são impostas sem sofrer flambagem global;

- Não há a necessidade de se utilizar armaduras longitudinais nos perfis mistos para obter bons resultados, condição que fornece uma execução mais rápida dos elementos estruturais;

- As treliças que utilizaram três cordas em sua geometria (ver Figura 3.8) apresentaram, de modo geral, menores consumos de aço, quando comparado com as treliças com seções com quatro cordas;

- A influência do tipo de seção transversal nas flechas não pôde ser confirmada, estando esses deslocamentos verticais da estrutura relacionadas a outros parâmetros, tais como a altura da treliça e tipo de perfil da corda.

\section{2. \\ Sugestões para trabalhos futuros}

A linha de pesquisa pode ser continuada a partir das seguintes sugestões:

- Adotar um sistema de triangulação de modo que as diagonais trabalhem sempre que possível à tração;

- Verificar o comportamento da estrutura utilizando ligações capazes de transmitir momentos fletores e analisar se apresenta menor consumo de aço dos que as desenvolvidas nesse trabalho;

- Utilizar outro tipo de configuração de treliça para os travamentos das cordas, a fim de verificar se essa nova configuração é capaz de obter melhores resultados que os obtidos aqui;

- Considerar outras taxas de conversão do volume de concreto em aço equivalente e verificar se haverá alterações na viabilidade técnico e econômica na escolha da solução; 
- Estudar o comportamento da estrutura sob situações de incêndio. 


\section{8 \\ Referências bibliográficas}

ASSOCIAÇÃO BRASILEIRA DE NORMAS TÉCNICAS. NBR8800 - Projeto de estruturas de aço e mistas de aço e concreto de edifícios. Rio de Janeiro, 2008. $237 \mathrm{p}$.

ALMEIDA, S. B. Instabilidade de estruturas metálicas planas compostas de perfis de chapa dobrada. Universidade Federal do Rio de Janeiro - Tese (Doutorado). Rio de Janeiro: 1989. 97 p.

AMERICAN INSTITUTE OF STEEL CONSTRUCTION. Specification for structural steel buildings (AISC 360-16). Illinois: 2016. 620 p.

ANDRADE, S. A. L.; VELLASCO, P. Comportamento e projeto de estruturas de aço. 1 ed. Rio de Janeiro: Elsevier: Editora PUC-Rio, 2016. 390 p.

BELLEI, I. H. Edifícios industriais em aço. 2 ed. São Paulo: Pini, 1998. 489 p.

CANADIAN STANDARTS ASSOCIATION (CSA). CAN/CSA - S16-09: Design of steel structures. Ontario: 2009. 190 p. 76 p.

CARNEIRO, F.; MARTINS, J. G. Análise de estruturas: contraventamento de edifícios. 1 ed. [S. 1.]: Série ESTRUTURAS: 2008.

CENTRO BRASILEIRO DE CONSTRUÇÃO EM AÇO (CBCA). Galpões para usos gerais. Rio de Janeiro: CBCA, 2010.

Treliças tipo steel joist. Rio de Janeiro: CBCA, 2007. 85p.

Dimensionamento de estruturas de aço - Módulo 3: Galpões estruturados em aço. Rio de Janeiro: CBCA, 2012. 74p.

CENTRO DE ESTUDOS DE ESTRUTURAS DE AÇO E MISTAS DE AÇO E CONCRETO DA UFMG. Histórico. Disponível em: < https://www.sites.google.com/site/acoufmg/home/historico>. Acessado em: 27 nov. 2017.

CHEN, Y.; FENG, R.; GAO, S. Experimental study of concrete-filled multiplanar circular hollow section tubular trusses. Em: Thin-Walled Structures, Vol. 94, pp. 199-213, 2015. 
CIMADEVILA, J. E.; CÉSAR, I. L. La Galería de las Máquinas de 1889. Reflexiones histórico-estructurales. Vol.2(2), VLC arquitectura: Corunha, 2015.

COMPUTERS AND STRUCTURES, INC. CSI analysis reference manual. Berkley: California: 2011. 479 p.

DIASE. UNILEVER - Pouso Alegre: Portifólio. Barueri, 2013. Disponível em: <https://www.diase.com.br/portfolio>. Acesso em: 20 nov. 2017.

ELCHALAKANI, M; ZHAO, X., L.; GRZEBIETA, R., H. Concrete-filled circular steel tubes subjected to pure bending. Journal of constructional steel research, 57(11), 1141-1168, 2001.

EUROCODE. (2001): prEN 1994, Design composite steel and concrete structures - Part 1.1: General rules and rules for building, 153p.

FISHER, J. M. Industrial buildings - Roofs to anchor rods. 2ed. USA: AISC, 2004. 98 p.

FONG, M; CHAN, S. L.; UY, B. Advanced design for trusses of steel and concrete-filled tubular sections. Em: Engineering structures. Vol. 33, pp. 3162-3171, 2011.

FURTINI, F. M. Estudo de cobertura para grandes vãos utilizando perfis tubulares. Universidade Federal de Ouro Preto - Dissertação (Mestrado). Ouro Preto: 2005. $204 \mathrm{f}$.

GALAMBOS, T. V.; SUROVEK, A. E. Structural stability of steel: conceptes and applications for structural engineers. John Wiley \&Sons, Inc: New Jersey, 2008. $373 \mathrm{p}$.

GALVATEC. Steel joist. Hartley, 2015. Disponível em: <http://galvatecinc.com/steel-joist/>. Acesso em: 21 nov. 2017.

GAMBHIR, M. L. Fundamentals of Structural Steel Design. Patiala: McGraw Hill, 2013. 1216 p.

HAN, L. H. Tests on stub columns of concrete-filled RHS sections. Journal of Constructional Steel Research, Vol 58, 2002, p. 353-372.

HAN, L. H. Investigation on life-cycle based theory of concrete-filled steel tubular (CFST) structures. Em: Eighth International Conference on steel and aluminium structures, Hong Kong: 2016.

HOU. C; HAN, L. H.; MU, T. M.; HE, S. H. Analytical behaviour of CFST chord to CHS brace truss under flexural loading. Em: Journal of Constructional Steel Research, Volume 134, 2017, Pages 66-79, ISSN 0143-974X. 
INSTITUTO AÇO BRASIL. Ligações em estruturas metálicas. 4 ed. Rio de Janeiro: Instituto Aço Brasil/CBCA, 2011.59 p.

JOHNSON, R. P. Composite structures of steel and concrete. 3 Publishing ed. Blackwell Inc., UK: 2004. 230 p.

LIANG, Q. Q. Analysis and design of steel and composite structures. CRC Press: Florida, 2015. 429 p.

LIBERDRONE TV. Drone do maior centro de distribuição da América Latina

- Casas Bahia. Youtube, 27 mar. 2017. Disponível em <https://www.youtube.com/watch?v=ui28xF9s92s>. Acesso em: 19 nov. 17.

MONTGOMERY, D. C.; RUNGER, G. C. Estatística aplicada e probabilidade para engenheiros. 4 ed. Rio de Janeiro: LTC, 2009. 490 p.

PADUAN, R. Um tour pela Casas Bahia. Exame, São Paulo, 8 out. 2008. Tecnologia. Disponível em: <https://exame.abril.com.br/tecnologia/um-tour-pela-casasbahia-m0075268/>. Acesso em: 19 nov. 2017.

PINTO, J. T. Q. S. Optimização de pórticos metálicos de grandes vãos. Faculdade de Engenharia da Universidade do Porto - Dissertação (Mestrado). Porto: 1997. 209 p.

ROEDER, C.W., CAMERON, B.; BROWN, C.B. Composite Action in Concrete Filled Tubes. Journal of Structural Engineering, ASCE, Vol. 125, No. 5, pp. 477484, 1999.

SAMARRA, F. A. Estudo numérico-experimental de treliças tubulares planas para coberturas padronizadas para grandes vãos. Universidade Estadual de Campinas (UNICAMP) - Dissertação (Mestrado). Campinas: 2007. 303 p.

SHANTONG, Z.; KURANOVAS, A. The unified theory for concrete-filled steel tube (cfst) columns under various loads. Em: Modern Building Materials, Structures and Techniques, v. 235, n. 90, p. 20-100. Lituânia, 2007.

SILVA, T. M. Teste $\boldsymbol{t}$-Student - Teste igualdade de variâncias. Trabalho apresentado para obtenção de nota parcial na disciplina Estatística Aplicada. Universidade Federal do Pará: 2014. 14 p.

SOUZA, A., S., C. Análise teórica e experimental de treliças espaciais. Escola de Engenharia de São Carlos da Universidade de São Paulo - Tese (Doutorado). São Carlos: 2003. 338 p.

SPIEGEL, M. R. Probabilidade e estatística. McGraw-Hill: Recife, 1977. 529 p. 
TARANATH, B. S. Structural analysis and design of tall buildings - Steel and composite construction. CRC Press: Boca Raton, 2012. 710 p.

VIEIRA, R. C. et al. Real scale experimental analyses of circular hollow section multi-planar steel trusses. Em: Stability and ductility of steel structures. Rio de Janeiro: 2010.

VIEIRA, R. C. Estudo comparativo entre terças de aço, convencionais em vigas, em treliças planas e em treliças multiplanares. Universidade Estadual de Campinas (UNICAMP) - Dissertação (Mestrado). Campinas: 2009. $197 \mathrm{f}$.

WANG, Y. C. Steel and composite structures: Behaviour and design for fire safety. Spon Press: Londres, 2002. 331 p.

WINTER, G. Lateral bracing of columns and beams. In: TRANSACTIONS, 1960. Anais... ASCE, 1960, p. 116-135. 